\begin{abstract}
UNIVERSIDADE DE SÃO PAULO
FACULDADE DE FILOSOFIA, LETRAS E CIÊNCIAS HUMANAS

DEPARTAMENTO DE LINGUÍSTICA

PROGRAMA DE PÓS-GRADUAÇÃO EM SEMIÓTICA E LINGUíSTICA GERAL
\end{abstract}

Aline Garcia Rodero TaKahira

COMPOSTOS NA LÍNGUA DE SINAIS BRASILEIRA

(VERSÃo CORRIGIDA)

SÃO PAULO

2015 


\author{
UNIVERSIDADE DE SÃO PAULO \\ FACULDADE DE FILOSOFIA, LETRAS E CIÊNCIAS HUMANAS \\ DEPARTAMENTO DE LINGUÍSTICA \\ PROGRAMA DE PÓS-GRADUAÇÃO EM SEMIÓTICA E LINGUÍSTICA GERAL
}

Aline Garcia Rodero Takahira

\title{
COMPOSTOS NA LÍNGUA DE SINAIS BRASILEIRA
}

(VERSÃo CORRIGIDA)

Tese apresentada ao Programa de PósGraduação em Semiótica e Linguística Geral da Faculdade de Filosofia, Letras E CIÊnCias Humanas da Universidade de São Paulo para a OBTENÇÃo DO TÍTULO DE DOUTOR EM LINGUíSTICA.

Área de CONCENTRAÇÃo: LINGUísticA

Orientadora: Profa Dra Ana Paula Scher

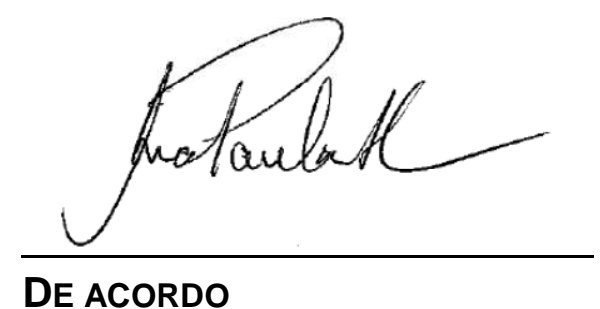

SÃO PAULO

2015 
RODERO-TAKAHIRA, Aline Garcia. Compostos na língua de sinais brasileira. Tese apresentada aO Programa de Pós-GraduaÇão EM Semiótica E Linguística GERAL dA FACULDADE DE FILOSOFIA, LETRAS E CIÊNCIAS HUMANAS DA UNIVERSIDADE DE SÃO PAULO PARA OBTENÇÃO DO TÍTULO DE DOUTOR EM LINGUÍSTICA.

APROVADO EM:

\section{BANCA EXAMINADORA}

Profa. Dra. Ana Paula Scher (Presidente)

Departamento de Linguística da Faculdade de Filosofia, Letras e Ciências Humanas da Universidade de São Paulo Julgamento:

Assinatura:

Prof. Dr. Felipe Venâncio Barbosa

Departamento de Linguística da Faculdade de Filosofia, Letras e Ciências Humanas da Universidade de São Paulo Julgamento:

Assinatura:

Prof. Dr. Paulo Chagas de Souza

Departamento de Linguística da Faculdade de Filosofia, Letras e Ciências Humanas da Universidade de São Paulo

Julgamento:

Assinatura:

Prof. Dr. André Nogueira Xavier

Instituição:

Julgamento:

Assinatura:

Prof. Dr. Rafael Dias Minussi

Instituição: Universidade Federal de São Paulo

Julgamento:

Assinatura: 


\section{ESTA PESQUISA FOI APOIADA POR:}

- CAPES - Coordenação de Aperfeiçoamento de Pessoal de Nível Superior, entre 07/2011 e 03/2014;

- ProQuali - Universidade Federal de Juiz de Fora (UFJF), entre 04/2014 e 06/2015. 
A Deus, por me guiar em todos os momentos. 


\section{AGRADECIMENTOS}

Agradeço, principalmente, à $\operatorname{Prof}^{\mathrm{a}} \mathrm{Dr}^{\mathrm{a}}$ Ana Paula Scher pela orientação, pelas leituras e discussões de cada capítulo ${ }^{1}$, pelo incentivo sempre, por acreditar nessa pesquisa e aceitar o desafio de orientar uma pesquisa sobre a libras, por tudo que me ensinou ao longo desses últimos nove anos, e pela amizade que cultivamos.

Agradeço também ao Prof. Dr. Felipe Venâncio Barbosa pela discussão de alguns pontos da pesquisa, principalmente pelas discussões sobre os dados e sobre possíveis análises.

Agradeço aos integrantes do GREMD (Grupo de Estudos em Morfologia Distribuída) que, por diversas vezes, discutiram pontos desta pesquisa comigo: Indaiá Bassani, Janayna Carvalho, João Paulo Lazzarini-Cyrino, Julio Barbosa, Mayara, Paula Armelin, Rafael Minussi e Vitor Nóbrega.

Em especial, agradeço ao Rafael Dias Minussi pelo incentivo e apoio, pelas discussões e parcerias de pesquisa. Sem o seu incentivo essa pesquisa não teria existido.

Agradeço aos professores Felipe Venâncio Barbosa, Paulo Chagas e Rafael Dias Minussi por terem participado da minha banca de qualificação e por terem chamado minha atenção para vários pontos da pesquisa que poderiam ser aprofundados.

Agradeço aos Professores André Xavier, Felipe Barbosa, Paulo Chagas e Rafael Dias Minussi por fazerem parte da minha banca de defesa e pelos comentários e pelas discussões preciosas que trouxeram em pauta.

À Aslï Göksel por ter discutido generosamente pontos cruciais do meu trabalho em duas ocasiões e por ter partilhado suas idéias sobre composição e seus dados de compostos simultâneos em TID.

Ao Roland Pfau pela discussão minuciosa do meu trabalho em duas ocasiões, pelos comentários e pelo incentivo para eu seguir adiante em minhas investigações.

\footnotetext{
${ }^{1}$ Qualquer equívoco que permanece é de minha inteira responsabilidade.
} 
Ao público do 3rd Venice FEAST Colloquium (Formal and Experimental Advances in Sign Language Theory) e 4th FEAST Conference 2015 Barcelona pelos comentários e questões levantadas, em especial: Aslï Göksel, Carlo Geraci, Caterina Donati, Elena Benedicto, Josep Quer, Onno Crasborn e Roland Pfau pela discussão dos meus trabalhos apresentados.

Aos amigos Indaiá, Janayna, Marcus e Rafa pela amizade em todas as horas e pelo apoio sempre.

À Paulinha pela valiosa ajuda com a revisão das referências e pelo apoio nos momentos finais.

Aos colegas e professores do Departamento de Linguística da USP, pelo convívio, pelo aprendizado e pela amizade. À Érica Flávia, ao Robson e ao Ben Hur pela ajuda, atenção e competência sempre.

Agradeço aos meus colaboradores, sinalizantes surdos, Daniel Choi, Ricardo Nakasato e Rodrigo Florentino da Silva, que se disponibilizaram a fazer gravações, testes e discutir diversos dados da libras comigo.

Agradeço aos meus professores de Libras e de interpretação em Libras com quem sempre pude discutir diversos fenômenos linguísticos.

Agradeço aos dirigentes, professores e alunos do instituto SELI com quem aprendi muito sobre a libras, surdez e educação para surdos. Em especial, agradeço à Sibelle Traldi que me impulsionou a conhecer mais sobre esses temas e abriu muitas portas.

Aos meus monitores: Anderson, Andressa, Cleyton, Daiane, Davi, Fábio e Laíza, que me ajudaram muito na fase final da tese. Aos alunos do curso de LetrasLibras da Universidade Federal de Juiz de Fora (UFJF) e aos participantes do Grupo de Estudos Linguísticos da Libras (GELLI) pelas discussões linguísticas em aula e em diversos outros contextos.

Em especial, agradeço ao Davi Medeiros, que discutiu muitas das glosas da tese comigo trazendo questões interessantes.

Aos novos colegas de trabalho na UFJF e aos novos amigos juiz foranos (ou aqueles "forasteiros" como eu que agora amam Juiz de Fora) pelo acolhimento e amizade, o que tornou um período que poderia ser tão conturbado em algo tão leve 
e gratificante. Em especial: Ana Lúcia, Ana Paula, Andréia, Camila, Carla, Carlos Rodrigues, Daniel, Davi, Érica, José, Luciana, Maria Lúcia, Mayra, Michelle, Mirella, Neiva, Raquel, Rosani, Sonia e Vania.

Aos velhos amigos que se fazem sempre presentes de mil maneiras! Roseli, Ailton, Camila, Juliana, Vinicius, Thais e Andrelino. E um agradecimento especial aos amigos que também fazem parte de nosso grupo de corrida "Ciativa": Fê, Mari, Su, Ana Rosa e todo o grupo!

Finalmente, agradeço aos meus pais amados, meus irmãos queridos, meu marido amado e minha família amorosa. Todos que me apoiaram em vários momentos, mesmo nas decisões mais difíceis. Eu amo vocês!

Em especial agradeço ao meu marido Marcos por me fazer companhia em dias, noites e madrugadas enquanto eu trabalhava. Pela ajuda, pelo apoio, pela compreensão e pela amizade. Te amo!

Às instituições que tornaram essa pesquisa possível: CAPES e ProQualiUFJF. E ao Departamento de Linguística da USP pelo apoio em diversos eventos.

O Doutorado é uma empreitada longa, que envolve mais do que imaginamos, caminhos inesperados, muitas vozes que se cruzam com as nossas ao longo da jornada e acontecimentos do cotidiano que se misturam a uma vida acadêmica intensa. Foram muitas pessoas maravilhosas que Deus colocou em caminho em todos os âmbitos e, de uma forma ou de outra, elas influenciaram no resultado final desta tese. Agradeço por isso e, se eu me esqueci de mencionar alguém, desculpome imensamente desde já. Guardo todos em meu coração. 
We see then, in Sign, at every level - lexical, grammatical, syntactic - a linguistic use of space: a use that is amazingly complex, for much of what occurs linearly, sequentially, temporally in speech, becomes simultaneous, concurrent, multileveled in Sign. The surface of Sign may appear simple to the eye, like that of gesture or mime, but one soon finds that this is an illusion, and what looks so simple is extraordinarily complex and consists of innumerable spatial patterns nested, three dimensionally, in each other.

Oliver Sacks (1989, p.87) 


\section{RESUMO}

RODERO-TAKAHIRA, Aline Garcia. Compostos na língua de sinais brasileira.

2015. 161 f. Tese (Doutorado) - Faculdade de Filosofia, Letras e Ciências Humanas, Universidade de São Paulo, São Paulo, 2015.

Composição é um fenômeno muito produtivo nas línguas de sinais. Estudos pioneiros na ASL (língua de sinais americana) identificaram compostos formados sequencialmente que se caracterizam por regras de redução fonológica e assimilação nos constituintes dos compostos (KLIMA; BELLUGI, 1979; LIDDELL; JOHNSON, 1986). Um estudo sobre compostos na BSL (língua de sinais britânica) mostra a possibilidade de realização simultânea de dois sinais, que são dois classificadores (CLs), em um composto (BRENNAN, 1990). Na libras (língua brasileira de sinais), há estudos que tratam de compostos realizados sequencialmente com dois ou três sinais (QUADROS; KARNOPP, 2004; FELIPE, 2006; FIGUEIREDO SILVA; SELL, 2009). No entanto, nenhum deles trata da possibilidade da ocorrência de CLs em compostos, tampouco da possibilidade da realização de compostos simultâneos. Se as línguas de sinais apresentam dois articuladores primários, as mãos, é natural pensarmos na possibilidade da ocorrência de sinais simultâneos. Sendo assim, o objetivo deste trabalho é descrever os tipos de compostos que ocorrem na libras e investigar a possibilidade de ocorrência de CLs e marcadores não-manuais em compostos, formando compostos simultâneos. Através do conjunto de dados levantado em dicionários, conversas espontâneas e gravações eliciadas por figuras, classificamos os compostos da libras em três grandes grupos, que são os compostos: i) sequenciais; ii) simultâneos e iii) simultâneo-sequenciais. Observamos que todos os compostos simultâneos apresentam um predicado CL sinalizado simultaneamente com mais um sinal CL, ou apresentam um sinal realizado pela boca, o que possibilita a simultaneidade com um sinal manual. O grupo de compostos simultâneos é o menos investigado nas línguas de sinais e será o objeto principal de nossa pesquisa. A descrição detalhada desses dados, bem como a investigação da natureza dos CLs e dos sinais boca, levarão a um maior conhecimento dos processos morfológicos nas línguas de sinais e viabilizarão a indicação de caminhos para uma proposta de análise formal para a composição na libras. A análise desenvolvida nesta tese segue os pressupostos teóricos da Morfologia Distribuída (HALLE; MARANTZ, 1993).

Palavras-chave: compostos; classificadores; sinais boca; simultaneidade; libras. 


\section{ABSTRACT}

RODERO-TAKAHIRA, Aline Garcia. Compounds in Brazilian Sign Language. 2015. 161 f. PhD Thesis - Faculdade de Filosofia, Letras e Ciências Humanas, Universidade de São Paulo, São Paulo, 2015.

Compound formation is a very productive phenomenon in sign languages. Pioneering studies of ASL (American Sign Language) identified compounds formed sequentially, which are characterized by rules of phonological reduction and assimilation in the members of the compounds (KLIMA; BELLUGI, 1979; LIDDELL; JOHNSON, 1986). An investigation of compound formation in BSL (British Sign Language) shows the possibility of simultaneous realization of two signs, which are two classifiers (CLs), in a compound (BRENNAN, 1990). In libras (Brazilian Sign Language), there are studies that deal with compounds realized sequentially, with two or three signs (QUADROS; KARNOPP, 2004; FELIPE, 2006; FIGUEIREDO SILVA; SELL, 2009). However, none of them deals with the possibility of occurrence of CLs in compounds, nor with the possibility of signing simultaneous compounds. If sign languages have two primary articulators, that is, the hands, it is natural to think of the possibility of occurrence of simultaneous signs. Thus, the aim of this thesis is to describe the types of compounds that occur in libras, and investigate the possibility of occurrence of CLs and non-manual markers in compounds, forming simultaneous compounds. Drawing on data collected in dictionaries, spontaneous conversations and recordings elicited by figures, we classify the compounds in libras into three major groups, which are: i) sequential compounds; ii) simultaneous compounds and iii) simultaneoussequential compounds. We observed that all the simultaneous compounds exhibit a $\mathrm{CL}$ predicate simultaneously realized with another $\mathrm{CL}$ sign, or exhibit a sign realized by the mouth, which enables the simultaneity with a manual sign. The group of simultaneous compounds is the least investigated one in sign languages and it will be the main topic of our research. Both the detailed description of these data and the investigation of the nature of CLs and signs realized by the mouth will lead to a better understanding of the morphological processes in sign languages, paving the way for a formal analysis of the compound formation in libras. The analysis developed in this work follows the theoretical assumptions of the Distributed Morphology framework (HALLE; MARANTZ, 1993).

Key words: compounds; classifiers; mouth lexemes; simultaneity; Libras. 


\section{LISTA DE FIGURAS}

Figura 1: ACIDENTE (carro + bater) (QUADROS; KARNOPP, 2004, p.105) 21

Figura 2: Arquitetura da gramática - componentes 41

Figura 3: Arquitetura da gramática - listas 42

Figura 4: Derivação por fase 45

Figura 5: SASSes estáticos - ASL (SUPALLA, 1986, p.215) 64

Figura 6: Classificação de compostos (BISETTO; SCALISE, 2005, p.9) 92

Figura 7: Pares nome-verbo na libras (QUADROS; KARNOPP, 2004, p.97) 116 


\section{LISTA DE QUADROS}

Quadro 1: Compostos em Quadros \& Karnopp (2004), Felipe (2006) e Figueiredo Silva \& Sell (2009) 20

Quadro 2: Construções sequenciais em Capovilla, Raphael \& Maurício (2012) compostos potenciais 35

Quadro 3: Construções simultâneas em Capovilla, Raphael \& Maurício (2012) compostos potenciais 37

Quadro 4: Construções simultâneo-sequenciais em Capovilla, Raphael \& Maurício (2012) - compostos potenciais 39

Quadro 5: Classificadores da libras (FERREIRA-BRITO, 1995) 72

Quadro 6: Formação de compostos do PB por subordinação e coordenação 89

Quadro 7: Características de pares nome-verbo na libras 121

Quadro 8: Tipos de compostos sequenciais e simultâneos na libras 136 


\section{LISTA DE ABREVIATURAS E SIGLAS}

a

ABSL

Argentinean SL

ASL

Auslan

BSL

Catalan SL

$\mathrm{CL}$

$\mathrm{CM}$

DGS

D

DS

ENM

EXP

IPSL

ISL

IV

JakSL

$\mathrm{L}$

LF

LO

LS

LSB

adjetivo

Língua de Sinais Beduína Al-Sayyid

Língua de Sinais Argentina

Língua de Sinais Americana (do inglês, American Sign Language)

Língua de Sinais Australiana

Língua de Sinais Britânica (do inglês, British Sign Language)

Língua de Sinais Catalã

Classificador

Configuração de Mãos

Língua de Sinais Alemã

Direcionalidade (ou O, Orientação da palma da mão)

Estrutura Profunda (do inglês, Deep Structure)

Expressões não-manuais (ou Expressões faciais e corporais)

Expressões faciais e corporais (ou Expressões não-manuais)

Língua de Sinais Indo-paquistanesa

Língua de Sinais Israelense

Item de Vocabulário

Língua de Sinais da Jakarta

Localização, Locação (ou Ponto de Articulação)

Forma Lógica

Língua oral

Língua de sinais

Língua de Sinais Brasileira 


\begin{tabular}{ll} 
LSF & Língua de Sinais Francesa \\
LSQ & Língua de Sinais Quebequense \\
M & Movimento \\
MD & Morfologia Distribuída \\
md & mão direita \\
me & mão esquerda \\
MS & Estrutura Morfológica (do inglês, Morphological Structure) \\
n & nome \\
nP & Sintagma nominal (do inglês, noun phrase) \\
NGT & Língua de Sinais Holandesa \\
O & Orientação da palma da mão (ou D, Direcionalidade) \\
PA & Ponto de Articulação (ou Localização, Locação) \\
PB & Português brasileiro \\
PF & Forma Fonológica (do inglês. Phonological Form) \\
SASS & Especificadores de tamanho e forma (do inglês, Size and shape \\
SS & specifiers) \\
TID & Estrutura Superficial (do inglês, Superficial Structure) \\
vP & Língua de Sinais Turca (do turco, Türk Issaret Dill) \\
& verbo \\
\hline
\end{tabular}




\section{CONVENÇÕES PARA A TRANSCRIÇÃO E ANOTAÇÃO DOS SINAIS}

A anotação para os sinais da libras, que será usada em vários pontos desta tese para citações e glosas, segue a seguinte convenção:

\begin{tabular}{|c|c|c|}
\hline Anotação para: & Convenção: & Exemplo da anotação: \\
\hline $\begin{array}{l}\text { Um sinal da libras } \\
\text { transcrito por uma } \\
\text { palavra do português }\end{array}$ & Caixa alta & POEMA \\
\hline $\begin{array}{l}\text { Um sinal da libras } \\
\text { transcrito por mais de } \\
\text { uma palavra do } \\
\text { português }\end{array}$ & Caixa alta e hífen & NÃO-GOSTAR \\
\hline Marcação de gênero & Substituir por @ & AMIG@ \\
\hline Verbos & Infinitivo & GOSTAR \\
\hline $\begin{array}{l}\text { Um sinal da libras que é } \\
\text { composto realizado } \\
\text { sequencialmente }{ }^{2}\end{array}$ & $\wedge$ & 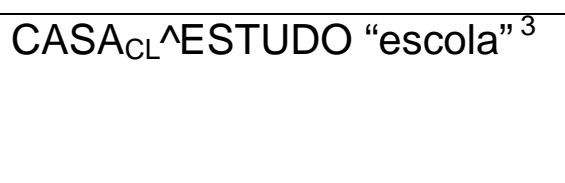 \\
\hline $\begin{array}{l}\text { Expressões não- } \\
\text { manuais (ENMs) }\end{array}$ & $\begin{array}{l}\text { Sobrescrito em caixa baixa } \\
\text { com uma linha indicando } \\
\text { quanto a marcação } \\
\text { perdura durante a } \\
\text { sinalização } 0^{5}\end{array}$ & $\begin{array}{l}\text { interrogativa }- \\
\text { ENTENDER }\end{array}$ \\
\hline $\begin{array}{l}\text { Um sinal articulado pela } \\
\text { boca, bochecha e/ou } \text { língua }^{6}\end{array}$ & $\begin{array}{l}\text { b em caixa baixa ao lado } \\
\text { do sinal }\end{array}$ & SEXOb \\
\hline $\begin{array}{l}\text { Um sinal simples ou } \\
\text { sinal classificador }(C L) \\
\text { diferente realizado por } \\
\text { cada mão }\end{array}$ & $\begin{array}{l}\text { md (caixa baixa) para o } \\
\text { sinal realizado com a mão } \\
\text { direita e me (caixa baixa) } \\
\text { para o sinal realizado com }\end{array}$ & 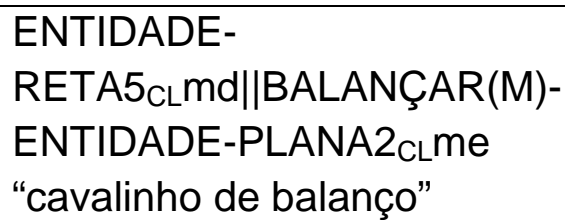 \\
\hline
\end{tabular}

\footnotetext{
${ }^{2}$ As cinco primeiras anotações são apontadas já no trabalho de Ferreira-Brito (1995) e usadas em diversas pesquisas.

${ }^{3}$ O estatuto de sinais mais icônicos como CLs semânticos será discutido no capítulo 3.

${ }^{4}$ Além de escrevermos o significado das siglas por extenso na primeira ocorrência de cada uma delas, disponibilizamos todas na "Lista de Abreviaturas e Siglas", nas páginas vii e viii dos elementos pré-textuais, para possibilitar uma consulta rápida sempre que necessário.

${ }^{5}$ Esta anotação é feita como em Pfau \& Quer (2002) entre outros trabalhos dos autores.

${ }^{6}$ A partir da sétima linha são convenções adotadas por nós para deixarmos claras as anotações de nossos dados.
} 


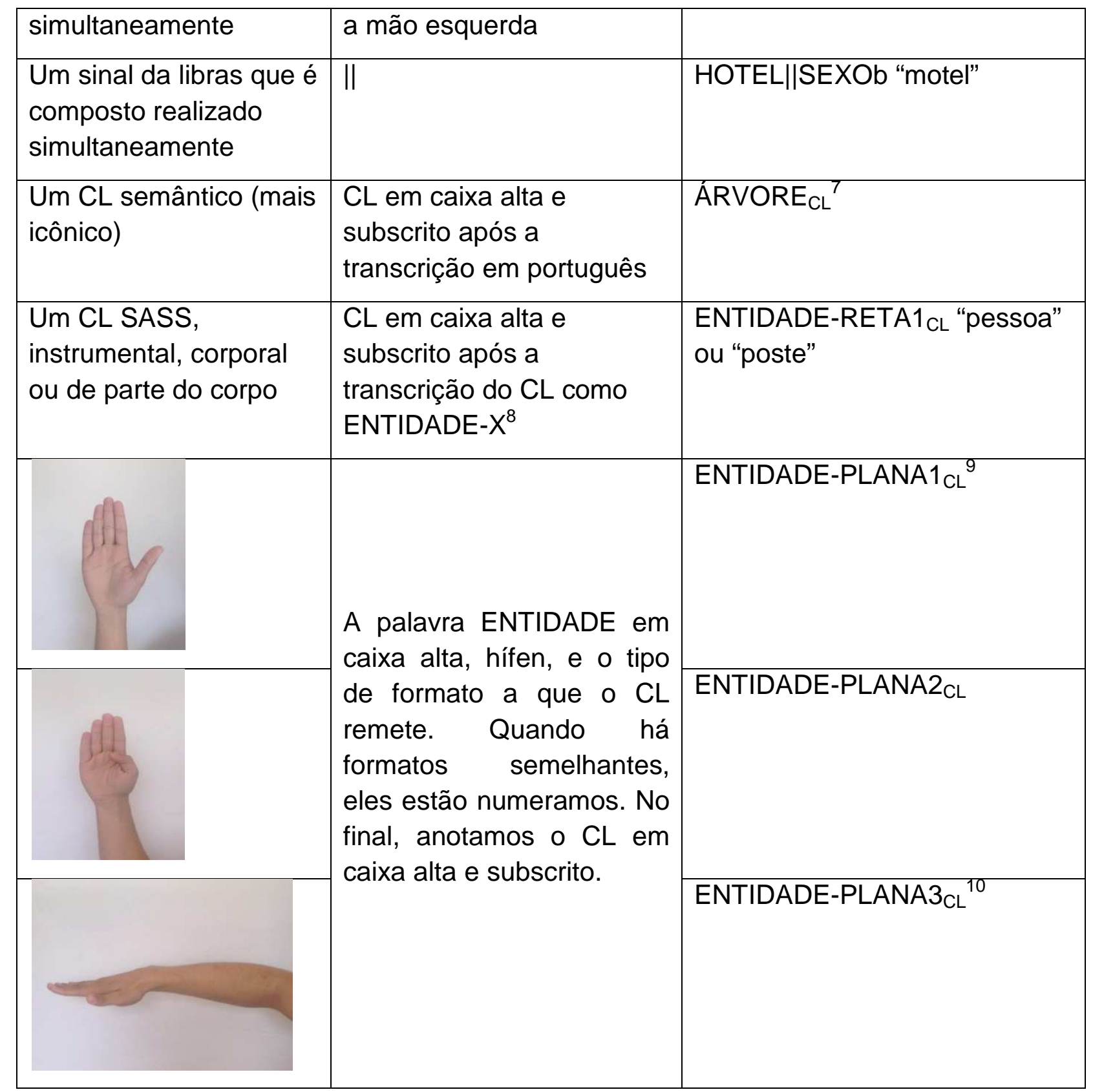

\footnotetext{
${ }^{7}$ Assumimos que esses CLs semânticos sempre remetem a "forma de", como "forma de casa" ou "forma de árvore", por exemplo. Para remetermos ao seu valor altamente icônico, optamos por usar apenas $C_{A S A} A_{C L}$ ou ÁRVORE $E_{C L}$, diferenciando-os da forma de anotação dos CLs de traço para os quais usamos "FORMA-QUADRADA $A_{C L}$ ", como na última linha deste quadro, ou FORMA-MEIA-LUA $A_{C L}$, por exemplo, nos quais o formato do objeto é traçado.

${ }^{8}$ Onde "X" é a forma. Essa convenção com o uso de "ENTIDADE-X" visa trazer a propriedade geral do CL esvaziando-o de um significado específico com o intuito de evitar que o uso de palavras da língua portuguesa, como uma das possíveis interpretações do CL no dado em questão, influencie em análises morfossintáticas do dado. Esse ponto será abordado nos capítulos 3 e 5 . O detalhamento dos tipos de ENTIDADE-X que encontramos em nossos dados está nas próximas linhas.

${ }_{9}$ Para este $\mathrm{CL}$, não diferenciamos se o dedão está unido aos demais dedos ou distendido, pois consideramos que o dedão distendido, nesses casos, é resultado da regra do dedão distendido e não tem implicações morfológicas (Cf. BATTISON; MARKOWICZ; WOODWARD, 1975 - na ASL; WOODWARD, 1976 - na ASL e LSF, língua de sinais francesa; SUWIRYO, manuscrito - na JakSL, língua de sinais da jakarta). ${ }^{10}$ Idem.
} 


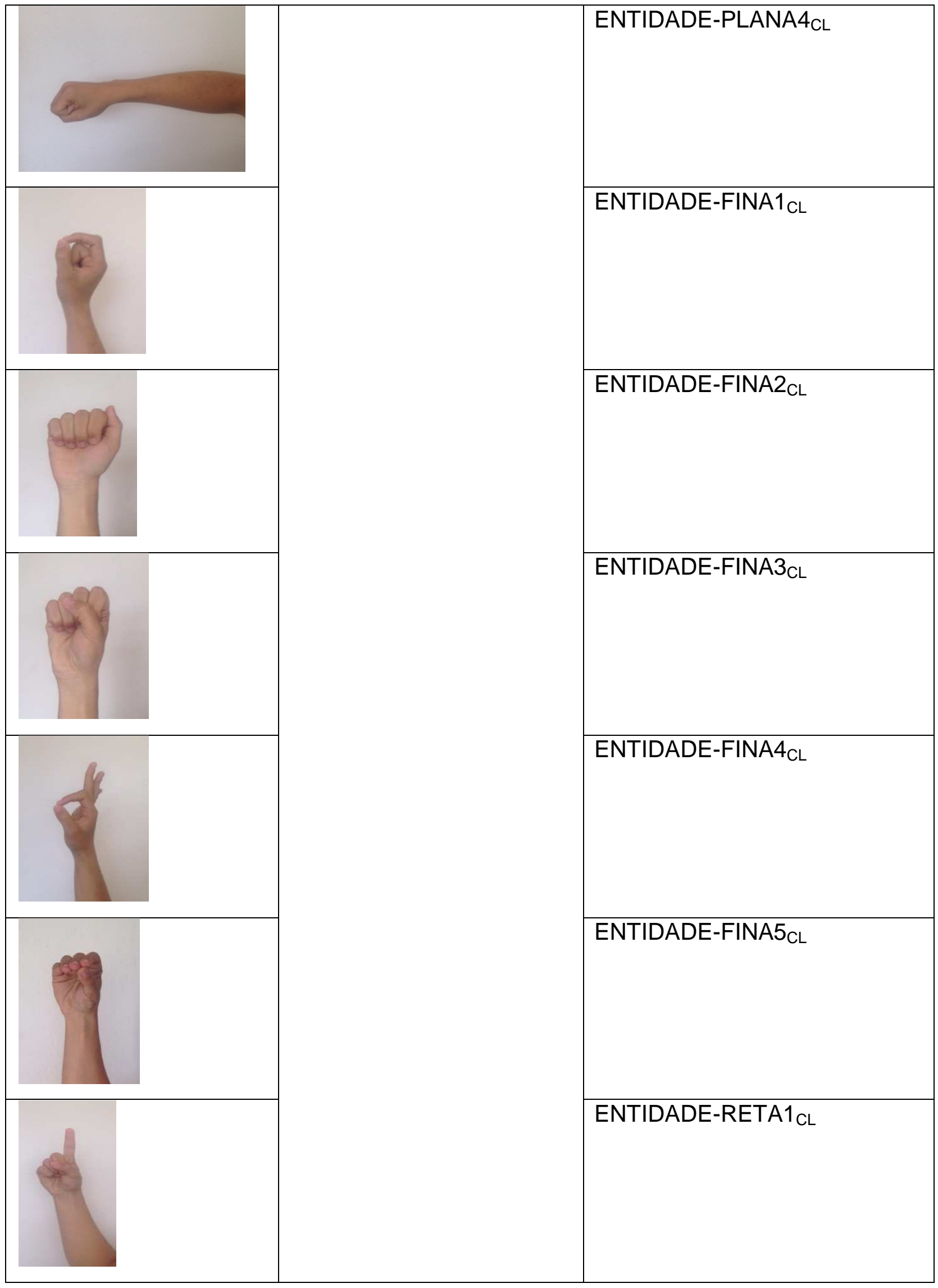




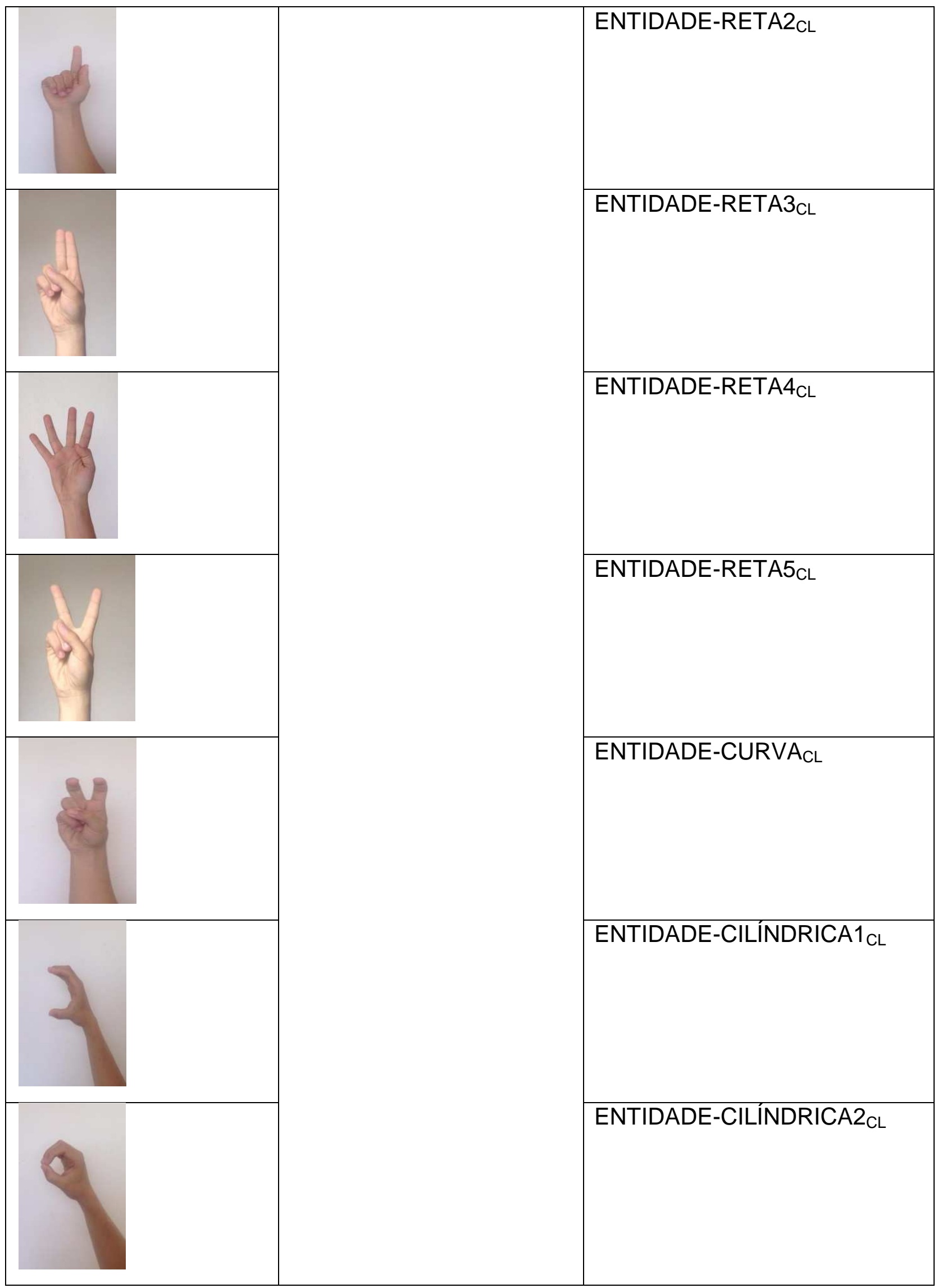




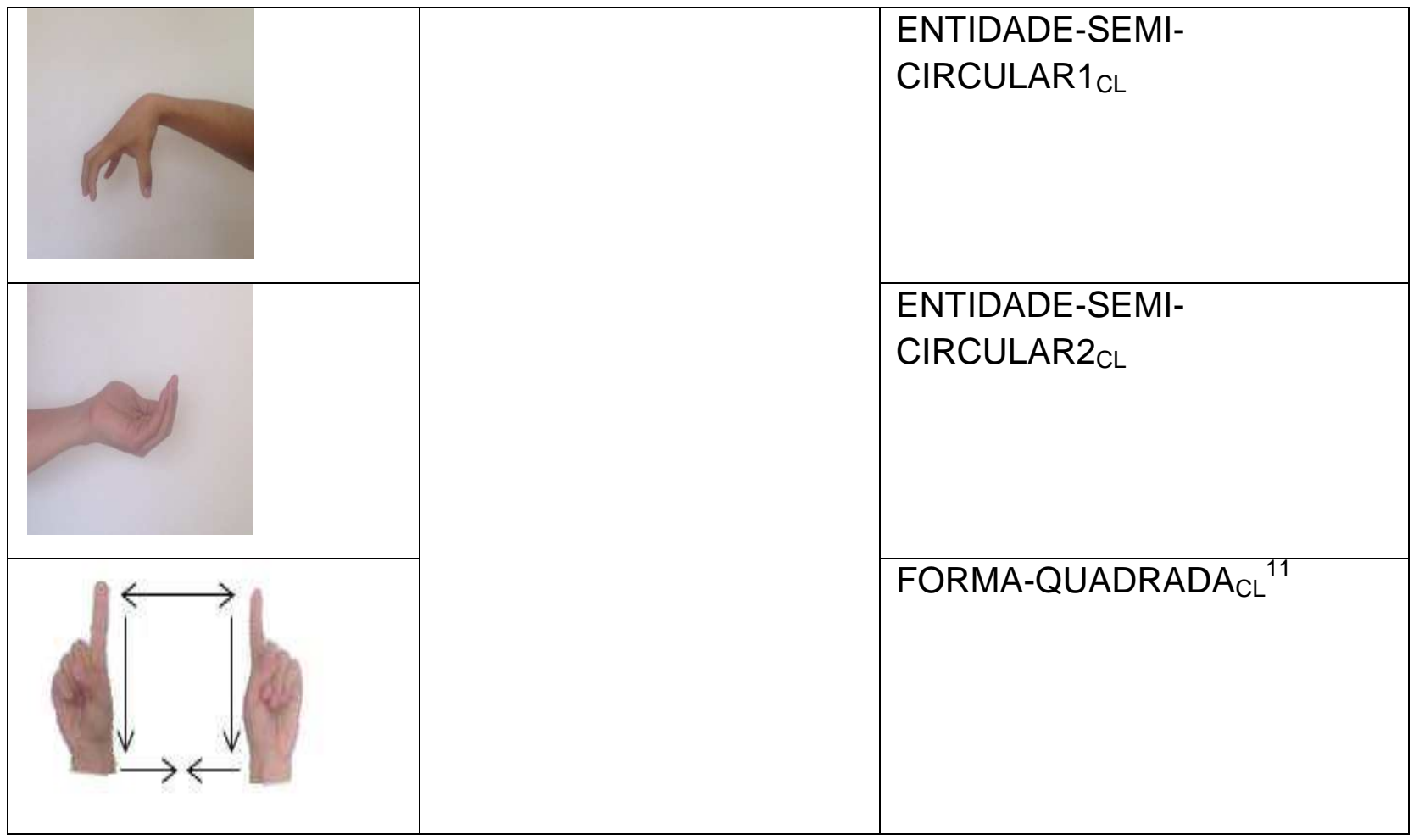

${ }^{11}$ Os vinte CLs especificados ao fim deste quadro são CLs não semânticos que apareceram em nossa coleta de dados, mas eles não representam, necessariamente, todas as possibilidades de CLs da libras. Já os CLs semânticos, mais icônicos, serão anotados como especificamos na sétima linha deste quadro. 


\section{SUMÁRIO}

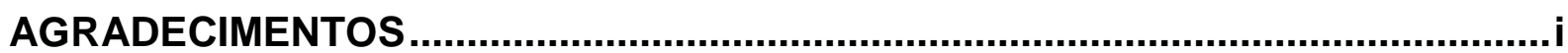

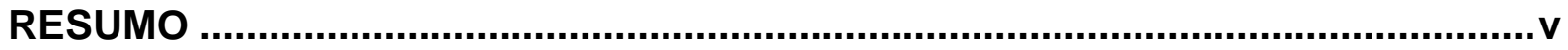

ABSTRACT

LISTA DE FIGURAS ................................................................................................... vii

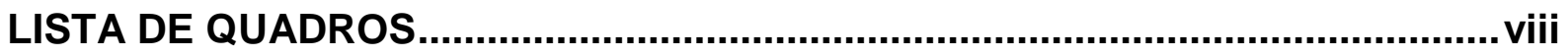

LISTA DE ABREVIATURAS E SIGLAS ...............................................................

CONVENÇÕES PARA A TRANSCRIÇÃO E ANOTAÇÃO DOS SINAIS .................xi

APRESENTAÇÃO

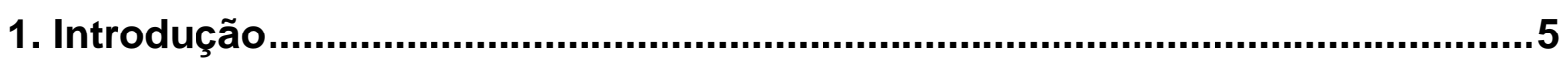

2. Compostos potenciais e pressupostos teóricos..............................................15

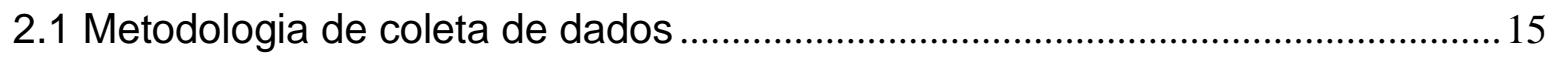

2.2 Compostos na literatura da libras e padronização das glosas .............................18

2.3 Uma classificação dos possíveis compostos na libras: dados da coleta ............22

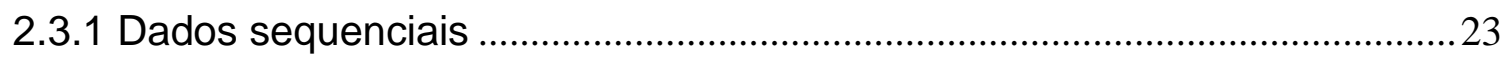

2.3.2 Dados simultâneos .....................................................................................2

2.3.3 Dados simultâneo-sequenciais......................................................................

2.4 Uma classificação dos possíveis compostos na libras: dados em Capovilla, Raphael e Maurício (2010) ............................................................................................33

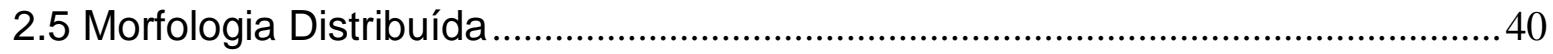

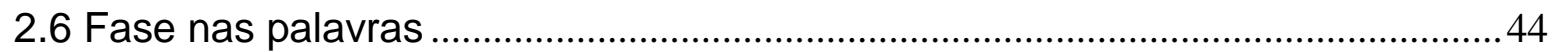

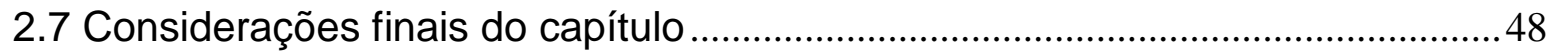

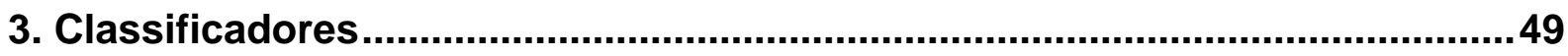

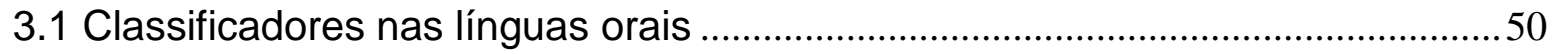

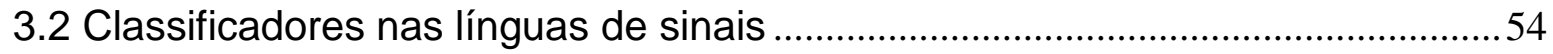

3.2.1 Cuxac e Sallandre (2007): classificadores e iconicidade ...............................59

3.2.2 Supalla $(1982,1986)$ : classificadores como morfemas.....................................62 
3.2.3 Ferreira-Brito (1995): classificadores na libras 70

3.2.4 Zwitserlood (2003): uma proposta morfossintática para os classificadores

3.3 A natureza dos classificadores na libras e a derivação de sinais com

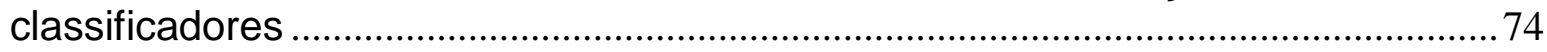

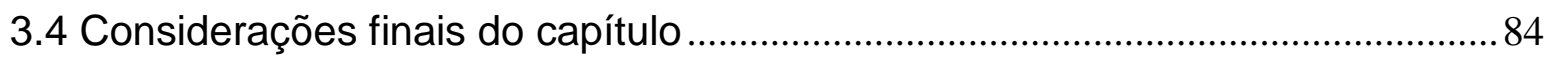

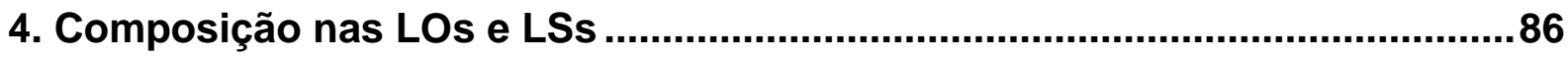

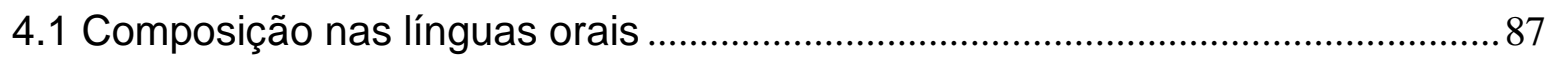

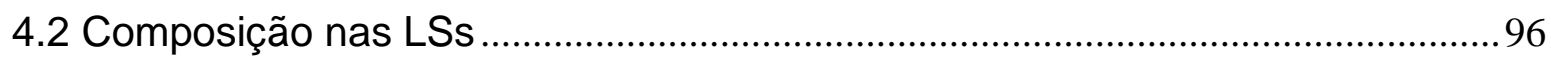

4.2.1 Identificando compostos sequenciais na libras................................................... 104

4.2.2 Identificando compostos simultâneos na libras - critérios da literatura..... 107

4.3 Categorização e classes de palavras ……………………………….....................111

4.3.1 Classes de palavras nas LSs.....................................................................112

4.3.2 Morfemas categorizadores na libras........................................................... 118

4.3.3 Identificando as classes de palavras envolvidas na composição ................126

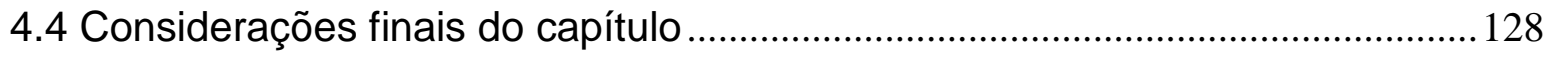

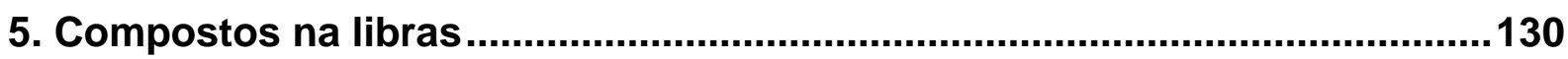

5.1 Indicando caminhos para uma análise de compostos na libras .........................131

5.2 Por uma especificação das construções simultâneas...........................................134

5.3 Sinais boca na libras: explorando novas possibilidades de simultaneidade ...137

5.3.1 Padrões de boca: mouthings, morfemas boca e sinais boca .....................139

5.3.2 Compostos simultâneos com sinais boca........................................................ 143

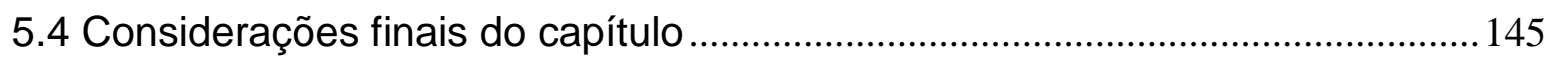

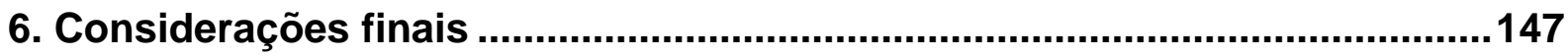

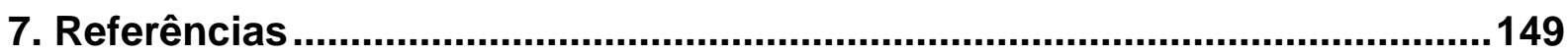




\section{APRESENTAÇÃO}

A presente tese traz uma análise formal dos compostos da língua de sinais brasileira (LSB ou libras) ${ }^{12}$ e foi desenvolvida durante meu curso de Doutorado em Linguística do Programa de Pós-graduação em Linguística da Universidade de São Paulo (USP), compreendendo o período entre 07/2011 e 06/2015.

A libras é uma língua visuo-espacial usada como principal meio de comunicação pela comunidade surda brasileira. Em 24 de abril de 2002, a libras foi reconhecida como "meio legal de comunicação e expressão" pela Lei oㅜ 10.436 . Essa lei foi regulamentada pelo Decreto ํㅜ 5.626, de 22 de dezembro de 2005, que assegura uma série de direitos aos surdos ${ }^{13}$, dentre eles direitos linguísticos que envolvem: i) o direito de educação da criança surda em sua própria língua, através da criação de escolas bilíngues para surdos; e, ii) a necessidade de se formarem profissionais especializados para a educação dos surdos, professores e intérpretes.

Em termos mais regionais, a cidade de São Paulo também apresenta legislação sobre a matéria. O Decreto no 52.785, de 10 de novembro de 2011, cria as Escolas Municipais de Educação Bilíngue para Surdos, e a Portaria ํㅡ 5.707, de 12 de dezembro de 2011, regulamenta o Decreto citado, garantindo o ensino bilíngue para os surdos no município de São Paulo, ou seja, o ensino considerando a libras como primeira língua (L1) do aluno surdo e a língua portuguesa escrita como sua segunda língua (L2). As comunidades surdas de outros municípios brasileiros vêm lutando pelo mesmo direito.

Muitas vezes, é através da escola bilíngue que o surdo tem acesso à sua língua natural, a libras, e à cultura surda. Isso ocorre porque a maior parte dos surdos são filhos de pais ouvintes e há casos em que a surdez é diagnosticada tardiamente, além do fato de que, muitas vezes, a família demora para aceitar a surdez e, em alguns casos, isso nunca acontece. Assim, algumas crianças surdas adquirem a libras no contato com a comunidade surda desde os primeiros anos de

\footnotetext{
${ }^{12}$ Neste trabalho usamos a forma "libras" para nos referir à língua de sinais brasileira, também conhecida internacionalmente e academicamente pela sigla LSB. "Libras" é a forma por meio da qual essa língua é reconhecida pela maior parte dos brasileiros, surdos ou ouvintes.

${ }^{13}$ O termo "surda/o" é usado para se referir ao indivíduo que tem identidade surda, ou seja, usa a libras como principal forma de comunicação e está inserido na comunidade surda, sendo, então, conhecedor da cultura surda.
} 
vida, porém, é comum que outras adquiram a libras tardiamente na escola, através do contato com professores sinalizantes, ouvintes e/ou surdos. Da mesma forma que acontece com qualquer ser humano, a aquisição tardia da L1 pode levar a sequelas tanto linguísticas como cognitivas (BARBOSA, F. et al, 2003).

O primeiro trabalho que reconheceu uma língua de sinais como língua natural foi o trabalho de Stokoe (1960), sobre a língua de sinais americana (ASL). Stokoe foi um linguista escocês, ouvinte ${ }^{14}$, que trabalhou na primeira universidade para surdos do mundo, a Gallaudet, e a partir da observação da sinalização dos alunos surdos na Gallaudet ele pôde perceber que a sinalização se tratava de uma língua e não mera gesticulação (QUADROS; KARNOPP, 2004). Inicialmente, ele reconheceu configurações de mãos (formas que as mãos tomam), pontos de articulação ou localizações (locais tomados no corpo ou no espaço para sinalização) e movimentos (movimentações das mãos durante a sinalização) como formadores de um sinal na ASL. Posteriormente, outras características foram depreendidas de um sinal, como discutiremos com mais detalhes ao longo da pesquisa. A partir do trabalho de Stokoe (1960), diversos linguistas no mundo voltaram seus olhares para as mais diversas línguas de sinais (LSs).

Apesar de a libras ter sido reconhecida como meio legal de comunicação e expressão apenas em 2002, os trabalhos pioneiros sobre essa língua datam do fim dos anos 80 e anos 90, como Ferreira-Brito $(1984,1986,1995)$ e Ferreira-Brito \& Langevin (1995). Dentre esses, Ferreira-Brito (1995) discute, de forma geral, aspectos fonológicos, morfológicos e sintáticos da libras, e, posteriormente, Quadros \& Karnopp (2004) também o fazem, com base em diversas análises da ASL. Há, ainda, os trabalhos de Karnopp (1994) e Quadros (1997), que se voltam para aspectos da aquisição da libras, Quadros (1995, 1999), que discutem aspectos sintáticos dessa língua, além de Felipe (1998), que traz um estudo morfossintático e semântico dos verbos da libras.

Seguindo esses trabalhos, hoje em dia, contamos com pesquisas mais detalhadas na linguística da libras sobre os mais diversos aspectos, tais como: o sistema fonético-fonológico, em Xavier (2006, 2011, 2014); a estrutura morfêmica dos sinais, em Maurício (2009); CLs, em Bernardino (2006, 2012), Veloso (2008) e

\footnotetext{
14 "Ouvinte" é o termo usado para a pessoa que não é surda.
} 
Mendonça (2012); depicção ${ }^{15}$, em Silva (2014); padrões em formação de palavras, em Rodero-Takahira \& Minussi (2013) e Minussi \& Rodero-Takahira (2013); morfemas-boca, em Pêgo (2013); categorização e classes de palavras, em Pizzio (2011); incorporação de numeral, em Rodero-Takahira (2013); concordância, caso e ergatividade, em Lourenço (2014); a segmentação na libras, em Leite (2008); o sistema de pronomes pessoais e verbos indicadores, em Moreira (2007); o processo de referenciação em narrativas, em Barbosa, T. (2013); o sistema de anotação nas LSs, em McCleary \& Viotti (2007), e McCleary, Viotti \& Leite (2010); a língua de sinais atípica, em Barbosa, F., et al. (2003); entre outras pesquisas. Esses são desdobramentos e avanços que repercutiram a partir daqueles trabalhos pioneiros.

Com esta breve apresentação, pretendemos mostrar o quanto é jovem a área dos estudos linguísticos da libras no Brasil e, apesar de já haver muitos trabalhos específicos, como acabamos de mencionar, também pretendemos mostrar o quanto essa área ainda carece de investigações linguísticas, nos mais diversos níveis de análise. Como Meir (2012, p.86) já ressalta, a questão da diferença de modalidade, a juventude das LSs e a idade da área de pesquisa fazem com que os estudos linguísticos das LSs sejam desafiadores e nada triviais.

Podemos dizer que um passo anterior a todas as medidas acerca dos direitos linguísticos dos surdos sinalizantes de libras é conhecer a fundo essa língua e, para tanto, pesquisas como as citadas acima contribuem para a descrição e análise dos diversos fenômenos observáveis nessa língua. Nesse sentido, esta tese vem oferecer mais algumas contribuições para o entendimento da formação de palavras ${ }^{16}$ na libras em construções sequenciais e simultâneas, o que aponta para uma discussão acerca: i) dos elementos envolvidos em tais construções (sinais CLs, sinais boca ou faciais e sinais simples); ii) da sequencialidade e simultaneidade nas LSs; iii) da formação de compostos; e, iv) da chamada morfologia não-concatenativa em contraposição à morfologia concatenativa.

O desenvolvimento desta pesquisa vem corroborar e aprofundar os estudos linguísticos da libras com uma investigação sobre os tipos de compostos possíveis nessa língua. $O$ estudo desse fenômeno em uma língua de modalidade vísuo-

\footnotetext{
${ }^{15}$ Pode-se dizer que depicção equivale a CLs, porém, em uma perspectiva cognitivista (Liddell, comunicação pessoal).

${ }^{16}$ Ao nos referirmos às LSs, estamos usando o termo "palavras" ou "sinais" como equivalentes, independendo da diferença de modalidade.
} 
espacial fomenta o entendimento: i) do funcionamento da linguagem humana, ii) do desenvolvimento das línguas naturais, de modo mais geral, e iii) da teoria que usaremos para a análise, a Morfologia Distribuída (MD, HALLE; MARANTZ, 1993) ${ }^{17}$.

Ao longo desta tese, procuramos responder: como são formados os compostos da libras, quais elementos estão envolvido na composição e como eles se articulam, seja sequencialmente ou simultaneamente?

$\overline{{ }^{17} \text { Veja mais sobre a MD no capítulo } 2 .}$ 


\section{Introdução}

A literatura sobre os processos de formação de palavras e sentenças sugere que eles devem ser universais e se aplicar a qualquer língua natural. Uma diferença de modalidade, tal como a que se observa entre as línguas orais (LOs) e as LSs, revela que algumas particularidades podem estar em jogo. A libras, objeto de estudo desta pesquisa, é uma língua natural articulada em uma modalidade diferente das LOs. Enquanto uma LO é oral-auditiva, uma LS é visuo-espacial ou visuo-gestual, ou seja, ela é percebida pelos olhos e produzida pelas mãos e pelo corpo, considerando-se, por exemplo, inclinações do corpo, direção do olhar e expressões faciais, ou seja, as ENMs, que podem ser dotadas de valor gramatical. Segundo Meir (2012), entre outros, essa diferença de modalidade acarreta diferenças estruturais. Um exemplo que vale ressaltar é o fato de as LSs possibilitarem a realização de construções simultâneas em que informações diferentes podem ser sinalizadas por cada mão. Isso tem reflexo também no sistema de formação de palavras dessa língua, levando à possibilidade de formação de sinais simultâneos, por exemplo.

As LSs são reconhecidas por apresentarem, na maior parte dos casos, processos morfológicos não-concatenativos. Em outras palavras, as LSs possibilitam a realização de sinais simultâneos, em que um sinal ou um morfema diferente é realizado por cada mão ou, como atestamos nesta pesquisa, em que um sinal é realizado pela mão e outro sinal é realizado pela boca (lábios, bochecha e língua), como exemplificaremos mais adiante. Segundo Meir et al (2010), o fenômeno da composição é reconhecido como um dos poucos processos que caracteriza a morfologia sequencial, concatenativa, nas LSs. Ainda assim, há registros de compostos simultâneos na literatura, como se atesta em Bellugi \& Newkirk (1981), sobre a ASL, Brennan (1990) e Sutton-Spence \& Woll (1999), sobre a língua de sinais britânica (BSL), e Göksel (2014), sobre a língua de sinais turca (TID).

$\mathrm{Na}$ libras, os estudos pioneiros sobre aspectos linguísticos trazem um panorama geral dos aspectos morfológicos e fazem pouca menção ao fenômeno da composição (Cf. FERREIRA-BRITO, 1995; QUADROS; KARNOPP 2004; FELIPE, 2006), como detalharemos no cap. 5. Alguns estudos mais recentes começam a 
tratar mais especificamente da composição, principalmente, no que diz respeito à formação de compostos sequenciais (Cf. FIGUEIREDO SILVA; SELL, 2009).

De modo geral, esta pesquisa visa investigar a estrutura morfológica da libras descrevendo e analisando os elementos que participam na composição de novos sinais e explorando todas as possibilidades de composição nessa língua, seja sequencialmente ou simultaneamente. Para tanto, buscaremos investigar a natureza do fenômeno da composição explicitando também a natureza dos elementos envolvidos na formação de compostos nessa língua.

Para falarmos da formação de palavras nas LSs é importante ressaltar o trabalho de Stokoe (1960) que reconheceu que os sinais de uma LS, a ASL, não são unidades indivisíveis, inanalisáveis, mas que podiam, sim, ser decompostos em unidades menores. Ele descreveu essas unidades como sendo finitas e de caráter distintivo, assim como os fonemas ${ }^{18}$. Inicialmente, Stokoe (op. cit.) identificou três tipos de unidades contrastivas, na ASL, as quais ele chamou de parâmetros ${ }^{19}$ :

a) configuração de mãos $(\mathrm{CM})^{20}$ : o formato que a mão toma para realizar um sinal;

b) locação ou localização (L): a localização espacial do sinal; e,

c) movimento (M): o tipo de movimento realizado.

Posteriormente, outros dois tipos de unidades contrastivas são adicionados a essa lista:

d) orientação (O): a orientação ou direção para a qual a palma da mão está voltada durante a produção de um sinal.

\footnotetext{
${ }^{18}$ Pode parecer estranho falar-se em fonemas ou fonologia quando levamos em conta uma LS; no entanto, essa terminologia vem sendo empregada na referência às menores unidades distintivas das LSs e suas regras combinatórias. Stokoe (op. cit.), inicialmente, usou o termo quirema (do grego khéir - mãos) e quirologia; porém, em trabalhos subsequentes e em trabalhos de outros linguistas sobre as LSs, os termos "fonema", "fonética" e "fonologia" foram mantidos para expressar a semelhança entre os fenômenos nas LSs e nas LOs.

19 Os "parâmetros" que compõem um sinal, conforme apresentado no texto, nada têm a ver com os parâmetros em Gramática Gerativa.

${ }_{20}$ Para uma descrição das CMs e dos parâmetros da libras, veja Ferreira-Brito (1995), Ferreira-Brito \& Langevin (1995) e Xavier (2006).
} 
e) ENMs: englobam expressões faciais e corporais que podem se dividir em expressões com valor afetivo e com valor gramatical.

Battison (1978, p.200) ressalta que Stokoe (1960) já faz uso desse quarto elemento formacional em seu sistema de transcrição, apesar de não detalhá-lo. A partir do meio da década de 70, vários autores passam a destacar a $O$ na descrição de sinais, como Frishberg (1975, p.698), para a ASL, entre outros. Baker-Shenk ${ }^{21}$ (1983, apud FERREIRA-BRITO; LANGEVIN, 1995, p.240-242) é uma das primeiras autoras a explorar as ENMs nas LSs como marcadoras de formas sintáticas e atuantes do componente lexical. Liddell \& Johnson (1989) também passam a investigar as ENMs e as incluem entre os primitivos fonológicos das LSs. As ENMs podem envolver a parte superior da face, sobrancelhas e olhos; ou a parte inferior, a boca; além de inclinação da cabeça ou do tronco, por exemplo. Em (1), abaixo, podemos ver um exemplo de cada uma das unidades contrastivas na formação do sinal TRABALHAR na libras:

(1) TRABALHAR "trabalhar"

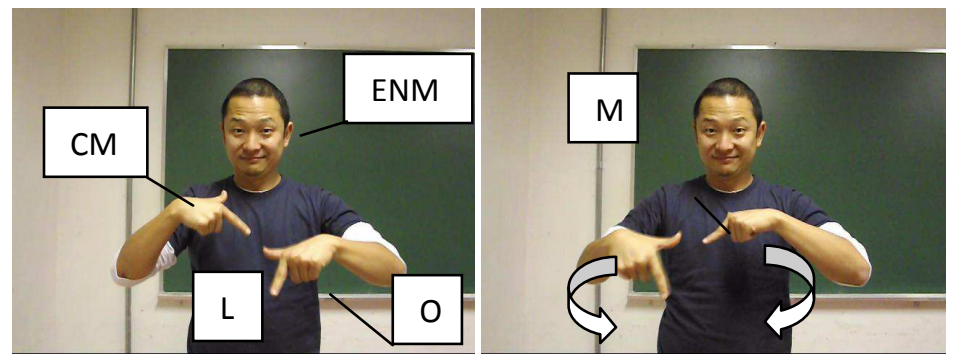

Na primeira imagem do sinal, destacamos: a CM, em "L"22; a $L$, no espaço neutro, o espaço na frente do tronco; a $O$, palmas voltadas para baixo; as ENMs, com as sobrancelhas levemente erguidas, olhos mais abertos, com os lábios fechados. Na segunda imagem, que representa um segundo quadro de $M$ do mesmo sinal, semi-circular alternado, destacamos o $\mathrm{M}$ com as setas. Então, os sinais da libras, bem como das outras LSs, são constituídos por uma combinação desses

\footnotetext{
${ }^{21}$ Não tivemos acesso à versão original desse trabalho.

${ }^{22} \mathrm{Na}$ forma da letra $L$ no alfabeto datilológico. Veja também os Anexos 2, 3 e 4 para CMs da libras.
} 
cinco tipos de elementos: CM, L, M, O e ENM. Esses cinco parâmetros, ou cinco grupos de fonemas disponíveis na língua, contêm as menores unidades distintivas da libras que, quando combinadas, formam um sinal.

Os sinais das LSs, por sua vez, podem ser combinados sequencialmente ou simultaneamente formando compostos. Composição é um processo bastante produtivo nas LSs estudadas até agora (KLIMA; BELLUGI, 1979; LIDDELL, 1984; LIDDELL; JOHNSON, 1986; BRENNAN, 1990; SUTTON-SPENCE; WOLL, 1999; GÖKSEL, 2014).

Para averiguarmos a possibilidade de formação de compostos na libras, fizemos um levantamento de dados na literatura dessa língua em busca de sinais considerados como compostos e sinais formados por mais de uma parte ou mais de um componente, manual ou não-manual. Além disso, eliciamos dados a partir de figuras com três colaboradores surdos sinalizantes ${ }^{23}$. Comprovamos que, na libras, há diversos exemplos em que um conceito é expresso por mais de um sinal, ou morfema livre, indicando compostos potenciais. Os dados abaixo, por exemplo, são formados por mais de um sinal, sequencialmente ou simultaneamente:

(2) $\mathrm{CASA}_{\mathrm{CL}}{ }^{\wedge} \mathrm{ESTUDO}$ "escola"24

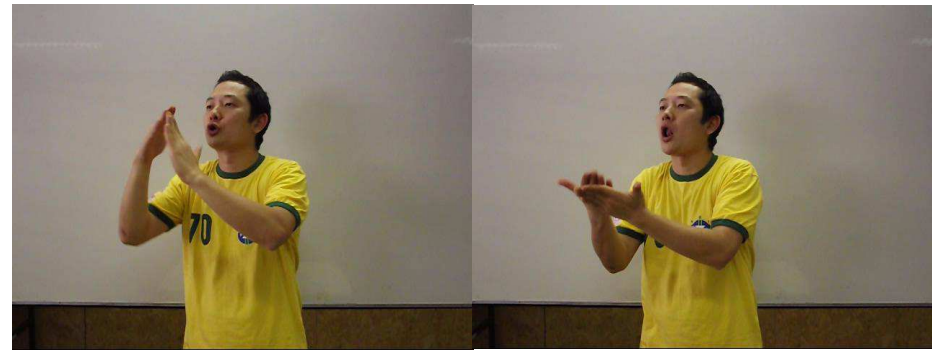

$\mathrm{CASA}_{\mathrm{CL}}$ ESTUDO 25

\footnotetext{
${ }^{23}$ A metodologia dessa coleta será detalhada no capítulo 2.

${ }^{24} \mathrm{O}$ sistema de convenção para anotação de nossos dados está disponível no início desta tese, p.xi a $x V$.

${ }^{25}$ Nos exemplos ilustrados por fotos, o pontilhado mostra até onde vai o sinal com o significado descrito na glosa.
} 
(3) CAVALO^ENTIDADE-PLANA2 $C$-BALANÇAR(M)||ENTIDADE-RETA5 ${ }^{26}{ }_{\mathrm{CL}}$ "cavalinho de balanço"

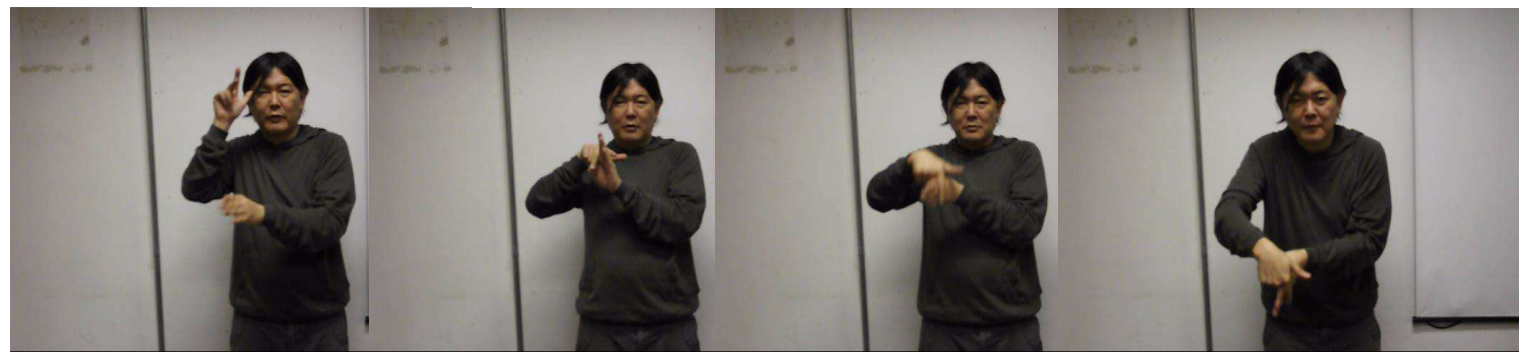

CAVALO

ENTIDADE-PLANA2 2 L-BALANÇAR(M)me||ENTIDADE-

$\operatorname{RETA} 5_{\mathrm{CL}} \mathrm{md}^{27}$ 28

(4) SEXOb||VIAJAR "lua de mel"

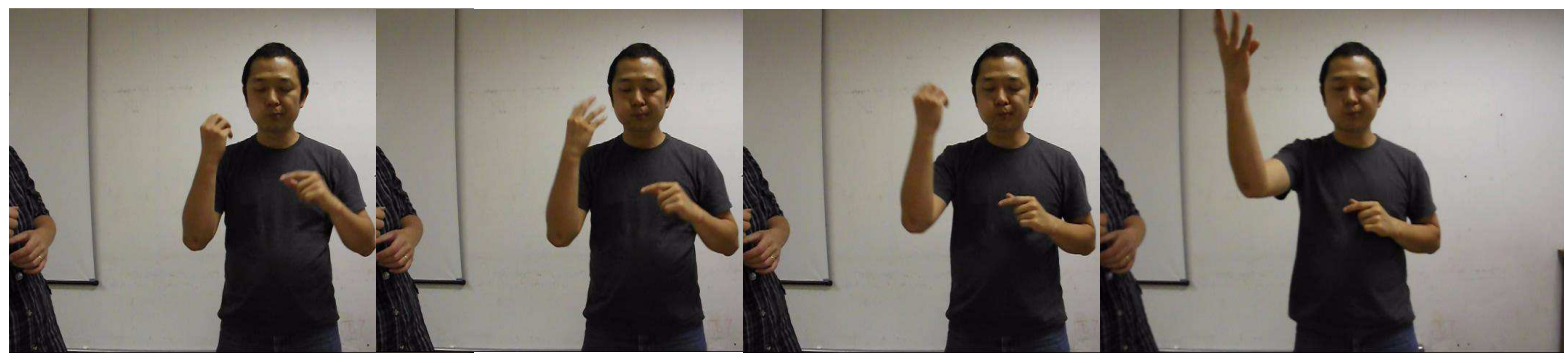

SEXOb||VIAJARmd

${ }^{26}$ Optamos por anotar esse CL como ENTIDADE-RETA5 $5_{C L}$ e não como ENTIDADE-COM-PERNAS, como é usado na literatura (Cf. Zwitserlood, 2008, entre outros), com o intuito de caminharmos em direção as generalizações na descrição dos CLs almejadas nesta pesquisa. ENTIDADE-COMPERNAS parece remeter apenas a entidades humanas. No entanto, há exemplos que fazem uso desse mesmo CL, mas não remetem a "pernas", como o sinal BARATA (no qual o CL remete as antenas) ou BODE (no qual o CL remete ao chifre). Agradecemos ao Professor André Xavier por nos chamar atenção para essa questão.

${ }^{27} \mathrm{O}$ sinal CL ENTIDADE-RETA5 $\mathrm{CL}$ está sendo realizado com o dedão distendido. Consideramos que esse uso do dedão reflete a regra do dedão distendido (Cf. BATTISON; MARKOWICZ; WOODWARD, 1975; WOODWARD, 1976; SUWIRYO, manuscrito). Na libras, esse dedão distendido ocorre comumente na realização dos CLs ENTIDADE-RETA5 $5_{C L}$, ENTIDADE-PLANA1 $1_{C L}$, ENTIDADEPLANA3 ${ }_{C L}$, e com vários sinais, como NÃO-PODER, por exemplo.

${ }^{28} \mathrm{Em}$ (3), lê-se: "cavalinho de balanço" é composto pelo sinal CAVALO e, na sequência, o sinal CL ENTIDADE-PLANA2 $C L$ com um verbo de $M$, BALANÇAR, realizado pela mão esquerda $e$, simultaneamente, o sinal CL ENTIDADE-RETA5 $5_{C L}$ é realizado com a mão direita. 
(5)

ENTIDADE-RETA3 $3_{C L}-P I N T A R(M)|| E N T I D A D E-P L A N A 1_{C L}$ "desenhar"

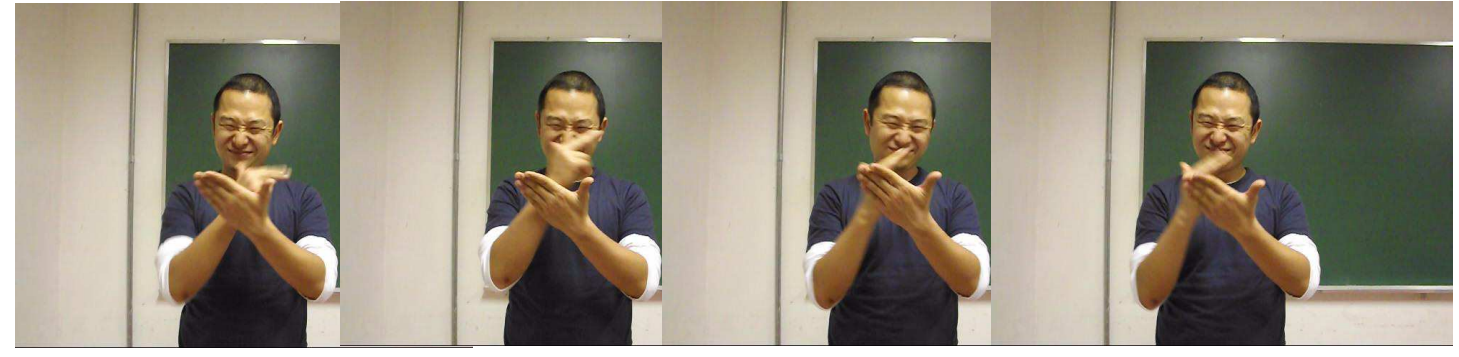

ENTIDADE-RETA3 ${ }_{C L}-P I N T A R(M) m d|| E N T I D A D E-P L A N A 1_{C L} m e-$

O sinal em (2) apresenta duas partes, dois outros sinais, compondo seu significado, CASA $A_{C L}$ e, sequencialmente, ESTUDO, formando "escola". O sinal em (3) apresenta uma série de curiosidades: i) apresenta dois sinais CLs diferentes, nomeadamente ENTIDADE-PLANA2 ${ }_{C L}$ e ENTIDADE-RETA5 ${ }_{C L}$; ii) um desses sinais CLs está acompanhado por um verbo de $M$, ENTIDADE-PLANA2 $\mathrm{CL}^{-}$ BALANÇAR(M)me, o outro não; iii) o $C L$ com o verbo de $M$ e $\circ C L$ simples são realizados simultaneamente; iv) $O C L$ com o verbo de $M$ pode ser reinterpretado como "cavalo" ou "animal grande em pé" e o outro $C L$ pode ser reinterpretado como "pessoa"; v) o primeiro sinal, CAVALO, é realizado sequencialmente; vi) todos esses sinais compõem um novo significado "cavalinho de balanço". O sinal em (4) também é simultâneo e forma um novo significado, mas é peculiar porque é formado por um sinal manual e um não-manual, ou seja, uma ENM realizada pela boca ${ }^{29}$. O sinal em (5) é frequentemente analisado como monomorfêmico, "desenhar", possivelmente pela influência da glosa em português que, comumente, apresenta uma única palavra. No entanto, com um olhar mais atento percebemos que é possível depreender duas unidades, ambas envolvendo CLs, ENTIDADE-RETA3 $\mathrm{CL}^{-}$ PINTAR(M) e ENTIDADE-PLANA1 1 LL. A primeira unidade pode ser reinterpretada como "pintar com pincel". E a segunda unidade pode ser reinterpretada como "papel" ou "superfície sobre a qual se pode pintar", contribuindo na composição do sinal.

Neste trabalho, seguimos as idéias de Brennan (1990), Meir et al (2005, e trabalhos subsequentes) e Zwitserlood (2002, e trabalhos subsequentes) no sentido de que consideramos que os sinais são formados por regras de formação de sinais

${ }^{29}$ Usamos "boca" aqui de forma mais simples para remetermos a sinais como SEXOb, em (4), nos quais estão envolvidos os lábios, a bochecha e, opcionalmente, a língua, como articuladores primários. 
bastante produtivas. Assumimos que, bem como nas LOs, na libras encontraremos palavras que também equivalem a um morfema, como "sim" no PB (português brasileiro). Porém, em diversos casos, temos sinais morfologicamente complexos, o que será mais detalhado a partir do capítulo 3.

Para determinarmos se os dados observados são, de fato, compostos na libras precisaremos investigar, primeiramente, a estrutura interna desses dados, 0 que, requer a investigação de quatro eixos principais: a) a natureza dos CLs que aparecem naqueles dados; b) o estatuto do sinal realizado não-manualmente, pela boca; c) as classes de palavras dos elementos envolvidos na estrutura interna desses dados; e, d) a natureza do fenômeno da composição nas línguas naturais.

Sobre os CLs envolvidos nos dados apresentados, podemos fazer algumas observações iniciais. Por um lado, há CLs com verbos de $M$, o que sugere uma estrutura de incorporação (Cf. MEIR, 2001). Na literatura, esse tipo de dado é chamado de predicados CLs (Cf. SUPALLA, 1982, 1986; BERNARDINO, 2006; VELOSO, 2008). Por outro lado, há CLs sem verbos de $M$, como em (2), CASA ${ }_{C L}$; (3) ENTIDADE- RETA5 $\mathrm{CL}$, "pessoa"; (5), ENTIDADE-PLANA1 $1_{\mathrm{CL}}$, "papel”, ou seja, formando nomes. Se, por um lado, as construções apresentadas de (2) a (5) são muito comuns nas LSs, por outro, há controvérsia sobre esse tipo de formação tratar-se ou não de composição. A natureza dessa dúvida reside nas diferentes concepções atribuídas aos CLs, como morfemas, sinais ou gestos, por exemplo. Assim, a partir da observação desses dados, algumas perguntas são pertinentes:

1- Qual é o estatuto dos CLs?

2- Como as construções simultâneas com CLs são formadas?

Os sinais realizados não-manualmente, como SEXOb em (4), sugerem as seguintes questões:

3- Qual é o estatuto de elementos sinalizados com a boca como articulador primário? 
4- Como as construções simultâneas formadas por elementos sinalizados pela boca e sinais manuais são formadas? Podemos dizer que elas formam compostos na libras?

Quanto ao terceiro eixo apontado, observamos que algumas análises sobre formação de compostos nas LOs levam em conta a classe de palavras à qual pertence cada uma das bases que formam um composto. Por sua vez, identificar a categoria das bases que formam um composto na libras não é tarefa trivial. Como detalharemos no capítulo 4, estudos sobre classes de palavras na libras revelam que há diversos pares nome-verbo que, aparentemente, figuram em uma única forma. Sendo assim, nossos dados requerem descrição e análise minuciosas no que concerne à natureza das classes de palavras nessa língua. Pretendemos, portanto, buscar outras formas de identificação para as classes de palavras na libras. Dessa forma, poderemos avaliar os sinais que formam os dados sob investigação nesta tese, definir se tratam-se de compostos ou não e sugerir uma estrutura para tais dados. Assim, mais algumas questões se colocam:

5- Quais são as semelhanças e diferenças entre os membros dos pares nomes-verbos na libras?

6- Como é possível identificar a categoria das partes envolvidas nos dados que vimos observando?

Sobre a composição na libras, podemos dizer que dados sequenciais, como aquele em (2), vêm sendo tratados como compostos na literatura (Cf. QUADROS; KARNOPP 2004; FELIPE, 2006; FIGUEIREDO SILVA; SELL, 2009). Já dados com CLs, sinais realizados pela boca, ou dados simultâneos como aqueles em (3), (4) e (5) ainda não foram estudados na libras, bem como em muitas outras LSs. Com base nos apontamentos e nos sinais apresentados acima, algumas questões se colocam de modo mais geral:

7- O que são compostos? 
8- Quais são os tipos de compostos existentes na libras? Podemos dizer que construções com CLs formam compostos nessa língua? O conhecimento das propriedades das classes naturais na libras nos revela algo sobre as suas formas compostas?

9- Como identificaremos compostos sequenciais e compostos simultâneos na libras?

10- Como se dá, morfossintaticamente, a formação dos compostos nessa língua, considerando-se as possibilidades de sequencialidade e de simultaneidade?

Por conta da interpretação mais geral dos dados já apresentados, nos quais a junção de dois sinais leva a um significado diferente, nossa hipótese principal é que dados como os de (2) a (5) são formas compostas.

Para a sustentação da hipótese principal, outras três hipóteses secundárias se colocam:

a) os CLs são morfemas;

b) os sinais boca funcionam da mesma forma que sinais simples; $\mathrm{e}$,

c) a simultaneidade observada em nossos dados é apenas superficial.

Como já indicamos acima, precisamos fazer uma discussão sobre o estatuto dos CLs, pois a definição de CL lançará luz sobre a natureza dos dados apresentados e do fenômeno da composição nas LSs. Se os CLs são morfemas anexados a raízes, fazendo parte de estruturas minimamente complexas (um morfema categorizador e uma raiz), podemos dizer que dados comumente chamados de CLs, como a última parte do sinal em (3), ENTIDADE-RETA5 $5_{\mathrm{CL}}$, "pessoa", na verdade, é um "sinal CL" (a raiz concatenada com um CL, formando um nome, $n \mathrm{n}[\mathrm{n}[\mathrm{CL}] \sqrt{ }]$ ). De modo geral, os dados apresentados poderiam, então, ser tratados como compostos formados com dois ou mais sinais CLs, sequencialmente ou simultaneamente, como a segunda parte do sinal em (3), ENTIDADE-PLANA2 $\mathrm{CL}^{-}$ BALANÇAR(M)||ENTIDADE-RETA5 $5_{C L}$ "bichinho de balanço". Nos casos de simultaneidade, consideraríamos que há uma mesma derivação que forma 
compostos nas línguas naturais, de modo geral, e a simultaneidade só se daria na realização, pós-sintaticamente.

Essa investigação nos levará a uma descrição apurada dos dados da libras e, assim, a um maior conhecimento dos processos morfológicos dessa língua. Além disso, verificaremos como o modelo da MD funciona considerando-se uma língua de modalidade visuo-espacial.

Esta tese está organizada da seguinte forma. No capítulo 2, explicitaremos nossa metodologia de coleta de dados e nosso primeiro agrupamento para os compostos potenciais encontrados, dividindo-os em formações sequenciais, simultâneas e simultâneo-sequenciais. Introduziremos também os pressupostos teóricos adotados na tese.

A seguir, no capítulo 3, apresentaremos a literatura sobre CLs nas LOs e nas LSs e definiremos o estatuto dos CLs, conforme o assumiremos para a análise dos dados nesta tese.

No capítulo 4, apresentaremos a literatura sobre classes de palavras nas LSs. Nesse último caso, investigaremos as possíveis diferenciações entre os membros dos pares nome-verbo na libras, e determinaremos se a identificação categorial dos sinais da libras pode, ou não, ser relevante para a definição dos dados em análise nesta tese como compostos dessa língua.

No capítulo 5, apresentaremos a literatura sobre compostos nas LOs e nas LSs, visando discutir mecanismos de identificação de compostos nas línguas naturais, de modo geral, e determinar se os dados da libras coletados podem, ou não, ser morfossintaticamente formados por composição.

O capítulo 6 traz nossas considerações finais. 


\section{Compostos potenciais e pressupostos teóricos}

Este capítulo traz a base empírica e teórica que vai dar suporte para esta pesquisa e será de grande relevância para as análises apresentadas nos próximos capítulos.

Primeiramente, traremos uma série de dados que apontamos como "compostos potenciais". Durante a apresentação desses dados, traremos uma divisão inicial entre dados sequenciais, simultâneos, e simultâneo-sequenciais. Em seguida, apresentaremos os pressupostos teóricos relevantes para nossa pesquisa.

Este capítulo tem a seguinte organização. Detalharemos, em 2.1, a metodologia de coleta de dados usada para eliciar dados naturais da libras e, em 2.2, apresentaremos os compostos dessa língua descritos na literatura, discutindo a padronização das anotações. Na sequência, em 2.3, estão nossos dados eliciados com dois colaboradores surdos já com as glosas seguindo nossa convenção e, em 2.4, apresentamos um levantamento de compostos potenciais dicionarizados em Capovilla, Raphael \& Maurício (2012), também acompanhado com nossas glosas. Os pressupostos teóricos da MD serão apresentados em 2.5 e, em 2.6, discutiremos a noção de fase na palavra. Finalmente, em 2.7, apresentaremos as considerações finais deste capítulo.

\subsection{Metodologia de coleta de dados}

Para o desenvolvimento desta pesquisa, fizemos um levantamento de dados de composição na literatura da libras. Consultamos o maior dicionário de libras em duas versões Capovilla \& Raphael (2001) e Capovilla, Raphael \& Maurício (2012). Além disso, fizemos uma coleta da produção de três sinalizantes da libras, adultos, membros da comunidade surda, moradores do estado de São Paulo, e que são professores de libras ${ }^{30}$.

\footnotetext{
${ }^{30}$ Os dados foram coletados dentro do projeto intitulado "As alterações no processamento da linguagem expressas na língua de Sinais Brasileira por surdos com lesão cerebral" desenvolvido pelo Prof. Or. Felipe Venâncio Barbosa (USP), pela Profa. Dra. Bencie Woll (College London), e Aline Garcia Rodero Takahira (Doutoranda pela USP). Os dados coletados por mim e que usamos para o
} 
No que concerne à coleta de dados, primeiramente, observamos os dados em contexto natural, em conversas com membros da comunidade surda, fluentes no uso da libras. Em seguida, fizemos gravações com os três colaboradores surdos ${ }^{31}$ com o intuito de confirmar a produtividade de alguns dados já observados em uso e de ilustrar os sinais mencionados neste trabalho. Nossa preocupação em trazer dados de fato usados por sinalizantes surdos exigiu de nós um cuidado com o sistema de coleta de dados, para que não fossem contaminados pela influência do PB. Usamos, então, diversas figuras para eliciar os dados. Foram 3 testes coletados em épocas diferentes com os três sinalizantes surdos (um deles participou apenas da primeira coleta piloto, em 2012, que posteriormente foi descartada) ${ }^{32}$.

Para a coleta de dados de forma espontânea, mostramos figuras, fotos e/ou quadrinhos, sem o uso da língua portuguesa escrita ou de datilologia. Os PPT contendo as imagens e/ou figuras utilizadas estão disponíveis no Anexo 5 desta tese. Cada slide foi mostrado, um por vez, e foi pedido aos colaboradores que fizessem uma frase, contassem uma história, verdadeira ou não, ou dessem sua opinião sobre o assunto ilustrado pela(s) figura(s). Dessa forma, os dados necessários foram eliciados. As ilustrações mostradas tinham como intuito fazer 0 sinalizante usar vários tipos de sinais na sinalização, entre eles: sinais que consideramos formados por composição, CLs, incorporação de numeral, verbos direcionais ou pares nome-verbo. Os estímulos foram apresentados randomicamente de forma a não permitir o reconhecimento dos objetivos da pesquisa por parte dos colaboradores.

Foi necessária, ainda, uma grande atenção ao sistema de transcrição e anotação de dados. Em um primeiro momento, adotamos uma ferramenta de anotação amplamente utilizada para as LSs, o ELAN (the Eudico - "European Distributed Corpus" Project - Linguistic Annotator) que é um programa desenvolvido

desenvolvimento desta tese serviram como "teste piloto" para o referido projeto, que foi aprovado pela Comissão de Ética em Pesquisas com Seres Humanos do Instituto de Ciências Biomédicas da USP (ICB-USP), na sessão realizada no dia 07.12.2011 sob o parecer 1035/CEP. As gravações foram realizadas entre 2012 e 2013.

${ }^{31} \mathrm{O}$ termo de consentimento livre e esclarecido está no Anexo 6.

32 Agradecemos ao Prof. Dr. Felipe Venâncio Barbosa (comunicação pessoal) por ter nos chamado atenção para o fato de que o uso da datilologia antes da apresentação das histórias por um dos sinalizantes poderia fazer com que o português escrito influenciasse a sequência da sinalização. Tais dados foram descartados nesta pesquisa e não prosseguimos novas coletas com um dos colaboradores. Também devemos agradecer ao Professor Felipe pelas discussões de metodologia de coleta de dados. 
pelo Max Planck Institute for Psycholinguistics in The Netherlands ${ }^{33}$, e, como Bickford (2005) ressalta, pode facilitar muito o estudo das LSs. Essa ferraenta é muito útil no sentido de possibilitar uma análise minuciosa dos vídeos permitindo fazer anotações em um arquivo de vídeo, sinal por sinal, descrevendo-os minuciosamente em relação à cada parâmetro e com glosas. Para aprendermos a usar essa ferramenta, inicialmente seguimos o manual da versão 4.6 (Cf. HELLWIG, 2013), disponível no site no qual baixamos o programa. Para conhecermos as anotações usadas em transcrições da libras e em outras LSs, partimos da investigação sobre sistemas de transcrição, como Ferreira-Brito (1995); Bickford (2005); Bickford \& Fraychineaud (2006); McCleary \& Viotti (2007); e, McCleary, Viotti \& Leite (2010). Esses trabalhos buscam especificar um sistema de anotação das LSs para uso no ELAN.

Mesmo com os avanços desses trabalhos, o sistema de anotação a ser usado no ELAN ainda é um projeto de pesquisa em andamento, ou seja, ainda não há especificações detalhadas para todos os tipos de anotações a serem usadas. Podemos exemplificar com ENMs que ainda representam um desafio para se chegar a uma convenção para anotação. Não encontramos especificações para o tipo de anotação usada para configurações e movimentos de cabeça, tronco ou ombros naqueles trabalhos. Bickford \& Fraychineaud (2006), que trazem uma forma de anotação para alguns movimentos de boca, atrelam movimentos de boca a outros articuladores não manuais: a cabeça e os ombros. Um sistema de anotação individual para cada ENM é algo de grande importância, pois como McCleary, Viotti \& Leite (2010) afirmam, a descrição de cada detalhe pode levar à percepção de características linguísticas antes despercebidas.

Apesar de ser de nosso interesse, esta pesquisa não se debruça sobre as diversas formas propostas para transcrição que talvez pudessem servir como forma de anotação para diversas trilhas no ELAN, e nem para encontrar formas de anotação de ENMs. Ressaltamos que o uso do ELAN foi fundamental para: i) observarmos detalhes das sinalizações em vídeo, desacelerando o ritmo da gravação e congelando imagens, o que nos permitiu observar detalhes que passariam despercebidos no ritmo normal de sinalização; e ii) fazer anotações iniciais em cada vídeo, as quais pudemos consultar ao longo da pesquisa.

\footnotetext{
${ }^{33}$ Veja mais sobre o ELAN em http://tla.mpi.nl/, de onde o programa pode ser baixado gratuitamente.
} 
Com o intuito de se chegar a uma apresentação e anotação mais claras, práticas e detalhadas dos sinais da libras, nesta tese, decidimos usar as convenções apresentadas nas páginas $x i$ a $x v$ dos elementos pré-textuais, acima, junto com as imagens dos dados coletados. As convenções tomam como base as anotações de dados utilizadas em vários trabalhos, como Ferreira-Brito (1995), Quadros \& Karnopp (2004) e Felipe (2006). Buscamos padronizar pequenas diferenças entre as glosas utilizadas naqueles trabalhos, como será um pouco mais detalhado na próxima seção, para otimizar a visualização e o entendimento dos dados nesta pesquisa. Principalmente no que diz respeito à anotação de CLs, buscamos chegar a uma forma de anotação o mais transparente possível, de modo que as palavras do português usadas na anotação não interferissem ou influenciassem na interpretação, no entendimento e na análise dos dados, como já foi apresentado nas páginas $x i$ a $x v$ dos elementos pré-textuais e será discutido no capítulo 3.

\subsection{Compostos na literatura da libras e padronização das glosas}

Para começarmos a discussão voltada mais especificamente para a questão da composição na libras, fizemos um levantamento inicial de compostos na literatura sobre essa língua: Quadros \& Karnopp (2004), Felipe (2006) e Figueiredo Silva \& Sell (2009). Esses dados estão listados no quadro abaixo e, aqueles que apresentam fotos ou figuras, os dados de Quadros \& Karnopp (2004), estão no Anexo 1.

\begin{tabular}{|l|l|}
\hline Autor & Compostos apresentados $^{34}$ \\
\hline Quadros \& Karnopp (2004) & a. ACREDITAR (saber + estudar) \\
& b. ESCOLA (casa + estudar) \\
& c. PAIS (PAI + MÃE) \\
& d. BOA-NOITE (BOA + NOITE) \\
& e. ACIDENTE (carro + bater) \\
\hline
\end{tabular}

\footnotetext{
${ }^{34}$ Estamos mantendo a anotação exata do dado como apresentada em cada trabalho.
} 


\begin{tabular}{|c|c|}
\hline Felipe $(2006)^{35}$ & $\begin{array}{l}\text { a. CAVALO^LISTRA-PELO-CORPO (CAVALO + } \\
\text { LISTRA-PELO-CORPO = "zebra") } \\
\text { b. MULHER^BEIJO-NA-MÃO (MULHER + BEIJO-NA } \\
\text { MÃO = "mãe") } \\
\text { c. CASA^ESTUDAR (CASA + ESTUDAR "escola") } \\
\text { d. ASSINAR^SEPARAR (ASSINAR + SEPARAR = } \\
\text { "divórcio") } \\
\text { e. COMER^MEIO-DIA (COMER + MEIO-DIA = } \\
\text { "almoço") } \\
\text { f. coisa-pequena^PERFURAR "alfinete" } \\
\text { g. coisa-pequena^APLICAR-NO-BRAÇO "agulha" } \\
\text { h. DORMIR^pessoa+ "alojamento" } \\
\text { i. COSTURAR-COM-AGULHA^A-G-U-L-H-A "agulha". }\end{array}$ \\
\hline $\begin{array}{l}\text { Figueiredo Silva \& } \\
\text { (2009) }\end{array}$ & $\begin{array}{l}\text { i) [HOMEM / MULHER + N] para profissões: } \\
\text { a. HOMEM^VIGIA [vigia] } \\
\text { b. HOMEM^RURAL [agricultor] } \\
\text { c. HOMEM^MANGUEIRA [bombeiro] } \\
\text { d. HOMEM^VENDA [vendedor] } \\
\text { e. HOMEM^CONSTRUÇÃO [pedreiro] } \\
\text { f. HOMEM^CONSERTO [mecânico] } \\
\text { g. HOMEM^DIGITAÇÃO [caixa de banco, de } \\
\text { lotérica, etc] } \\
\text { h. HOMEM^FEIRA [feirante] } \\
\text { i. MULHER^COSTURA [costureira] } \\
\text { ii) [CASA + N] para lugares/locais: } \\
\text { a. CASA^ESTUDO [escola] } \\
\text { b. CASA^CRUZ [igreja] } \\
\text { c. CASA^ANTIG@ [museu] } \\
\text { iii) Combinações diferentes da forma [CASA + N] para } \\
\text { lugares/locais: } \\
\text { a. MORTE^CRUZ [cemitério] } \\
\text { b. CONSERTO^CARRO [oficina mecânica] }\end{array}$ \\
\hline
\end{tabular}

${ }^{35}$ A autora menciona que há links no anexo para pastas com as filmagens dos compostos, mas os links não abrem. As filmagens já não estão mais disponíveis online. 


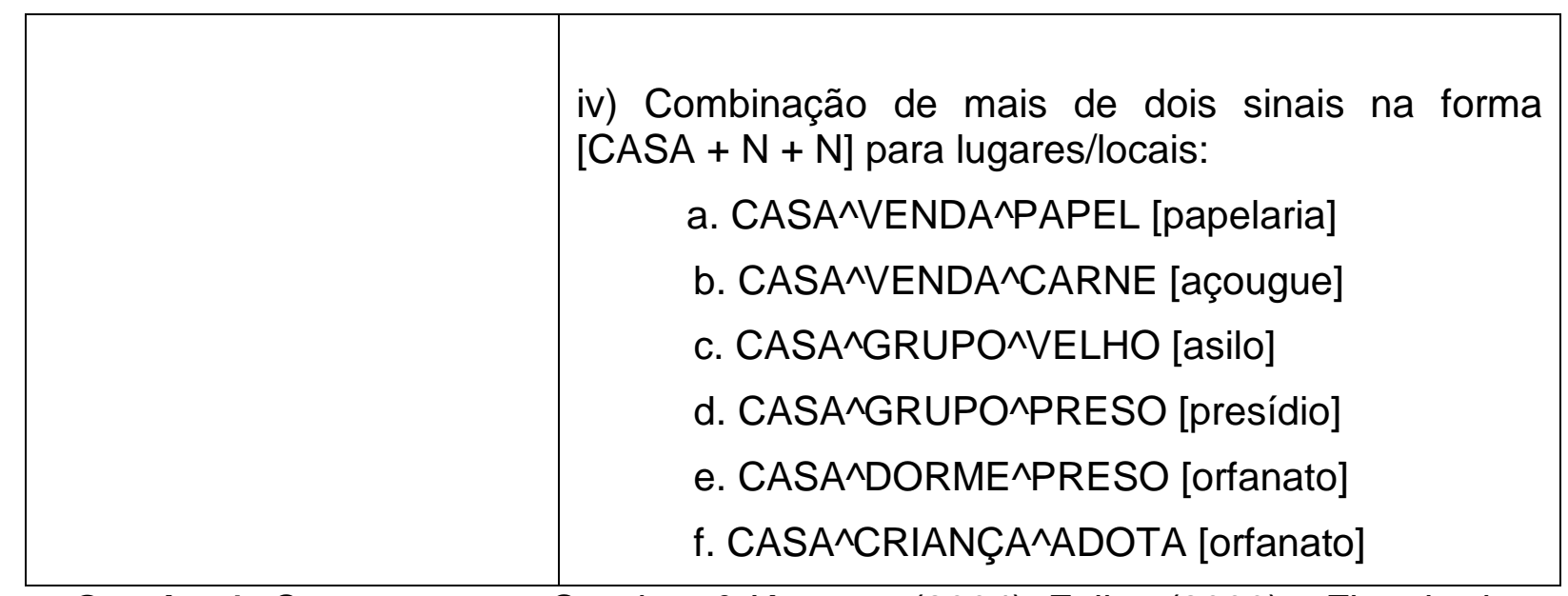

Quadro 1: Compostos em Quadros \& Karnopp (2004), Felipe (2006) e Figueiredo Silva \& Sell (2009)

Pensando no modo que as transcrições vêm sendo apresentadas na literatura sobre a libras, a primeira forma em caixa alta no trabalho de Quadros \& Karnopp (2004), ACREDITAR, por exemplo, é uma tradução do composto para seu significado final em português. No entanto, caixa alta faz pensar que remete a um único sinal da libras, o que não é o caso. E "(saber + estudar)" dão a impressão de serem traduções para o português por estarem em caixa baixa, mas, na verdade, remetem aos dois sinais que formam o composto. A informação entre parênteses varia entre caixa alta e caixa baixa. O sinal de + mostra que é uma composição, mas, em outros trabalhos, serve para indicar plural.

Já Felipe (2006), usa caixa alta para mostrar que as palavras do português referem-se a sinais da libras, ^ para indicar que o sinal é composto, e hífen para indicar que são várias palavras em português remetendo a um único sinal da libras. A autora varia no conteúdo entre parênteses, algumas vezes coloca cada sinal da libras em caixa alta, com um + para indicar composição e = para indicar a tradução entre aspas (como em a/b/d/e), outras vezes não usa o sinal de = (como em c) e, em outras ainda, coloca apenas a tradução entre aspas (como em f/g/h/i). Ela também usa caixa baixa para indicar um sinal realizado como um CL (como em f/g/h), e + sobrescrito para representar a marca de plural de "pessoa", que na libras pode ser realizada pela repetição do sinal ou do CL (como em h).

Figueiredo Silva \& Sell (2009) são as autoras que trazem uma maior padronização, usando palavras do português em caixa alta, para se referir a cada 
um dos sinais que formam o composto, ^ para indicar que os dois sinais formam um composto, e a tradução em português em caixa baixa entre colchetes.

Em busca de uma padronização ainda mais refinada, tomamos esses trabalhos como base e propusemos as "convenções para a transcrição e anotação dos sinais" conforme indicado nos elementos pré-textuais desta tese. Resumidamente, os pontos principais são a adoção de:

a) ^ para indicar sequencialidade;

b) II para indicar simultaneidade;

c) CL subscrito para indicar um classificador semântico ${ }^{36}$; e,

d) ENTIDADE-X (onde $X$ é um formato) para indicar, neutramente, outros tipos de CLs.

Além de padronizarmos a glosa com o sistema para transcrição e anotação dos sinais, padronizamos a apresentação de uma tradução para o PB entre aspas na sequência.

Também vale ressaltar que, no quadro acima, há exemplos que são apontados como compostos e que contêm CLs. Há um exemplo realizado simultaneamente: ACIDENTE (carro+bater) ${ }^{37}$, na figura 1, no qual ACIDENTE é o significado do composto, "carro" é um dos sinais que forma o composto e "bater" é o verbo de $M$ :

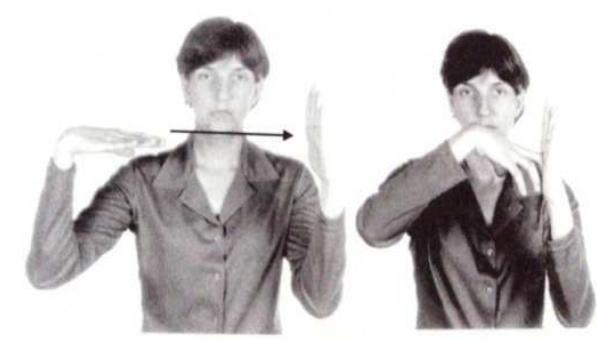

Figura 1: ACIDENTE (carro + bater) (QUADROS; KARNOPP, 2004, p.105)

\footnotetext{
${ }^{36}$ São CLs mais icônicos, que serão explicitados no capítulo 3.

37 Nesta subseção, mantivemos a apresentação dos dados conforme usado pelas autoras mencionadas no quadro.
} 
Usando nossas glosas deixamos mais claro o estatuto desse sinal como composto evidenciando suas partes realizadas simultâneo-sequencialmente: ENTIDADE-PLANA2 ${ }_{\mathrm{CL}-M O V E R(M)|| E N T I D A D E-P L A N A} 1_{\mathrm{CL}}{ }^{\wedge}$ ENTIDADE-SEMICIRCULAR1_-BATER(M)||ENTIDADE-PLANA1 $\mathrm{CL}$. E há alguns exemplos realizados sequencialmente, como: ESCOLA (casa + estudar), em que "casa" é um CL semântico; CAVALO^LISTRA-PELO-CORPO (CAVALO+LISTRA-PELO-CORPO = "zebra"), em que LISTRA-PELO-CORPO é um CL do tipo SASS de forma; coisapequena^PERFURAR "alfinete" e coisa-pequena^APLICAR-NO-BRAÇO "agulha", em que "coisa-pequena" é um CL instrumental; DORMIR^pessoa" "alojamento", em que "pessoa" é um CL de partes do corpo; MULHER^COSTURA [costureira], em que costura envolve um $C L$ instrumental e um $C L$ de mão base (ENTIDADE-PLANA1 $1_{C L}$ ); entre outros ${ }^{38}$.

Tais exemplos mostram que, apesar de as autoras não explicitarem esse fato, elas consideram dados com CLs, realizados sequencial ou simultaneamente, como sinais formados por composição. No próximo capítulo e no capítulo 5 , vamos esmiuçar a natureza de dados desse tipo.

Pensando nessa possibilidade de se formarem compostos com sinais envolvendo CLs, ampliamos nossa lista buscando mais dados em sinalização natural e nos dicionários de libras de Capovilla \& Raphael (2001) e, principalmente, Capovilla, Raphael \& Mauricio (2012), como mostramos nas próximas subseções.

\subsection{Uma classificação dos possíveis compostos na libras: dados da coleta}

Como já mencionamos acima, nas LSs, é possível formarem-se construções sequencial e simultaneamente. Também é possível formarem-se compostos com sinais envolvendo, ou não, CLs, como apontado na literatura. Pensando nesses casos, seria potencialmente possível encontrarmos, também, sinais simultâneosequenciais.

Ao observarmos os dados coletados, identificamos uma primeira possibilidade de organização desse material em subgrupos menores, ou seja, em construções:

\footnotetext{
${ }^{38}$ Todos esses tipos de CLs serão apresentados no próximo capítulo.
} 
i) sequenciais com:
a) dois sinais simples ( $\left.\sin a{ }^{\wedge} \operatorname{sinal}\right)$;
b) um sinal simples e um sinal $\mathrm{CL}($ sinal^sinal $\mathrm{CL})$;
c) dois sinais $C L s$ (sinal $\mathrm{CL}^{\wedge}$ sinal $\left.C L\right)$;
d) três ou mais sinais.

ii) simultâneas com:

a) um sinal boca e um sinal simples (sinal boca||sinal);

b) um sinal boca e um sinal CL (sinal bocal|sinal $\mathrm{CL})$;

c) um sinal CL (mão base) e um sinal CL (sinal CL base\|sinal CL);

d) um sinal CL (com verbo) e um sinal CL (sinal CLverbo||sinal $\mathrm{CL})$.

iii) simultâneo-sequenciais com: a) um sinal e, na sequência, dois sinais CLs - não necessariamente nessa ordem.

Nas próximas subseções, apresentaremos alguns exemplos de cada tipo.

\subsubsection{Dados sequenciais}

Encontramos dados sequenciais com dois sinais simples, um sinal simples e um sinal CL (não necessariamente nessa ordem) ou dois sinais CLs, como dividimos abaixo:

\section{a) Sinais simples (sinal^sinal):}


(6) CARNE^VENDER "açougue"

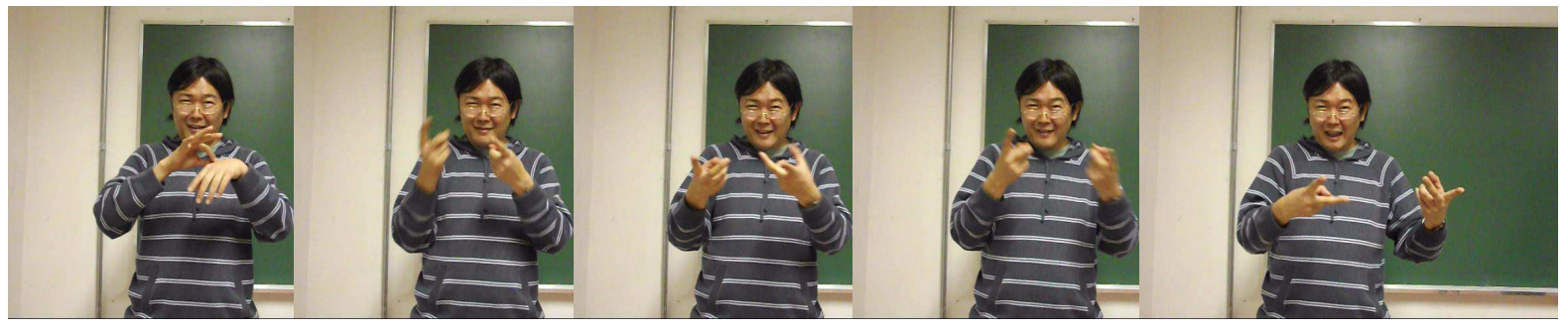

CARNE

VENDER

(7) SABER^ESTUDAR "acreditar"

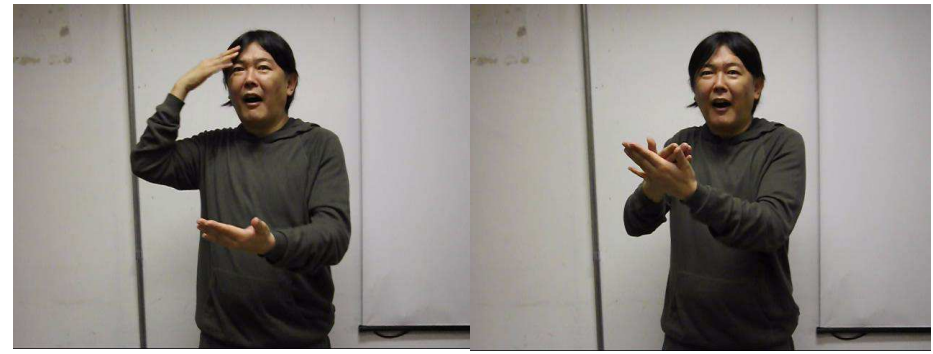

SABER

ESTUDAR

b) Sinal simples e Sinal Classificador (sinal^sinal CL) ${ }^{39}$

(8) $\mathrm{CASA}_{C L}{ }^{\wedge} \mathrm{ESTUDO}$ "escola"

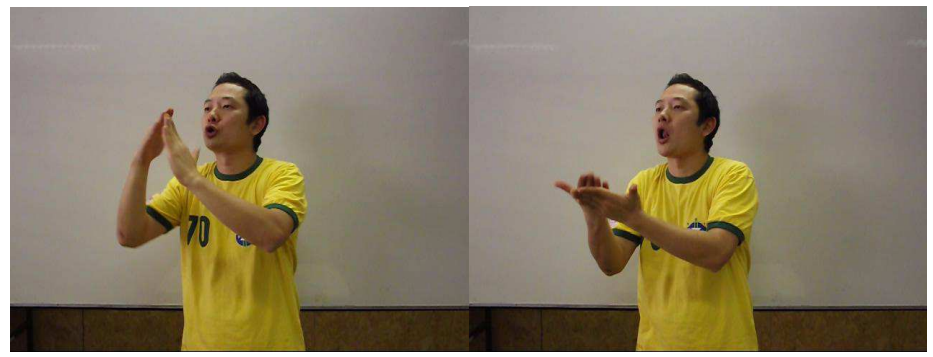

$\mathrm{CASA}_{\mathrm{CL}}$ ESTUDO

\footnotetext{
${ }^{39} \mathrm{Na}$ ordem "sinal^sinal CL" ou "sinal $\mathrm{CL}^{\wedge}$ sinal".

${ }^{40} \mathrm{O}$ estatuto do sinal CASA como sendo formado com um CL será discutido no capítulo 3.
} 
(9) FORMA-MEIA-LUA $\mathrm{CL}^{\wedge}$ VIAGEM "lua de mel"41

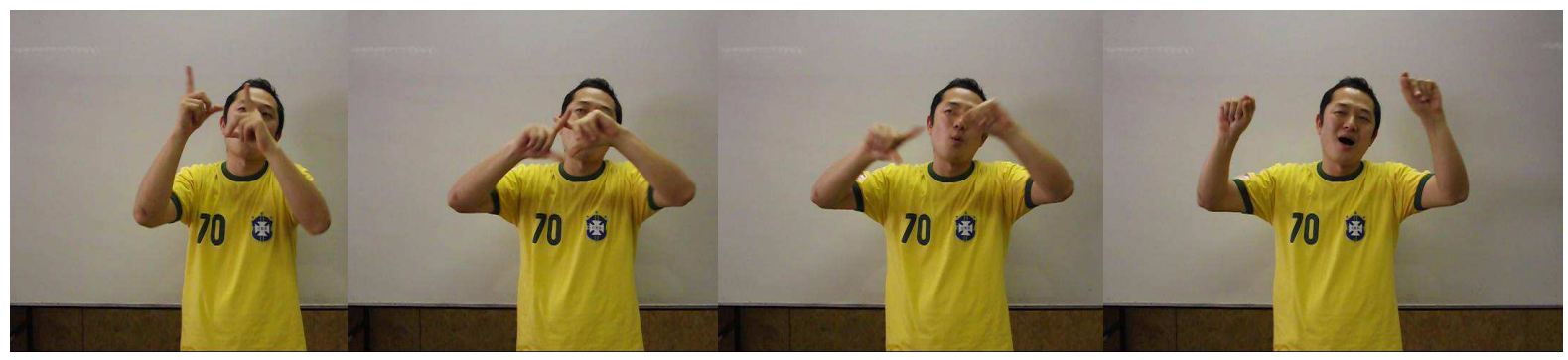

FORMA-MEIA-LUA $\mathrm{CL}$

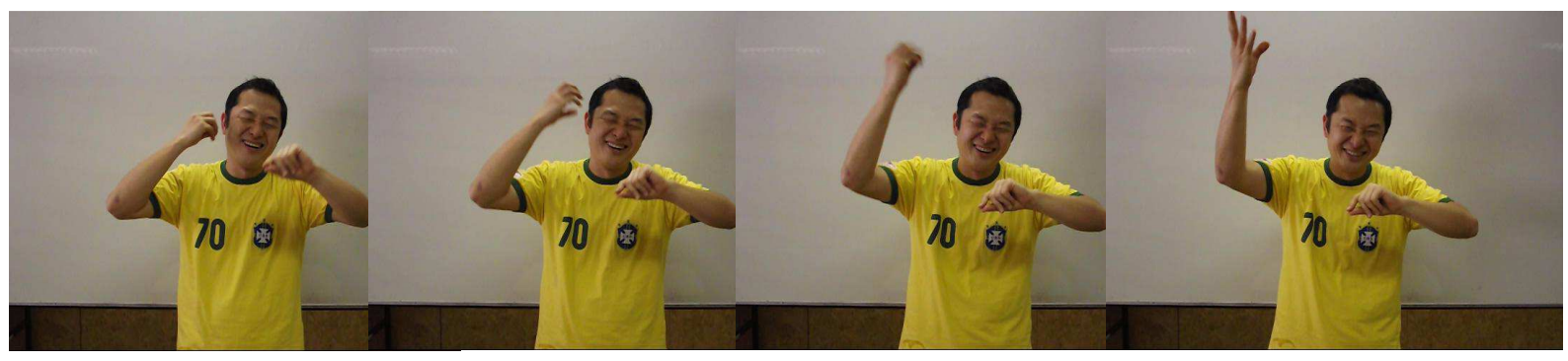

VIAGEM

ÁGUA^FORMA-CAMINHO CL "rio"

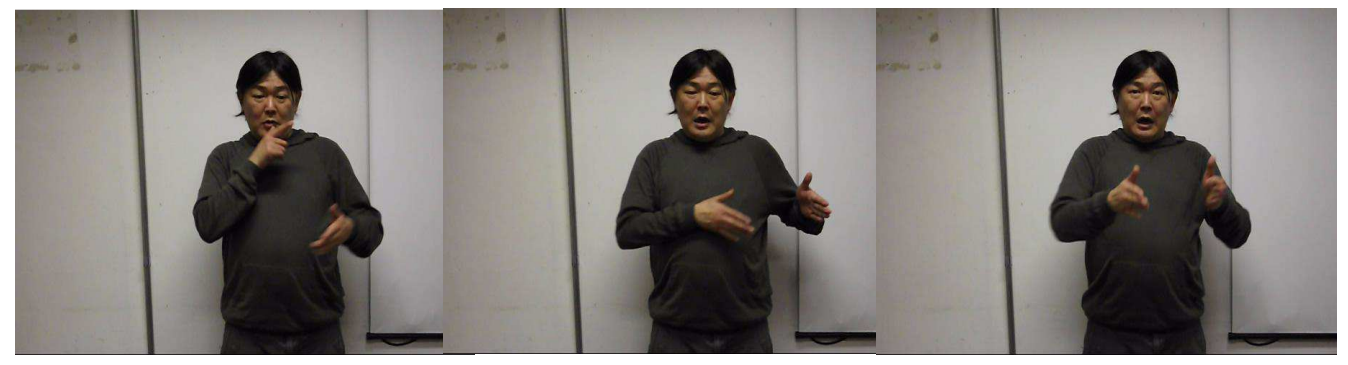

ÁGUA

FORMA-CAMINHO

c) Sinais Classificadores (sinal $C L^{\wedge}$ sinal $C L$ ):

\footnotetext{
${ }^{41}$ Nos CLs de forma, usamos a tradução do sinal para colocar o nome da glosa, no entanto, o que nos interessa aqui é o formato FORMA-MEIA-LUA que pode remeter à "lua", "melancia", ou até mesmo esse formato para um objeto, como uma caixa ou um gancho, por exemplo.
} 


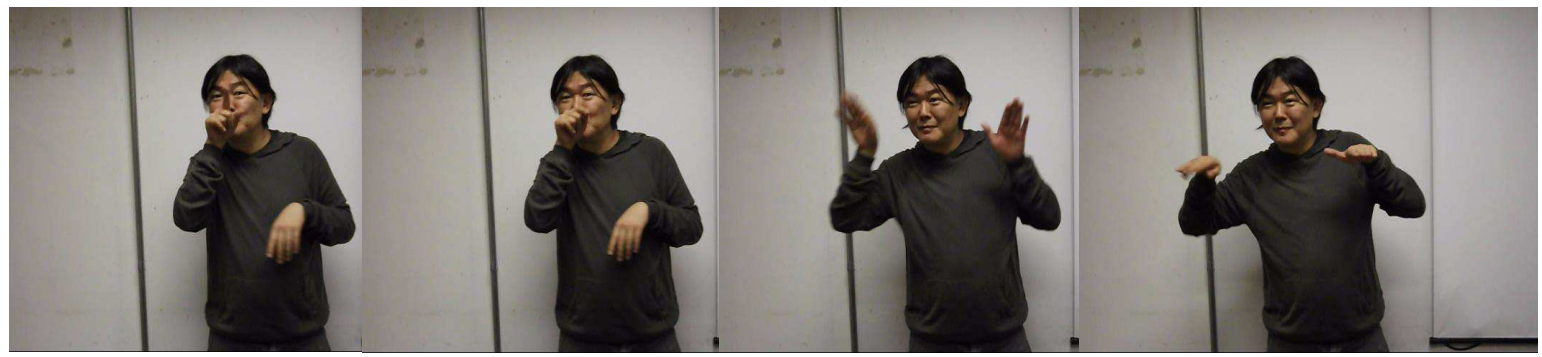

$\mathrm{BICO}_{\mathrm{CL}}$

$\mathrm{ASA}_{\mathrm{CL}}$

$\mathrm{CASA}_{\mathrm{CL}}{ }^{\wedge} \mathrm{CRUZ} \mathrm{Z}_{\mathrm{CL}}(1)^{42}$ “igreja”

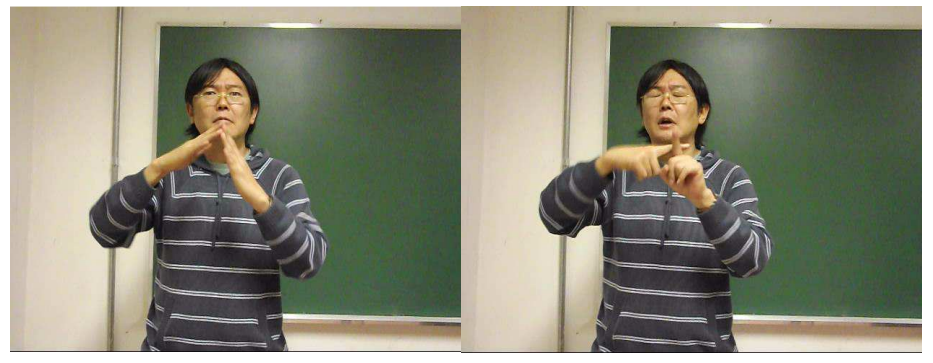

CASA $C L$

$\mathrm{CRUZ} \mathrm{Z}_{\mathrm{CL}}$

d) Dados sequenciais com três ou mais sinais:

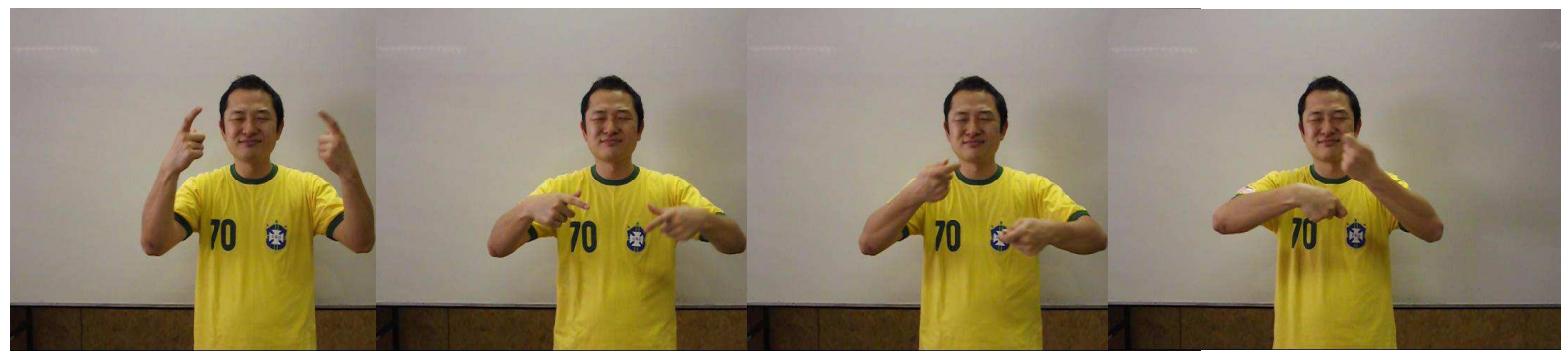

LUGAR LOJA

${ }^{42}$ Este número entre parênteses após o exemplo significa que essa é uma de duas ou mais formas encontradas para esse sinal, "igreja", em nosso conjunto de dados. Não remete ao exemplo (1), também indicado entre parênteses em outros pontos desta pesquisa. 


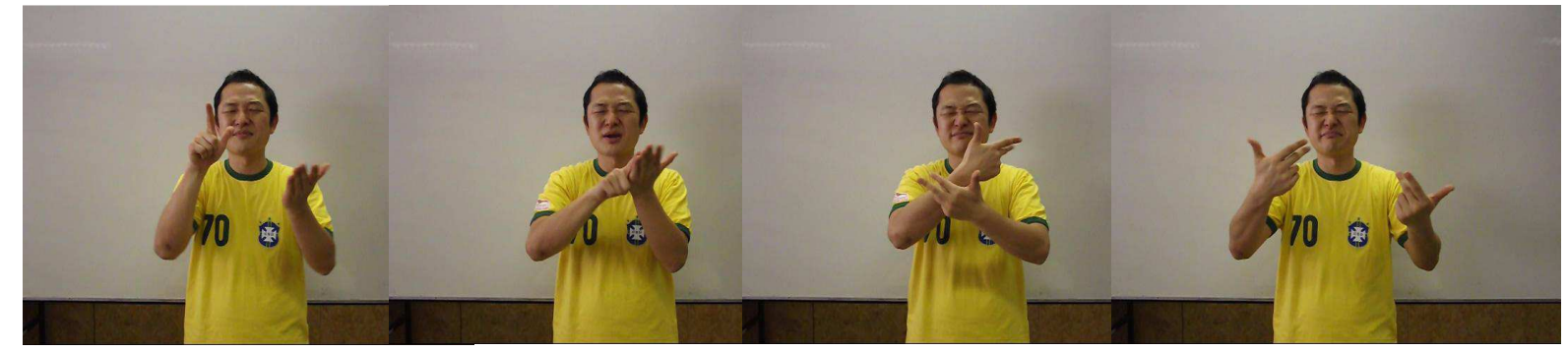

PAPEL

VÁRIOS

Também encontramos esse sinal como: CANETA $\mathrm{CL}^{\wedge}$ FORMA-

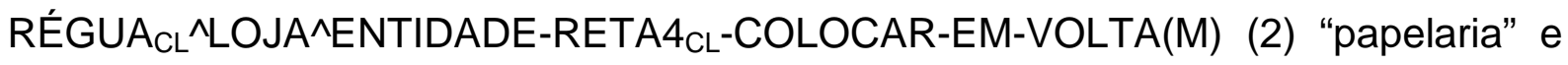
PAPEL^MATERIAL^VÁRIOS (3) "papelaria” (veja os exemplos no Anexo VII). Todas essas formas foram encontradas em nossos testes feitos com as coletas eliciadas por figuras com o intuito de gerar uma sinalização espontânea. No caso de CANETA $_{C L}{ }^{\wedge}$ FORMA-RÉGUA ${ }_{C L}{ }^{\wedge}$ LOJA^ENTIDADE-RETA4 $_{C L}-$ COLOCAR-EM-VOLTA (M) (2), é muito possível que a ilustração apresentada (veja a última figura do Anexo V) tenha influenciado na sinalização para uma forma de descrição, em vez do uso de um composto.

(14) HOMEM^INDIVÍDUO^TRABALHAR^CONSERTAR (1) "mecânico"

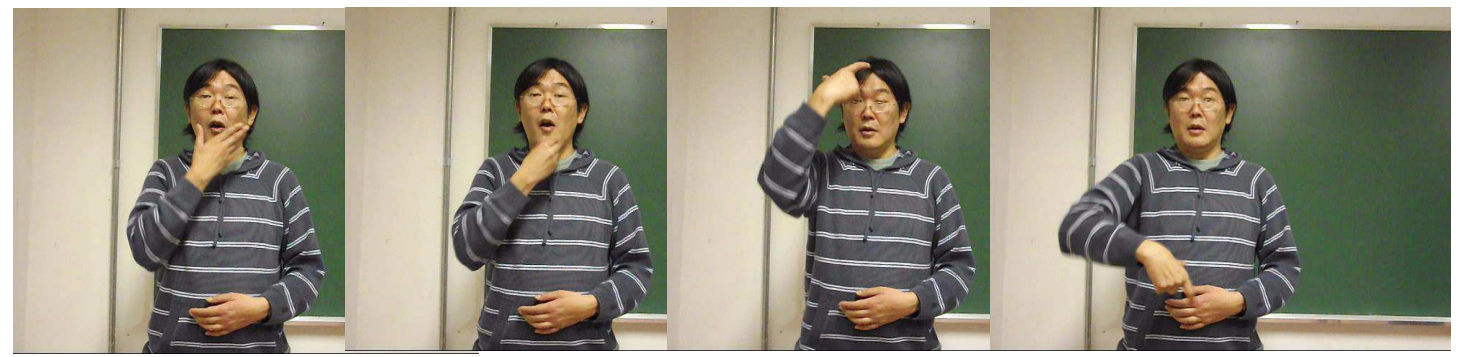

HOMEM INDIVÍDUO 


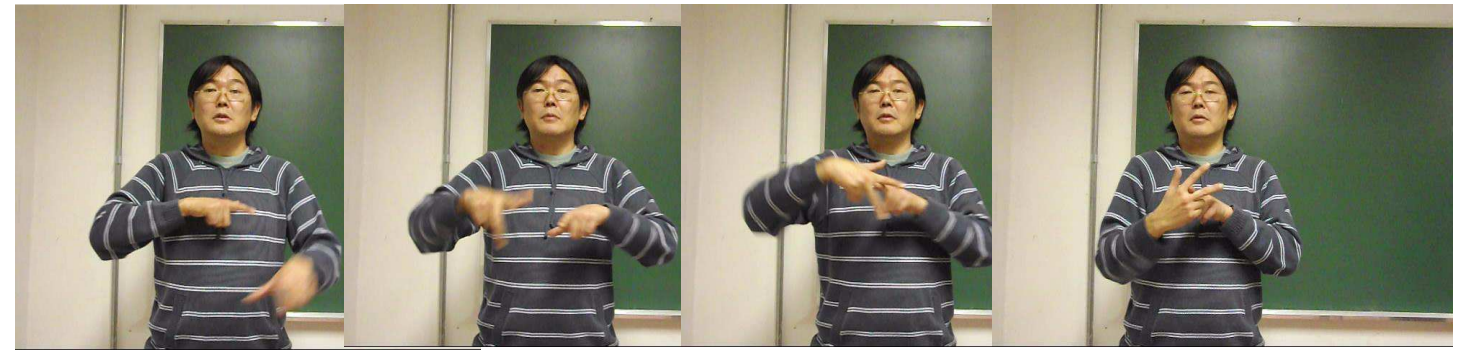

TRABALHAR

CONSERTAR ${ }^{43}$

Também encontramos o mesmo sinal apenas como: INDIVÍDUO^TRABALHAR^CONSERTAR (2) "mecânico".

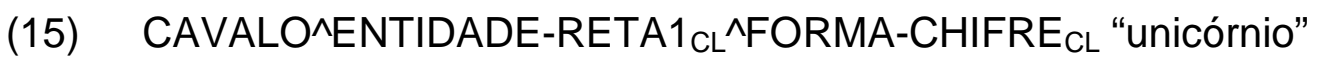

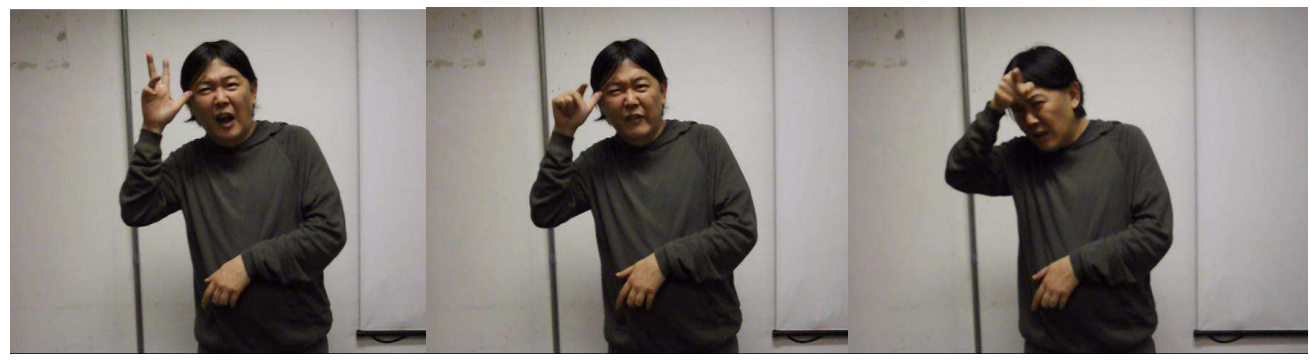

CAVALO

ENTIDADE-RETA1 $\mathrm{CL}$

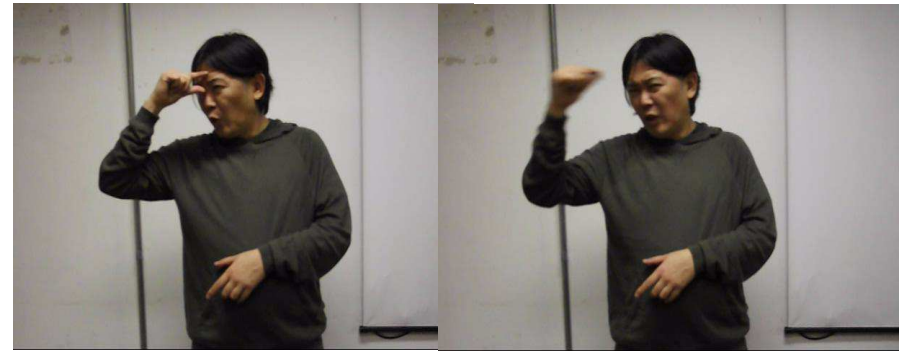

FORMA-CHIFRE ${ }_{C L}$

\subsubsection{Dados simultâneos}

Encontramos dados simultâneos com um sinal boca e um sinal simples; ou com sinais CLs, como dividimos abaixo:

$\overline{43}$ CONSERTAR, em (14), CAMA $A_{C L}$, em (17), ENTIDADE-RETA3 ${ }_{C L}$, "pincel", em (18), e ENTIDADE-

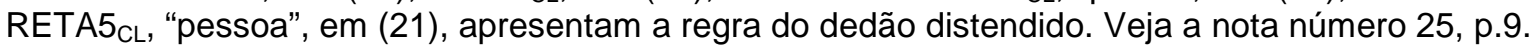


a) Sinal boca e Sinal simples (sinal boca||sinal):

(16)

SEXOb||VIAJAR "lua de mel"

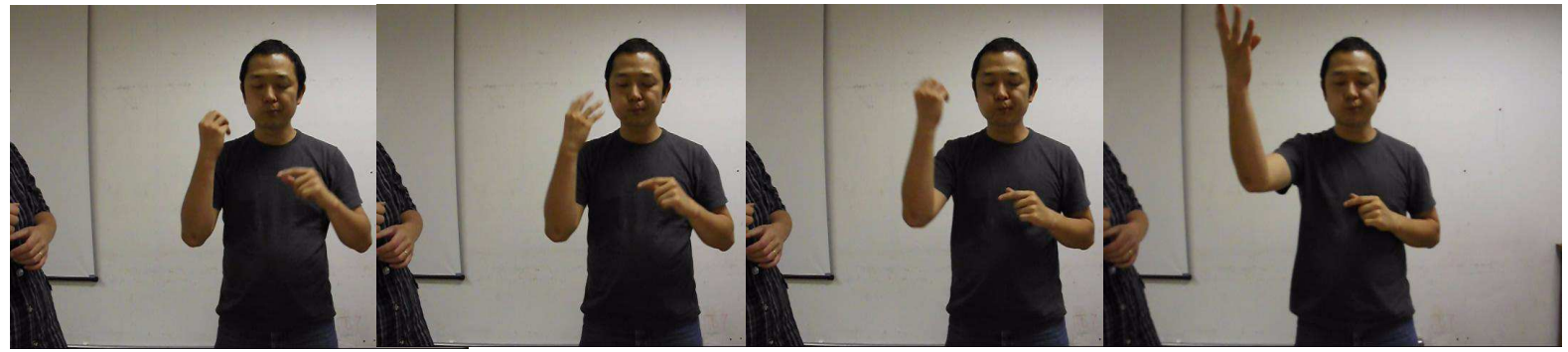

SEXOb||VIAJARmd

b) Sinal boca e Sinal Classificador (sinal boca||sinal CL):
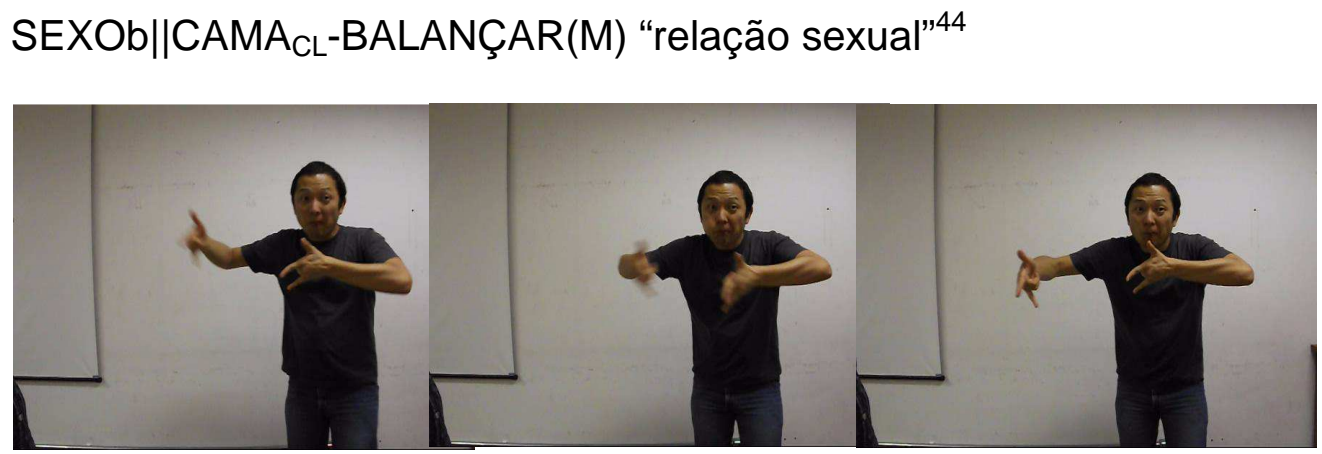

SEXOb ||CAMA ${ }_{C L}-B A L A N C ̧ A R(M)$

c) Sinal Classificador (mão base) e Sinal Classificador (Sinal CL-base ||Sinal $\mathrm{CL})$

44 BALANÇAR(M) aparece em 5 sinais ao longo da tese compondo os seguintes significados: "cavalinho de balanço", "relação sexual", "animal grande balançando" (ou "bichinho de balaço"), "aferir a temperatura" e "acrobata". Apesar de termos usado a mesma glosa em todos eles, alertamos para o fato de que o $\mathrm{M}$ em cada um desses sinais é qualitativamente diferente, o que pode sugerir que são verbos diferentes (agradecemos ao Professor André Xavier por nos chamar atenção para esse fato). No entanto, não vamos focar no detalhamento desse tipo de glosa para verbos de $M$ nesta tese e, portanto, optamos por adotar uma única forma, BALANÇAR(M). 
(18) ENTIDADE-RETA3 ${ }_{C L}-P I N T A R(M)|| E N T I D A D E-P L A N A 1_{C L}$ "desenhar"

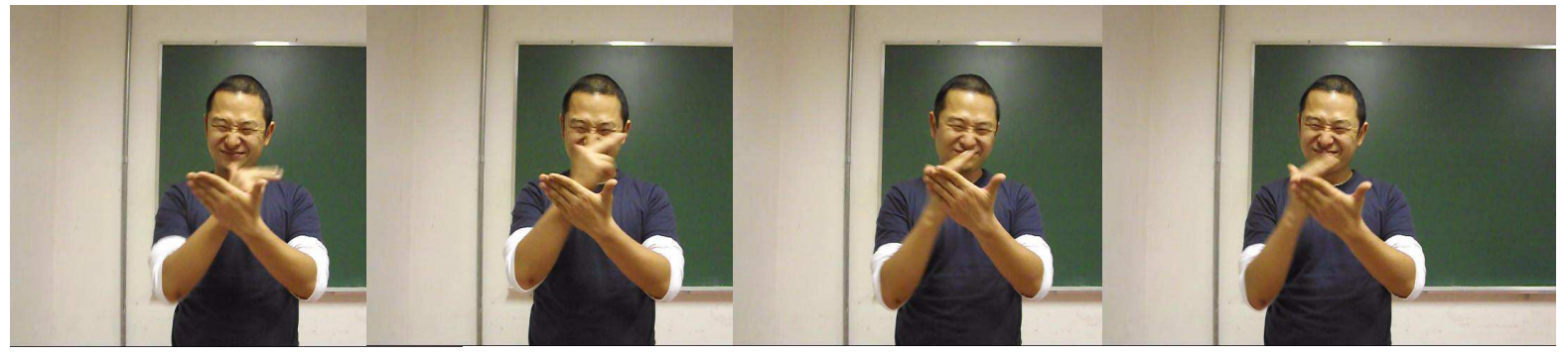

ENTIDADE-RETA3 ${ }_{\mathrm{CL}-}$ PINTAR(M)md||ENTIDADE-PLANA1 ${ }_{\mathrm{CL}} \mathrm{me}$

d) Sinal Classificador (com verbos) e Sinal Classificador (Sinal CLverbo||sinal $\mathrm{CL}$ )

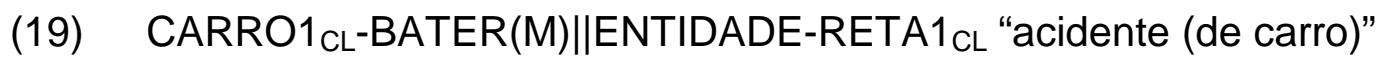

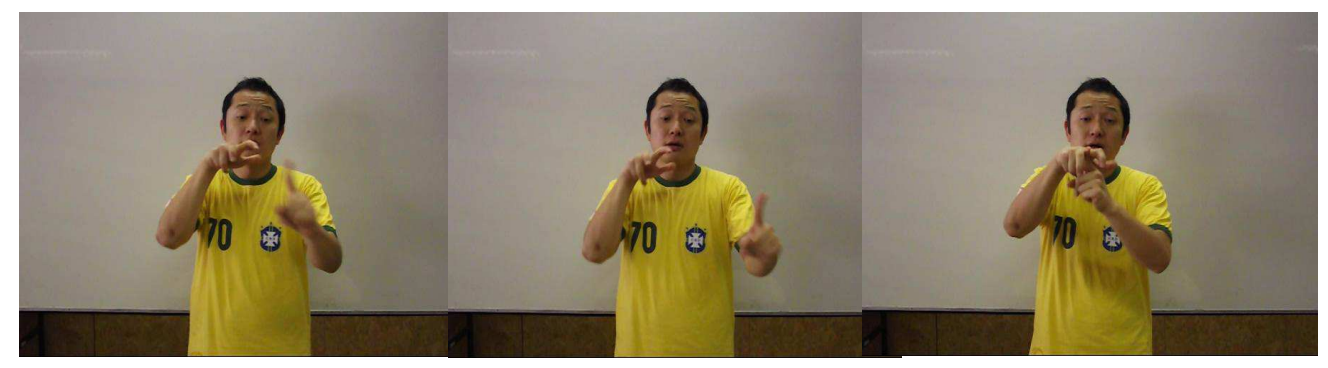

CARRO1 ${ }_{\mathrm{CL}} \mathrm{md}-\mathrm{BATER}(\mathrm{M})|| \mathrm{ENTIDADE}-\mathrm{RETA} 1_{\mathrm{CL}} \mathrm{me}$

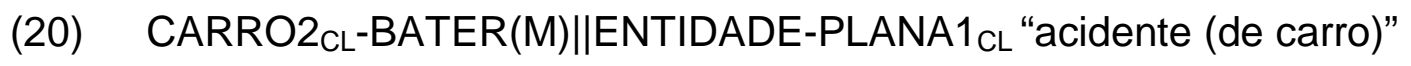

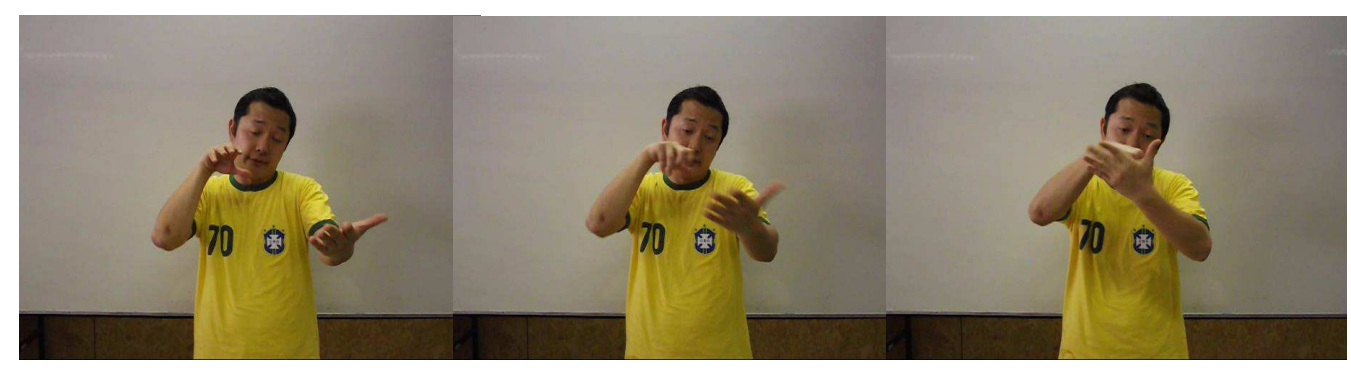

CARRO2 ${ }_{\mathrm{CL}}$ md-BATER(M)||ENTIDADE-PLANA1 $1_{\mathrm{CL}} \mathrm{me}$ 


\subsubsection{Dados simultâneo-sequenciais}

Os dados simultâneo-sequenciais são realizados com um sinal e, na sequência, dois sinais CLs realizados simultaneamente, não necessariamente nessa mesma ordem.

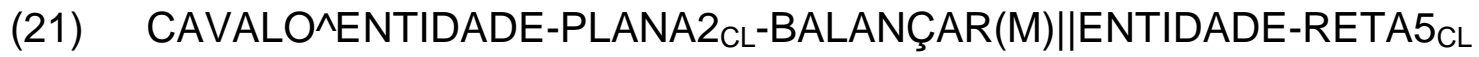
"cavalinho de balanço"

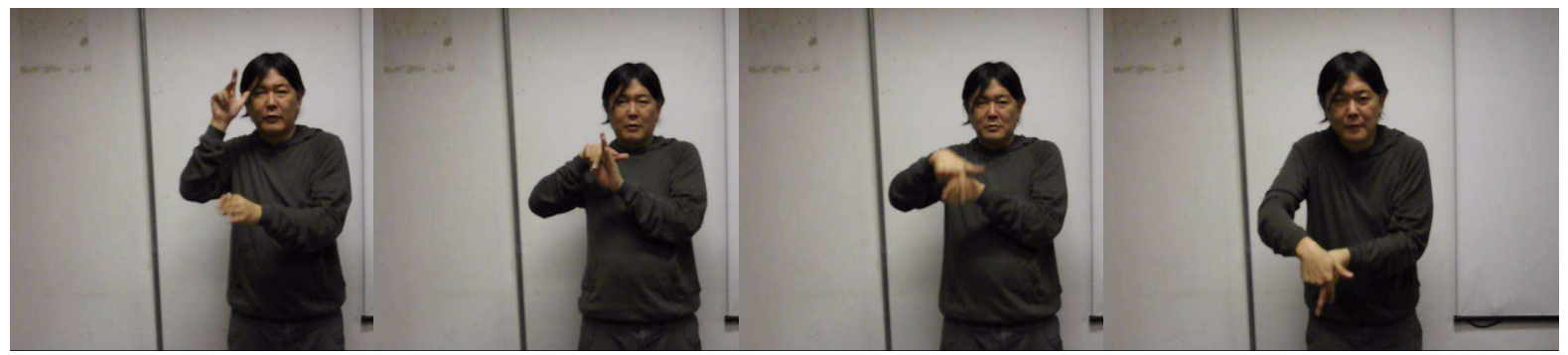

CAVALO

ENTIDADE-PLANA2CL-BALANÇAR(M)me||ENTIDADE-

RETA5 $\mathrm{CL}$ md

Nossos dados mostram que ENTIDADE-RETA5 ${ }_{\mathrm{CL}}$ "pessoa" e ENTIDADEPLANA2 $C L-B A L A N C ̧ A R(M)$ "animal grande balançar" são sinais diferentes porque ambos podem ocorrer isoladamente. Atestamos a ocorrência isolada de ENTIDADEPLANA2 ${ }_{C L}-B A L A N C ̧ A R(M)$, como em:

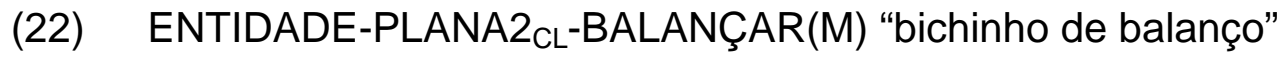

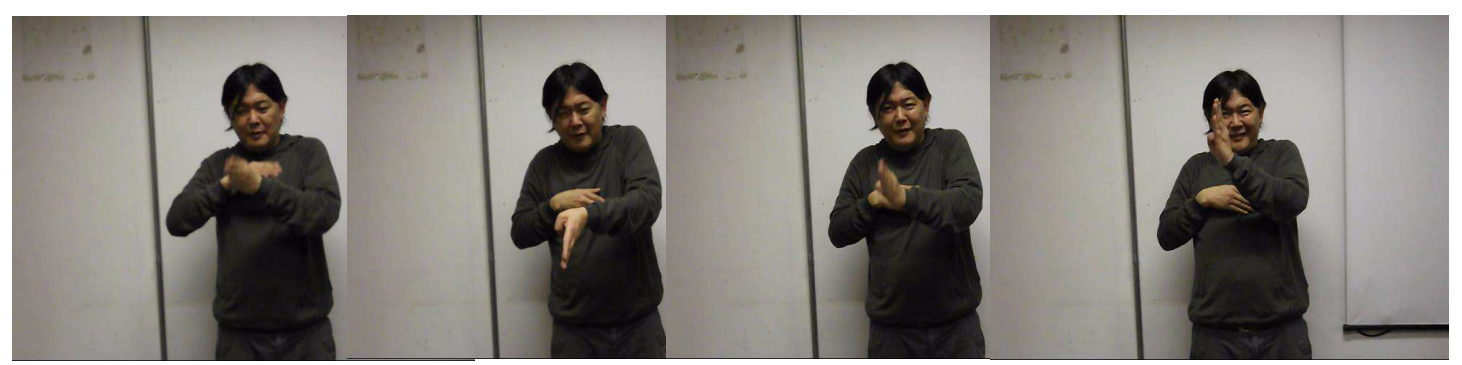

ENTIDADE-PLANA2 ${ }_{\mathrm{CL}}$-BALANÇAR(M) 
(23) $\operatorname{COSTAS}_{\mathrm{CL}}{ }^{\wedge}$ ENTIDADE-PLANA3 ${ }_{\mathrm{CL}}|| E N T I D A D E-S E M I-C I R C U L A R 1_{\mathrm{CL}}$ "crocodilo"

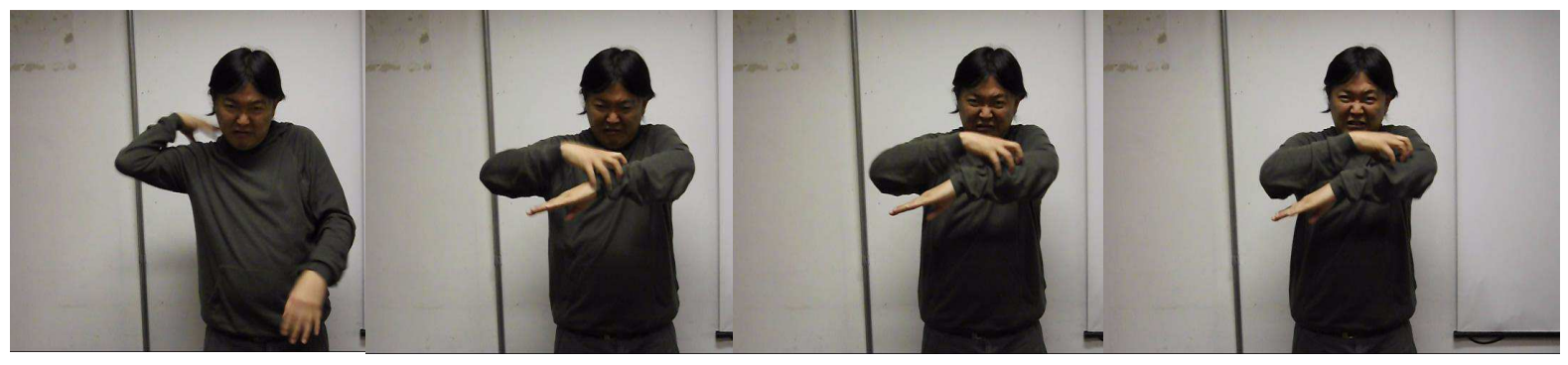

$\operatorname{COSTAS}_{\mathrm{CL}}$ ENTIDADE-PLANA3 ${ }_{\mathrm{CL}}$ me||ENTIDADE-SEMI-CIRCULAR1 $1_{\mathrm{CL}} \mathrm{md}$--

(24) CISNE $_{C L}-N A D A R(M)\left\|E N T I D A D E-P L A N A 3_{C L}{ }^{\wedge} C I S N E_{C L}\right\| P E S S O A^{\wedge} C I S N E_{C L} \|$ ENTIDADE-CURVA $A_{C L}-S E N T A R(M)^{\wedge} P E ́ S_{C L}-P E D A L A R(M)^{\wedge} C_{I S N E} L_{C-}^{-}$ $\operatorname{NADAR}(\mathrm{M})||$ ENTIDADE-PLANA3 ${ }_{\mathrm{CL}}{ }^{\wedge} \mathrm{PÉS}_{\mathrm{CL}}-\operatorname{PEDALAR}(\mathrm{M})^{\wedge} \mathrm{CISNE}_{\mathrm{CL}}-\mathrm{NADAR}$ (M)||ENTIDADE-PLANA3 ${ }_{C L}$ "pedalinho"

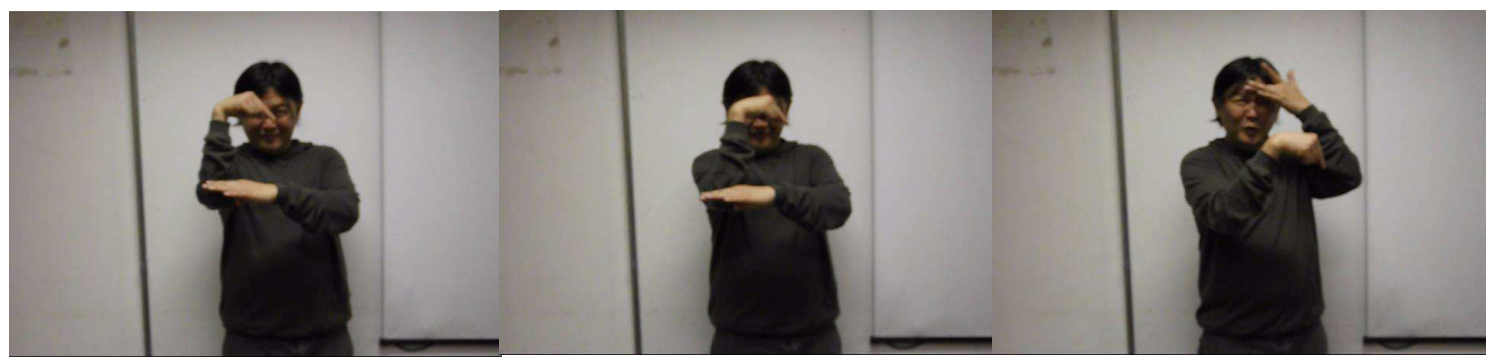

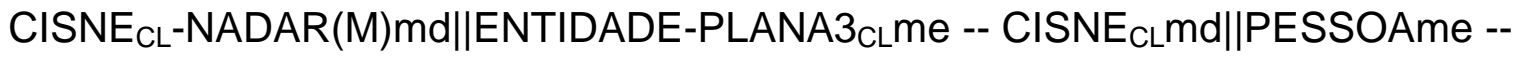

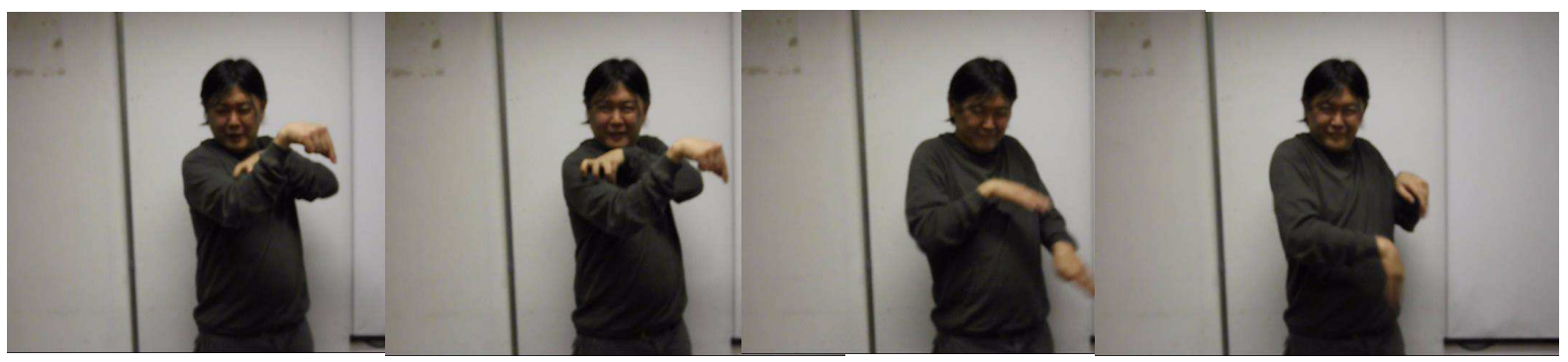

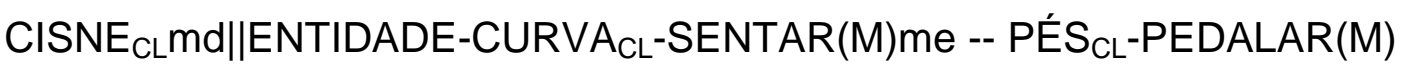




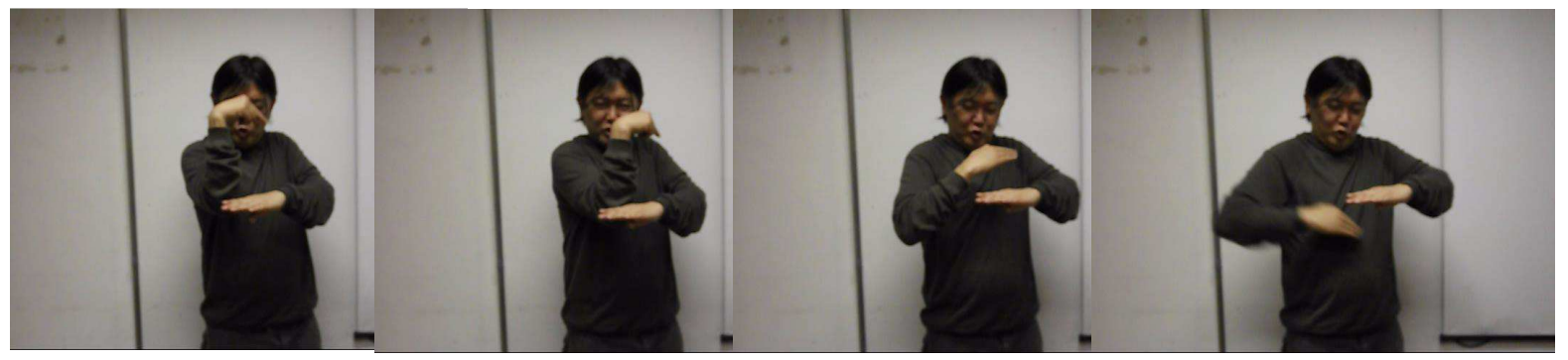

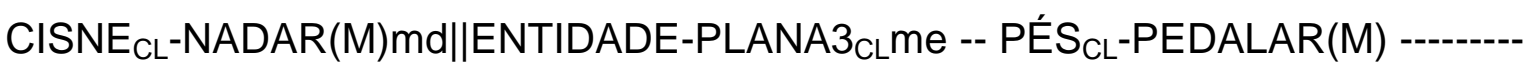

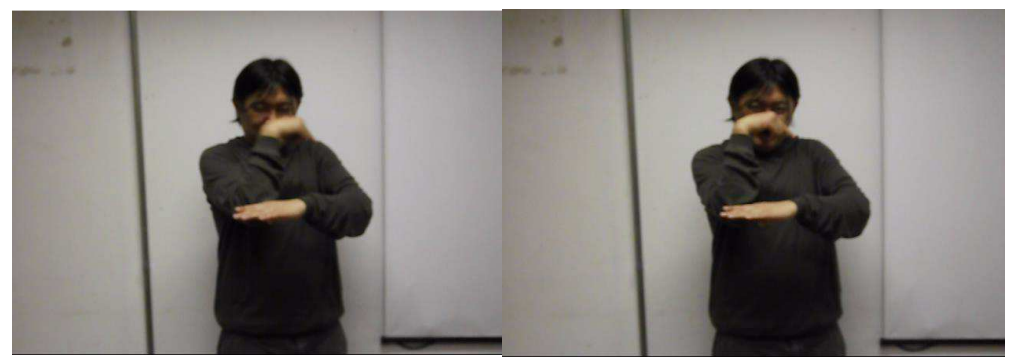

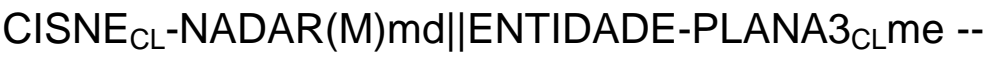

Como já dissemos anteriormente, nossa hipótese é que esses dados sejam compostos. Nos capítulos de 3 a 5, analisaremos a natureza dos elementos envolvidos nesses sinais e as características básicas de formação de compostos com o intuito de averiguarmos essa hipótese. Na próxima subseção, apresentamos mais alguns dados que compõem nossa base empírica.

\subsection{Uma classificação dos possíveis compostos na libras: dados em Capovilla, Raphael e Maurício (2010)}

Nesta seção, apresentamos dados coletados em Capovilla, Raphael \& Maurício (2012), formados por dois ou mais sinais, considerando sinais formados por mais de uma parte, morfologicamente complexos, incluindo ou não CLs. Os dados que apresentam tais características são, possivelmente, compostos - o que verificaremos no andamento desta pesquisa.

Selecionamos apenas os dados na letra $A$, o que já foi suficiente para montarmos uma amostra maior de dados envolvendo sequencialidade e simultaneidade. Foram 76 dados coletados inicialmente, dos quais 22 são sequenciais, 34 são simultâneos e 20 são simultâneo-sequenciais. 
Os quadros a seguir trazem as seguintes informações: i) o "nome do sinal", conforme anotado no dicionário; ii) a página em que o dado se encontra, como referência às imagens dos sinais que não serão reproduzidas nesta tese; iii) a glosa convencionada nesta tese; e, iv) o tipo de formação (quanto a sequencialidade ou simultaneidade):

\section{a) Sequenciais:}

\begin{tabular}{|c|c|c|c|c|}
\hline & $\begin{array}{l}\text { Nome do sinal } \\
\text { no dicionário }\end{array}$ & Pg. & Glosa na tese & $\begin{array}{l}\text { Tipo da } \\
\text { formação }\end{array}$ \\
\hline 01 & Abafado(a) & 239 & AMBIENTE-REDONDO ${ }_{\mathrm{CL}}{ }^{\wedge} \mathrm{CHEIO}$ & Sequencial \\
\hline 02 & Abafar & 239 & $\mathrm{CHEIO}^{\wedge} \mathrm{A}-\mathrm{R}$ & Sequencial \\
\hline 03 & $\begin{array}{c}\text { Abaixar (3) (a } \\
\text { voz) }\end{array}$ & 240 & $A B A I X A R^{\wedge} V O Z$ & Sequencial \\
\hline 04 & Abelha (2) & 246 & ANTENA $_{C L}{ }^{\wedge}$ A-B-E-L-H-A & Sequencial \\
\hline 05 & $\begin{array}{l}\text { Abóbora (2) } \\
\text { (abóbora } \\
\text { moranga) }\end{array}$ & 249 & $\begin{array}{c}\text { LARANJA^ENTIDADE- }^{\wedge} \\
\text { REDONDA }_{C L^{\wedge}{ }^{\wedge N T I D A D E-R E D O N D A}}{ }_{C L}\end{array}$ & Sequencial \\
\hline 06 & $\begin{array}{l}\text { Abolição dos } \\
\text { escravos (1) }\end{array}$ & $\begin{array}{l}249, \\
250\end{array}$ & LIVRE^NEGRO & Sequencial \\
\hline 07 & $\begin{array}{l}\text { Academia de } \\
\text { ginástica }\end{array}$ & 260 & ÁREA $\mathrm{CL}^{\wedge}{ }^{\wedge} \mathrm{MUSCULAÇÃO}$ & Sequencial \\
\hline 08 & $\begin{array}{l}\text { Acautelar-se (2) } \\
\text { (tomar cuidado) }\end{array}$ & 264 & VER^JÁ & Sequencial \\
\hline 09 & $\begin{array}{c}\text { Achar (3) } \\
\text { (localizar objetos) }\end{array}$ & 268 & VER^PEGAR & Sequencial \\
\hline 10 & $\begin{array}{l}\text { Achar, achar-se } \\
\text { (1) (pensar, } \\
\text { supor) }\end{array}$ & 269 & PENSAR^ACONTECER & Sequencial \\
\hline 11 & Aço & 272 & A-Ç-O^FERRO & Sequencial \\
\hline 12 & Açougue (2) & 277 & CARNE^VENDER & Sequencial \\
\hline 13 & Açougueiro & 277 & VENDER^CARNE & Sequencial \\
\hline 14 & Acreditar & 278 & SABER^ESTUDAR & Sequencial \\
\hline
\end{tabular}




\begin{tabular}{|c|c|c|c|c|}
\hline 15 & Açude (1) & 280 & ÁGUA^ÁREA ${ }^{45} \wedge A G R I C U L T U R A$ & Sequencial \\
\hline 16 & Adicionar (2) & 284 & 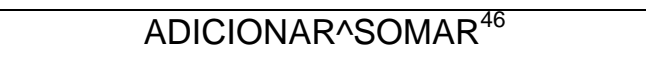 & Sequencial \\
\hline 17 & Admissão & 287 & TRABALHO^INGRESSAR & Sequencial \\
\hline 18 & Adorar (2) & 290 & $\mathrm{AMAR}^{\wedge} \mathrm{ADORAR}$ & Sequencial \\
\hline 19 & $\begin{array}{l}\text { Aeromoça (1) } \\
\text { (comissária de } \\
\text { bordo) }\end{array}$ & 294 & $\begin{array}{l}\text { AVIÃO }{ }_{\mathrm{CL}}^{\wedge}{ }^{\wedge} M U L H E R \wedge E N T I D A D E- \\
\text { PLANA1 } 1_{\mathrm{CL}}-\mathrm{SERVIR}(\mathrm{M})\end{array}$ & Sequencial \\
\hline 20 & $\begin{array}{l}\text { Aeromoça }(2) \\
\text { (comissária de } \\
\text { bordo) }\end{array}$ & 294 & ENTIDADE-PLANA $1_{\mathrm{CL}}{ }^{\wedge}{ }^{\wedge} \mathrm{AVIÃO} \mathrm{CL}_{\mathrm{CL}}$ & Sequencial \\
\hline 21 & $\begin{array}{l}\text { Aeróstato }(2) \\
\text { (tipo zepelim) }\end{array}$ & 297 & $\begin{array}{c}\text { FORMA-OVAL } \mathrm{CL}^{\wedge}{ }^{\wedge} \text { ENTIDADE-PLANA1 } \mathrm{CL}^{-} \\
\text {SUBIR(M) }\end{array}$ & Sequencial \\
\hline 22 & $\begin{array}{l}\text { Aferir a } \\
\text { temperatura }\end{array}$ & 299 & $\begin{array}{l}\text { ENTIDADE-RETA1 } 1_{\mathrm{CL}-\mathrm{BALANC} A R(\mathrm{M})^{\wedge}} \\
\text { ENTIDADE-RETA1 } 1_{\mathrm{CL}-\mathrm{COLOCAR-}} \\
\text { SOB(M)-BRAÇO }{ }_{\mathrm{CL}}{ }^{\wedge} \mathrm{GRAU}\end{array}$ & Sequencial \\
\hline
\end{tabular}

Quadro 2: Construções sequenciais em Capovilla, Raphael \& Maurício (2012) compostos potenciais

b) Simultâneos:

\begin{tabular}{|c|c|c|c|c|}
\hline & $\begin{array}{l}\text { Nome do sinal } \\
\text { no dicionário }\end{array}$ & $\mathrm{Pg}$. & Glosa na tese & $\begin{array}{l}\text { Tipo da } \\
\text { formação }\end{array}$ \\
\hline 01 & Abacate (1) & 237 & 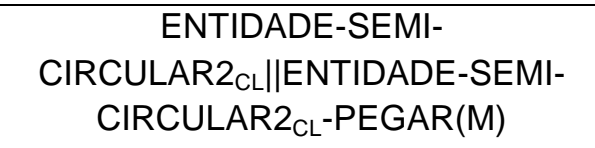 & Simultâneo \\
\hline 02 & Abafador & 239 & $\begin{array}{l}\text { ENTIDADE-SEMI-CIRCULAR1 } 1_{\mathrm{CL}} \\
\text { TAMPAR(M)|| ENTIDADE-PLANA1 } 1_{\mathrm{CL}}\end{array}$ & Simultâneo \\
\hline 03 & Abaixo & 240 & $\begin{array}{c}\text { ENTIDADE-PLANA1 }{ }_{\mathrm{CL}^{-}} \\
\text {SUBPOR(M)||ENTIDADE-PLANA1 } \mathrm{CL}\end{array}$ & Simultâneo \\
\hline 04 & Abaixo-assinado & 240 & $\begin{array}{c}\text { SEGURAR-ENTIDADE-FINA1 } \mathrm{CL}^{-} \\
\text {ASSINAR(M)\|ENTIDADE-PLANA1 } 1_{\mathrm{CL}}\end{array}$ & Simultâneo \\
\hline 05 & Abajur (1) & 240 & $\begin{array}{l}\text { SEGURAR-ENTIDADE-FINA2 } \mathrm{CL}^{-} \\
\text {PUXAR(M)||LUZ }\end{array}$ & Simultâneo \\
\hline
\end{tabular}

${ }^{45}$ Sinal não dicionarizado.

${ }^{46} \mathrm{O}$ mesmo sinal é usado para TOTAL. 


\begin{tabular}{|c|c|c|c|c|}
\hline 06 & Abelha (3) & 246 & $\mathrm{ENTIDADE}-\mathrm{FINA}_{\mathrm{CL}}-\mathrm{PICAR}(\mathrm{M})|| \mathrm{MÃO}_{\mathrm{CL}}$ & Simultâneo \\
\hline 07 & Abocanhar & 249 & $\begin{array}{c}\text { ENTIDADE-SEMI- } \\
\text { CIRCULAR } \text { RLMORDER(M) ||ENTIDADE- }_{\text {SEMI-CIRCULAR }} \\
\text { SEL }\end{array}$ & Simultâneo \\
\hline 08 & $\begin{array}{l}\text { Abridor de } \\
\text { garrafas }\end{array}$ & 253 & $\begin{array}{c}\text { SEGURAR-ENTIDADE-FINA2 } \mathrm{CL}^{-} \\
\text {ABRIR(M)\|SEGURAR-ENTIDADE- } \\
\text { FINA3 }{ }_{\mathrm{CL}}\end{array}$ & Simultâneo \\
\hline 09 & $\begin{array}{l}\text { Abridor de latas } \\
\text { (1) (automático) }\end{array}$ & 254 & $\begin{array}{c}\text { ENTIDADE-RETA2 }{ }_{\mathrm{CL}^{-}} \\
\text {FURAR(M)||ENTIDADE-CILÍNDRICA1 } 1_{\mathrm{CL}}\end{array}$ & Simultâneo \\
\hline 10 & $\begin{array}{l}\text { Abridor de latas } \\
\text { (2) (manual) }\end{array}$ & 254 & $\begin{array}{c}\text { SEGURAR-ENTIDADE-FINA2 } \mathrm{CL}^{-} \\
\text {ABRIR(M)||ENTIDADE-CILÍNDRICA1 } 1_{\mathrm{CL}}\end{array}$ & Simultâneo \\
\hline 11 & Abrir (2) (garrafa) & 255 & $\begin{array}{c}\text { ABRIDOR }_{\mathrm{CL}}-\mathrm{ABRIR}^{\mathrm{A}}(\mathrm{M})|| \mathrm{ENTIDADE}- \\
\text { RETA1 }_{\mathrm{CL}}\end{array}$ & Simultâneo \\
\hline 12 & Abrir (3) (janela) & 255 & $\begin{array}{c}\text { ENTIDADE-PLANA2 } \mathrm{CL}^{-} \\
\text {ABRIR(M)||ENTIDADE-PLANA2 } \mathrm{CL}^{-} \\
\text {ABRIR(M) }\end{array}$ & Simultâneo \\
\hline 13 & Abrir (4) (janela) & $\begin{array}{l}255 \\
256\end{array}$ & $\begin{array}{c}\text { SEGURAR-ENTIDADE-FINA3 }{ }_{\mathrm{CL}^{-}} \\
\text {ABRIR(M) } \| \text { SEGURAR-ENTIDADE- } \\
\text { FINA3 }{ }_{\mathrm{CL}}-\text { ABRIR(M) }\end{array}$ & Simultâneo \\
\hline 14 & Abrir (5) (porta) & 256 & $\begin{array}{c}\text { ENTIDADE-PLANA2 } \mathrm{CL}^{-} \\
\text {ABRIR(M)||ENTIDADE-PLANA2 }{ }_{C L}\end{array}$ & Simultâneo \\
\hline 15 & Abrir (6) (tampa) & 256 & $\begin{array}{c}\text { ENTIDADE-SEMI-CIRCULAR1 } 1_{\mathrm{CL}}^{-} \\
\text {ABRIR(M)||ENTIDADE-CILÍNDRICA } 1_{\mathrm{CL}}\end{array}$ & Simultâneo \\
\hline 16 & $\begin{array}{l}\text { Absorver (4) } \\
\text { (sugar) (extrair) }\end{array}$ & 257 & $\begin{array}{l}\text { ENTIDADE-SEMI-CIRCULAR } 1_{\mathrm{CL}^{-}} \\
\text {SUGAR(M)||ENTIDADE-CILÍNDRICA } 1_{\mathrm{CL}}\end{array}$ & Simultâneo \\
\hline 17 & Acariciar & 263 & $\begin{array}{c}\text { MÃO }_{C L}-A C A R I C I A R(M)|| E N T I D A D E- \\
\text { PLANA } 4_{C L}\end{array}$ & Simultâneo \\
\hline 18 & Acasalar & 263 & $\begin{array}{c}\text { ENTIDADE-RETA5 } \mathrm{CL}^{-} \\
\text {ACASALAR(M)||ENTIDADE-RETA5 } 5_{\mathrm{CL}}\end{array}$ & Simultâneo \\
\hline 19 & $\begin{array}{l}\text { Acelerar }(2) \\
\text { (veículos) }\end{array}$ & 265 & $\begin{array}{c}\text { ENTIDADE-PLANA1 } 1_{\mathrm{CL}^{-}} \\
\text {EMPURRAR(M)||ENTIDADE-PLANA1 }{ }_{\mathrm{CL}}\end{array}$ & Simultâneo \\
\hline 20 & Acima & 271 & $\begin{array}{c}\text { ENTIDADE-PLANA1 } 1_{\mathrm{CL}^{-}} \\
\text {SOBREPOR(M)||ENTIDADE-PLANA1 } \mathrm{CL}\end{array}$ & Simultâneo \\
\hline 21 & $\begin{array}{c}\text { Acrobata (2) } \\
\text { (trapezista) }\end{array}$ & 279 & $\begin{array}{c}\text { ENTIDADE-CURVA } \mathrm{CL}^{-} \\
\text {BALANÇAR(M)||ENTIDADE-RETA1 } \mathrm{CL}\end{array}$ & Simultâneo \\
\hline 22 & Acupuntura & 281 & $\begin{array}{c}\text { ENTIDADE-RETA1 }{ }_{\mathrm{CL}^{-}} \\
\text {ESPETAR(M)||ENTIDADE-PLANA3 } \mathrm{CL}\end{array}$ & Simultâneo \\
\hline
\end{tabular}




\begin{tabular}{|c|c|c|c|c|}
\hline 23 & $\begin{array}{l}\text { Admirar, admirar- } \\
\text { se (2) (surpreso) }\end{array}$ & 287 & $\begin{array}{c}\text { QUEIXO-CAIR(M)||ENTIDADE- } \\
\text { PLANA1 } 1_{\mathrm{CL}}\end{array}$ & Simultâneo \\
\hline 24 & Adoçante (1) & 288 & $\begin{array}{c}\text { ENTIDADE-FINA1 } \mathrm{CL}^{-} \\
\text {GOTEJAR(M)||ENTIDADE- } \\
\text { CILÍNDRICA1 } 1_{\mathrm{CL}}\end{array}$ & Simultâneo \\
\hline 25 & Aeroporto (1) & 295 & $\begin{array}{c}\text { ENTIDADE-PLANA1 } 1_{\mathrm{CL}^{-}} \\
\text {POUSAR(M)||ENTIDADE-PLANA1 } \mathrm{CL}^{-} \\
\text {POUSAR(M) }\end{array}$ & Simultâneo \\
\hline 26 & Aeroporto (3) & 295 & $\begin{array}{c}\text { AVIẪ }_{\mathrm{CL}}-\mathrm{POUSAR}(\mathrm{M}) \mid{ }_{47} \mathrm{ENTIDADE}- \\
\text { PLANA } 1_{\mathrm{CL}}{ }^{4}\end{array}$ & Simultâneo \\
\hline 27 & Aeróstato (1) & 296 & $\begin{array}{c}\text { ENTIDADE-SEMI- } \\
\text { CIRCULAR2 } 2_{\mathrm{CL}}|| E_{\text {ENTIDADE- }} \\
\text { CILÍNDRICA2 }_{\mathrm{CL}-\text { SUBIR(M) }}\end{array}$ & Simultâneo \\
\hline 28 & Aferir (1) (checar) & 298 & $\begin{array}{l}\text { SEGURAR-ENTIDADE-FINA1 }{ }_{\mathrm{CL}^{-}} \\
\text {CHECAR(M)||ENTIDADE-PLANA1 } 1_{\mathrm{CL}}\end{array}$ & Simultâneo \\
\hline 29 & Afeto & 299 & $\begin{array}{c}\mathrm{MAOO}_{\mathrm{CL}-} \text {-ACARICIAR(M)||ENTIDADE- } \\
\text { PLANA4 } 4_{\mathrm{CL}}\end{array}$ & Simultâneo \\
\hline 30 & Afiar & 300 & $\begin{array}{c}\text { ENTIDADE-RETA3 } \mathrm{CL}^{-} \\
\text {AFIAR(M)||ENTIDADE-RETA1 } 1_{\mathrm{CL}}\end{array}$ & Simultâneo \\
\hline 31 & $\begin{array}{l}\text { Afiliar-se (tornar- } \\
\text { se membro) }\end{array}$ & 300 & $\begin{array}{c}\text { POLEGAR }_{\mathrm{CL}^{-}} \\
\text {PRESSIONAR(M)||ENTIDADE- } \\
\text { PLANA1 } 1_{\mathrm{CL}}\end{array}$ & Simultâneo \\
\hline 32 & Afundar & 302 & $\begin{array}{c}\text { ENTIDADE-RETA1 } 1_{\mathrm{CL}^{-}} \\
\text {AFUNDAR(M)\|ENTIDADE- } \\
\text { CILÍNDRICA } 1_{\mathrm{CL}}\end{array}$ & Simultâneo \\
\hline 33 & Agendar (2) & 304 & $\begin{array}{l}\text { SEGURAR-ENTIDADE-FINA5 } \mathrm{CL}^{-} \\
\text {PÔR(M)||ENTIDADE-PLANA1 }{ }_{\mathrm{CL}}\end{array}$ & Simultâneo \\
\hline 34 & Agogô & 305 & $\begin{array}{c}\text { SEGURAR-ENTIDADE-FINA2 } \mathrm{CL}^{-} \\
\text {BATER(M)||SEGURAR-ENTIDADE- } \\
\text { FINA2 }{ }_{\mathrm{CL}}\end{array}$ & Simultâneo \\
\hline
\end{tabular}

Quadro 3: Construções simultâneas em Capovilla, Raphael \& Maurício (2012) compostos potenciais

\footnotetext{
${ }^{47}$ A glosa está de acordo com o sinal dicionarizado. Há outra realização desse sinal que é bastante comum na região Sudeste que é AVIÃO-POUSAR(M)||ENTIDADE-PLANA3cL. Neste trabalho, manteremos as glosas para os sinais como estão dicionarizados.
} 


\section{c) Dados Simultâneo-Sequenciais}

\begin{tabular}{|c|c|c|c|c|}
\hline & $\begin{array}{l}\text { Nome do sinal } \\
\text { no dicionário }\end{array}$ & Pg. & Glosa na tese & $\begin{array}{l}\text { Tipo da } \\
\text { formação }\end{array}$ \\
\hline 01 & Abacate (2) & 238 & $\begin{array}{c}\text { ENTIDADE-SEMI- } \\
\text { CIRCULAR2 } 2_{\mathrm{CL}} \mid \text { ENTIDADE-SEMI- } \\
\text { CIRCULAR2 }{ }_{\mathrm{CL}} \text { PEGAR(M)^VERDE }\end{array}$ & $\begin{array}{l}\text { Simultâneo- } \\
\text { sequencial }\end{array}$ \\
\hline 02 & Abajur (3) & 241 & $\begin{array}{l}\text { FORMA-TRAPEZOIDAL }{ }_{\mathrm{CL}}{ }^{\wedge} \text { ENTIDADE- } \\
\text { CILÍNDRICA } 1_{C L}|| L U Z\end{array}$ & $\begin{array}{l}\text { Simultâneo- } \\
\text { sequencial }\end{array}$ \\
\hline 03 & Abelha (1) & 245 & $\begin{array}{c}\text { ENTIDADE-FINA1 } \mathrm{CL}^{-} \\
\text {GIRAR(M)^ENTIDADE-FINA1 }{ }_{\mathrm{CL}^{-}} \\
\operatorname{PICAR(M)\| PESCOÇO}{ }_{\mathrm{CL}}\end{array}$ & $\begin{array}{l}\text { Simultâneo- } \\
\text { Sequencial }\end{array}$ \\
\hline 04 & $\begin{array}{c}\text { Abertura } \\
\text { cerimonial (1) }\end{array}$ & $\begin{array}{l}247 \\
248\end{array}$ & $\begin{array}{l}\text { CORTAR }_{C L} \| \text { ENTIDADE- } \\
\text { RETA1 } 1_{C L} \wedge \text { ABRIR }\end{array}$ & $\begin{array}{l}\text { Simultâneo- } \\
\text { sequencial }\end{array}$ \\
\hline 05 & $\begin{array}{l}\text { Abrigo (1) } \\
\text { (alojamento) }\end{array}$ & 254 & $\begin{array}{c}\text { DORMIR^ENTIDADE-RETA3 } \mathrm{CL}^{-} \\
\text {DEITAR(M)||ENTIDADE-RETA3 }{ }_{\mathrm{CL}^{-}} \\
\text {DEITAR }^{48}\end{array}$ & $\begin{array}{l}\text { Simultâneo- } \\
\text { sequencial }\end{array}$ \\
\hline 06 & $\begin{array}{l}\text { Acender (2) } \\
\quad(\text { vela) }\end{array}$ & 265 & 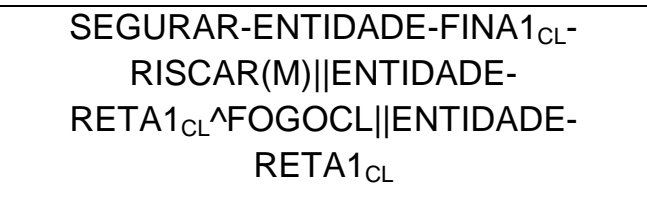 & $\begin{array}{l}\text { Simultâneo- } \\
\text { sequencial }\end{array}$ \\
\hline 07 & $\begin{array}{l}\text { Acertar (1) } \\
\text { (atingir) }\end{array}$ & 267 & $\begin{array}{c}\text { ENTIDADE-RETA1 }{ }_{\mathrm{CL}^{-}} \\
\text {BATER(M) } \| \text { TESTA }_{\mathrm{CL}}{ }^{\wedge}{ }^{\mathrm{CERTO}}\end{array}$ & $\begin{array}{l}\text { Simultâneo- } \\
\text { Sequencial }\end{array}$ \\
\hline 08 & Acetona & 268 & $\begin{array}{l}\text { ACETONA }{ }_{C L}{ }^{\wedge} \text { SEGURAR-ENTIDADE- } \\
\text { FINA2 } 2_{C L}-E S F R E G A R(M) \| U N H A_{C L}\end{array}$ & $\begin{array}{l}\text { Simultâneo- } \\
\text { sequencial }\end{array}$ \\
\hline 09 & $\begin{array}{c}\text { Acidente de carro } \\
\text { (1) }\end{array}$ & 270 & $\begin{array}{c}\text { SEGURAR-ENTIDADE-FINA3 }{ }_{\mathrm{CL}^{-}} \\
\text {GIRAR(M) }^{\wedge} \text { CARRO }_{\mathrm{CL}}{ }^{49}- \\
\text { BATER(M) } \| \text { ENTIDADE-PLANA1 }{ }_{\mathrm{CL}}\end{array}$ & $\begin{array}{l}\text { Simultâneo- } \\
\text { Sequencial }\end{array}$ \\
\hline 10 & $\begin{array}{l}\text { Acidente de } \\
\text { carro (2) }\end{array}$ & 270 & $\begin{array}{c}\text { SEGURAR-ENTIDADE-FINA3 } \mathrm{CL}^{-} \\
\text {GIRAR(M)^ENTIDADE-SEMI- } \\
\text { CIRCULAR1 } 1_{\mathrm{CL}-\mathrm{BATER}(\mathrm{M}) \| \mathrm{ENTIDADE}-} \\
\text { SEMI-CIRCULAR1 }{ }_{\mathrm{CL}}\end{array}$ & $\begin{array}{l}\text { Simultâneo- } \\
\text { sequencial }\end{array}$ \\
\hline
\end{tabular}

\footnotetext{
${ }^{48} \mathrm{Na}$ literatura (Cf. Zwitserlood, 2008, por exemplo), exemplos como esse tratam o que chamamos de ENTIDADE-RETA3 como ENTIDADE-COM-PERNAS por remeter a uma pessoa. Buscando uma generalização maior para a descrição dos CLs, optamos por chamar esse CL de ENTIDADERETA3 ${ }_{C L}$, pois, esse $C L$ aparece em outros dados nos quais não remete a uma entidade humana. Em (5), ENTIDADE-RETA3 ${ }_{\mathrm{CL}}$-PINTAR(M)||ENTIDADE-PLANA1 ${ }_{\mathrm{CL}}$ "desenhar", ENTIDADE-RETA3 $3_{\mathrm{CL}}$ remete ao pincel, e no quadro anterior, ENTIDADE-RETA3 $3_{C L}-A F I A R(M)|| E N T I D A D E-R E T A 1_{C L}$ "afiar", ENTIDADE-RETA3 ${ }_{C L}$ remete à faca ou ao objeto a ser afiado.

${ }^{49} \mathrm{CM}$ em S, representando o carro como um todo.
} 


\begin{tabular}{|c|c|c|c|c|}
\hline 11 & Açougue (3) & 277 & $\begin{array}{l}\text { CARNE^ENTIDADE-PLANA1 }{ }_{\mathrm{CL}^{-}} \\
\text {FATIAR(M) } \| \text { ENTIDADE-PLANA4 }{ }_{\mathrm{CL}}\end{array}$ & $\begin{array}{l}\text { Simultâneo- } \\
\text { sequencial }\end{array}$ \\
\hline 12 & $\begin{array}{l}\text { Acrobata (1) } \\
\text { (andador de } \\
\text { corda bamba) }\end{array}$ & 279 & $\begin{array}{c}\text { ENTIDADE-FINA4 } 4_{\mathrm{CL}}{ }^{\wedge} \text { ENTIDADE- } \\
\text { RETA5 }_{\mathrm{CL}}-\mathrm{ANDAR}(\mathrm{M}) \| \mathrm{ENTIDADE}- \\
\text { RETA }_{\mathrm{CL}}\end{array}$ & $\begin{array}{l}\text { Simultâneo- } \\
\text { sequencial }\end{array}$ \\
\hline 13 & Acumular & 281 & $\begin{array}{c}\text { PEGARreduplicação^ENTIDADE- } \\
\text { PLANA1 } 1_{\mathrm{CL}-S U B I R(M) \| E N T I D A D E-} \\
\text { PLANA1 } 1_{\mathrm{CL}-S U B I R(M)}\end{array}$ & $\begin{array}{l}\text { Simultâneo- } \\
\text { Sequencial }\end{array}$ \\
\hline 14 & $\begin{array}{l}\text { Aeroporto de } \\
\text { Congonhas (SP, } \\
\text { SP) }\end{array}$ & 296 & $\begin{array}{c}\text { ENTIDADE-PLANA1 }{ }_{\mathrm{CL}^{-}} \\
\text {POUSAR(M)||ENTIDADE-PLANA1 }{ }_{\mathrm{CL}^{-}} \\
\text {POUSAR(M)^C-O-N-G-O-N-H-A-S }\end{array}$ & $\begin{array}{l}\text { Simultâneo- } \\
\text { Sequencial }\end{array}$ \\
\hline 15 & $\begin{array}{l}\text { Aeroporto de } \\
\text { Cumbica } \\
\text { (Aeroporto de } \\
\text { Guarulhos) } \\
\text { (Guarulhos, SP) }\end{array}$ & 296 & $\begin{array}{c}\text { ENTIDADE-PLANA1 } \mathrm{CL}^{-} \\
\text {POUSAR(M)||ENTIDADE-PLANA1 }{ }_{\mathrm{CL}^{-}} \\
\text {POUSAR(M)^G }\end{array}$ & $\begin{array}{l}\text { Simultâneo- } \\
\text { Sequencial }\end{array}$ \\
\hline 16 & Agenda (2) & 303 & $\begin{array}{c}\text { ENTIDADE-PLANA } 1_{\mathrm{CL}}-\mathrm{FOLHEAR(M) \|} \\
\text { ENTIDADE-PLANA } 1_{\mathrm{CL}}{ }^{\wedge} \text { SEGURAR- } \\
\text { ENTIDADE-FINA5 }{ }_{\mathrm{CL}-} \\
\text { PÔR(M)\|ENTIDADE-PLANA } 1_{\mathrm{CL}}\end{array}$ & $\begin{array}{l}\text { Simultâneo- } \\
\text { Sequencial }\end{array}$ \\
\hline 17 & Agendar (1) & 304 & $\begin{array}{c}\text { ENTIDADE-PLANA1 } 1_{\mathrm{CL}-\mathrm{FOLHEAR}(\mathrm{M}) \|} \| \\
\text { ENTIDADE-PLANA1 } 1_{\mathrm{CL}}{ }^{\wedge} \text { SEGURAR- } \\
\text { ENTIDADE-FINA5 } \mathrm{CL}^{-} \\
\text {PÔR(M)\|ENTIDADE-PLANA } 1_{\mathrm{CL}}\end{array}$ & $\begin{array}{l}\text { Simultâneo- } \\
\text { Sequencial }\end{array}$ \\
\hline 18 & Aglomerar & 305 & $\begin{array}{c}\text { PEGARreduplicação^ENTIDADE- } \\
\text { PLANA1CL-SUBIR(M)||ENTIDADE- } \\
\text { PLANA1CL-SUBIR(M) }\end{array}$ & $\begin{array}{l}\text { Simultâneo- } \\
\text { Sequencial }\end{array}$ \\
\hline 19 & Aeronáutica & 295 & 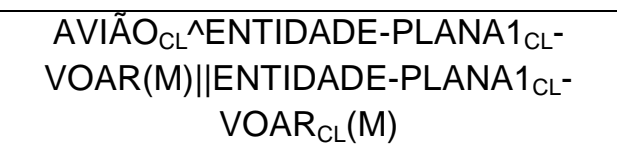 & $\begin{array}{l}\text { Simultâneo- } \\
\text { Sequencial }\end{array}$ \\
\hline 20 & $\begin{array}{l}\text { Agenda de } \\
\text { endereço }\end{array}$ & 304 & $\begin{array}{l}\text { SEGURAR-ENTIDADE-FINA5 }{ }_{\mathrm{CL}}^{-} \\
\text {PÔR(M)||ENTIDADE-PLANA } 1_{\mathrm{CL}}{ }^{\wedge} \mathrm{R} U A\end{array}$ & $\begin{array}{l}\text { Simultâneo- } \\
\text { Sequencial }\end{array}$ \\
\hline 21 & $\begin{array}{l}\text { Agenda de } \\
\text { telefones }\end{array}$ & 304 & 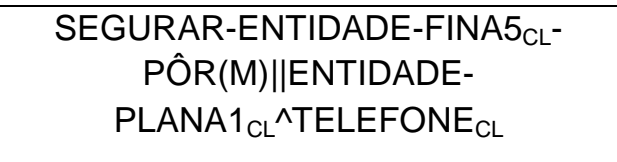 & $\begin{array}{l}\text { Simultâneo- } \\
\text { Sequencial }\end{array}$ \\
\hline
\end{tabular}

Quadro 4: Construções simultâneo-sequenciais em Capovilla, Raphael \& Maurício (2012) - compostos potenciais

Vale destacar que a metodologia de coleta de dados para o dicionário foi muito diferente da metodologia de coleta de dados utilizada nesta tese. O dicionário 
e suas atualizações foram construídos com base em listas de verbetes em português que, posteriormente, foram vertidos para o sinal correspondente em libras por sinalizantes surdos (Cf. MARTINS, 2012; TEMOTEO, 2012). A tradução dessas listas pode levar à influência da sinalização pela palavra em língua portuguesa, à perda dos contextos nos quais os sinais são usados e da especificidade que poderia ser encontrada para alguns sinais, e à perda de informações morfossintáticas presentes na sinalização que podem ser observadas em contextos naturais. Por isso, essa não foi nossa única fonte de consulta, nem a fonte principal, mas sim uma fonte extra de consulta para verificarmos mais ocorrências de possíveis compostos em libras.

\subsection{Morfologia Distribuída}

Nesta seção, trazemos os pressupostos teóricos e mecanismos da MD (HALLE; MARANTZ, 1993), uma vez que esse é o modelo teórico adotado para nossas análises.

A MD, um dos desenvolvimentos mais recentes da Teoria Gerativa, assume que a formação de palavras e sentenças se dá no único componente gerativo da arquitetura da gramática, o componente sintático. Não há, nesse modelo, um componente lexical com caráter gerativo. O que, em modelos anteriores, era resolvido no léxico, na MD, é distribuído pelos outros componentes da gramática, que é organizada, basicamente, como mostra a figura abaixo. 
DS (Estrutura Profunda)

SS (Estrutura Superficial)

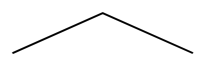

(Forma Lógica) LF MS (Estrutura Morfológica)

PF (Forma Fonológica)

Figura 2: Arquitetura da gramática - componentes ${ }^{50}$

(traduzida a partir de HALLE \& MARANTZ, 1993, p.114)

A Estrutura Morfológica (MS, do inglês Morphological Structure) faz interface com a sintaxe e com a fonologia, e essa última é vista como o componente interpretativo que realiza representações sintáticas fonologicamente.

Segundo Harley \& Noyer (1999), há três propriedades centrais que definem a MD:

i) Inserção Tardia - categorias sintáticas são puramente abstratas, não têm conteúdo fonológico. A expressão fonológica dos nós terminais sintáticos é inserida apenas no mapeamento para a Forma Fonológica (PF, do inglês Phonological Form);

ii) Subespecificação de Itens de Vocabulário - as expressões fonológicas não precisam ser completamente especificadas para as posições sintáticas em que vão ser inseridas. Os Itens de Vocabulário (IVs) podem ser formas default inseridas quando um item mais especificado não estiver disponível; e,

iii) Estrutura Hierárquica Sintática All The Way Down (por toda a derivação) - elementos dentro da sintaxe e da morfologia entram nos mesmos tipos de estruturas sintáticas.

A sintaxe opera (através de mover e concatenar) sobre os traços morfossintáticos selecionados do inventário disponível na língua relevante. Os IVs

\footnotetext{
${ }^{50}$ As siglas foram mantidas do inglês e referem-se a: DS (Deep Structure), SS (Superficial Structure), LF (Logical Form), MS (Morphological Structure) e PF (Phonological Form).
} 
competem para inserção nos nós terminais das derivações sintáticas, sendo que o item mais especificado ganha essa competição.

A MD prevê a existência de três listas na arquitetura da gramática, conforme a figura 3 abaixo:

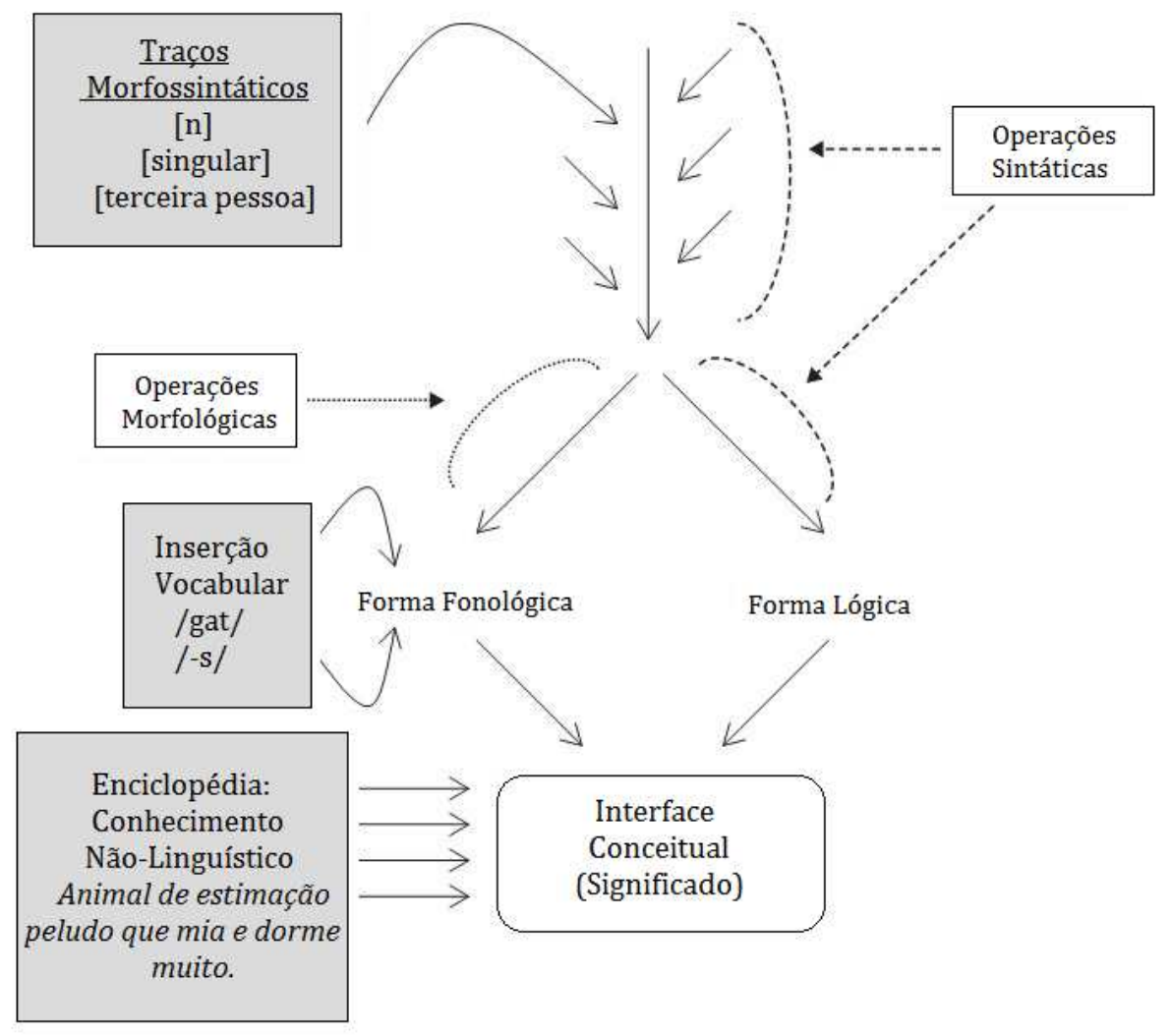

Figura 3: Arquitetura da gramática - listas ${ }^{51}$

A lista 1 contém raízes acategoriais e traços morfossintáticos abstratos, sem conteúdo fonológico. Esses elementos só recebem conteúdo fonológico, disponível na forma de regras de inserção, na lista 2, ou Vocabulário, após a derivação (inserção tardia). A lista 3, ou Enciclopédia, é responsável por interpretações especiais ou idiomáticas.

Em nossa pesquisa, argumentamos que CLs são morfemas que se anexam a certas raízes. Pensando que haveria, então, unidades formacionais em jogo em um

${ }^{51}$ Figura adaptada e traduzida em Lazzarini-Cyrino, Armelin \& Minussi (2013), a partir de Siddiqi (2009, p.14). 
processo concatenativo (entre morfemas $\mathrm{CL}$ e raízes, por exemplo), a sintaxe operaria com esses elementos que sofreriam spell-out, ou seja, receberiam conteúdo fonológico, pós-sintaticamente. Em outras palavras, após todas as operações sintáticas serem realizadas, o resultado dessas operações é enviado para as interfaces LF e PF. Em LF há a interpretação do conteúdo da derivação e acesso à Enciclopédia, responsável pela interpretação de expressões idiomáticas. No caminho para PF, há o componente morfológico, que faz os últimos ajustes morfossintáticos, por meio de operações morfológicas, e há a inserção de vocabulário (spell-out). A inserção de vocabulário se dá pela associação que é feita entre os IVs (peças fonológicas) e o feixe de traços (ou morfema abstrato). Se as "peças fonológicas" são inseridas pós-sintaticamente, é possível assumirmos uma mesma derivação sintática para a formação de compostos com realizações diferentes, sequenciais ou simultâneos.

Nessa teoria, é a partir de raízes acategoriais (MARANTZ, 1997) que se formam palavras ou sinais e essas raízes só recebem uma categoria sintática quando concatenadas sintaticamente a um categorizador, nome (n), adjetivo (a) ou verbo $(v)$. Como apontamos acima, há pares verbo-nome na libras que apresentam uma mesma forma superficial. Sendo assim, nesse modelo, deve ser possível assumir que tais dados são categorizados e diferenciados sintaticamente por um $v$ ou por um $n$ categorizador com realização fonológica $\varnothing$, ou com realização específica em alguns membros dos pares em que há uma diferenciação entre o sinal para o nome ou para o verbo, como discutiremos no capítulo 4, mais adiante. Essa proposta deverá corroborar a premissa da MD de que raízes são acategoriais.

Pensando nos dados simultâneos, é importante ressaltar que a tendência a formações não-concatenativas apontada na literatura sobre as LSs por si só já é um desafio para modelos baseados em um sistema concatenativo para a morfologia e para a sintaxe, como a MD. Se a derivação dos dados apresentados acontecer no sentido que hipotetizamos até aqui, mostraremos que a simultaneidade na formação de sinais da libras é puramente superficial, evidenciando que o que muitas vezes é chamado de não-concatenativo é, na verdade, apenas reflexo da simultaneidade superficial, possível para a línguas da modalidade vísuo-espacial, ou seja, quando se está diante de uma língua com a possibilidade de vários articuladores. 


\subsection{Fase nas palavras}

A noção de fase, de modo mais geral, vem do trabalho de Chomsky (2001) que assume que as fases são domínios de spell-out ( $v P$ e CP) que são partes da estrutura sintática sentencial. O autor também assume que spell-out é cíclico. Depois que uma cadeia sofre spell-out, ou seja, tem sua pronúncia determinada em uma sentença, ela não fica mais acessível para os próximos estágios da derivação; ela é impenetrável para as operações mais altas, como prevê a Condição de Impenetrabilidade da Fase (PIC, do inglês, Phase Impenetrability Condition), em (25):

(25) PIC: Para [zp Z... [HP a [H YP]]]: O domínio de H não está acessível para operações em ZP; apenas $\mathrm{H}$ e sua borda estão acessíveis para tal operação ${ }^{52}$ (CHOMSKY, 2001, p.13)

Com base em Chomsky (op. cit.), Marvin (2003, p.20) aponta que fases: i) são locais de reconstrução (FOX, 1999); ii) são proposicionais; iii) têm independência fonética: elas podem ser movidas, pronunciadas, etc.; iv) são alvos potenciais para movimento, elas devem ter um traço EPP.

A ideia de fase dentro das palavras foi desenvolvida pela primeira vez em Marantz (2001). Para o autor, na derivação da palavra núcleos formadores de categoria, $n, v$ e a determinam a borda de um domínio cíclico, ou seja, a fase. Acompanhando essa linha, Marvin (2003) também assume que núcleos formadores de categoria constituem domínios de spell-out (fases no nível da palavra). A autora busca mostrar que palavras são construídas pelos mesmos princípios que sentenças, uma vez que a existência de fases no nível da palavra dá suporte para uma teoria da morfologia que assume que a formação de palavras ocorre no componente sintático, seguindo as mesmas regras de formação de frases sintáticas. Dessa forma, a derivação de objetos linguísticos acontece por fases (veja a figura 4).

\footnotetext{
52 "The domain of $H$ is not accessible to operations at ZP; only $H$ and its edge are accessible to such operation" (CHOMSKY, 2001, p.14).
} 


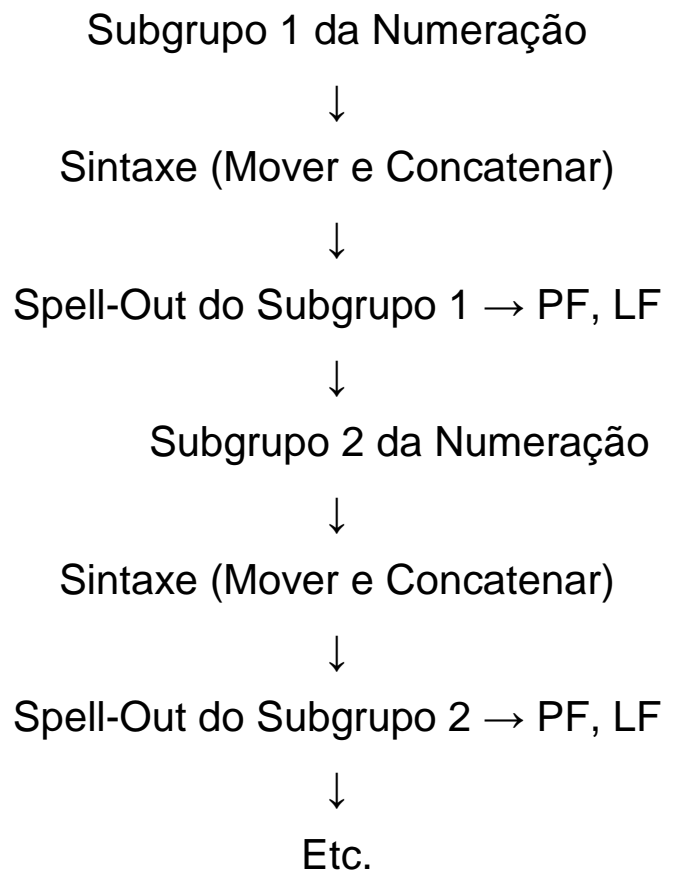

Figura 4: Derivação por fase

(traduzida a partir de MARVIN, 2003, p.19)

Marvin (op. cit.) assume que cada fase é determinada por um subgrupo da Numeração localizada na memória ativa. Assim, os objetos linguísticos não sofrem spell-out como um todo, mas ciclicamente, em cadeias determinadas pela estrutura sintática. Ela ressalta que esse processo é dirigido por economia, ou seja, a derivação por fases resulta em uma redução da carga computacional porque cada vez que a fase é enviada, o mecanismo pode esquecer a estrutura interna da unidade que sofreu spell-out, e a unidade continua sendo uma unidade na estrutura sintática (MARVIN, op. cit., p.19).

A autora explica que o complemento do $x$ sofre spell-out no ponto de concatenação do núcleo formador de categoria $x$ e, a partir desse ponto, fica inacessível para os núcleos mais altos que se anexam, como vemos em (26):

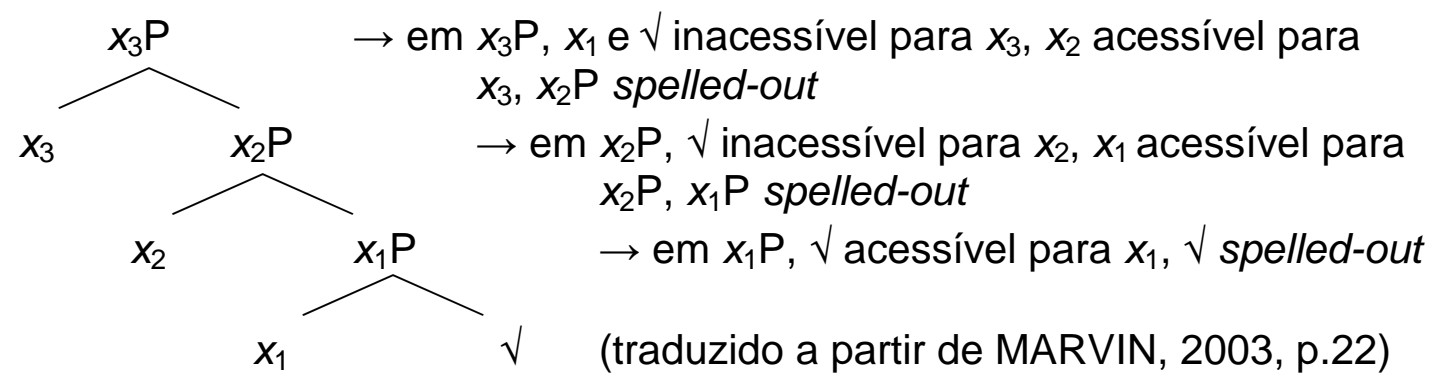


Marvin (op. cit.) ressalta que essa análise assume a condição de impenetrabilidade de fase no nível da palavra. Segue dessa proposta que afixos que se anexam fora de uma fase terão o poder de influenciar o spell-out do núcleo daquela fase, mas não o seu complemento, uma vez que o significado e pronúncia do último já serão conhecidos no momento da anexação. Assim, um afixo que poderia potencialmente afetar a pronúncia da base a qual ele se anexa (disparando uma regra fonológica), só será capaz de fazê-lo se a base estiver em seu domínio de spell-out (MARVIN, op. cit., p.22).

A autora defende que o local de anexação dos afixos formadores de categoria é relevante tanto para o significado quanto para a pronúncia. Ela apresenta, então, alguns exemplos extraídos de Marantz (2001):

(i) Afixação de -er agentivo é completamente produtiva e tem um significado previsível - isso se dá porque o afixo se anexa fora dos afixos formadores de categoria e envolve o argumento externo do verbo. -er não influencia a pronúncia da raiz - o acento de nominalizações com -er é o mesmo que o acento de verbos que em que -er se anexa, como em: wórk - wórker / pláy - player / términate - términator.

(ii) Afixação de -ee, por outro lado, resulta em palavras cujos significados envolvem consistentemente uma negociação particular com a semântica da raiz e nunca implica na estrutura argumental verbal. Barker (1998) mostra que a nominalização -ee não se refere a nenhum argumento sintático particular do verbo. Ele pode se referir ao objeto direto (nominee, employee), mas não necessariamente (amputee, twistee). Além disso, o afixo -ee é capaz de afetar o acento da raiz, colocando-o na última sílaba: emplóy - employée / escape escapée ${ }^{53}$. (MARVIN, 2003, p.32)

\footnotetext{
${ }^{53}$ Tradução nossa.
} 
Marvin (op. cit.) aponta algumas previsões que seguem a partir da assunção de fases no nível da palavra. Se um afixo $x_{1}$ se anexa direto a uma raiz, como em (27)a, ele pode afetar a PF da raiz e do todo; já se ele se anexa como em (27)b, acima de uma raiz já categorizada, ele não afetará a pronúncia ou o significado da raiz.

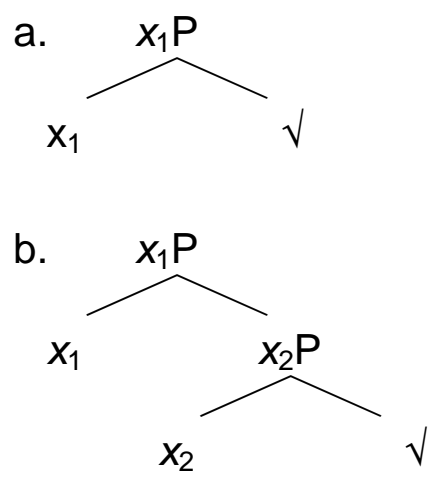

(MARVIN, 2003, p.22)

Núcleos formadores de categorias lexicais definem fases e, então, no seu momento de anexação seu complemento sofre spell-out, não ficando mais acessível para elementos mais altos.

Nesta pesquisa, assumimos também uma extensão dessa proposta, a teoria de fase de Embick (2010), teoria C1-LIN. Em uma derivação como em (28), o autor considera que $x$ é um núcleo categorizador, cíclico, ou seja, é um núcleo de fase.

(28) Fases

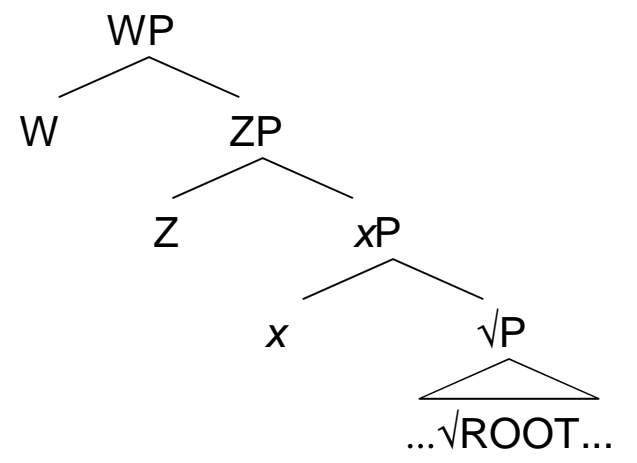

(EMBICK, 2010, p.36)

Considerando $\mathrm{W}$ e $\mathrm{Z}$ núcleos funcionais, não-cíclicos, é apenas quando um segundo núcleo cíclico concatena-se a essa estrutura, acima de WP, que o complemento do núcleo $x(\mathrm{a} \sqrt{\mathrm{P}})$, o núcleo $x$, ele mesmo, e o material presente em 
sua borda, W e Z, sofrem Spell-Out. Assim, é garantido que a informação categorial, tal como os demais traços presentes nos núcleos categorizadores sejam enviados às interfaces em conjunto com a raiz.

\subsection{Considerações finais do capítulo}

O objetivo do levantamento de dados apresentado neste capítulo foi trazer uma base empírica maior para as argumentações que seguirão nos próximos capítulos.

Uma vez que os dados coletados já foram apresentados acima e os dados na seção em 2.4 estão dicionarizados, a partir daqui remeteremos a eles apenas pelas glosas já apresentadas. Os dados que não estão nesta seção, como é o caso de exemplos de fenômenos específicos, tais como certos CLs ou dados com incorporação de numeral, serão devidamente apresentados por imagem e/ou glosa ao longo do texto.

Os pressupostos teóricos apresentados inicialmente nas últimas subseções servirão como base para as discussões e análises que serão desenvolvidas nos próximos capítulos. 


\section{Classificadores}

CLs são comuns em algumas línguas naturais. LOs, como o mandarim e o vietnamita, por exemplo, bem como LSs, como a libras e a ASL, apresentam CLs de diversos tipos (numerais classificadores, predicados classificadores, entre outros), como detalharemos adiante.

Nas LSs o estatuto dos CLs ainda é bastante discutido. Há autores que consideram CLs como gestos (Cf. COGILL-KOEZ, 2000); outros consideram CLs como uma combinação de componentes linguísticos e gestuais (Cf. LIDDELL, 2003, que os chama de depictivos, ou seja, que retratam pictorialmente certos aspectos de seu significado); um terceiro grupo trata alguns CLs como morfemas, tal como nos predicados classificadores com verbos de movimento e localização (Cf. SUPALLA, 1982, 1986); outros, ainda, tratam alguns CLs como raízes semanticamente motivadas, formando compostos raízes (Cf. ZWITSERLOOD, 2002, 2003, 2008); finalmente, um quinto grupo discute se os CLs poderiam ser definidores de classe de palavras (Cf. MEIR, 2012; ZWITSERLOOD, 2012). Além disso, uma questão que é sempre retomada nas pesquisas é se os CLs das LSs seriam, ou não, iguais aos CLs das LOs.

Este capítulo visa discutir a noção de $C L$ presente na literatura com o intuito de esclarecer a natureza dos CLs que figuram em construções como aquelas já apresentadas no capítulo 2. As análises para os CLs que retomaremos aqui servirão como ponto de partida para nossa investigação e para 0 tratamento que ofereceremos aos nossos dados a partir de agora. Uma vez que o tipo de construções complexas apresentadas é bastante produtivo na libras, é imprescindível entendermos a natureza dos CLs para que possamos, posteriormente, determinar a natureza dessas formações, verificando se se tratam de formações compostas, ou não.

As próximas seções se desenvolverão da seguinte maneira: em 3.1, apresentaremos brevemente o estatuto dos CLs nas LOs; em 3.2, discutiremos alguns estudos já realizados sobre os CLs nas LSs; em 3.3, proporemos uma estrutura para sinais com CLs que figuram em outras formações complexas, como as já apresentadas; e, em 3.4, estão as considerações finais do capítulo. 


\subsection{Classificadores nas línguas orais}

Em LOs, CLs numerais são comuns (Cf. YIP, 2008, para o mandarim e o vietnamita, por exemplo). Com base em Lyons (1977), Yip (op. cit.) divide os CLs do mandarim em: i) CLs de tipo, como em (29)a, que individualiza seus referentes, em relação ao tipo de entidade; e, ii) CLs de medida, como em (29)b, que individualiza seus referentes, em relação à quantidade.

Mandarim

a. yi tiao xiangjiao

one CL banana

'one banana'

b. yi tong shui

one CL water

'one bucket of water'

Esses CLs dividem o grupo de nomes entre contáveis e massivos. Se observarmos os exemplos em (29), podemos perceber que, no mandarim, o CL ocorre entre um numeral e um nome. Grinevald (2000, p.63) afirma que CLs numerais são assim denominados porque ocorrem em contexto de quantificação, podendo ocorrer também com demonstrativos e, ocasionalmente, com adjetivos. Eles marcam categorias de nomes por morfemas livres ou presos (afixos, infixos ou reduplicação em algumas línguas); são sistemas de classificação motivados semanticamente que classificam apenas alguns nomes; e estão sujeitos a condições pragmáticas de uso - em muitos casos, a presença ou ausência de um nome CL se dá por fatores pragmático-discursivos em vez de sintáticos.

Aikhenvald (2000, p.99) afirma que, em alguns poucos casos, CLs numerais podem formar um constituinte com o nome em vez de formar um constituinte com o 
numeral, como na língua kana ${ }^{54}$. O CL numeral também pode aparecer fundido com um modificador dentro de uma construção com numeral, como em nauru ${ }^{55}$. A autora também aponta que, em línguas com sistemas de numerais bem elaborados, o uso de CLs numerais pode depender do próprio numeral. Mais precisamente, CLs podem ser restritos ao uso com numerais menores. Aikhenvald (op. cit.) cita o exemplo da língua minangkabau ${ }^{56}$, na qual os CLs numerais ocorrem obrigatoriamente com numerais de um a três e são opcionais com outros numerais. Ela cita também o exemplo da língua telugu ${ }^{57}$, na qual CLs numerais não ocorrem com numerais maiores que dez. Além disso, ela assume que a possibilidade de se omitir o CL tem a ver com a organização semântica do sistema. Para a autora, CLs numerais podem ser: i) lexemas independentes; ii) afixos ou clíticos anexados ou fundidos com numerais; iii) ou podem ser anexados ou fundidos com núcleos nominais, sendo essa última situação a mais rara observada em línguas kegboid, como o kana (AIKHENVALD, op. cit., p.101). Ela também aponta que os CLs em kana formam uma palavra fonológica e morfológica com o núcleo do nome, e não com o numeral (AIKHENVALD, op. cit., p.111).

Alguns dados que observamos na libras, como aquele em (30), ANO-UM "um ano" e HORAS-DOIS "duas horas" ("incorporado"), que vem sendo chamado na literatura das LSs como "incorporação de numeral"58, apresentam algumas dessas propriedades dos CLs numerais destacadas por Aikhenvald (op. cit.).

\footnotetext{
${ }^{54}$ Kana é uma língua da família kegboid falada na Nigéria.

${ }^{55}$ Nauru ou língua nauruana é uma língua austronésia falada na República de Nauru, Oceania.

${ }^{56}$ Minangkabau é uma língua austronésia falada pelo povo da Sumatra Ocidental e em diversas cidades da Indonésia e também na Malásia.

${ }^{57}$ Telugu é uma língua dravídica oficial em Andhra Pradesh, na Índia.

${ }^{58}$ Sobre a incorporação de numeral nas LSs, Cf. Schuit (2007 - análises de dados nas LSs holandesa (NGT), argentina (Argentinean SL), catalã (Catalan SL), ASL e BSL); Mathur; Rathmann (2011 - análises de dados nas LSs alemã (DGS), japonesa (Nihon Shuwa) e na ASL).
} 


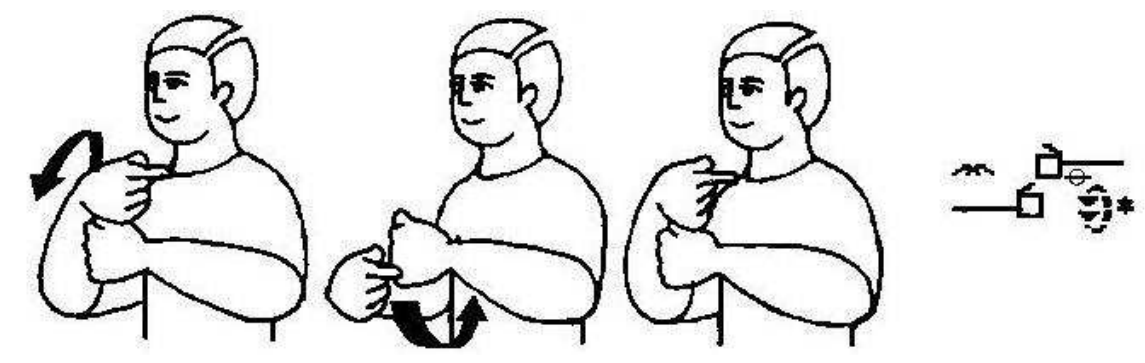

b. HORAS-DOIS "duas horas"

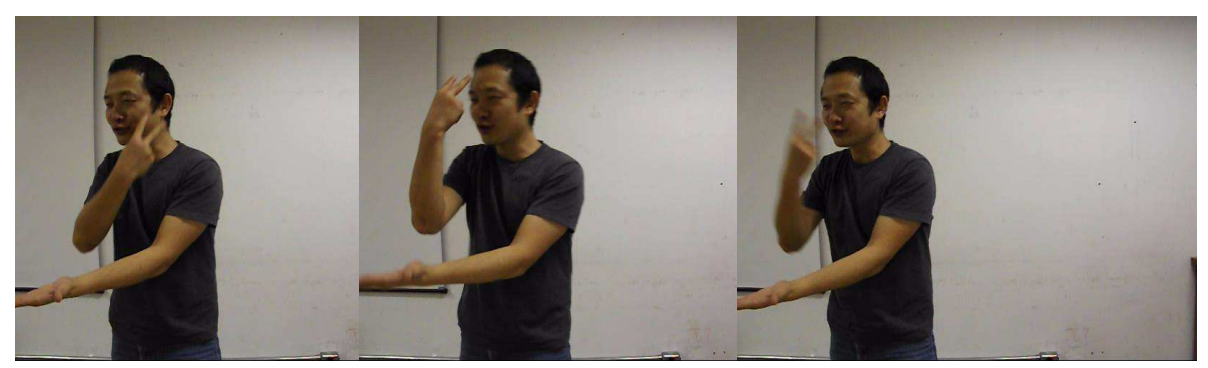

Esse fato nos levou a pensar se dados desse tipo poderiam ser, de fato, CLs numerais $^{60}$. Ao observarmos a ocorrência de exemplos como esse em sinalização natural, vimos que eles realmente se assemelham aos CLs numerais, pois, na libras, ele é bastante produtivo, mas apresenta distribuição limitada. É um fenômeno que ocorre frequentemente com numerais de um a quatro, com menos frequência, de cinco a nove, e nunca com numerais a partir de dez. A incorporação de numeral ocorre em dados como HORA, HORA (2), DIA, SEMANA, MÊS, ANO, VEZ e REAL (moeda). Em alguns contextos, a sinalização do numeral é realizada separadamente da sinalização do nome, o que mostra que incorporação é opcional (Cf. Dedino, 2012; e Rodero-Takahira, 2013). Nesses casos, tem-se ênfase na expressão facial e na lentidão e/ou repetição do movimento para o numeral. No entanto, diferentemente do que vemos em CLs numerais das LOs, a estrutura que a libras apresenta não é

\footnotetext{
${ }^{59}$ O sinal ilustrado aqui foi adaptado de Capovilla \& Raphael (2001).

${ }^{60}$ Agradecemos aos participantes do GREMD que levantaram essa discussão em um de nossos encontros.
} 
Num $+\mathrm{CL}+\mathrm{N}$, mas apenas numeral||nome, simultaneamente, sugerindo um possível tipo de composto simultâneo ${ }^{61}$.

CLs numerais não são o único tipo de CL identificado nas LOs. Há, por exemplo, CLs que remetem a tamanho ou formato, chamados de CLs de tipo. De modo mais geral, Grinevald (2002, p.260) define CLs como morfemas que aparecem em um grande número de classes, constituem sistemas abertos de categorização nominal, não fundem com categorias gramaticais (da forma que nomes poderiam fundir com número ou caso), não são marcados no $\mathrm{N}$ por si só, não fazem parte de sistemas de concordância, podem ter variação de falante para falante, apresentam variação de registro (formal vs. Informal), e são de natureza lexical, usados em construções morfossintáticas específicas.

Grinevald (op. cit.) afirma que expressões de medida, como "a glass of water" (um copo de água), sendo "água" um nome massivo em inglês, e expressões de classe, como "strawberry" e "blueberry" (morango e mirtilo) ou "apple tree" e "banana tree" (macieira e bananeira) são, às vezes, confundidos com CLs. A autora aponta que em línguas classificadoras com sistemas de CL numeral, há dois tipos de CL: o CL de medida, que é igual às expressões de medida em línguas não classificadoras, e os CLs de tipo, que são os CLs mais tradicionais:

a. [measural classifier] two [bags of] oranges a [stack of] shirts three [circles of] children

b. [SORTAL classifier] two [ROUND] oranges a [FLAT.FLEXIBLE] shirt three [HUMAN] children

\author{
"CLs de medida"62 \\ "duas [sacolas de] laranjas" \\ "uma [pilha de] camisas" \\ "três [círculos de] crianças" \\ "CL categorial" \\ "duas laranjas [REDONDAS]" \\ "uma camisa [LISA.FLEXÍVEL]" \\ "três crianças [HUMANAS]"
}

\footnotetext{
${ }^{61}$ Cf. Fuentes et al. (2010) para uma comparação da incorporação de numeral da ASL com os numerais CLs das LOs; e Jones (2013), para um tratamento dos mesmos dados com sendo formados por composição.

62 Traduções nossas.
} 
Esses CLs de tipo são muito parecidos com os que vimos nos dados apresentados no capítulo anterior, o que indica que a libras deve ter um sistema CL do tipo visto em outras línguas naturais.

\subsection{Classificadores nas línguas de sinais}

Em comunicação com sinalizantes nativos da libras, percebemos que, de forma geral, a visão que eles têm dos CLs é a de um elemento que serve para descrever, detalhar, dar características para um objeto, animal ou pessoa.

Podemos afirmar, no entanto, que o uso dos CLs é muito mais sistemático, no sentido em que o CL é um elemento linguístico, e como tal respeita os processos de formação de palavras e a sintaxe dessa língua. Detalharemos essa sistematicidade ao longo desta subseção.

Em uma definição utilizada em seu dicionário de libras, Capovilla, Raphael \& Mauricio (2012, p.58) afirmam que:

\footnotetext{
O conceito de classificador diz respeito aos diferentes modos como um sinal é produzido, dependendo das propriedades físicas específicas do referente que ele representa. Os classificadores geralmente representam algumas características físicas do referente como seu tamanho e forma, ou seu comportamento ou movimento, o que confere grande flexibilidade denotativa e conotativa aos sinais. O sinal CAIR, por exemplo, é classificador, pois sua forma varia de acordo com o objeto referido, ou seja, que sofre a queda (e.g., papel, copo, pessoa). Quando um sinal funciona como classificador, sendo que sua forma específica varia dependendo das circunstâncias particulares de seu uso, a sigla $C L$ aparece após o verbete (...).
}

Essa definição, de certa forma, descreve a flexibilidade de um CL na libras. Mas, de fato, não esclarece o que é um CL. De acordo com essa definição, um CL poderia implicar o modo de produção de um sinal, poderia ser um sinal, propriamente dito, como CAIR, ou, ainda, poderia ser um sinal com a função de um CL. Sendo assim, será importante investigarmos a origem dessa flexibilidade, bem como buscarmos outras fontes que nos ajudem a compreender os aspectos formais (morfológicos e sintáticos) para que possamos definir o que é um CL.

Os exemplos citados acima com o verbo CAIR, verbo CL, são os seguintes: 
(32) a. CAIR-CANETA (CL)

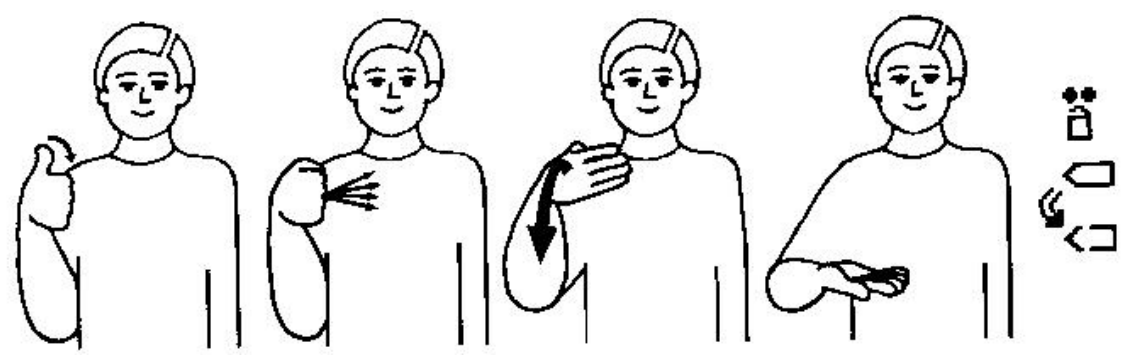

(CAPOVILLA; RAPHAEL, 2001, p.337)

b. CAIR-COPO (CL)

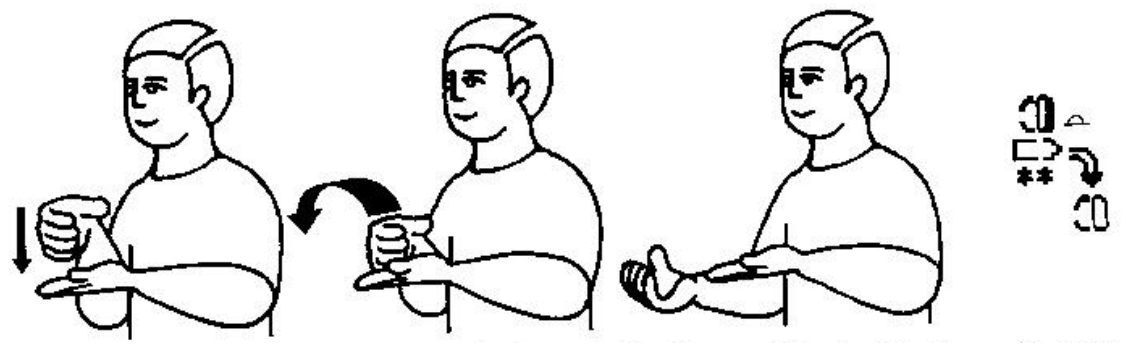

(CAPOVILLA; RAPHAEL, 2001, p.337)

c. CAIR-PAPEL (CL)

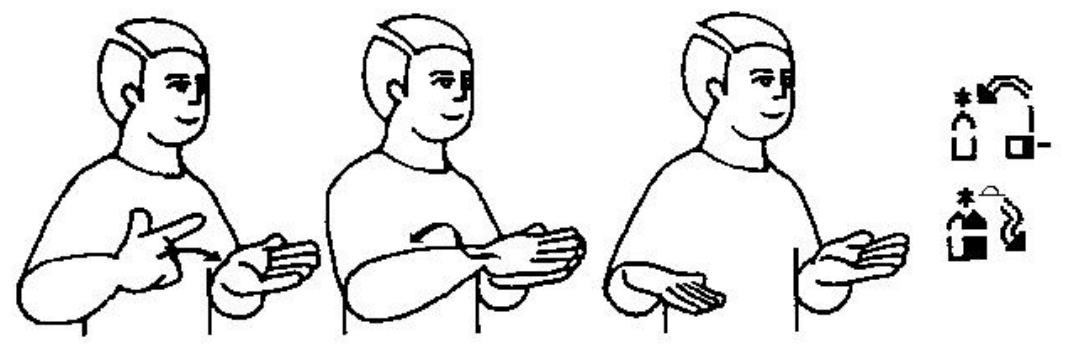

(CAPOVILLA; RAPHAEL, 2001, p.338)

55 
d. CAIR-PESSOA (CL)

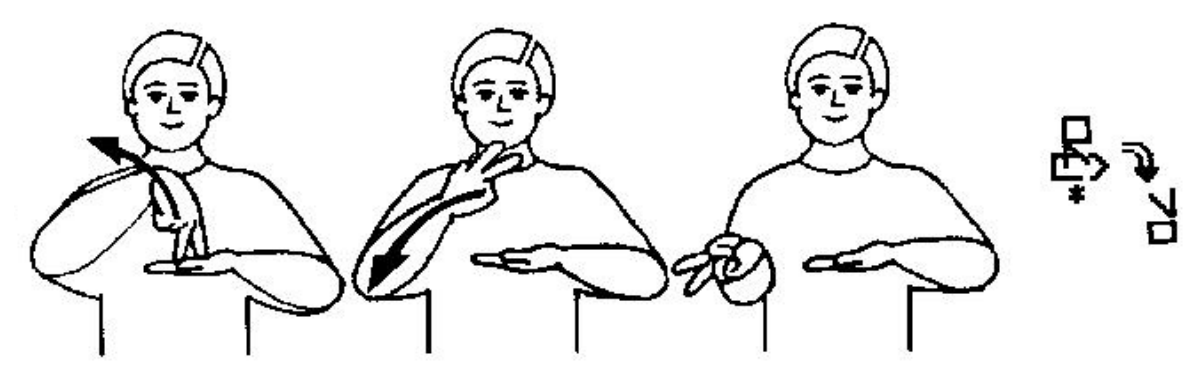

(CAPOVILLA; RAPHAEL, 2001, p.338)

Alguns autores (Cf. SUPALLA, 1982, 1986, entre outros) analisam esse tipo de exemplo como um verbo que apresenta um morfema $C L$, expresso pela $C M$, que se refere ao objeto ou à entidade que sofreu a queda. Esses morfemas CLs tomam a forma do objeto ou pessoa e ocorrem junto à raiz que, para Supalla $(1982,1986)$, por exemplo, é realizada pelo M, CAIR. Ele chama esse tipo de dado de predicados CLs. Podemos ver outros exemplos desse tipo na libras, como parte das formações apresentadas de (17) a (22), do capítulo 2, repetidas abaixo ${ }^{63}$, em (33)a-e:
a. CAMACL-BALANÇAR(M) "cama balançando ou ato sexual"
b. ENTIDADE-RETA3 ${ }_{C L}-P I N T A R(M)$ "desenhar"

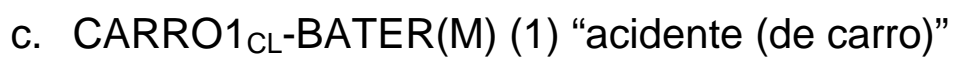
d. CARRO2 ${ }_{C L}-B A T E R(M)(2)$ "acidente (de carro)"
e. ENTIDADE-PLANA2 2 -BALANÇAR(M) "bichinho de balanço"

Supalla $(1982,1986)$ analisa esse tipo de dado na ASL e considera que eles são morfemas que se referem a nomes e ocorrem com dois tipos de verbos, os de movimento e os locativos, como em (34):

\footnotetext{
${ }^{63}$ Repetimos apenas a parte da formação que envolve o predicado CL e sua respectiva tradução.
} 


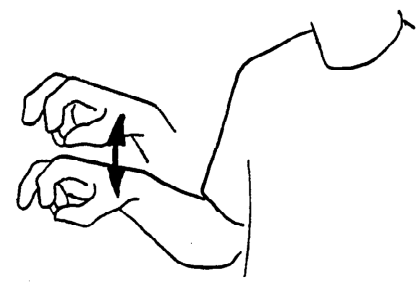

ANIMAL-HOP "um pequeno animal pula" (SUPALLA, 1982, p.49)

Ele considera que esse tipo de verbo é formado por morfemas que, muitas vezes, são transparentemente relacionados com seu significado (de forma icônica) e tendem a ser combinados simultaneamente. $O$ autor afirma que essas duas características dos morfemas das LSs dão aos verbos da ASL a aparência de representação dos objetos e movimentos do mundo real, mas:

apesar da iconicidade aparente dos morfemas classificadores da ASL, e apesar de eles poderem potencialmente retratar um número infinito de variados objetos do mundo real, a ASL desenvolveu apenas aqueles tipos de classificação que também são encontrados nas LOs do mundo ${ }^{64}$. (SUPALLA, 1986, p.182)

Sobre a questão da semelhança, ou não, entre os CLs das LSs e os CLs das LOs, ressaltamos, então, que Supalla (op. cit.) defende que o sistema classificador na ASL é bastante semelhante ao sistema classificador das LOs, apesar de as LSs contarem com uma organização potencialmente diferente por conta da modalidade vísuo-espacial. Um dos efeitos dessa modalidade destacado no trecho acima é a questão da iconicidade aparente. Entendemos que a "iconicidade aparente" é a iconicidade expressa visualmente. É aparente porque a sistematicidade fonológica da língua é respeitada, ou seja, a produção de sinais icônicos se dá respeitando o sistema fonológico da língua, as CMs, Ms, etc., disponíveis, bem como aspectos

\footnotetext{
${ }^{64}$ Tradução nossa.
} 
morfossintáticos, e esses sinais são convencionalizados, de forma que os sinais ditos icônicos variam de uma LS para outra LS $^{65}$.

Johnston e Schembri (1999) analisam os dados das LSs como lexemas ou sinais. Para eles, lexemas são um tipo de sinal que é lexicalizado, monomorfêmico, formado no léxico; enquanto que sinais são formados por morfemas, apresentam muitas possibilidades de significado dependendo do contexto e são tratados na gramática (na sintaxe). Por essa visão, exemplos como aqueles que envolvem o verbo "cair" na libras, em (32)a-d, em que diferentes usos de CMs remetem a diferentes objetos que sofreram a queda, mostram que esses são predicados classificadores; já em outras LSs, como na NGT, por exemplo, em que apenas a forma correspondente a (32)a ocorre, independentemente do objeto que sofreu a queda, para remeter ao significado de CAIR, temos um caso que os autores chamam de lexicalização.

Pensando nos dados como aqueles apresentados em (32), por um lado, percebemos que, na libras, podemos observar o uso de CLs em predicados classificadores, como aqueles que já apontamos no capítulo 2 e repetimos em (33), com os verbos de M BALANÇAR, BATER e PINTAR; mas, por outro lado, também há o uso de CLs em construções que não incluem um verbo junto com o CL, como os CLs em negrito em (35):
a. CASA $_{\mathrm{CL}}{ }^{\wedge} \mathrm{ESTUDO}$ "escola"
b. FORMA-MEIA-LUACL ${ }^{\wedge}$ VIAGEM "lua de mel"
c. ÁGUA^FORMA-CAMINHO $\mathrm{CL}$ "rio"
d. $\mathrm{BICO}_{\mathrm{CL}}{ }^{\wedge} \mathrm{ASA} \mathrm{CL}_{\mathrm{CL}}$ "pássaro"
e. CASA $_{C L}{ }^{\wedge} \mathbf{C R U Z} Z_{C L}(1)$ "igreja"
f. CANETA CL $^{\wedge}$ FORMA-RÉGUACL ${ }^{\wedge}$ LOJA^ENTIDADE-RETA4 ${ }_{C L}-C O L O C A R-$ EM-VOLTA(M) "papelaria" (2)

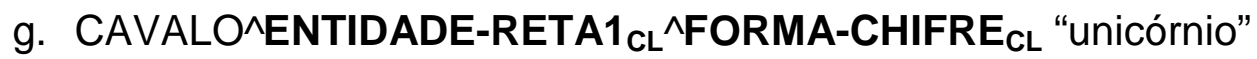

h. ENTIDADE-RETA3 ${ }_{\mathrm{CL}}$-PINTAR(M)||ENTIDADE-PLANA1 $\mathrm{CL}$ "desenhar"

\footnotetext{
${ }^{65}$ Alguns autores relacionam a iconicidade aparente com o desenvolvimento da língua em processos miméticos ou gramaticalizações. Para esses tipos de análises, veja Felipe (2006), Liber \& Pavol (2009) e Fitch (2010). Já esta tese traz uma visão diferente que será desenvolvida nas próximas subseções por conta da natureza dos dados apresentados.
} 


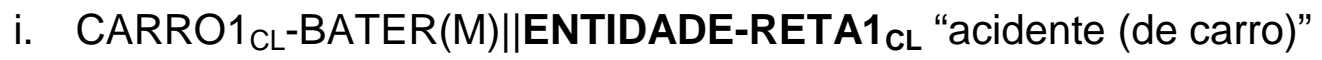

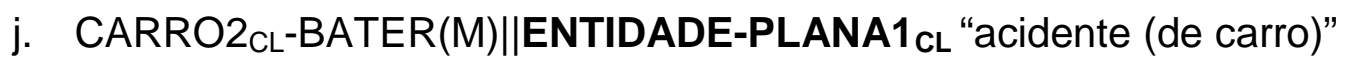

k. CAVALO^ENTIDADE-PLANA2 ${ }_{\mathrm{CL}-B A L A N C ̧ A R(M)|| E N T I D A D E-R E T A 5} \mathrm{CL}$ "cavalinho de balanço"

I. $\operatorname{cosTAS}_{\mathrm{CL}}{ }^{\wedge}{ }^{E N T I D A D E-P L A N A 3}{ }_{\mathrm{CL}}|| E_{\text {ENTIDADE-SEMI-CIRCULAR1 }} \mathrm{CL}$ "crocodilo"66.

Esse tipo de sinal CL é muito pouco estudado nas LSs. No geral, encontramos muitas pesquisas que tratam de predicados CLs, mas não sobre sinais CLs que são nomes. Em 3.3, vamos detalhar a estrutura para esse segundo tipo de dados, os sinais CLs ou nomes CL.

Diferentemente de Johnston e Schembri (1999), mostraremos que a interpretação semântica dos CLs não se dá apenas por contexto, mas as diferentes interpretações também podem ser explicadas pela própria derivação sintática. Em outras palavras, consideramos o CL um morfema que será anexado a alguns tipos de raízes e, ao final deste capítulo, procuraremos apontar as diferenças de assumirmos que ele pode se anexar diretamente a uma raiz, ou a uma categoria acima dela. Nos dois casos estaremos assumindo a teoria de fase (Cf. capítulo anterior).

Nas próximas subseções, apresentaremos quatro trabalhos sobre CLs nas LSs e traremos discussões empíricas com base nos dados já apresentados no capítulo 2.

\subsubsection{Cuxac e Sallandre (2007): classificadores e iconicidade}

Pode-se perceber que o uso de CLs nas LSs pode ter um caráter que se aproxima do imagético, por se tratar de línguas vísuo-espaciais. Sendo assim, remetemo-nos também ao trabalho de Cuxac \& Sallandre (2007), que apresenta dados da língua de sinais francesa, doravante LSF, e divide iconicidade em três

\footnotetext{
${ }^{66}$ Esses são os exemplos (8) a (12), (15), (18) a (21), e (23) já apresentados no capítulo 2. As fotos dos sinais para o exemplo "f", mencionado no capítulo 2, encontra-se no Anexo 7, exemplo (4).
} 
tipos. Os autores afirmam que os dois primeiros tipos (em A e B) são chamados de CL na literatura ${ }^{67}$ :

A - Estruturas altamente icônicas, aquelas que envolvem intenção ilustrativa, quando o sinalizante busca mostrar o referente no mundo. Esse tipo de iconicidade pode ser expresso de três formas:

i) Transferência de tamanho e forma - essas estruturas são usadas para representar o tamanho parcial ou total e/ou a forma de lugares, objetos ou características:

(36)

$$
\text { TRONCO-DE-ÁRVORE }{ }^{68}
$$
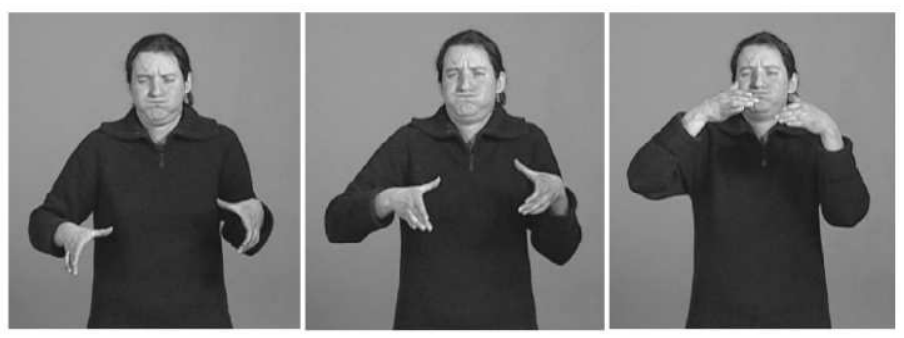

(CUXAC; SALLANDRE, 2007, p.16)

ii) Transferência de situação - o sinalizante usa o espaço em frente a ele para reproduzir iconicamente cenas representando o movimento espacial de um actante em relação a um locativo estável funcionando como um ponto de referência:

\footnotetext{
${ }^{67}$ Veja também Emmorey (2003).

${ }^{68}$ Esse CL apresentado em Cuxac \& Sallandre (2007) é da LSF, mas o mesmo CL pode ser usado na libras.
} 


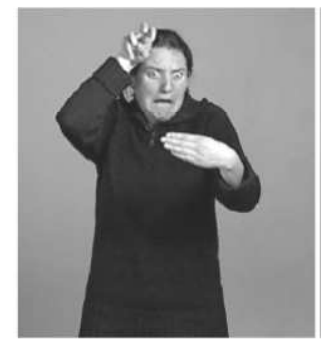

(CUXAC; SALLANDRE, 2007, p.18)

iii) Transferência de pessoa - essas estruturas envolvem o corpo todo do sinalizante para produzir uma ou mais ações desempenhadas ou sustentadas por um actante no curso da sinalização. Os actantes geralmente são humanos ou animais, mas também podem ser inanimados. O narrador "se torna" a pessoa, o animal ou o objeto sobre o qual ele/ela está falando. Ex.: incorporação de narrador, role shift. Em (38), o narrador passa a ser o cavalo da história:

(38) Incorporação de narrador

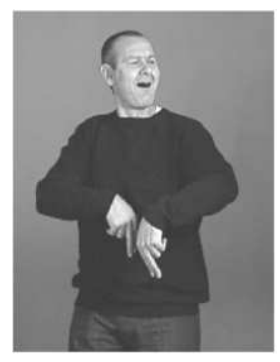

(CUXAC; SALLANDRE, 2007, p.19)

B - Iconicidade degenerativa de sinais congelados: não envolve intenção ilustrativa, não é o caso de uma tentativa de se mostrar o referente no mundo.

Os autores exemplificam a iconicidade degenerativa com os sinais PEIXE e SEXTA-FEIRA na LSF. Naquela língua, o sinal SEXTA-FEIRA foi derivado do sinal PEIXE, prato típico das sextas-feiras, e, apesar das mudanças na sinalização de

\footnotetext{
${ }^{69}$ Idem.
} 
uma e outra forma, os sinalizantes surdos sabem que o sinal SEXTA-FEIRA veio de PEIXE.

C - Iconicidade Diagramática pode ocorrer na construção de uma referência de espaço (Ex.: eye gaze, a direção do olhar marca o espaço); na construção de uma referência de tempo (Ex.: marcação da sinalização em relação ao corpo, para frente ou longe do corpo indica futuro e para trás ou próximo ao corpo indica passado); e, na construção de uma referência de pessoa (Ex.: apontamento e verbos direcionais).

Para Cuxac \& Sallandre (2007), os CLs em A e B são altamente icônicos e passíveis de serem desmembrados em morfemas composicionais que, por sua vez, envolvem diferentes partes do corpo de forma multilinear (ou simultânea). Em outras palavras, para eles os CLs são sinais morfologicamente complexos. No entanto, eles não trazem uma proposta morfossintática para os dados apresentados.

Se exemplos do tipo em A e B, dois tipos de construções icônicas, são CLs, um exemplo como CASA $\mathrm{CL}_{\mathrm{C}}$, que aparece em alguns de nossos dados, se enquadra como CL uma vez que apresenta uma forma e, por ser um sinal dicionarizado, talvez seja um tipo de sinal CL que caminha no sentido apontado na literatura como "iconicidade degenerativa de sinais congelados" (CUXAC; SALLANDRE, 2007). Nas próximas seções, discutiremos mais detalhes sobre os tipos de CLs nas LSs e sobre a questão da iconicidade com base em mais exemplos.

\subsubsection{Supalla (1982, 1986): classificadores como morfemas}

Já discutimos brevemente que CLs e iconicidade podem ser conceitos estreitamente correlacionados. Cuxac \& Sallandre (2007) afirmam que entre as três formas coexistentes de iconicidade (a imagética, a diagramática e a degenerada) na LSF, mesmo a iconicidade mais imagética é organizada em macro estruturas, articuladas em elementos morfêmicos composicionais em um nível inicial. Eles seguem uma nova leitura de Saussure sobre a natureza arbitrária do signo para 
demonstrar que iconicidade não é um conceito contraditório em relação ao conceito de arbitrariedade radical. O intuito é desmistificar a ideia de que "icônico" significaria "não estruturado". Assim, partem da premissa de que estruturas icônicas podem ser desmembradas em morfemas composicionais e esses, por sua vez, envolvem diferentes partes do corpo de forma multilinear (ou concomitante).

Nesta pesquisa, adotamos as ideias de que CLs têm valor icônico (CUXAC; SALLANDRE, 2007) e são estruturas morfologicamente complexas (SUPALLA, 1982, 1986) e partimos em busca de uma análise morfossintática para nossos dados.

Supalla (1986) discute o sistema de CLs na ASL. Com base em seus trabalhos de 1978 e 1982, ele discute a formação de construções com verbos de movimento ou localização. Para ele, os parâmetros formacionais (fonológicos) nesses tipos de verbos também são morfemas que, às vezes, são transparentemente relacionados com seu significado e tendem a ser combinados simultaneamente, o que dá aos verbos da ASL a aparência de representação dos objetos e movimentos do mundo real (SUPALLA, 1986, p.182).

O autor assume que a raiz dos verbos de movimento da ASL é um M (dentre poucos Ms possíveis). Esses verbos contêm morfemas CLs, que geralmente são CMs localizadas no caminho do M. A CM varia na forma e classifica o nome associado ao verbo (por exemplo, a CM nesses verbos pode variar de um objeto com duas pernas para um com quatro pernas). Com o intuito de estabelecer uma comparação entre os CLs da ASL e aqueles das LOs, Supalla (op. cit.) descreve os CLs da ASL, ressaltando que há as seguintes formas para se classificar substantivos:

1- SASSes (do inglês, size and shape specifiers):

São um tipo de CL no qual a CM de uma ou das duas mãos, em alguns casos também o antebraço, representa o tamanho e/ou o formato do objeto. "SASSes representam atributos geométricos visuais do objeto referente através de partes internas da mão com valor morfológico" (SUPALLA, 1986, p.190). O autor divide os SASSes em: 
a) estáticos - aqueles em que a CM representa o formato e/ou o tamanho de um objeto, como por exemplo, o dedo curvo remetendo a um objeto em forma curva, ou o dedo indicador reto, remetendo a um objeto comprido e reto, etc.;

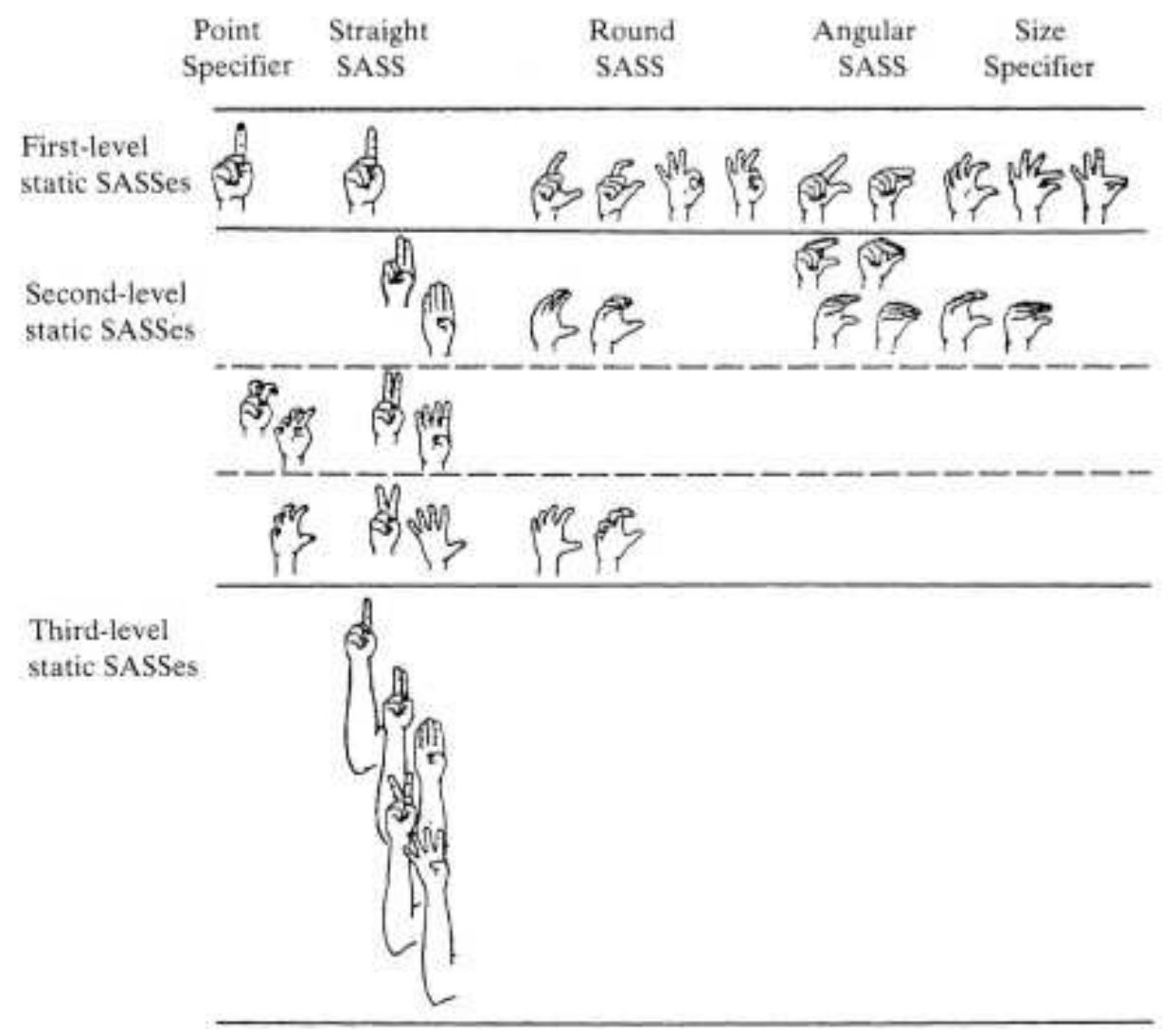

Figura 5: SASSes estáticos - ASL (SUPALLA, 1986, p.215)

Nos dados considerados nesta pesquisa, temos SASSes estáticos em:

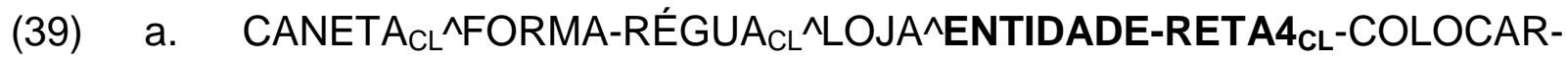
EM-VOLTA(M) "papelaria" (2)

b. CAVALO^ENTIDADE-RETA1 ${ }_{\mathrm{CL}}^{\wedge}{ }^{\wedge}$ FORMA-CHIFRE $\mathrm{CL}_{\mathrm{CL}}$ "unicórnio"

c. ENTIDADE-RETA3 ${ }_{\mathrm{CL}}$-PINTAR(M)||ENTIDADE-PLANA1 $\mathrm{CL}$ "desenhar"

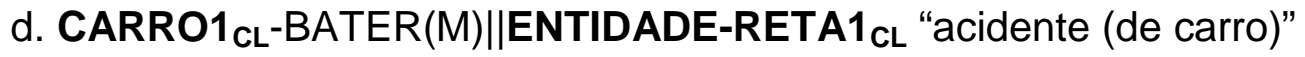

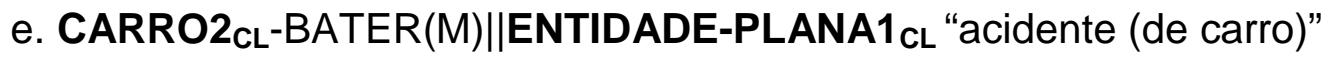


f. CAVALO^ENTIDADE-PLANA2 ${ }_{\mathrm{CL}-B A L A N C ̧ A R(M)}{ }^{-}$ENTIDADE-RETA5 $\mathrm{CL}$ "cavalinho de balanço"

g. ENTIDADE-PLANA2 CL-BALANÇAR(M) "bichinho de balanço"

h. $\quad$ COSTAS $_{\mathrm{CL}}{ }^{\wedge}$ ENTIDADE-PLANA3 ${ }_{\mathrm{CL}} \mid$ ENTIDADE-SEMI-CIRCULAR1 ${ }_{\mathrm{CL}}$ "crocodilo"70

O SASS estático destacado em (39)a, ENTIDADE-RETA4 $4_{C L}$, remete a objetos finos e compridos, como canetas, lápis e lapiseiras, que estão colocados verticalmente em alguma parte da papelaria; ENTIDADE-RETA1 $1_{\mathrm{CL}}$, em (39)b, remete ao chifre do unicórnio; em (39)c, ENTIDADE-RETA3 $3_{C L}$, remete a largura do pincel usado para pintar, e ENTIDADE-PLANA1 $1_{C L}$ à superfície que será pintada, um caderno, uma folha ou uma tela, por exemplo; em (39)d, ENTIDADE-RETA1 $1_{\mathrm{CL}}$ remete a um objeto fino e comprido no qual o carro bate, podendo ser uma árvore ou uma poste; em (39)e, ENTIDADE-PLANA1 CL remete ao muro ou local largo no qual o carro bate; nesses dois últimos exemplos, CARRO1 $1_{C L}$ e CARRO2 $\mathrm{CL}$ remetem, de fato, ao carro; em (39)f/g, ENTIDADE-PLANA2 $C L$ na vertical remete a uma animal grande em pé; e, finalmente, em (39)h, ENTIDADE-PLANA3 ${ }_{C L}$ remete ao corpo do crocodilo.

b) de traço - aqueles que se movimentam no espaço, de forma que a mão traça o formato ou tamanho do objeto.

(40) SASSes de traço da ASL

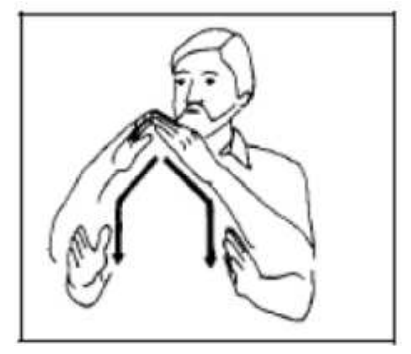

(SUPALLA, 1986, p.207)

\footnotetext{
${ }^{70}$ Mais uma vez remetemo-nos ao capítulo 2. Esses são os exemplos (15), (18) a (23). As fotos dos sinais para o exemplo "a" encontram-se no Anexo 7, exemplo (4).
} 
Nos dados considerados nesta pesquisa, temos SASSes de traço em:

(41) a. FORMA-MEIA-LUA ${ }_{C L}^{\wedge}$ VIAGEM "lua de mel"

b. ÁGUA^FORMA-CAMINHO ${ }_{\mathrm{CL}}$ "rio"

c. CAVALO^ENTIDADE-RETA1 ${ }_{\mathrm{CL}}^{\wedge}{ }^{\wedge}$ FORMA-CHIFRE ${ }_{\mathrm{CL}}$ "unicórnio"

d. CANETA $\mathrm{CL}^{\wedge}$ FORMA-RÉGUA ${ }_{C L}{ }^{\wedge}$ LOJA^ENTIDADE-RETA4 $_{\mathrm{CL}}-\mathrm{COLOCAR-}^{\wedge}$ EM-VOLTA(M) "papelaria" (2) ${ }^{71}$

Nesses exemplos em (41), as mãos traçam o formato indicado no nome desses CLs.

\section{2- CL semântico:}

A CM representa a categoria semântica do objeto referente de forma mais abstrata que os SASSes; além disso, a mão inteira, e não só parte dela, é um morfema que se refere ao objeto. Os CLs semânticos são especificados para algum tipo de movimento, seja o trajeto do verbo de movimento ou um movimento ondulado (um aceno de mão) para objetos mais fixos no espaço. Supalla exemplifica com ÁRVORE, que tem origem motivada, o antebraço em posição vertical representa o tronco e a mão aberta, as folhagens. Esse sinal pode remeter a qualquer árvore, de modo mais geral, de forma que esse $C L$ representa a categoria "árvores" de forma abstrata, não com foco em seu formato e tamanho. Outro exemplo sem motivação aparente que o autor cita é o CL para CARRO que na ASL é formado pelo dedão, o indicador e o dedo médio distendidos e a mão é posicionada em uma $\mathrm{L}$ e $\mathrm{O}$ como se fosse o carro. Supalla divide os CLs semânticos em dois grupos:

a) refere-se a entidades com pernas, sejam pessoas, animais ou objetos (mobília), e os dedos distendidos representam cada uma dessas pernas;

\footnotetext{
${ }^{71}$ Idem, para os dados em (9), (10) e (15).
} 


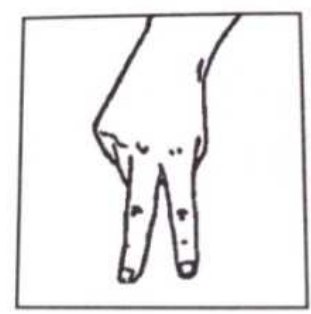

Nos dados considerados nesta pesquisa, temos esse tipo de CL Semântico em exemplos como:

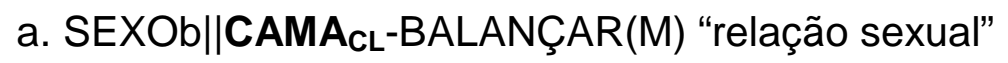

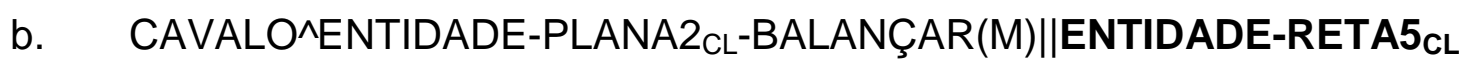
"cavalinho de balanço"72

Em (43)b, ENTIDADE-RETA5 $\mathrm{CL}$ remete a uma pessoa.

b) inclui outros três tipos de CLs em relação à sua função e orientação (espacial): aqueles em posição horizontal, aqueles em posição vertical, e os fixos em uma coluna.

Consideramos que os sinais mais icônicos das LSs se enquadram nesse grupo de CLs semânticos, como:

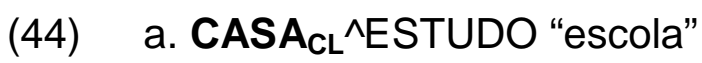

b. $\mathrm{BICO}_{\mathrm{CL}}{ }^{\wedge} \mathrm{ASA} \mathrm{AL}_{\mathrm{CL}}$ "pássaro"

c. CASA $_{C L} \wedge C R U Z_{C L}$ (1) "igreja"

d. CANETA ${ }_{C L}^{\wedge}{ }^{\wedge}$ ORMA-RÉGUA ${ }_{C L}^{\wedge}{ }^{\wedge} O J A^{\wedge} E N T I D A D E-R E T A 4_{C L}-C O L O C A R-$ EM-VOLTA(M) "papelaria" (2) ${ }^{73}$

\footnotetext{
${ }^{72}$ Idem, para os dados em (17) e (21).
} 
Consideramos exemplos como CASA $A_{C L}, B_{C l} O_{C L}, A S A_{C L}, C R U Z_{C L}$ e CANETA $_{C L}$ como sinais CLs não só pela descrição apresentada em Supalla (1986), mas também por conta da discussão que desenrolamos acima acerca da pesquisa de Cuxac \& Sallandre (2007). Como vimos, esses autores afirmam que estruturas altamente icônicas são expressas por transferência de tamanho e forma (uso de SASSes, na terminologia de SUPALLA, 1986) para representar o tamanho parcial ou total e/ou a forma de lugares, objetos ou características, ou são expressas pela iconicidade degenerativa de sinais congelados. Os exemplos que apontamos já são dicionarizados e são muitas vezes vistos como sinais mais (ou um pouco menos) icônicos pelos sinalizantes da libras. Observando os dados citados cuidadosamente, vemos que todos apresentam alguma iconicidade e fazem uso de CMs que tipicamente aparecem em sinais CLs. Sendo assim, afirmamos que esses sinais CLs são CLs do tipo semântico, que expressam algum grau de iconicidade, mesmo que essa origem mais icônica desses sinais esteja se perdendo com o passar do tempo.

\section{3- CL corporal:}

O corpo se refere a seres animados que têm corpo e membros. Supalla assume que o $\mathrm{CL}$ corporal só pode se referir a seres animados; quando se incorpora a um verbo só pode se referir a um objeto; e, se o corpo todo é usado para se referir a um agente que desempenha a ação, o CL corporal não pode ser combinado com o $M$ da trajetória no espaço. Ele afirma que há CLs de partes do corpo que podem ser representados pela $\mathrm{CM}$ de uma mão enquanto que a localização do corpo marca sua $O$ espacial. Localizações no corpo do sinalizante também podem ser usadas como nos olhos, no nariz ou na boca, tal como se vê em, por exemplo, SOCAR-OOLHO.

Em nossos dados, temos o exemplo:

(45) $\quad \operatorname{coSTAS}_{\mathrm{CL}}{ }^{\wedge}$ ENTIDADE-PLANA $3_{\mathrm{CL}} \mid$ ENTIDADE-SEMI-CIRCULAR $1_{\mathrm{CL}}$ "Crocodilo"74

\footnotetext{
${ }_{74}^{73}$ Idem, para os dados em (8), (11) e (12).

74 Idem, para os dados em (23).
} 
Nesse exemplo, o sinalizante indica suas costas para marcar as costas do crocodilo que, em seguida, passa a ser representada pelo sinal CL ENTIDADEPLANA3 ${ }_{\mathrm{CL}}$ realizado pelo braço e pela mão esquerda. ENTIDADE-PLANA3 $\mathrm{CL}$ remete ao corpo todo do crocodilo e a parte de cima do braço, usada na sinalização, remete às costas.

4- CL de partes do corpo (representado por SASSes ou membros do corpo):

Um SASS estático pode marcar uma parte do corpo, como o CL que representa vários objetos longos e finos, colocado na boca, pode representar os dentes de um tigre (SUPALLA, 1986, p.195). E CLs também podem marcar membros de objetos animados com duas pernas, como diferentes CMs usadas para se referir aos pés de diferentes animais (que também é um SASS).

Em nossos dados, temos o exemplo:
a. CAVALO^ENTIDADE-RETA1 ${ }_{\mathrm{CL}}^{\wedge}{ }^{\wedge}$ FORMA-CHIFRE ${ }_{\mathrm{CL}}$ "unicórnio"
b. $\operatorname{COSTAS}_{\mathrm{CL}}{ }^{\wedge}$ ENTIDADE-PLANA3 ${ }_{\mathrm{CL}} \mid$ ENTIDADE-SEMI-CIRCULAR1 $\mathrm{CL}$ "crocodilo" 75

Em (46)a, ENTIDADE-RETA1 $1_{C L}$ é um SASS estático que marca uma parte do corpo do unicórnio, seu chifre, e FORMA-CHIFRE $E_{C L}$ é um SASS de traço que traz aproximadamente a mesma informação, o formato do chifre. Em (46)b, ENTIDADEPLANA3 ${ }_{C L}$ é um SASS estático que marca o tronco do crocodilo em posição horizontal com as costas para cima, e ENTIDADE-SEMI-CIRCULAR $1_{\mathrm{CL}}$ marca as placas córneas nas costas do crocodilo.

\section{5- CLs instrumentos:}

Supalla ressalta que cada substantivo tem seu próprio inventário de CLs, logo, há vários CLs para se referir a um mesmo objeto. A seleção de um CL de um inventário depende do foco que vai ser dado a algum aspecto da interação entre o

\footnotetext{
${ }^{75}$ Idem, para os dados em (15) e (23).
} 
agente, o instrumento e o paciente. O autor afirma que, quando o foco está na manipulação do objeto por um agente, há algumas formas de se referir ao instrumento:

a) se o agente é humano, um CL instrumento manual vai ser selecionado;

b) se a manipulação do instrumento se dá com uma ferramenta, um CL de ferramenta vai ser selecionado (ou o CL de ferramenta pode incorporar movimentos miméticos de como o agente manipula o instrumento);

c) se a manipulação do instrumento se dá com outra parte do corpo (com os pés), um SASS de parte do corpo será selecionado (SUPALLA, 1986, p.196 e 197).

Em nossos dados, temos o exemplo:

(47) ENTIDADE-RETA3-PINTAR(M)||ENTIDADE-PLANA1 CL "desenhar"76

Com os exemplos apontados, observamos que nosso conjunto de dados abrange todos os tipos de CLs descritos por Supalla (1986). O autor traz um detalhamento dos tipos de CLs existentes na ASL e que são realizados com verbos de $\mathrm{M}$ e L. No entanto, ele também não traz uma análise morfossintática para os dados.

\subsubsection{Ferreira-Brito (1995): classificadores na libras}

Ferreira-Brito (1995) é o primeiro trabalho que descreve CLs na libras. Com base no trabalho de McDonald (1982) sobre classes semânticas nos CLs da ASL, a autora considera os CLs: x-tipo de objeto (como em VOTAR, em que a CM

\footnotetext{
${ }^{76}$ Idem, para os dados em (18).
} 
representa a cédula de votação); e, segurar x-tipo de objeto (como em CHÁ, em que a CM representa a forma de se segurar a xícara).

Já com base em Baker \& Cokely (1980), a autora considera CLs que veiculam a maneira como a ação acontece, funcionando como advérbios, como em DIRIGIR, que "refere-se não apenas ao ato como também à maneira de se segurar o objeto que se move (o volante)" (FERREIRA-BRITO, 1995, p.106).

Os CLs da libras que ela descreve são:

\begin{tabular}{|l|l|}
\hline CL: & $\begin{array}{l}\text { Descrição / uso (FERREIRA-BRITO, } \\
\text { 1995, p.106 a 111): } \\
\text { "Uma pessoa andando". }\end{array}$ \\
\hline "Duas pessoas andando ou paradas \\
uma ao lado da outra".
\end{tabular}




\begin{tabular}{|l|l|}
\hline "Descreve com a extremidade do \\
indicador, com as duas mãos, objetos \\
ou locais, fios ou tiras; localiza com a \\
ponta do indicador cidades, locais e \\
outros referentes; o indicador \\
representa objetos longos e finos".
\end{tabular}

Quadro 5: Classificadores da libras (FERREIRA-BRITO, 1995)

O inventário para os CLs que levantamos nesta pesquisa vai um pouco além dos CLs apresentados por essa autora, como pode ser visto no sistema de convenções nas páginas $x i$ a $x v$ desta tese ${ }^{77}$.

Com essa tabela não pretendemos descrever, necessariamente, todos os CLs que são realizados na libras, mas descrevemos todos encontrados em nossa base de dados (gravações e dicionarizados).

\subsubsection{Zwitserlood (2003): uma proposta morfossintática para os classificadores}

Zwitserlood $(2003,2008)$ analisa sinais semanticamente motivados da NGT e considera que eles formam compostos raiz, ou seja, ela considera que CM e M são morfemas.

\footnotetext{
${ }^{77}$ Para mais especificações dos CLs na libras e sua aquisição, Cf. Bernardino (2006, 2012).
} 
(48) NGT

a.

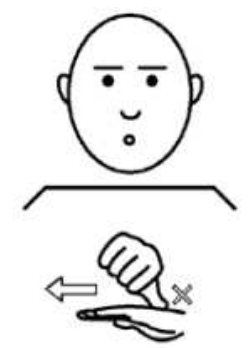

Move-manip.knife-hand

"incision in hand / incise hand" b.

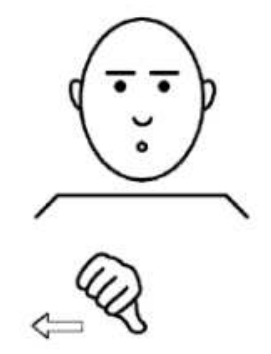

Move-manip.knife

"to operate / operation"

(ZWITSERLOOD, 2008, p.263)

Para derivar o exemplo em (48)a, a autora propõe:

(49)

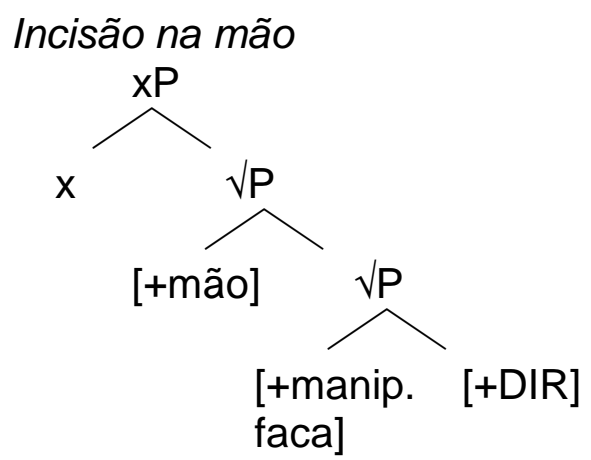

(ZWITSERLOOD, 2008, p.263)

Essa estrutura considera a formação de uma construção com CL que não tem, necessariamente, a presença de um verbo. No entanto, além de a autora considerar apenas a formação de sinais semanticamente motivados, a estrutura proposta parece trazer uma equivalência um a um entre os traços de cada raiz e cada fonema inserido. Olhando para essa derivação e para o exemplo em (48), podemos observar que o traço [+mão] é uma localização que remete ao uso da mão, o traço [+manipular faca] remete a realização da CM, com o dedão distentido, no mesmo exemplo, e o $\mathrm{M}$ é aquele de se fazer um corte na mão. Dessa forma, temos 
a impressão de que a estrutura considera fonologia durante a formação sintática das palavras, o que vai contra os pressupostos do modelo teórico da $\mathrm{MD}^{78}$.

Nossa base empírica mostra claramente que temos não só construções com verbos (predicados classificadores) e sinais semanticamente motivados, mas também temos sinais CLs realizados como um nome, com SASSes estáticos e de traços, bem como outros tipos de CLs, como já mostramos nas seções anteriores. Explicitaremos o tratamento de tais construções na próxima seção.

\subsection{A natureza dos classificadores na libras e a derivação de sinais com classificadores}

Com o exposto até aqui, entendemos que CLs podem ser:

i) morfemas que podem ser realizados junto a verbos, predicados CL, como em (33)a-e, repetido logo abaixo:
a. CAMAcL-BALANÇAR(M) "cama balançando ou ato sexual"
b. ENTIDADE-RETA3 ${ }_{\mathrm{CL}}$-PINTAR(M) "pintar (com pincel) ou desenhar"

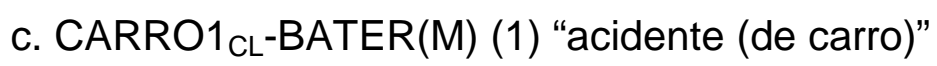

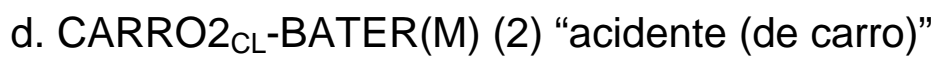
e. ENTIDADE-PLANA2 CL-BALANÇAR(M) "bichinho de balanço"

O que podemos argumentar, com base em nosso conjunto de dados, é que todos os CLs têm um valor nominal, mesmo aqueles em predicados CLs, como nos exemplos em (50). Em todos aqueles exemplos o sinal marcado como CL é um argumento do verbo ou um instrumento para a realização do evento descrito por esse verbo. Em (50)a, por exemplo, o CL semântico CAMAcL combinado com

\footnotetext{
${ }^{78}$ Agradecemos ao Rafael Dias Minussi por nos chamar atenção para esse fato e por uma série de discussões sobre esse e outros pontos do trabalho. Para uma análise que considera categorização na libras sem essa equivalência um a um entre traços semânticos e fonologia, veja também RoderoTakahira \& Minussi (2013) e Minussi \& Rodero-Takahira (2013).
} 
BALANÇAR(M) forma "cama balançando ou ato sexual"; em (50)b, ENTIDADERETA3 $C$, um CL instrumento para "pincel", combina com PINTAR(M) e forma "pintar (com pincel) ou desenhar"; em (50)c/d, CARRO1 $1_{\mathrm{CL}}$ e CARRO2 $2_{\mathrm{CL}}$ combinam com $\operatorname{BATER}(\mathrm{M})$ e formam "acidente (de carro)"; e, por fim, em (50)e, ENTIDADE$P L A N A 2_{C L}$ é um $C L$ usado para animal grande em pé e quando combinado com BALANÇAR(M) forma "bichinho de balanço". Nesses exemplos com um verbo de M, o sinal com o CL tem valor nominal, o que nos leva a assumir uma etapa nominal na derivação desses dados.

ii) morfemas que ocorrem em alguma construção sem a realização de um verbo, como exemplificamos em (35) e repetimos abaixo:
a. CASACL $^{\wedge}$ ESTUDO "escola"
b. FORMA-MEIA-LUA ${ }_{C L}^{\wedge}$ VIAGEM "lua de mel"
c. ÁGUA^FORMA-CAMINHO $\mathrm{CL}^{\wedge}$ "rio"
d. $\mathrm{BICO}_{\mathrm{CL}}{ }^{\wedge} \mathrm{ASA} \mathrm{ALL}_{\mathrm{CL}}$ "pássaro"
e. $\operatorname{CASA}_{C L}{ }^{\wedge} \mathbf{C R U Z} \mathrm{ZL}_{\mathrm{CL}}$ (1) "igreja"
f. CANETA ${ }_{C L}{ }^{\wedge}$ FORMA-RÉGUA ALL $^{\wedge}$ LOJA^ENTIDADE-RETA4 ${ }_{C L}-$ COLOCAREM-VOLTA(M) "papelaria" (2)

g. CAVALO^ENTIDADE-RETA1 ${ }_{\mathrm{CL}}^{\wedge}{ }^{\wedge}$ FORMA-CHIFRE ${ }_{\mathrm{CL}}$ "unicórnio"

h. ENTIDADE-RETA3 ${ }_{\mathrm{CL}}$-PINTAR(M)||ENTIDADE-PLANA1 $\mathrm{CL}$ "desenhar"

i. CARRO1 ${ }_{\mathrm{CL}-B A T E R(M)|| E N T I D A D E-R E T A 1} \mathrm{CL}$ "acidente (de carro)"

j. CARRO2 $\mathrm{CL}-\mathrm{BATER}(\mathrm{M})$ ||ENTIDADE-PLANA1 $\mathrm{CL}$ "acidente (de carro)"

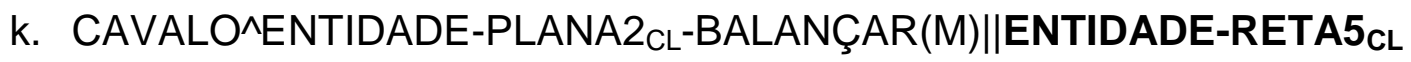
"cavalinho de balanço"

I. $\operatorname{coSTAS}_{\mathrm{CL}}{ }^{\wedge}$ ENTIDADE-PLANA3 $\mathrm{CL}||$ ENTIDADE-SEMI-CIRCULAR1 ${ }_{\mathrm{CL}}$ "crocodilo"79.

\footnotetext{
${ }^{79}$ Esses são os exemplos (8) a (12), (15), (18) a (21), e (23) já apresentados no capítulo 2. As fotos dos sinais para o exemplo “j”, mencionado no capítulo 2, encontra-se no Anexo 7, exemplo (4).
} 
Outra evidência para se pensar nessa etapa nominal é o fato de que todos esses CLs com valor nominal em (50) poderiam ocorrer em algum contexto sem a necessidade de realização do verbo de movimento, formando apenas:

(52) a. CAMACL "cama, mobília com quatro pernas (...)"

b. ENTIDADE-RETA3 $\mathrm{CL}$ "pincel, objeto razoavelmente largo (...)"

c. CARRO1 $\mathrm{CL}$ "carro, animal (...)"

d. CARRO2 $\mathrm{CL}$ "carro, objeto grande (...)"

e. ENTIDADE-PLANA2 $C L$ "animal em pé, moto, bicicleta (...)"

Bem como os dados em (52), aqueles dados em negrito em (51) poderiam ser realizados independentemente do restante da estrutura com a qual eles aparecem naqueles exemplos, com um significado nominal, como indicamos em (53):
a. CASA
b. FORMA-MEIA-LUACL "lua"
c. FORMA-CAMINHO CL "caminho / estrada (...)"
d. BICO $\mathrm{CL}$ "bico / pássaro"
e. ASA AL "pássaro / voar"
f. CRUZ $\mathrm{CL}$ "cruz"
g. CANETACL "caneta"
h. FORMA-RÉGUA $A_{C L}$ "régua"
i. ENTIDADE-RETA1 $\mathrm{CL}$ "chifre / poste / árvore / pessoa (...)"
j. FORMA-CHIFRE CL "chifre"
k. ENTIDADE-PLANA1 cL "papel / muro / chão / superfície / mar (...)"
I. ENTIDADE-RETA5 $\mathrm{CL}$ "pessoa (...)"
m. COSTAS $\mathrm{CL}$ "costas"
n. ENTIDADE-PLANA3 $\mathrm{CL}$ "corpo de animal / pessoa deitada / tronco (...)"
o. ENTIDADE-SEMI-CIRCULAR1 cL "placas ósseas (do crocodilo) / bola (...)". 
Os sinais CLs em (53) não estão concatenados com verbos de M. Eles também têm valor nominal e podem ser realizados livremente. Assim, é impossível assumir que essas unidades sejam a realização do morfema CL por si só, mas são formadas por CLs que se concatenam com uma raiz acategorial. Defendemos que esse morfema $\mathrm{CL}$ é um categorizador, que vai dar uma categoria nominal para uma raiz. Em um estágio posterior, essa formação, esse nome, pode se concatenar com um $\mathrm{VP}$, formando um verbo de $\mathrm{M}$ e funcionando como seu argumento ou instrumento. Em outras palavras, deve haver uma etapa nominal na derivação morfológica desses dados, mesmo daqueles cujo resultado final é um v, como em (50)b, pelo fato de eles poderem ser realizados sozinhos.

Assumimos, então, que o morfema $\mathrm{CL}$ é um categorizador que concatena com uma dada raiz formando um nome. Por isso, a partir daqui remetemos a esses morfemas categorizadores apenas como CLs, e aos elementos nominais que são formados com CLs, como em (52) e (53), chamaremos de sinais CL.

\section{(54) Classificadores}

Morfemas que se anexam a uma dada raiz $\sqrt{ }$, categorizando-a como um nome (morfemas categorizadores).

\section{Sinais Classificadores}

Nomes formados por uma raiz $\sqrt{ }$ já categorizada por um $n$. $O$ núcleo $n$, ou seja, o categorizador, é um morfema $\mathrm{CL}$, como em ${ }_{\mathrm{nP}}[\mathrm{n}[\mathrm{CL}] \sqrt{ }]$.

Se o CL é um morfema que será anexado a alguns tipos de raízes, primeiramente precisamos considerar qual é a raiz que entra na derivação. Vamos assumir junto com Harley (2009) que a raiz é um tipo de nó terminal e que:

"Raízes carregam o conteúdo semântico Enciclopédico nãogramatical de uma dada mensagem. Talvez seja mais fácil pensar nelas como a lexicalização de um conceito puro, embora suas interpretações possam variar dependendo dos contextos sintáticos nos quais elas se encontrem, como em expressões idiomáticas, por exemplo. Então, é mais preciso entendê-las como instruções de acesso para certos tipos de 
informação semântica, que pode variar dependendo do contexto morfossintático da raiz em questão" ${ }^{80}$

Assumimos que todos os tipos de sinais com CLs têm um significado mais geral de "entidade", que poderia ser uma pessoa, animal ou objeto. Ou seja, os CLs SASS estáticos remetem ao formato e tamanho de um objeto, os CLs SASS de traço traçam o formato do objeto, os CLs semânticos remetem a pessoas, animais ou objetos, mais iconicamente, os CLs corporais e de parte do corpo também remetem a entidades, e os CLs instrumentos fazem uso de todos os CLs anteriores para remeter à manipulação de um instrumento, por exemplo. Sendo assim, consideraremos que todos os morfemas CLs se anexam a uma raiz com um significado bem geral de "entidade" e classificam essa entidade em um tipo específico (pessoa, animal ou objeto). Na falta de um CL para delimitar o tipo de entidade, a raiz $\sqrt{E}$ NTIDADE poderia ser preenchida por um IV mais específico como INDIVÍDUO ou PESSOA ("pessoa"), MATERIAL ou COISAS ("objeto"), ou ANIMAL ("animal"), dependendo do contexto.

\section{a. INDIVÍDUO}
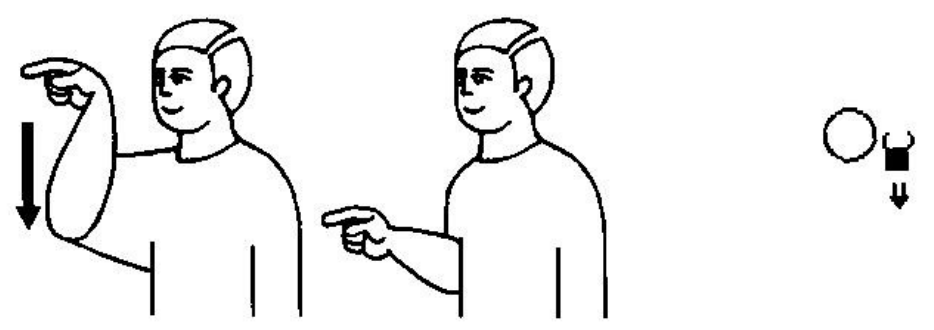

(CAPOVILLA, RAPHAEL, 2001, p.755)

\footnotetext{
${ }^{80}$ Roots carry the non-grammatical, Encyclopedic semantic content of a given message. It is perhaps easiest to think of them as the lexicalization of a pure concept, though their interpretations can vary depending on the syntactic contexts in which they find themselves, as in, e.g., idioms. It is thus more precise to understand them as instructions to access certain kinds of semantic information, which may vary depending on the morphosyntactic context of the Root in question.
} 
b. PESSOA

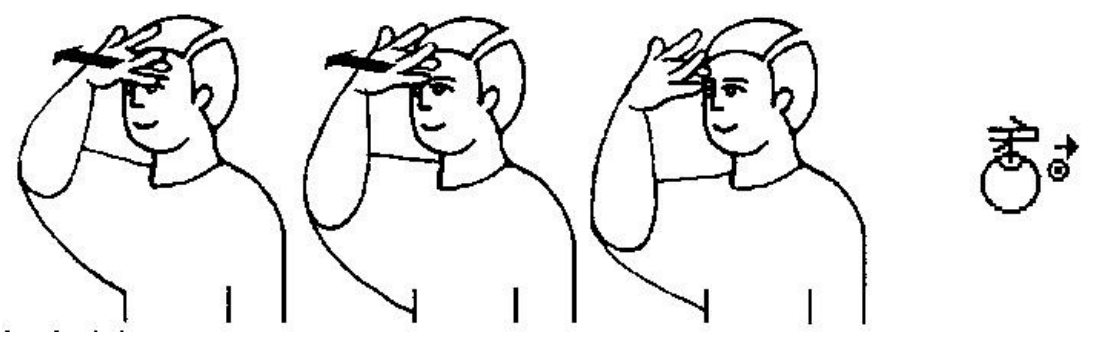

(CAPOVILLA, RAPHAEL, 2001, p.1041)

c. MATERIAL

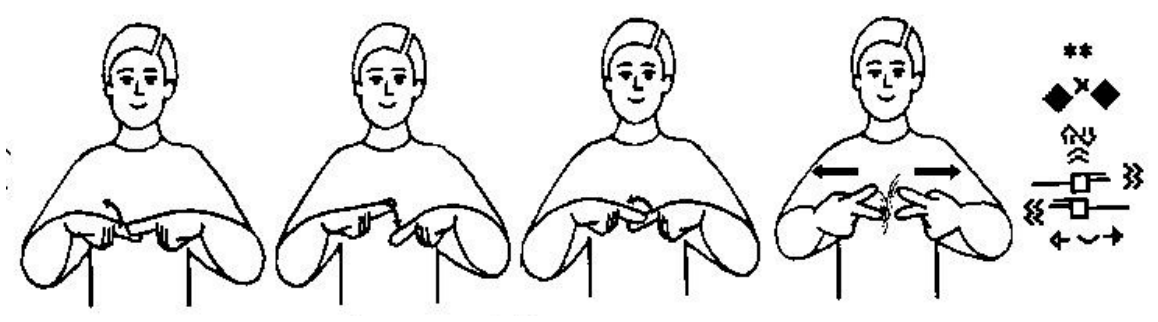

(CAPOVILLA, RAPHAEL, 2001, p.878)

d. COISAS

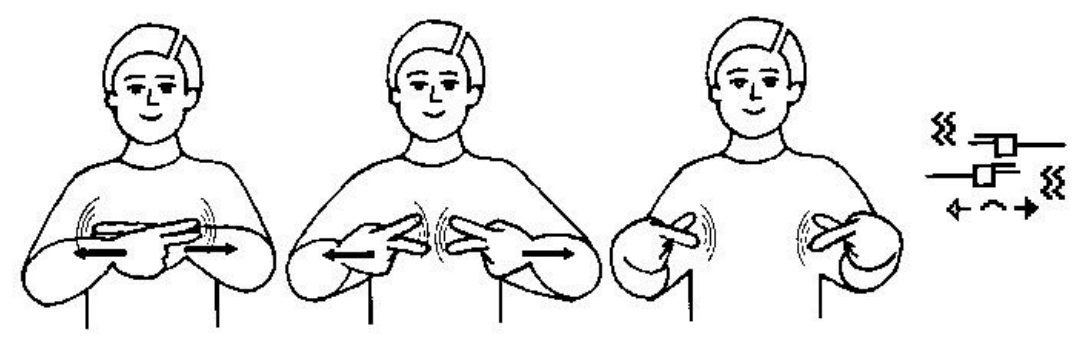

(CAPOVILLA, RAPHAEL, 2001, p.425)

e. ANIMAL

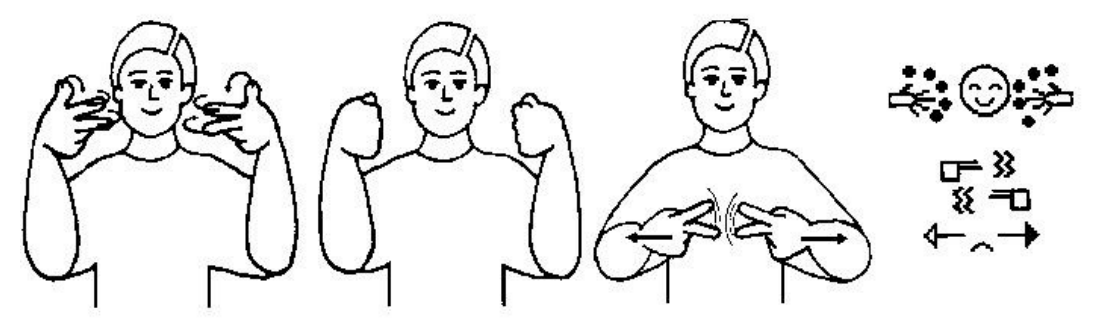

(CAPOVILLA, RAPHAEL, 2001, p.198)

79 
Precisamos esclarecer a natureza dessa raiz que consideramos para nossa derivação. Para tanto, seguimos a linha de Rocha (2008) que defende a hipótese das raízes abstratas, seguindo o modelo da MD, e trata de dados do PB envolvendo um IV /kojz/ para "coisa", "coisou", "coisado", etc. usado acidentalmente em exemplos como:
a. Não quebrei o coiso.
b. Não coisei o jarro.

A autora defende que o material fonológico, inserido pós-sintaticamente, /kojz/ não é a realização de uma raiz específica, mas sim um IV menos especificado, default. Ou seja, o falante sabe ao que está remetendo, mas produz uma realização fonológica muito menos específica.

Indo por um caminho semelhante, então, consideramos que, em relação aos nossos dados, quando o falante seleciona uma raiz VENTIDADE qualquer, ele está selecionando uma raiz específica, cujo spell-out pode se dar por uma forma bem geral, subespecificada, naquele mesmo sentido, o que será mais detalhado adiante.

Com base nos dados levantados e na noção de fase no nível da palavra (Cf. capítulo 2), vamos propor uma estrutura para a derivação das formas nominais com CLs. Com base nas estruturas apresentadas no capítulo anterior, em (27)a/b, representações propostas por Marvin (2003), e repetidas abaixo, e com base nos pressupostos teóricos, também discutidos no capítulo anterior, podemos prever as consequências da localização do morfema CL, mais perto ou mais longe da raiz.

(58) Fase na palavra - Marvin (2003)

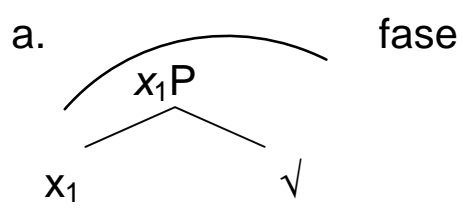




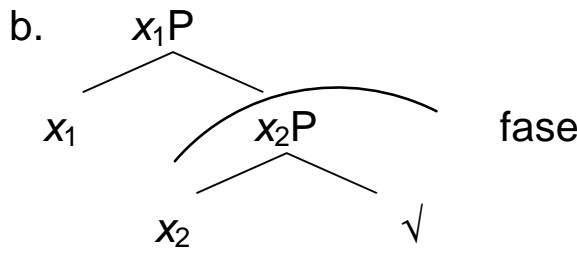

(adaptamos de MARVIN, 2003, p.22)

Podemos prever, por exemplo, que se o morfema CL se anexa diretamente a uma raiz, como em (58)a, o CL interfere diretamente no seu significado, pois encontra-se na mesma fase em que essa raiz sofrerá spell-out, como em (59):

(59)

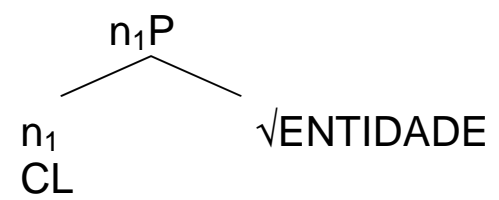

Quando $n_{1} P$ fecha a fase, a raiz $\sqrt{ }$ está acessível para $n_{1}$ e a raiz sofre spellout. Outros elementos que se anexam fora da fase teriam o poder de influenciar o spell-out do núcleo daquela fase, $\mathrm{CL}$, mas não o seu complemento, a raiz $\mathrm{V}$.

Já considerando a estrutura em (58)b, se o CL projeta e fica acima da projeção da raiz, temos a seguinte estrutura:

(60)

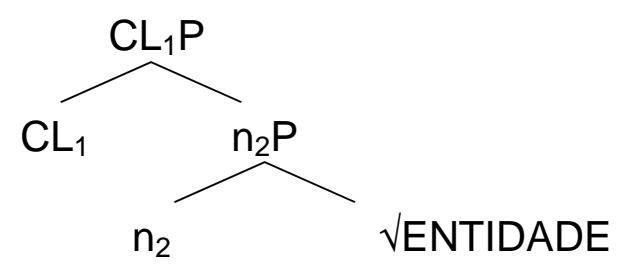

Se for assim, nesse caso o CL estaria fora do domínio da fase que determina o spell-out da raiz, segundo Marvin (2003) e, portanto, não influenciaria na pronúncia ou no significado da mesma, diferente do que nossos dados simultâneos de (16) a (20), repetidos abaixo, sugerem.
a. SEXOb||VIAJAR "lua de mel"
b. SEXOb||CAMACL-BALANÇAR(M) "relação sexual" 


\section{c. ENTIDADE-RETA3 ${ }_{C L}-P I N T A R(M)|| E N T I D A D E-P L A N A 1_{C L}$ "desenhar"

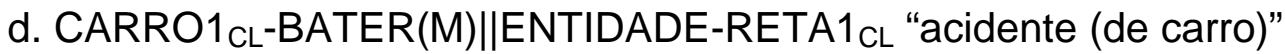 \\ e. CARRO2 ${ }_{\mathrm{CL}-B A T E R(M)|| E N T I D A D E-P L A N A 1} \mathrm{CL}$ "acidente (de carro)"}

Esses dados mostram construções com dois sinais CLs sendo realizados simultaneamente, um por cada mão, ou um pela mão e o outro pela boca. $A$ fonologia de um sinal interfere na fonologia do outro, como detalharemos no capítulo 4 , de forma que eles devem estar em uma mesma fase. Descartamos, então, a estrutura em (60).

A estrutura em (59) prevê que o morfema categorizador, o CL, influencia na pronúncia da raiz. No entanto, essa estrutura ainda não dá conta de nossos dados completamente, uma vez que temos exemplos simultâneos, como aqueles em (61). Se o núcleo categorizador marca uma fase, disparando o spell-out de seu complemento, como a simultaneidade superficial, a realização simultânea, desses elementos seria prevista estruturalmente? Uma possibilidade é considerarmos a noção de fase ampliada por Embick (2010), que define que é apenas quando um segundo núcleo categorizador se concatenar na derivação que o primeiro núcleo categorizador, seu complemento e os elementos de borda vão passar por spell-out.

Fase na palavra - Embick (2010)

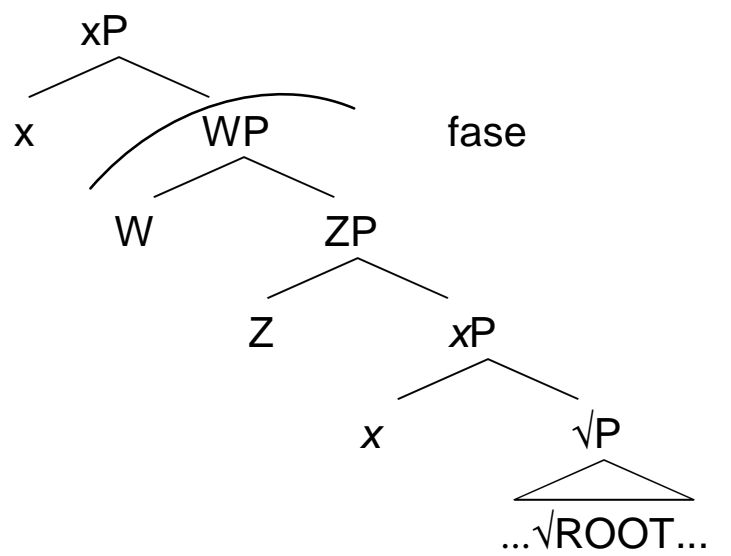

(adaptamos de EMBICK, 2010, p.36) 
Implementando nossas assunções em (54) e (55) com as ideias de fases expressas pelas derivações em (59) e (62), propomos, então, que os morfemas CLs são categorizadores, se anexando diretamente a uma raiz e podendo influenciar o spell-out e o significado dessa raiz. Acompanhando Embick (2010), sugerimos que o spell-out dessa derivação só ocorre quando um segundo núcleo categorizador se anexar a estrutura, como em (63):

\section{Estrutura morfossintática para os sinais CLs}

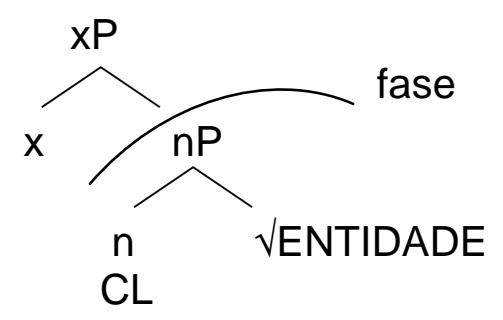

O sinal CL nominal formado por essa estrutura é bastante icônico como resultado da modalidade visuo-espacial, ou seja, o formato ao qual o morfema $\mathrm{CL}$ remete é realizado visualmente, por diferentes $\mathrm{CMs}$, objetos traçados ou partes do corpo. Essa iconicidade agregada ao uso de glosas da LO (Cf. ZWITSERLOOD, 2012, p.172, para uma crítica sobre o uso da LO em glosas de LSs) faz com que, de modo geral, na literatura remetam a um CL como ENTIDADE-RETA1 $1_{C L}$, em (19), repetido abaixo, diretamente como "o CL para ÁRVORE" ou "o CL para POSTE".

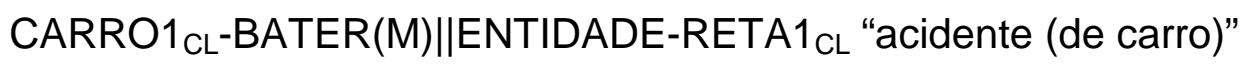

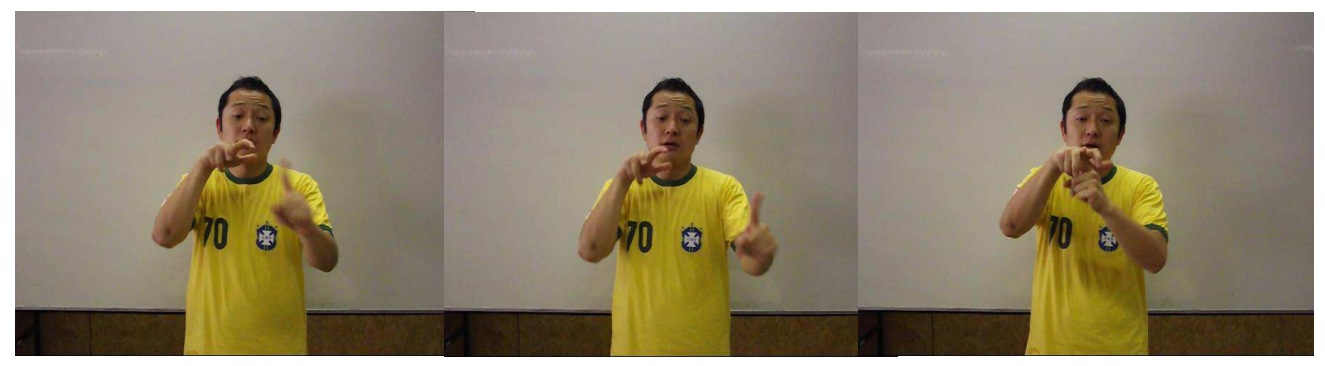

CARRO1 $1_{\mathrm{CL}} \mathrm{md}-\mathrm{BATER}(\mathrm{M})||$ ENTIDADE-RETA $1_{\mathrm{CL}}$ 
Com aquele tipo de tradução, perde-se a complexidade estrutural revelada acima. Assim, de acordo com (63) e com base no sinal realizado com a mão esquerda no exemplo acima, podemos dizer que nesse dado o morfema CL ENTIDADE-RETA1 $1_{C L}$ categoriza uma raiz $\sqrt{ }$ ENTIDADE formando o sinal CL "árvore" ou "poste".

Em próximos passos da derivação, esses sinais CLs podem se concatenar com outros sinais CLs ou sinais simples, como CARRO1 $\mathrm{CLmd-BATER(M)} \mathrm{no}$ exemplo em (64), possivelmente formando compostos. Vamos discutir esses tipos de formação em sua totalidade no capítulo 5.

\subsection{Considerações finais do capítulo}

Com base no detalhamento dos CLs descritos na literatura e em nosso conjunto de dados, podemos assumir que os CLs funcionam como morfemas categorizadores, que se anexam a uma raiz com um significado bastante geral e, ao se anexarem a ela, transmitem seus traços semânticos influenciando na composicionalidade do significado da raiz.

Resumidamente, entendemos que CLs são morfemas categorizadores que se concatenam às raízes formando sinais CLs, ou seja, nomes com CLs. Esse tipo de sinal CL, muitas vezes é tratado como monomorfêmico ou lexicalizado (Cf. JOHNSTON; SCHEMBRI, 1999). Acredita-se que isso ocorra pela influência de glosas feitas com o uso de uma LO (Cf. ZWITSERLOOD, 2012, p.172). Com um sistema de convenção mais neutro, como o que procuramos utilizar nesta tese, ou seja, utilizando glosas feitas com uma descrição de base visual, há menos influência da língua oral na hora de se avaliar a natureza desses dados. Cada dado em (53), por exemplo, pode remeter a significados diferentes. O dado em (51)g/i, ENTIDADERETA1 $\mathrm{CL}$, por exemplo, tem pelo menos dois significados diferentes: no primeiro exemplo, remete ao chifre do unicórnio; no segundo remete ao local no qual o carro bateu, podendo ser um poste ou uma árvore. Quando consideramos a glosa com ENTIDADE-RETA1 $1_{C L}$, em vez de ÁRVORE, POSTE ou CHIFRE, possibilitamos a interpretação e o estudo mais aprofundado para esse tipo de CL nominal que ganha novos significados na derivação. 
Se nosso entendimento sobre os CLs e se as nossas intuições sobre a natureza das construções até então tratadas como compostos raízes estiverem no caminho certo, nossos próximos passos devem ser testar a natureza dos dados apresentados no capítulo 2 para verificarmos se eles são, de fato, compostos, e, então, implementarmos nossa análise para tais dados. Essas serão as tarefas desenvolvidas nos dois próximos capítulos. 


\section{Composição nas LOs e LSs}

A composição é um processo de formação de palavras muito comum nas línguas naturais. Nesta pesquisa, vimos discutindo alguns tipos de dados que chamamos de "compostos potenciais" na libras (Cf. capítulo 2). Com o intuito de confirmarmos a natureza formacional desses dados, em 4.1, discutiremos algumas visões sobre a composição nas LSs e nas LOs.

Como já mencionamos na Introdução desta pesquisa, a composição é um dos poucos fenômenos que caracteriza a morfologia sequencial em várias LSs (Cf. MEIR et $a l$, 2010). Estudos pioneiros na ASL identificam compostos formados sequencialmente e que se caracterizam por regras de redução fonológica e assimilação nas bases, ou nas unidades morfológicas, que formam os compostos (Cf. KLIMA; BELLUGI, 1979; LIDDELL; JOHNSON, 1986). Alguns autores defendem a existência de compostos simultâneos nas LSs (Cf. BRENNAN, 1990; SUTTONSPENCE; WOLL, 1999 - BSL; GÖKSEL, 2014 - TID) como um fenômeno bastante produtivo. Na seção 4.2, apresentaremos uma discussão sobre os compostos nas LSs e discutiremos os critérios de identificação de compostos sequenciais e simultâneos, já os aplicando aos nossos dados coletados.

$\mathrm{Na}$ seção 4.3, procuraremos determinar como se identificam classes de palavras nas LSs. Entraremos nessa discussão com o intuito de acharmos caminhos para identificarmos a categoria envolvida nas partes que formam um composto e na categoria do composto como um todo. Essa identificação poderá nos levar a uma explicação mais minuciosa sobre a derivação dos compostos na libras, promovendo pistas para a determinação da categoria de seus núcleos, por exemplo. Apresentaremos trabalhos que já trataram das classes de palavras na libras, traremos um estudo sobre um tipo de morfema categorizador que identificamos nessa língua, e discutiremos o impacto da pesquisa sobre classes de palavras na formação de compostos.

Finalmente, em 4.4, traremos as conclusões deste capítulo. 


\subsection{Composição nas línguas orais}

O fenômeno da composição já foi amplamente estudado nas LOs. De modo bastante geral, composição é um processo de formação de palavras que permite criar palavras novas a partir de outras duas palavras já existentes em uma dada língua, envolvendo, então, duas raízes ou dois radicais e combinando várias classes de palavras (Cf. KEHDI, 2001; CARONE, 2006; BOOIJ, 2007; HASPELMATH; SIMS, 2010).

Kehdi (2001) discute as propriedades dos compostos no PB mostrando que são necessários pelo menos dois radicais para se formar um composto. Esses radicais perdem seu significado próprio compondo um novo significado global para 0 composto, como amor-perfeito, que designa uma flor. $\mathrm{O}$ autor argumenta que, em alguns casos, mantém-se uma relação significativa entre os elementos, como quebra-nozes, mas ainda assim pode-se dizer que há uma certa convencionalidade, uma vez que não se trata de qualquer objeto que quebre nozes. Ele explica que nas LOs há dois tipos de composição, por justaposição (ex. passatempo) em que os dois elementos mantém sua individualidade; ou por aglutinação (ex. boquiaberto) em que os dois elementos recebem um único acento - o primeiro perde elementos fonéticos variavelmente e o segundo pode apresentar alterações.

Com base em Carvalho (1973), Kehdi (op. cit.) aponta quatro propriedades morfossintáticas dos compostos: i) A ordem dos compostos é fixa e entre eles não se pode introduzir outro elemento, ou seja, qualquer modificador deve aparecer à esquerda ou à direita.
a. delicado amor-perfeito
b. amor-perfeito delicado
c. *amor-delicado-perfeito

A propriedade ii) diz que os elementos em um composto não podem ser substituídos nem suprimidos. 

a. amor-perfeito
b. * amor-imperfeito
c. colher amores-perfeitos
d. * colher amores $\varnothing$
e. colher $\varnothing$ perfeitos

Ele ressalta que em compostos formados por elementos determinados e determinantes, o determinante pode tomar o lugar do significado todo, como em carta circular, que pode ser usado apenas como circular.

A propriedade iii) é sobre a possibilidade de compostos serem formados por uma combinação sintática anômala, o que não ocorre com sintagmas. Kehdi (op. cit.) exemplifica com mestre-sala, em contraposição a mestre de sala.

A propriedade iv) diz que o composto funciona sintaticamente como uma única unidade ou palavra, podendo ser substituído por uma palavra só, como em: estrada de ferro que pode ser substituída por pista.

Para finalizar, Kehdi (op. cit.) mostra que a estrutura de compostos no PB é bastante variada, apresentando formações dos tipos: $n+n ; n+p r e p+n ; n+a$ (ou vice-versa); $a+a$; pronome + $n$; numeral $+n$; adv. + n / a / v; v + n; v + conjunção + $v ; v+a d v$.; um grupo de palavras ou frase.

Com essas quatro propriedades que o autor aponta, ele mostra que a estrutura dos compostos é sintática.

Carone (2006) discute o processo de formação de compostos considerando essas mesmas propriedades e ela também argumenta que as palavras que formam um composto estão relacionadas sintaticamente por subordinação ou coordenação, conforme quadro abaixo: 


\begin{tabular}{|c|c|}
\hline \multicolumn{2}{|l|}{ Por subordinação: } \\
\hline Verbo e complemento & Estraga-prazeres, porta-bandeira \\
\hline Substantivo e adjunto (adjetivo) & Cabra-cega, aguardente \\
\hline Substantivo e adjunto (SP) & Pé-de-moleque, mula-sem-cabeça \\
\hline Substantivo e aposto & Couve-flor, cirurgião-dentista \\
\hline Verbo e adjunto & Bota-fora, abaixo-assinado \\
\hline Adjetivo e adjunto & Sempre-viva \\
\hline Uma oração completa & Bem-te-vi, malmequer \\
\hline \multicolumn{2}{|l|}{ Por coordenação: } \\
\hline De verbos & Vaivém, leva-e-traz \\
\hline De adjetivos & $\begin{array}{l}\text { Auriverde, rubro-negro, franco-luso- } \\
\text { brasileiro }\end{array}$ \\
\hline
\end{tabular}

Quadro 6: Formação de compostos do PB por subordinação e coordenação

Ela ressalta que apesar de os verbos se prestarem à formação de compostos, o resultado do composto nunca é um verbo.

Booij (2007) ressalta que quando um composto é formado, já sabemos o significado de seus constituintes e, então, precisamos descobrir a relação semântica entre as duas partes. Em um composto $X Y, X$ denota algo sobre $Y$ ou vice-versa. $O$ autor defende que composição pode ser aplicada recursivamente, como em:

White House travel office staff.

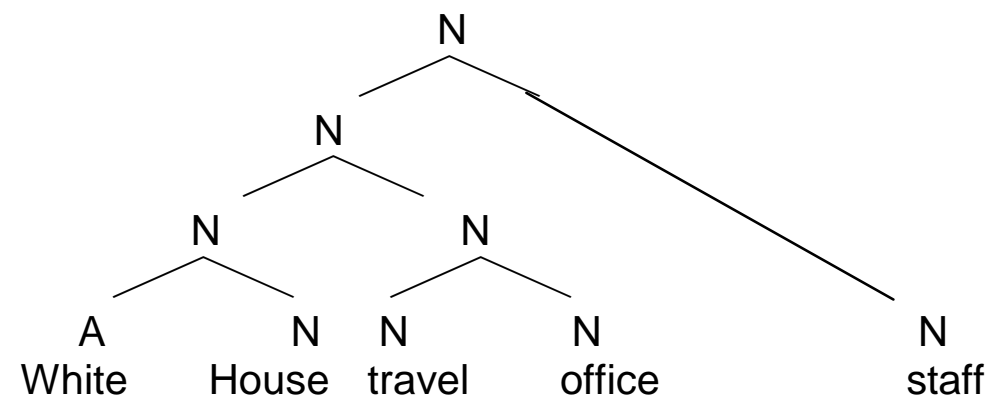

Em inglês, o núcleo geralmente está à direita. Assim, a maior parte dos compostos têm essa forma: $[X Y]_{Y}, Y=N, A, V$. Booij (2007) mostra que não só palavras lexicais ocupam posições de não-núcleo, mas também palavras funcionais, como preposições: Um-welt (do alemão, "pelo mundo"). Ele ressalta que os 
compostos não têm seu núcleo obrigatoriamente à direita. Há línguas com compostos com núcleo à esquerda, como é o caso da lingual Maori, em (68):

(68) Maori

Roro hiko

Brain electricity

Cérebro eletricidade "computador"

(BAUER 1993, p.518-20, apud BOOIJ, p.78)

Haspelmath \& Sims (2010) afirmam que o conceito de núcleo semântico é útil para se falar das relações semânticas entre os membros de um composto. Eles propõem as seguintes estruturas:

(69) Compostos com dois membros
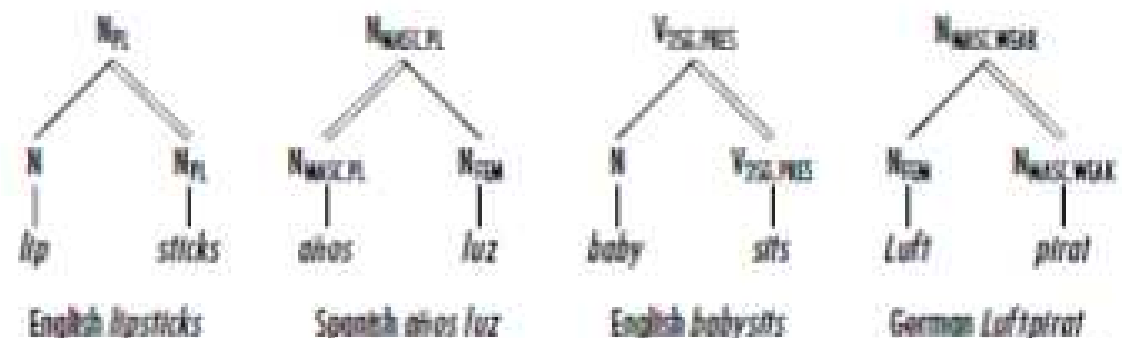

Spanch atos for

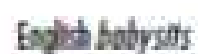

Germe Lutperat

'olr pliste, hipodker'

(70) Compostos com três membros
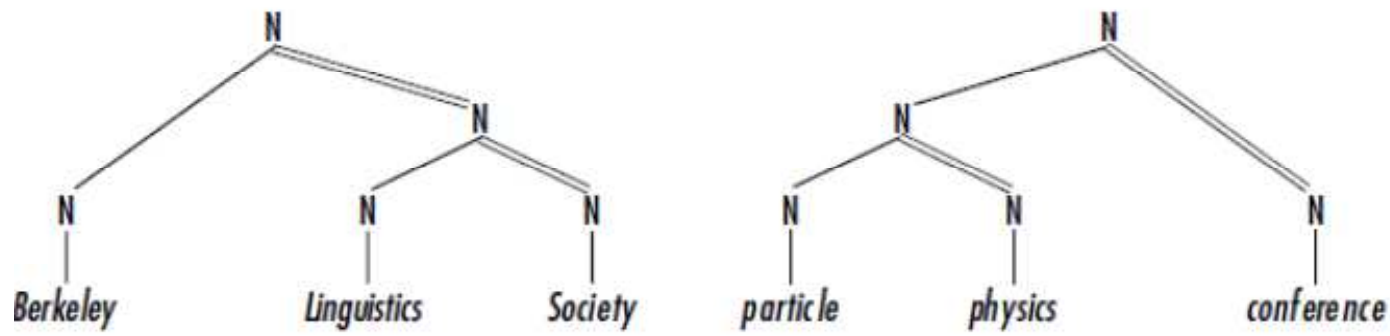

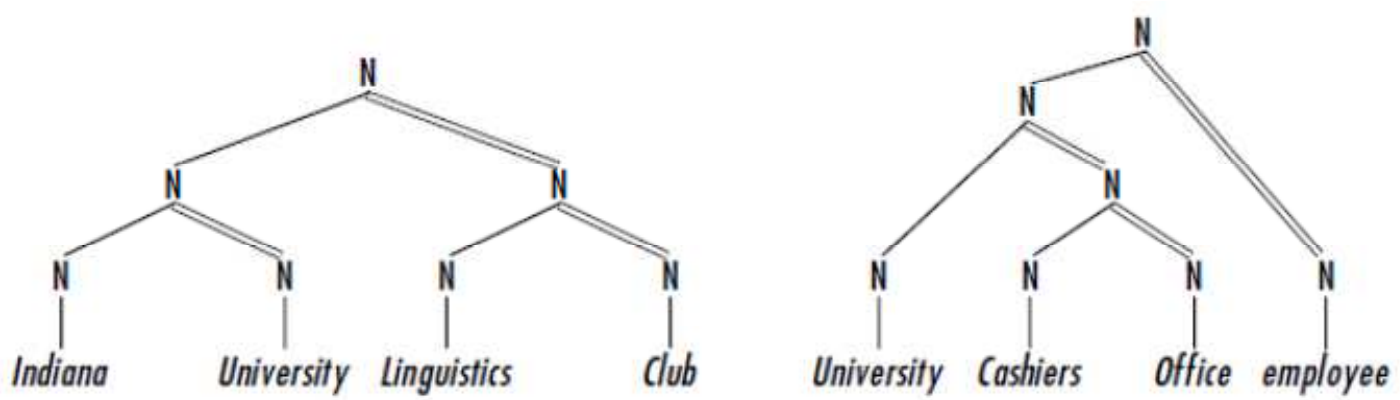

Nas construções acima, o núcleo de cada parte está indicado com duas linhas.

Em busca da definição dos compostos, Donalies (2004, apud LIEBER; ŠTEKAUER, 2009, p.5 e 6) lista uma série de critérios, como mostramos a seguir:

(72) Critérios para identificação de compostos

a. são complexos;

b. são formados sem afixação;

c. são pronunciados juntos;

d. têm um padrão acentual específico;

e. contém elementos de ligação;

f. têm núcleo a direita;

g. são flexionados como um todo;

h. são sintaticamente inseparáveis;

i. são ilhas sintático-semânticas;

j. são unidades conceituais.

(DONALIES, 2004, apud LIEBER; ŠTEKAUER, 2009, p.5 e 6) (1 $^{81}$

\footnotetext{
81 "Compounds: are complex; are formed without word-formation affixes; are spelled together; have a specific stress pattern; include linking elements; are right-headed; are inflected as a whole; are syntactically inseparable; are syntactico-semantic islands; are conceptual units". Traduzido em Nóbrega (2014, p.91), a partir de Lieber; Štekauer (2009).
} 
Lieber \& Štekauer (2009) ressaltam que apesar de haver muitos estudos sobre compostos nas línguas naturais, não há quase nenhum critério que seja universalmente aceito para se determinar a natureza de um composto. Os autores alertam que alguns desses critérios não se verificam, de fato, translinguisticamente.

Bisetto \& Scalise (2005) já apontavam para o fato de que as classificações de compostos encontradas na literatura apresentam problemas de natureza terminológica, de categorias lexicais negligenciadas e inconsistência dos critérios usados. Nesse sentido, os autores buscam encontrar critérios mais gerais para identificar a composição translinguisticamente. Eles propõem outra classificação para compostos, considerando que o critério que define os compostos é o fato de os seus constituintes estarem ligados por uma relação gramatical, como em:

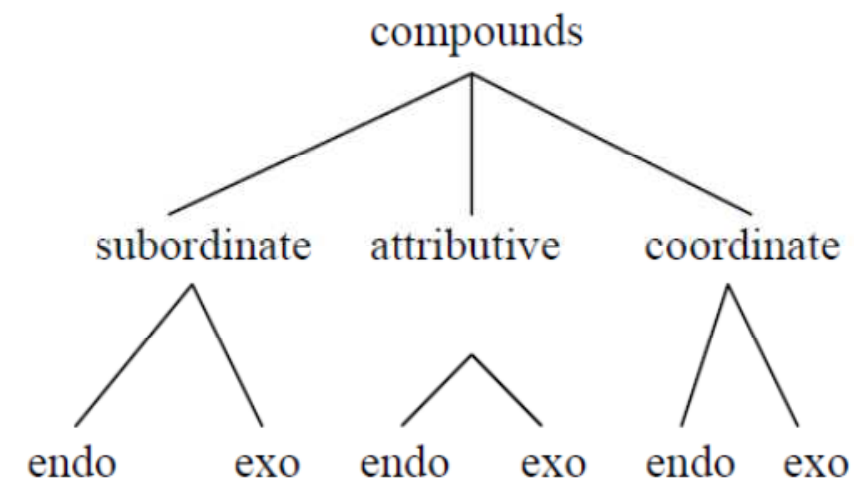

Figura 6: Classificação de compostos (BISETTO; SCALISE, 2005, p.9)

Nessa proposta de composição, os dois constituintes estão ligados por uma relação gramatical que é basicamente o mesmo tipo de relação que ocorre em construções sintáticas: subordinação (relação de complemento), (73); atribuição (relação de modificação), (74); e, coordenação (conectadas por um "e"), (75): 
(73) Subordinação
a. taxi driver
b. cut throat
c. lavapiatti

(74) Atribuição
a. blue cheese $(\mathrm{N}-\mathrm{A})$
b. snail mail $(\mathrm{N}-\mathrm{N})$
c. sword fish (N-N)

(75) Coordenação

Poet pittore regista (poeta-pintor-diretor)

Há também a noção de nuclearidade semântica dividida em: compostos endocêntricos, aqueles que apresentam um núcleo semântico interno ao composto, ou seja, a categoria da construção como um todo é idêntica à categoria de um de seus constituintes (BOOIJ, 2007); e, compostos exocêntricos, aqueles que apresentam uma categoria final diferente da categoria de seus membros. Em (73)a, táxi é o complemento do núcleo deverbal (endocêntrico); em (73)b/c, temos compostos exocêntricos, não tem o núcleo presente. Em (74)a, o adjetivo está em uma relação de modificação com o nome; e em (74)b/c, o não núcleo é interpretado metaforicamente como um atributo do núcleo. O tipo de composto em (75) pode ter dois núcleos "Poet pittore" é tanto poeta quanto pintor

Se as relações gramaticais entre dois constituintes de um composto são basicamente as relações de construções sintáticas, é lógico assumirmos uma teoria que deriva sentenças e palavras através dos mesmos mecanismos sintáticos. $\mathrm{Na}$ sequência, discutimos dois trabalhos sobre compostos em uma teoria sintática para formação de palavras, a MD.

Harley (2008) assume que a chave para se entender o processo de composição nas línguas naturais é entender a natureza da raiz dentro da MD. Para 
ela, um composto é uma forma morfologicamente complexa que contém duas ou mais raízes e que pode ser identificada como palavra por seu comportamento fonológico. Para a autora, o processo de composição se configura como um caso ideal de morfologia na sintaxe e um de seus objetivos principais será explicar por que esses elementos complexos se comportam, fonológica e sintaticamente, como um elemento em posição de núcleo. Sua sugestão vem em termos de duas assunções principais: compostos são formados, quando núcleos contendo raízes se incorporam e quando elementos sintagmáticos se concatenam a raízes antes que essas raízes sejam categorizadas. No texto, a autora usa compostos sintéticos como: truck-driver, drug-pusher, car-chasing (dog) ou grass-clipping (formados por um verbo nominalizado ou adjetivado e seu argumento interno - N-N ou N-A) para explorar as consequências dessa proposta, que se sustenta em dados de substituição por "one" (one replacement). Ela propõe a seguinte estrutura para esses compostos do inglês:

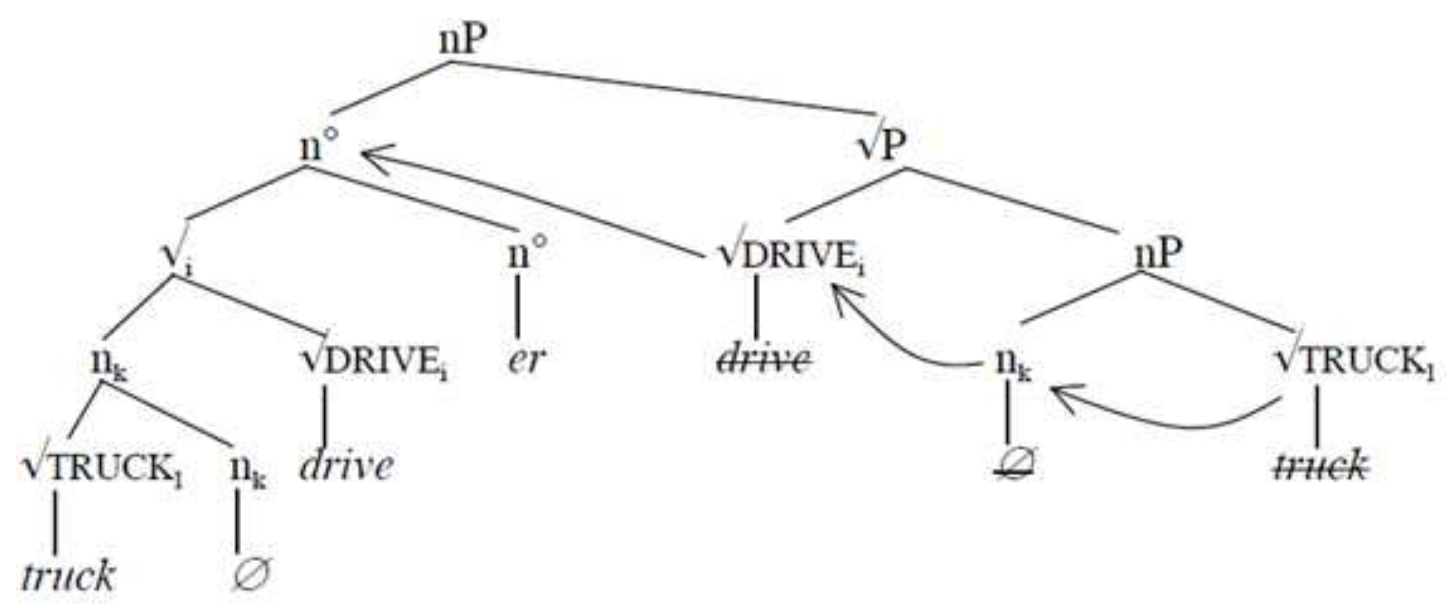

Nessa representação, o complemento da raiz $\sqrt{ }$ DRIVE se concatena a essa raiz antes mesmo que ela seja categorizada. Ou seja, a raiz $\sqrt{ }$ TRUCK se concatena com um núcleo nominalizador $n^{0}$ e se move para esse núcleo (movimento para núcleo); depois essa estrutura concatena como complemento da raiz VDRIVE e se incorpora a ela. A autora argumenta que essa incorporação sintática é dirigida por traços. Uma vez que elementos incorporados satisfazem sua necessidade de Caso 
pela incorporação, no sistema de Baker (1988), Harley (2008) assume que o traço envolvido tem a ver com Caso. Finalmente, o núcleo complexo $\left[\left[[\sqrt{T R U C K}]_{\sqrt{ }} n\right]_{n P}\right.$ $\sqrt{ }$ DRIVE] $\|_{P}$ se concatena com seu núcleo categorizador $n^{0}$ e se move para esse núcleo, criando o núcleo complexo $\left[\left[\left[[\sqrt{ } T R U C K]_{\sqrt{ }} n\right]_{n P}{ }_{n} D R I V E\right]_{\sqrt{P}} n\right]_{n P}$ que é realizado pelo IV como truck driver.

Trabalhando dentro do mesmo referencial teórico, Nóbrega ${ }^{82}$ (2014, p.129 e 130) assume que a raiz é definida por traços sintáticos e que, por esse motivo, "ela só se torna visível para o componente computacional se for concatenada a um núcleo definidor de categoria, pois será esse núcleo quem fornecerá seus traços gramaticais". Sendo assim, ele critica a combinação de duas raízes sem categorização, pois sem uma categoria elas estariam invisíveis para a sintaxe, e propõe a seguinte definição para compostos:

\section{Composto:}

Um composto é formado quando dois ou mais núcleos complexos, em determinada relação sintática, são recategorizados por um núcleo definidor de categoria - n, v ou a.

(NÓBREGA, 2014)

O autor assume que, posteriormente, essa estrutura é categorizada por outro núcleo definidor de categoria, entrando em um novo domínio categorial, que fornece informações categoriais e flexionais, além de justificar o uso do composto como uma única unidade sentencial.

Seguindo Bisetto \& Scalise (2005), Guevara \& Scalise (2009), e Scalise \& Bisetto (2009), Nóbrega (op. cit.) assume que esses núcleos complexos são concatenados em uma relação de subordinação, atribuição ou coordenação, como em (78):

\footnotetext{
${ }^{82} \mathrm{O}$ trabalho de Nóbrega (op. cit.) é muito mais extenso e complexo do que trazemos aqui. Ele faz uma análise requintada de compostos atributivos e subordinativos levando em conta um sistema de traços bastante detalhado. Uma vez que nosso foco principal é descrever e evidenciar as propriedades das formas compostas da libras, nesta pesquisa, vamos apenas adotar de modo bastante geral a idéia do autor sobre recategorização nos compostos sem pretendermos entrar nos detalhes da natureza de cada item daquela análise. Assim, indicações de uma proposta de representação seguindo essas linhas gerais devem aparecer ao longo do capítulo 5 quando aplicarmos nossos dados.
} 
(78)

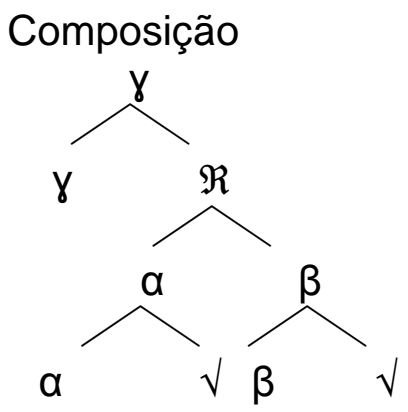

(NÓBREGA, 2014)

Ele assume que $\alpha, \beta$ e y são núcleos categorizadores e $\Re$ é um núcleo relacional que define as relações sintáticas de coordenação, subordinação e atribuição.

Em outras palavras, as relações gramaticais presentes na formação de compostos são as mesmas presentes na formação de frases, de forma que um mesmo componente gerativo, a sintaxe, oferece os mecanismos necessários para a derivação de palavras e sentenças.

$\mathrm{Na}$ próxima seção, discutiremos os critérios e classificação de compostos como vem sendo discutido nas LSs.

\subsection{Composição nas LSs}

A formação de palavras por composição dada sequencialmente já foi muito estudado nas LSs (Cf. KLIMA; BELLUGI, 1979; LIDDELL; JOHNSON, 1986; MEIR et al, 2010 - ASL e língua de sinais beduína Al-Sayyid (ABSL); FELIPE, 2006; FIGUEIREDO SILVA; SELL, 2009 - libras, entre outros). Uma série de critérios já foram considerados na literatura para a identificação de compostos sequenciais nas LSs, sejam critérios sintáticos, morfológicos ou semânticos. Esses critérios são:

(79) a. os dois sinais em um composto são raízes da língua (KLIMA; BELLUGI, 1979);

b. os dois sinais em um composto formam uma única unidade - não podem ser separados por outras formas (KLIMA; BELLUGI, 1979); 
C. o significado do composto difere do significado dos dois mesmos sinais em uma frase (KLIMA; BELLUGI, 1979);

d. as operações gramaticais que se aplicam a um sinal que funciona sintaticamente como um item independente não se aplicam ao mesmo sinal em um composto (KLIMA; BELLUGI, 1979);

e. redução ou assimilação de Ms ou toques (KLIMA; BELLUGI, 1979; LIDDELL; JOHNSON, 1986);

f. a realização dos sinais em um composto é obrigatória e a ordem dos sinais em um composto é fixa (FIGUEIREDO SILVA; SELL, 2009).

Vale ressaltar que o critério em (79)e indica mudanças previsíveis em relação a aspectos fonológicos de um composto, de forma que levam à identificação de compostos formados por aglutinação. Klima e Bellugi (op. cit.) destacam as seguintes mudanças de $\mathrm{M}$ ou toques:

(80) a) o M no primeiro sinal do composto é diminuído;

b) o segundo sinal perde repetição de toque ou $\mathrm{M}$;

c) se há o uso da mão não dominante no segundo sinal, ela se antecipa durante a realização do primeiro sinal;

d) o M de transição entre os dois sinais é diminuído.

Os autores defendem que, se essas características são observadas, os dois sinais em um composto são realizados em um mesmo tempo que a duração de um único sinal, portanto, formando uma única unidade.

Apesar de a morfologia concatenativa ser bastante comum apenas em compostos nas LSs, alguns estudos mostram também a possibilidade de realizações simultâneas com CLs formando compostos nessas línguas. Essa produção simultânea é possível nas LSs, uma vez que seria concebível a produção de dois sinais diferentes simultaneamente, um com cada mão (MEIR et al, 2010); ou, ainda, tendo um sinal realizado pela boca (Cf. seção 5.3). No entanto, Meir et al (op. cit.) 
afirmam que esse tipo de dado com CLs não é considerado composição na maior parte das análises, uma vez que eles consideram CLs como morfemas presos, e ressaltam que esses exemplos apontados na literatura são extremamente raros. Outros veem essas construções como sendo frasais ou oracionais (JOHNSTON; SCHEMBRI, 1999).

$\mathrm{Na}$ linha da proposta delineada no capítulo anterior, é possível argumentarmos em favor de uma análise dessas construções com CLs simultâneos como sendo formadas por composição, uma vez que, consideramos que o fato de os morfemas CLs se concatenarem a uma raiz, faz com que eles possam ser realizados livremente, como sinais CLs. Antes de levarmos essa análise adiante, olharemos para alguns dados apresentados em algumas LSs.

Brennan (1990), por exemplo, apresenta dados da BSL que ela chama de compostos simultâneos (ou compostos classificadores duplos simultâneos) ${ }^{83}$, como em:

$$
\text { a. MINICOM (TELEFONE DIGITAR) }{ }^{84}
$$

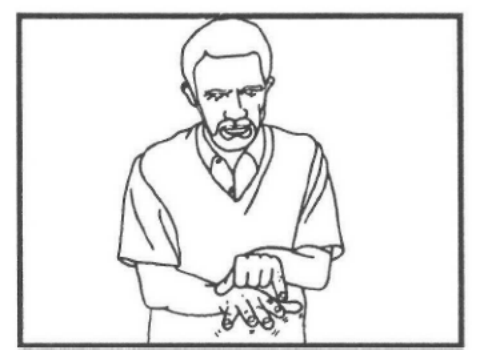

(BRENNAN, 1990, p.151)

\footnotetext{
${ }^{83}$ Brennan (op. cit.) considera duas grandes categorias de compostos simultâneos: uma é o grupo que faz uso de diferentes CLs como componentes de um sinal; a outra é a categoria que faz uso das combinações de morfemas metafóricos. Essa segunda categoria não faz parte de nossa pesquisa, mas para um estudo sobre morfemas metafóricos na libras, cf. Mauricio (2010).

${ }^{84}$ Máquina desenvolvida para surdos digitarem mensagens e transmitirem por uma linha telefônica para uma comunicação eficaz. Tira-se o telefone do gancho e coloca-se em cima do aparelho para digitar as mensagens.
} 
b. MERGULHADOR (ÁGUA PERNAS)

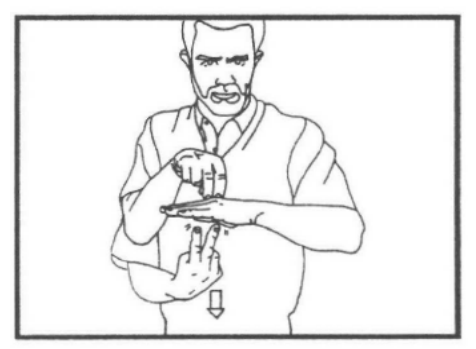

(BRENNAN, 1990, p.153)

Nesses dados em (81), cada uma das mãos é um CL que pode ocorrer livremente, ou seja, cada mão traz um sinal CL diferente, e participa na formação do composto nessa LS. Brennan (1990) afirma que todos os tipos de CLs identificados por Supalla (1986) aparecem na formação de compostos simultâneos na BSL.

A autora menciona também realizações sequencial-simultâneas com um sinal seguido de dois CLs realizados simultaneamente, como em:
a. EVIDÊNCIA 1 (formado por VER MOSTRAR)

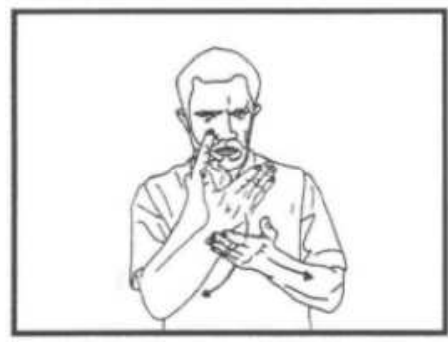

b. EVIDÊNCIA 2 / INDÍCIO (formado por VER PÁGINA) ${ }^{85}$

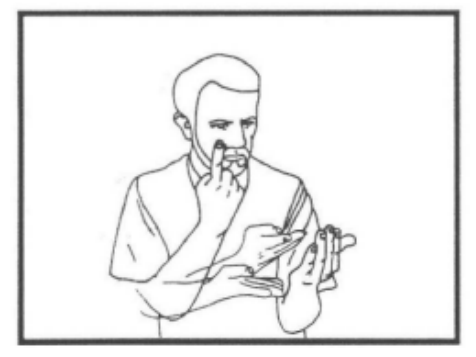

(BRENNAN, 1990, p156)

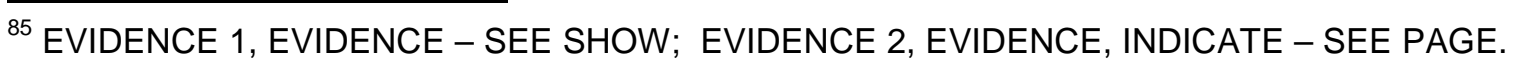


O exemplo em (82)a é formado pelos sinais VER e MOSTRAR sequencialmente. Na segunda sinalização, em (82)b, observa-se o sinal de VER, um sinal simples e, na sequência, o sinal para PÁGINA, o qual a autora considera ser um composto simultâneo formado por dois CLs, ou seja, cada mão contribui para o significado de "página", uma mão remete ao livro e a outra às folhas. Dessa forma, esse sinal é um composto sequencial simultâneo que remete a uma evidência com um significado mais restrito, de algo que foi realmente mostrado em uma página. $A$ autora afirma que muitos sinais inicialmente registrados como sequenciais são, na verdade, sequenciais-simultâneos e, na BSL, muitos deles usam o sinal PÁGINA ${ }^{86}$ em seu segundo elemento, marcando um elemento simultâneo na segunda posição do composto. Ela ainda ressalta que essa é uma classe muito pequena de sinais.

Brennan (1990) comprova que quase todas as CMs da BSL podem funcionar como CLs em sinais, como também podem funcionar de uma forma totalmente arbitrária. Além disso, a autora afirma que os CLs não se restringem a uma classe de palavras, mas podem sim ocorrer $\operatorname{com} n, v, a$, por isso, ela assume que CLs podem preencher uma série de funções na língua e uma delas é atuar nos processos de formação de palavras.

No mesmo sentido, Göksel (2014, c.p.) analisa construções com CLs que fazem uso de duas mãos. A autora traz uma classificação preliminar de sinais assimétricos, ou seja, que apresentam uma CM diferente em cada mão compondo, ou não, o sinal. Nos sinais que a autora descreve, uma das mãos sempre apresenta uma CM, descrita nesta tese como ENTIDADE-PLANA1 $\mathrm{CL}$, conforme vemos em (83):

86 O sinal PAGE da BSL está disponível no BSL SignBank, primeira ocorrência, em: http://bslsignbank.ucl.ac.uk/dictionary/words/page-1.html. Outros sinais de outras línguas de sinais mencionados nesta tese também podem ser encontrados em: http://www.spreadthesign.com/. 
(83) Compostos simultâneos em TID com ENTIDADE-PLANA1 $\mathrm{CL}$
a. TRANCAR

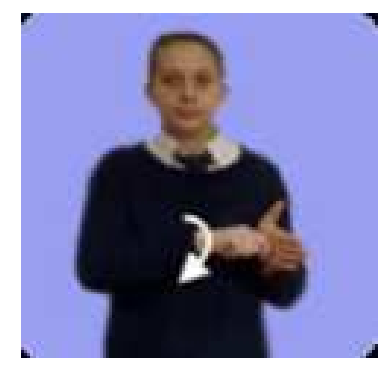

b. MONTANHA

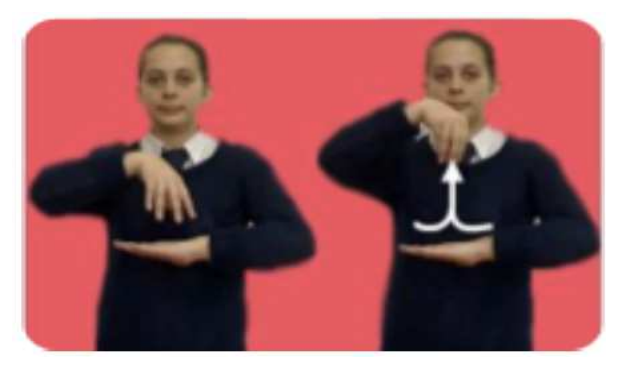

c. CORRESPONDÊNCIA

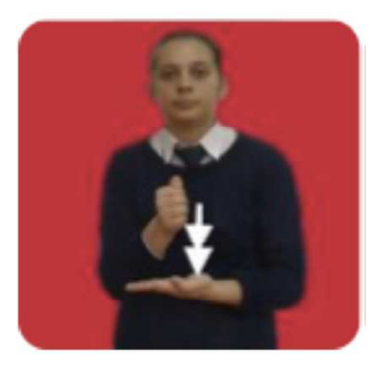

Em todos esses sinais a mão não-dominante é um CL ENTIDADE-PLANA1 $\mathrm{CL}$ que desempenha funções diferentes. Em (83)a, no sinal TRANCAR, a mão nãodominante é o núcleo semântico do composto (uma hiponímia). Em (83)b, MONTANHA, é a mão dominante que é o núcleo semântico do composto e ela é um radical preso. Em (83)c, CORRESPONDÊNCIA, a autora afirma que parece que as duas mãos poderiam ser um núcleo semântico. Ela assume que esses sinais são compostos simultâneos assimétricos. 
Em contraposição a esses sinais, Göksel (2014) apresenta outros sinais com o CL ENTIDADE-PLANA1 $1_{C L}$, na mão não dominante que ela não considera como composição.

(84) Dados com ENTIDADE-PLANA1 $C L$ que não formam compostos TID

a. TÓPICO

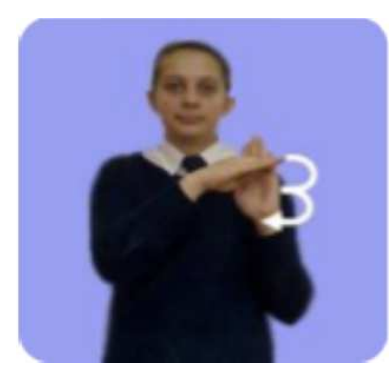

b. CAFÉ

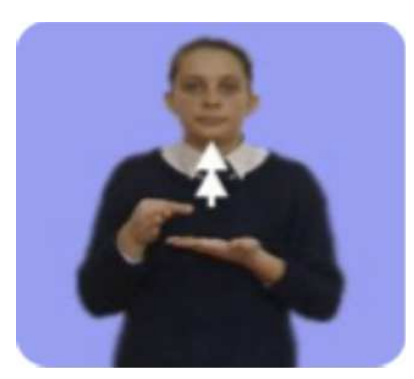

c. BORDADO

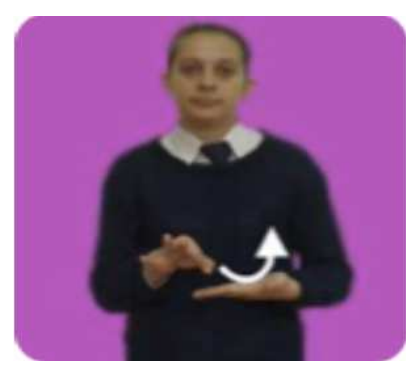

No exemplo em (84)a, TÓPICO, Göksel (2014) assume que a mão não dominante é um mero ponto de contato para a realização do sinal, então, para ela esse é um sinal simples. Em (84)b, CAFÉ, ela considera que a mão não-dominante é usada iconicamente como referência à própria mão ou uma superfície. Em (84)c, 
BORDADO, ela também considera a mão não-dominante sendo usada iconicamente como referência à parte do objeto, a um aspecto visual do item. Göksel ( $c p$ ) também assume que dados como CAPITAL $^{87}$, nos quais a mão não-dominante serve como um identificador visual de localização, não são casos de composição.

Concordamos com as impressões que a autora aponta sobre os dados em (83), tratando-os como compostos simultâneos. No entanto, na visão de CLs que apresentamos no capítulo anterior, devemos discordar das impressões apontadas para os dados em (84). Consideramos CLs como morfemas categorizadores que dão uma categoria nominal para as raízes e, em 3.2.1, argumentamos com base em Cuxac \& Sallandre (2007) que sinais mais icônicos são CLs, trazem um formato e se encaixam na categoria de CLs semânticos, como definido por Supalla (1986). Vale ressaltar que os sinais usados para a libras correspondentes aos sinais em (84)a-c da TID são bastante parecidos e podemos argumentar o seguinte. O exemplo em (84)a, TÓPICO, pode ser visto não apenas como um mero ponto de contato para a realização do sinal, mas sim como uma base, um "papel" no qual os tópicos estão, de fato, anotados. Em (84)b, CAFÉ, se a mão não-dominante é usada como referência à própria mão, ela é um $C L$ corporal, e se ela é usada como uma superfície, então ela pode remeter a um pires, um CL semântico, compondo esse sinal. Em (84)c, BORDADO, se a mão não-dominante se refere iconicamente à uma parte do objeto, é um CL semântico que remete ao objeto que é bordado.

Logo, no sentido desenvolvido por Brennan (1990) e Göksel (2014), consideramos todos esses dados como compostos simultâneos, ou seja, dados nos quais as duas mãos contribuem com sinais diferentes, significados diferentes, formando um composto. Concordamos com Göksel (op. cit.) sobre o último item, CAPITAL, no qual a mão não-dominante serve como um identificador visual de localização e, então, não forma uma entidade compondo o sinal. No próximo capítulo, continuaremos a discussão sobre esse tipo de dado e sua estrutura morfossintática, além de trazermos uma discussão sobre construções simultâneas com CLs.

\footnotetext{
${ }^{87}$ Não tivemos acesso a fotos para esse sinal.
} 
Com base nos dados apresentados até aqui, Brennan (1990) ressalta os seguintes critérios, ou as seguintes mudanças previsíveis que nos ajudam a identificar compostos simultâneos:

(85) Compostos simultâneos

i) a maior parte dos compostos simultâneos apresentam uma mão nãodominante que serve de base ou localização para a realização de outro sinal, com a mão dominante - as mãos não precisam, necessariamente, se tocar;

ii) Um sinal feito com duas mãos passa a ser feito com uma mão só, já que cada mão realizará um sinal diferente;

iii) A mão esquerda produz um sinal que normalmente seria feito com a mão direita;

iv) $\mathrm{O} M$ do sinal que seria feito com a mão esquerda geralmente é eliminado;

v) O posicionamento de um ou dos dois sinais será alterado.

Nas próximas subseções, vamos verificar se nossos dados apresentados no capítulo 2 passam pelos critérios de identificação de compostos sequenciais e simultâneos apresentados nesta seção.

\subsubsection{Identificando compostos sequenciais na libras}

Primeiramente, ressaltamos que os critérios apontados em (79) também já foram sugeridos para a identificação de compostos nas LOs e vimos que há críticas no sentido de eles não serem aplicados translinguisticamente. No entanto, os autores citados em (79) buscam fazer um paralelo entre as propriedades de compostos das LOs e os das LSs mostrando que esses critérios podem se aplicar a alguns dados das línguas de sinais, principalmente, no que se refere a compostos sequenciais. Nesse sentido, vamos considerar alguns dados que apresentamos no 
capítulo 2 como compostos sequenciais para comentarmos brevemente a aplicação desses critérios.

Quando consideramos compostos com sinais simples, como CARNE^VENDER “açougue”, em (6), ou LIVRE^NEGRO "abolição dos escravos", é fácil identificarmos as duas raízes que formam o composto. Mas quando se considera dados com CLs, é preciso deixar claro qual é a natureza desses dados.

Loos (2009), por exemplo, considera que CLs não formam compostos porque ela não os considera como um item lexical que pode ocorrer sozinho, mas sim que deve ser combinado com um item lexical (como afirmam KLIMA; BELLUGI, 1979). Então, para ela o critério em $(79) \mathrm{a}^{88}$, excluiria construções com mais de um sinal, que apresentam um sinal simples e um CL do tipo SASS ${ }^{89}$.

Brennan (1990), entre outros trabalhos discutidos na seção anterior, consideram sinais com CLs como compostos. Considerando o entendimento dos CLs conforme mostramos no capítulo 3 , há uma raiz $\sqrt{ }$ ENTIDADE com a qual o morfema CL se concatena. Assim, por exemplo, nosso dado em (9), FORMA-MEIALUA $_{C L} \wedge$ VIAGEM "lua de mel”, envolve uma raiz $\sqrt{ }$ ENTIDADE categorizada por um CL do tipo SASS de traço (FORMA-MEIA-LUA $\mathrm{CL}_{\mathrm{L}}$ ), e uma segunda raiz $\sqrt{\mathrm{VIAGEM}}$ Então, compostos com sinais simples bem como compostos com sinais CLs envolvem duas ou mais raízes, atendendo esse critério em (79)a.

O critério em (79) $\mathrm{b}^{90}$, sobre a inseparabilidade dos constituintes em um composto, também se aplica na libras. Podemos formar compostos sequenciais, como aqueles em (86)a, com sinais simples e sinais CL, ou (86)c, com dois sinais CLs, e adicionar um adjetivo após o composto, mas não podemos separá-los com o adjetivo, como em (86)b/d:
a. CASA $_{C L}{ }^{\wedge} E S T U D O$ GRANDE
"A escola é grande"
b. * CASA $\mathrm{CL}$ GRANDE ESTUDO
"A casa grande estuda"
?"A casa grande é escola"

\footnotetext{
${ }^{88}$ Repetindo o critério (79)a: "Os dois sinais em um composto são raízes da língua (KLIMA; BELLUGI, 1979)".

${ }^{89}$ Classificador que especifica tamanho e forma, como vimos no capítulo 3 (Cf. SUPALLA, 1986).

${ }^{90}$ Repetindo o critério em (79)b: "Os dois sinais em um composto formam uma única unidade - não podem ser separados por outras formas (KLIMA; BELLUGI, 1979)."
} 

c. $\mathrm{BICO}_{\mathrm{CL}}{ }^{\wedge} \mathrm{ASA} \mathrm{ALL}_{\mathrm{CL}} \mathrm{BONITO}$
"O pássaro é bonito"
d. $\mathrm{BICO}_{\mathrm{CL}}$ BONITO ASA $\mathrm{CL}$
"O pássaro bonito voa ${ }^{91 "}$

Em (86)a,c temos os compostos "escola" e "pássaro", que se formam a partir dos sinais para CASA $A_{C L}$ e ESTUDO, e BICO ${ }_{C L}$ e $A S A_{C L}$, respectivamente. (86)b/d mostram que, se os sinais formadores desses compostos são separados pelos sinais GRANDE e BONITO, respectivamente, a leitura original se perde, como em (86)d, que passa a ter outro significado, "voar", ou a sentença resultante torna-se agramatical, como em (86)b.

Os exemplos em (86)c/d acima também são úteis para demonstrar a aplicabilidade do critério em $(79) \mathrm{c}^{92}$ na libras. Como podemos ver, os dois sinais membros do composto geram uma forma com um significado diferente dos seus significados, quando inseridos independentemente em uma frase.

Sobre o critério em $(79) d^{93}$, podemos pensar na modulação de M para indicar intensidade, como em (87):
a. $\mathrm{CASA}^{\wedge} \mathrm{ESTUDO}$
"escola"
b. CASA^ESTUDO ELA ESTUDAR-MUITO
"Ela estuda muito na escola"
c. * ${ }^{*} A S A^{\wedge} E S T U D A R-M U I T O$
*"escola muito"

A modulação de $M$ se aplica a um sinal individual em uma sentença, como em (87)b, mas não no mesmo sinal em um composto, como em (87)c. Por conta disso, resolvemos glosar o sinal "escola" como CASA^ESTUDO, bem como fazem Figueiredo Silva \& Sell (2009), em vez de CASA^ESTUDAR, como é feito por Felipe (2006), entre outros.

\footnotetext{
${ }_{91}$ O sinal para ASA e VOAR pode ser realizado pelo mesmo sinal (CAPOVILLA \& RAPHAEL, 2001).

92 Repetindo o critério em (79)c: "O significado do composto difere do significado dos dois mesmos sinais em uma frase (KLIMA; BELLUGI, 1979)."

${ }^{93}$ Repetindo o critério em (79)d: "As operações gramaticais que se aplicam a um sinal que funciona sintaticamente como um item independente não se aplicam ao mesmo sinal em um composto (KLIMA; BELLUGI, 1979)."
} 
Sobre um critério fonológico, como (79) $\mathrm{e}^{94}$ detalhado em (80), ou seja, considerando-se propriedades fonológicas como reduções ou assimilações de $M$ nos compostos sequenciais, em CASA^ESTUDO, por exemplo, observamos que há redução de toques do primeiro e, opcionalmente, do segundo sinal, e o $M$ de transição entre os dois sinais é diminuído. Em SABER^ESTUDAR "acreditar" observamos todas as características apontadas em (80), ou seja, o M no primeiro sinal do composto é diminuído a um toque e a $L$ muda mais para o centro da testa; a mão não-dominante do segundo sinal, ESTUDAR, se antecipa durante a realização do primeiro sinal, de forma que, o $\mathrm{M}$ de transição entre os dois sinais é diminuído, além de que o segundo sinal perde repetição de toque ou M. Assim, o critério fonológico é observável com dados sequenciais.

Sobre o critério em (79)f $\mathrm{f}^{95}$. Figueiredo Silva \& Sell (2009) consideram compostos apenas aqueles sinais que apresentam realização obrigatória dos sinais envolvidos na composição e ordem fixa para tais sinais. Muitos dos nossos dados não apresentam uma ordem fixa. No entanto, muita variabilidade na ordem e produção dos sinais compostos é observada em várias LSs, ainda assim, mantendose outras das características anteriores para composição.

\subsubsection{Identificando compostos simultâneos na libras - critérios da literatura}

A realização simultânea é uma possibilidade das LSs. Assim, olhando para os critérios em (85), estabelecidos por Brennan (1990) para se identificar esse tipo de dado, observamos que, em relação à (85) i):

i) a maior parte dos compostos simultâneos apresentam uma mão nãodominante que serve de base ou localização para a realização de outro sinal, com a mão dominante - as mãos não precisam, necessariamente, se tocar;

\footnotetext{
${ }^{94}$ Repetindo o critério em (79)e: "Redução ou assimilação de Ms ou toques (KLIMA; BELLUGI, 1979; LIDDELL; JOHNSON, 1986)."

${ }_{95}$ Repetindo o critério em (79)f: "A realização dos sinais em um composto é obrigatória e a ordem dos sinais em um composto é fixa (FIGUEIREDO SILVA; SELL, 2009)."
} 
Observamos isso em (18) a (23), repetido em (88) abaixo:

(88) a. ENTIDADE-RETA3 ${ }_{C L}-P I N T A R(M)|| E N T I D A D E-P L A N A 1_{C L}$ "desenhar"

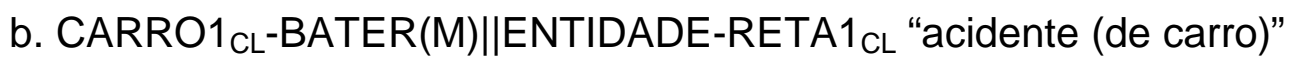

c. CARRO2 ${ }_{C L}-B A T E R(M)|| E N T I D A D E-P L A N A 1_{C L}$ "acidente (de carro)"

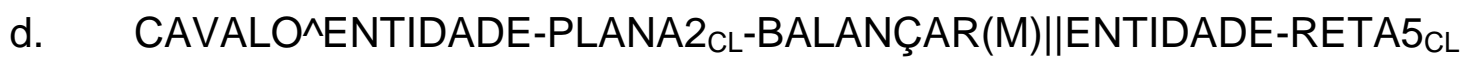
"cavalinho de balanço"

e. ENTIDADE-PLANA2 ${ }_{\mathrm{CL}}$-BALANÇAR(M) "bichinho de balanço"

f. $\operatorname{COSTAS}_{\mathrm{CL}}{ }^{\wedge}$ ENTIDADE-PLANA3 ${ }_{\mathrm{CL}} \mid$ ENTIDADE-SEMI-CIRCULAR1 $1_{\mathrm{CL}}$ "crocodilo"

Já as demais características em (85) não foram observadas, necessariamente, em nossos dados. No entanto, observamos uma série de características que podem auxiliar na identificação desses dados.

Considerando-se os critérios mais gerais, observados para os compostos sequenciais, podemos dizer que nos dados simultâneos apresentados no capítulo 2 , a inseparabilidade fica ainda mais evidente por razões articulatórias. Por exemplo, em:

SEXOb||VIAJAR "lua de mel"

Temos um sinal realizado pela boca e o outro manual simultaneamente. Não há como se adicionar outro sinal entre os membros desses compostos, a não ser colocando-os em forma sequencial, como nos exemplos em (90)a',b',d',e', abaixo, nos quais as expressões resultantes perdem sua leitura composicional, bem como ocorre nos exemplos (90)a",b",d",e", abaixo, com um sinal entre os compostos; ou em ambos os casos a sentença fica agramatical, como em (90)c',c": 
(90) a. EL@ SEXOb||VIAJAR ${ }^{96}$

Ele está em lua-de-mel.

a'. EL@ SEXOb VIAJAR

Ele fez sexo e viajou / Ele fez sexo na viagem.

a". EL@ SEXOb ÓTIMO VIAJAR

Ele fez sexo muito bem e viajou / Ele fez sexo muito bem na viagem.

b. DEPUTAD@ ROUBARb||DISFARÇAR

O deputado roubou escondido.

b'. DEPUTAD@ROUBARb DISFARÇAR

O deputado roubou e depois disfarçou / O deputado rouba e disfarça (habitualmente).

b". DEPUTAD@ ROUBARb DINHEIRO DISFARÇAR

O deputado roubou dinheiro e disfarçou / O deputado rouba dinheiro e disfarça.

c. EL@ ROUBARb||TROCAR

Ela enganou alguém.

c'. * EL@ ROUBARb TROCAR

Ela roubou (algo) e trocou (algo).

c'. * EL@ ROUBARb VASO TROCAR

Ela roubou o vaso e trocou (algo).

d. EL@ SEXOb||HOTEL

Ele está no motel.

d'. EL@ SEXOb HOTEL

${ }^{96}$ Agradecemos à Rosani Garcia por ter discutido esses dados conosco. 
Ele fez sexo no hotel.

d'. EL@ SEXOb ÓTIMO HOTEL

Ele fez sexo muito bem no hotel.

\section{e. EL@SEXOb||CAMA ${ }_{C L}-B A L A N C ̧ A R(M)$}

Ele fez sexo com alguém. / Ele está fazendo sexo com alguém.

e'. EL@ SEXOb CAMACL-BALANÇAR(M)

Ele fez sexo (intensamente) com alguém./ Ele fez sexo e a cama balançou.

e". EL@ SEXOb ÓTIMO CAMACL-BALANÇAR(M)

Ele faz sexo muito bem. A cama chega a balançar.

O mesmo acontece com outros compostos simultâneos, como os que são formados por CLs, como em (91):

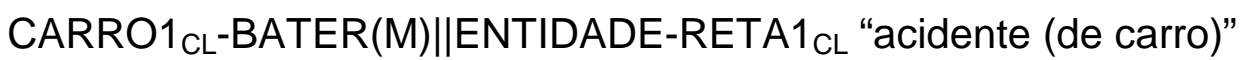

Se os dois sinais forem realizados em sequência para se inserir outro sinal entre eles, o significado do composto se perde.

Através desses exemplos em (90), também podemos afirmar que o critério em (79)c se aplica nos compostos simultâneos. Esses dados nos mostram que os dois sinais em um composto formam um significado diferente do significado dos mesmos dois sinais, independentemente, em uma frase.

Quando consideramos compostos simultâneos fica mais difícil identificar as reduções no $\mathrm{M}$, uma vez que os dois sinais são realizados simultaneamente pelas mãos ou um dos sinais constituintes do composto é realizado pela boca. No entanto, tendo em mente o critério fonológico, em (79)e, percebemos que há implicações de padronização de $M$ nos sinais simultâneos. Entre os compostos simultâneos 
estudados o $\mathrm{M}$ das mãos para a realização do sinal manual acompanha o padrão do movimento da língua para a realização do sinal não-manual, ou vice versa:

(92) a. em ROUBARb||DISFARÇAR, o $\mathrm{M}$ da língua se repete uma ou duas vezes junto com o $\mathrm{M}$ de mãos. De qualquer forma, esse sinal perde repetições, uma vez que ele é comumente sinalizado com três repetições.

b. em ROUBARb||TROCAR a língua faz um $M$ mais demorado acompanhando o M longo e demorado realizado pelas mãos em TROCAR.

c. em SEXOb||VIAGEM o mesmo ocorre: os $M$ de língua na bochecha acompanham cada $\mathrm{M}$ de fechamento de dedos do sinal VIAGEM.

d. em SEXOb||CAMACL-BALANÇAR(M) o $M$ da língua na bochecha acompanha os $\mathrm{M}$ do sinal manual.

e. em SEXOb||HOTEL não há M no sinal manual, logo os $M$ de bochecha são dois mais rápidos e curtos.

Assim, concluímos esta seção tendo evidenciado alguns padrões de formação que observamos nos compostos simultâneos. Traremos um detalhamento um pouco mais aprofundado desses dados no cap. 5 .

\subsection{Categorização e classes de palavras}

Nesta seção, procuraremos determinar como se identificam classes de palavras nas LSs. Entraremos nessa discussão com o intuito de acharmos caminhos para identificarmos a categoria envolvida nas partes que formam um composto e na categoria do composto como um todo. Essa identificação poderá nos levar a uma explicação mais minuciosa sobre a derivação dos compostos na libras, promovendo pistas para a determinação da categoria de seus núcleos, por exemplo.

Dividimos esta seção da seguinte forma: na seção 4.3.1, trataremos da identificação das classes de palavras nas LSs de modo geral e apresentaremos 
trabalhos que já trataram das classes de palavras na libras; a seção 4.3.2 retomará nosso estudo sobre um tipo de morfema categorizador nessa língua; na seção 4.3.3, discutiremos o impacto da pesquisa sobre classes de palavras na formação de compostos; e, finalmente, em 4.4, trazemos as conclusões do capítulo.

\subsubsection{Classes de palavras nas LSs}

Partimos do trabalho de Supalla \& Newport $^{97}$ (1978, apud LIDDELL; JOHNSON, 1989) que pesquisam mais de 100 pares nome-verbo na ASL e afirmam que esses pares apresentam uma mudança no padrão de movimento.

Enquanto o dicionário de ASL mais antigo (STOKOE et al, 1965) registra um único sinal para "sit" e "chair", Supalla \& Newport (op. cit.) identificam dois sinais diferentes para essas palavras. A diferença entre esses pares nome-verbo se dá por três características do M. Eles identificam SIT ("sentar") que apresenta um M único, unidirecional, seguido de uma suspensão" apresenta um $\mathrm{M}$ repetido, unidirecional, de maneira moderada, conforme as ilustrações abaixo mostram (sit, à esquerda, e chair, à direita):

Diferenças de M na ASL

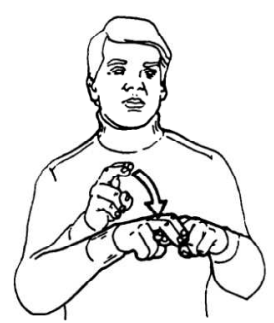

SIT

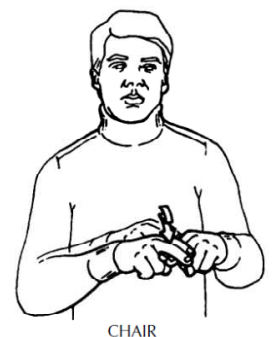

CHAIR
(LIDDELL; JOHNSON, 1989, p.271)

Trabalhos mais recentes, como Meir (2012), também tratam da questão das classes de palavras. A autora ressalta que classes de palavras geralmente se referem à classificação de palavras de acordo com seu comportamento morfossintático e semântico. Ela questiona se as línguas em modalidades diferentes

\footnotetext{
${ }^{97}$ Não tivemos acesso à versão original completa desse trabalho.

98 Uma parada.
} 
teriam tipos diferentes de classes de palavras. A autora afirma que são muito poucos os estudos sobre esse tema em LSs e aponta que uma primeira tentativa para identificar classes de palavras em LSs foi o trabalho de Padden (1988). Aquela autora sugeriu os seguintes critérios: i) nomes podem ser modificados por quantificadores; ii) adjetivos podem flexionar para aspecto intensivo; e, iii) verbos não podem ser modificadores de outros sinais. Meir (op. cit.) aponta que, por esses critérios, os verbos são definidos apenas negativamente. Ela também critica a falta de clareza sobre a aplicação desses critérios: não se pode afirmar que se apliquem a todos e somente aos membros de uma determinada classe.

Meir (2012) aponta algumas estruturas ou processos que diferenciam classes de palavras nas LSs, uma vez que se aplicam a classes de palavras específicas ou sub-partes dessas classes, o que envolve critérios morfológicos e distribucionais. As estruturas ou os processos que ela lista são:

i) pares nomes-verbos - cujos membros podem ser diferenciados pela qualidade do movimento em algumas LSs, como já mencionamos acima;

Meir (op. cit.) afirma que, apesar de esse M poder ser diferenciado por causa da iconicidade, em algumas LSs, parece que essa diferenciação já ultrapassou a iconicidade e está se tornando uma entidade morfológica.

ii) modulações flexionais - flexões tomam a forma de modulações no $M$ do sinal nas LSs. (MEIR, 2012, p. 91).

iii) afixos determinadores de classes de palavras - afixação sequencial não é muito comum nas LSs. Meir (op. cit.) aponta que há dois afixos relevantes na língua de sinais israelense (ISL) e dois na ABSL. Um dos exemplos vem de Aronoff, Meir \& Sandler (2005) que descrevem uma classe de prefixos da ISL que deriva verbos. São sinais realizados por 
apontamento a um órgão de sentido como o olho, o nariz, a orelha, a boca ou a cabeça, como em (94):

(94) EYE+CATCH 'to catch red handed'

OLHO+PEGAR 'ser pego com a boca na botija',99
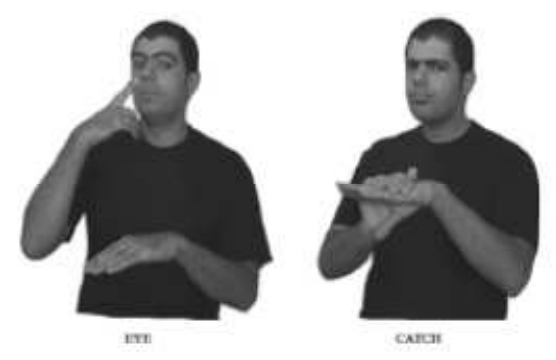

(MEIR, 2012, p.92)

iv) co-ocorrência com palavras funcionais - como, por exemplo, palavras de negação. Meir (op. cit.) remete a seu trabalho de (2004) sobre a ISL e mostra que há dois sinais para negação que co-ocorrem com nomes e outros dois (que significam "zero") que co-ocorrem com verbos.

v) co-ocorrência com traços não manuais - expressões faciais, balanço de cabeça, e movimentos de boca que desempenham papéis gramaticais nas diferentes LSs. A autora exemplifica com expressões faciais da ISL que denotam modo, como "rapidamente", "com esforço", etc. e, assim, modificam ações, evidenciando verbos.

Meir (op. cit.) afirma que é possível usar diagnósticos similares em LSs e LOs para se diferenciar classes de palavras. Assim, é possível considerar o significado, papéis sintáticos, distribuição, flexões morfológicas, e afixos derivacionais. Ela ressalta que as classes principais, nome, verbo e adjetivo, também são relevantes nas LSs. Porém, essas línguas apresentam pelo menos dois tipos de sinais de natureza claramente espacial: os classificadores, cuja classe de palavras ainda não foi determinada, e duas sub-classes de verbos, os verbos de concordância e os

\footnotetext{
${ }^{99}$ Tradução nossa.
} 
espaciais, que são verbos que apresentam $M$ das mãos no espaço de sinalização para marcar concordância com argumentos e ou localizações.

Se as observações feitas por Meir (op. cit.) para as classes de palavras na ISL podem, como pretende demonstrar a autora, se aplicar a outras LOs e LSs, então, poderemos trabalhar com a hipótese de que a libras, bem como outras LSs, deve poder fazer uso desses diagnósticos para diferenciar classes de palavras. Por um lado, isso favorece as análises que dependem da identificação da categoria das bases que formam um sinal mais complexo ou um composto. Por outro lado, a falta de diagnósticos para se indicar a classe de palavras a qual pertence um sinal pode ser problemática para essas análises.

A distribuição de palavras em classes de palavras foi muito pouco explorada na libras. No geral, encontramos trabalhos que apenas mencionam ou investigam o parâmetro M nos pares nome-verbo, com base em trabalhos da ASL, como Supalla \& Newport (1978).

Quadros \& Karnopp (2004, p.96-101), por exemplo, são pioneiras na descrição de aspectos linguísticos da libras. Nessa obra elas trazem observações iniciais sobre uma série de aspectos fonológicos, morfológicos e sintáticos, muitas vezes com base em pesquisas já desenvolvidas para dados da ASL. O trabalho de Quadros \& Karnopp (op. cit.) foi um grande avanço para os estudos linguísticos da libras à época de sua publicação. Ainda assim, a pesquisa relatada nesse trabalho não incluiu uma investigação minuciosa de uma série de fenômenos. Trabalhos mais recentes (cf. PIZZIO, 2011) vêm cumprindo essa tarefa e se ocupando da investigação de elementos que poderiam distinguir nomes de verbos.

Com base na pesquisa de Supalla \& Newport (op. cit.), Quadros \& Karnopp (op. cit., p.97) mostram alguns pares nome-verbo na libras, cujos membros também poderiam se diferenciar pela mudança no parâmetro $M$, uma vez que "o movimento dos nomes repete e encurta o movimento dos verbos" nesses pares. As autoras consideram que, assim como na ASL, a mudança de movimento deriva nomes a partir de verbo na Libras, como se vê nos pares TELEFONAR - TELEFONE, SENTAR - CADEIRA, como na Figura 7, PERFUMAR - PERFUME, PENTEAR PENTE, OUVIR - OUVINTE e ROUBAR - LADRÃO. 


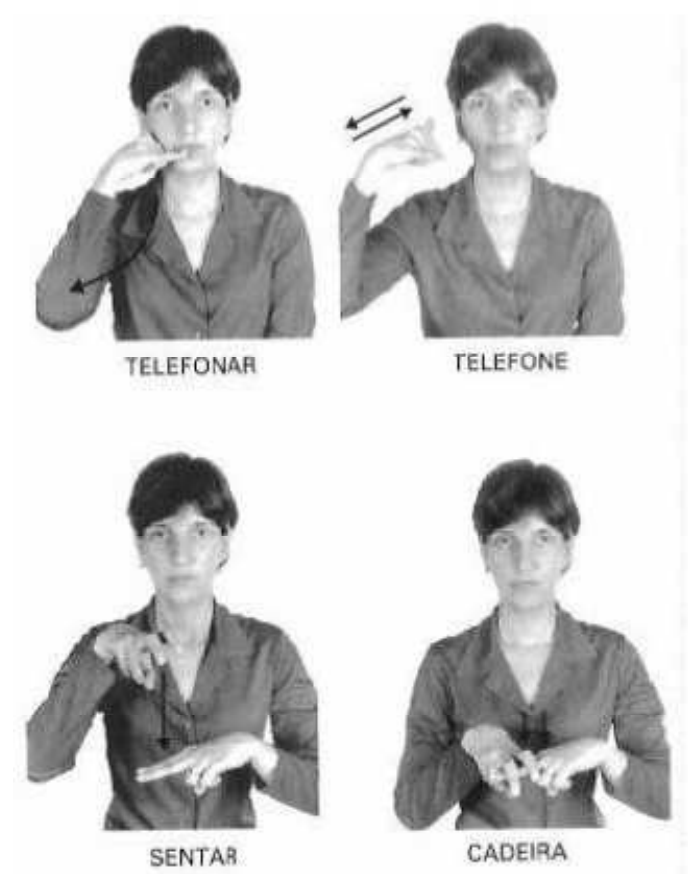

Figura 7: Pares nome-verbo na libras (QUADROS; KARNOPP, 2004, p.97)

Posteriormente, Felipe (2006, p.204-206) ressalta que nem todos os pares nome-verbo apresentam essas diferenças. A autora considera que a mudança de movimento ocorre apenas em alguns pares nome-verbo, tais como em: AVIÃO - IRDE-AVIÃO (M do verbo mais alongado que o do substantivo) e FERRO - PASSARCOM-FERRO ( $\mathrm{M}$ do verbo mais repetido e alongado que o do substantivo).

Em sua pesquisa, Felipe (op. cit.) observa que, em muitos casos, não há diferença na sinalização do membros do par nome-verbo por alguns sinalizantes. Alguns exemplos são: BRINCADEIRA - BRINCAR; CADEIRA - SENTAR; TESOURA - CORTAR-COM-TESOURA; BICICLETA - ANDAR-DE-BICICLETA; CARRO - DIRIGIR-CARRO; VIDA - VIVER. A autora trata os membros desses pares como formados por derivação zero e sugere que os elementos de cada par são identificados como nome ou verbo pelo contexto linguístico (FELIPE, 2006, p.205).

A variação e a falta de padronização na qualidade do $M$ nos pares nomeverbo é detalhada em Pizzio (2011), que busca determinar quais são as possíveis diferenças encontradas entre os membros desses pares considerando possíveis mudanças em algum dos parâmetros que formam o sinal. 
Pizzio (2011) é uma das poucas autoras que se atém exclusivamente à pesquisa de pares nome-verbo na libras ${ }^{100}$. Ela chega à conclusão de que há muita variação na produção desses pares nome-verbo pelos indivíduos surdos. A autora observa que, muitas vezes, o mesmo sinal é usado tanto para o nome quanto para o verbo; outras vezes, o sinalizante diferencia o par utilizando sinais compostos, principalmente para a contraparte nominal; e outras vezes, a diferenciação está no uso de visemas na produção simultânea do sinal, seja para o nome e/ou para o verbo.

Pizzio (op. cit) também observa que o padrão esperado nem sempre ocorre, principalmente, no que concerne aos pares nome-verbo que apresentam $M$ circular do sinal ou $M$ alternado de mãos e braços. Alguns exemplos são: ANDARBICICLETA e BICICLETA, CONSTRUIR e CONSTRUÇÃO, DIRIGIR-CARRO e CARRO. Nesses exemplos, quando há diferenciação, ela tem a ver com o número de repetições ou a velocidade de $M$.

A autora testa dados de nome-verbo isoladamente em testes de eliciação e compreensão. Assim, ela mostra que muitos pares nome-verbo não são diferenciados fora de contexto e a classe gramatical dos membros desse tipo de par não é identificada quando o sinal é produzido isoladamente.

No intuito de promover um avanço na sugestão de diagnósticos para a identificação de classes de palavras, bem como uma investigação empírico-teórica sobre a formação de sinais, Minussi \& Rodero-Takahira (2013) observam alguns pares nome-verbo e consideram diferenças de movimento, repetição ou aumento do movimento, na contraparte verbal dos pares. Trabalhando no modelo da MD, os autores sugerem que as raízes acategoriais a partir das quais se formam os nomes e verbos, membros desses pares são abstratas e não contêm o traço semântico de movimento, como em (95)a. Essas raízes acategoriais vão se concatenar com um categorizador $v$ marcado por um traço [+movimento] ${ }^{101}$, tornando-se um verbo, como em (95)b, ou com um categorizador $n$ vazio, portanto, sem o traço [+movimento], tornando-se um nome.

\footnotetext{
${ }^{100} \mathrm{Em}$ uma perspectiva cognitivo-funcional, veja Lima (2012).

101 Os autores consideram que os parâmetros atuam em três níveis diferentes com propriedades diferentes em cada nível. No início da derivação sintática, os parâmetros são traços abstratos (parâmetros abstratos); em outro momento, parâmetros específicos tomam o valor de morfemas (parâmetros morfológicos); e quando o sinal se realiza, os tipos de parâmetros são fonemas (parâmetros fonológicos) (MINUSSI \& RODERO-TAKAHIRA, 2013, p.214).
} 
(95)
a) $\sqrt{+} \mathrm{PA}^{102}$
$+\mathrm{CM}$
$+\mathrm{EXP}$
$+\mathrm{D}$
b)

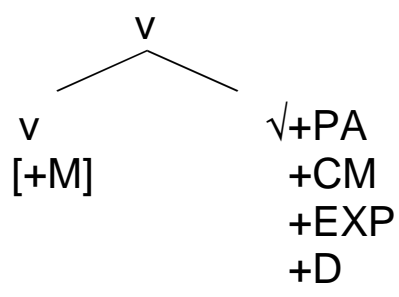

c)

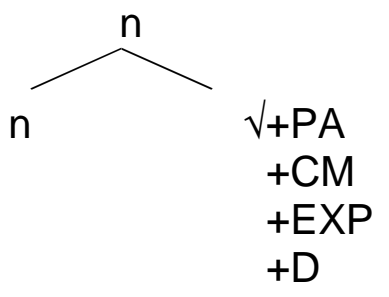

Os autores consideram que o movimento observável na forma verbal é a realização do traço [+movimento] presente no categorizador v (quando ele não está contido na raiz) que, associado a uma raiz acategorial, a transforma em verbo.

Na próxima seção, com base em alguns pares nome-verbo da libras, que coletamos para esta pesquisa, apresentamos alguns avanços sobre esse tema, propondo um outro tipo de categorizador, realizado por dois tipos de ENMs: o primeiro deles, evidenciando verbos, e o segundo, evidenciando nomes.

\subsubsection{Morfemas categorizadores na libras}

Nesta seção, investigamos a marcação das categorias gramaticais na libras, especialmente no que diz respeito a pares nome-verbo. Nossos objetivos são: i) determinar o padrão de sinalização de pares nome-verbo da Libras em contextos naturais de sinalização; e, ii) verificar como a categorização se dá e se existem evidências morfofonológicas para a marcação categorial em tais pares.

Como resultado da pesquisa, observamos que: i) o morfema que se realiza como um movimento, que contém o traço [+movimento], pode ser considerado um

\footnotetext{
102 "PA" é a sigla que os autores usam para Ponto de Articulação, ou seja, a Localização.
} 
morfema categorizador verbal, no sentido sugerido em Rodero-Takahira \& Minussi (2013) e Minussi \& Rodero-Takahira (2013); ii) um morfema boca da libras, que contém o traço [+expressão facial/boca], pode ser um categorizador verbal ${ }^{103}$; e, iii) o categorizador pode ser uma forma vazia $\varnothing$, quando não for realizado por $M$, nem por um morfema boca e, nesse caso, a diferenciação se dá por contexto sintático.

Para chegarmos aos resultados apontados acima, primeiramente, consideramos a proposta de Pizzio (2011). Uma vez que aqueles dados foram testados isoladamente e aquela pesquisa aponta para a necessidade de investigação dos mesmos dados em contextos naturais, fizemos uma coleta de dados com pares nome-verbo em contexto natural dentro da mesma coleta dos dados com o foco principal dessa pesquisa, os compostos. A metodologia da coleta de dados aplicada já foi detalhada em 2.1. Também tomamos como base alguns trabalhos que tratam de pares nome-verbo e categorização em ASL e em outras LSs e consideram padrões de $\mathrm{M}$ ou ENMs como pistas para se diferenciar membros dos pares nome-verbo (Cf. SUPALLA \& NEWPORT, 1978 (apud LIDDELL; JOHNSON, 1989); VALLI \& LUCAS, 1992; JOHNSTON, 2001; SCHEMBRI et al, 2002; VOGHEL, 2005; e, BRENTARI et al, 2012).

Apresentamos nossos dados com os pares nome-verbo a seguir, começando por alguns nomes retirados de contextos:

a. AVIÃO

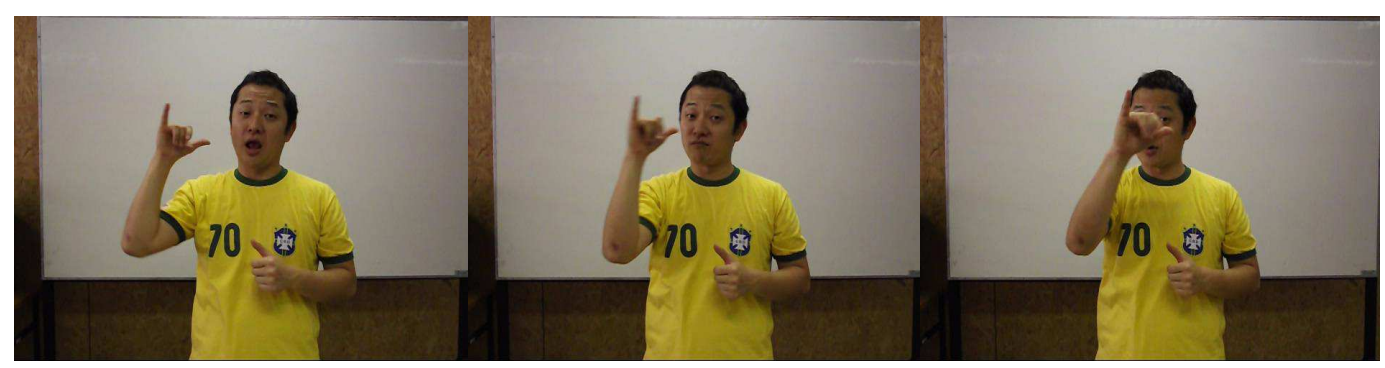

AVIÃO: Mouthing (visema ${ }^{104}$ ): palavra "avião" do PB, pronúncia [a.v.o].

\footnotetext{
${ }^{103}$ Agradecemos ao Professor Dr. Felipe Venâncio Barbosa por nos chamar atenção para o uso da boca em dados como DIRIGIR-CARRO e por sugerir que olhássemos para movimentos de boca em nossos dados. Esse insight foi fundamental para o aprofundamento desse tema.

${ }^{104}$ Seguindo terminologia usada em DeMartino (2005) e McCleary, Viotti \& Leite (2010). DeMartino (2005) define visemas como "representações para os padrões visuais de movimentação articulatória observáveis na face durante a fala" (p.3 e 17).
} 


\section{b. CARRO}

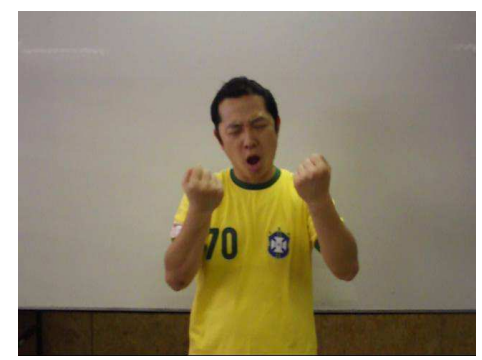

CARRO: Mouthing (visema): palavra "carro" do PB, pronúncia [ka:o]).

Johnston (2001) investiga pares nome-verbo na Auslan (língua de sinais australiana) e percebe que nomes são acompanhados por visemas com mais frequência do que verbos. Ele usa essa estratégia para identificar a categoria gramatical de alguns sinais. Voghel (2005) investiga se o uso de visemas e a diferença temporal contida no M do sinal na LSQ (Língua de Sinais Quebequense) também serve como pista para diferenciar pares nome-verbo em produções espontâneas nessa língua. A autora também conclui que nomes são acompanhados por visemas com mais frequência do que verbos, e verbos são acompanhados por morfemas boca (presos) com mais frequência do que os nomes.

Em nossos dados, podemos observar a pronúncia da palavra ou de parte da palavra em português (visema). E, conforme a tabela abaixo, será possível perceber que esse visema ocorre com quatro dos oito diferentes nomes coletados na gravação; em 39 ocorrências desses sinais, o visema aparece em 14 delas:

\begin{tabular}{|l|l|l|l|l|l|l|}
\hline Sinal & $\begin{array}{l}\text { Um } \\
\text { toque }\end{array}$ & $\begin{array}{l}\text { Dois } \\
\text { toques }\end{array}$ & $\begin{array}{l}\text { M } \\
\text { curto }^{105}\end{array}$ & M longo & Mouthing & $\begin{array}{l}\text { Morfema } \\
\text { boca }\end{array}$ \\
\hline CASA & 11 & 3 & 14 & 0 & 1 & 0 \\
\hline MORAR & 2 & 0 & 2 & 0 & 0 & 0 \\
\hline CADEIRA & 4 & 4 & 8 & 0 & 0 & 1 \\
\hline SENTAR & 3 & 0 & 0 & 3 & 0 & 1 \\
\hline
\end{tabular}

\footnotetext{
${ }^{105}$ Nesta pesquisa, os Ms curtos e longos foram divididos não por sua realização em milissegundos, mas sim por sua produção, uns em contraposição com os outros.
} 


\begin{tabular}{|c|c|c|c|c|c|c|}
\hline TELEFONE & -- & -- & 7 & 0 & 0 & 0 \\
\hline TELEFONAR & -- & -- & 0 & 2 & 0 & 2 \\
\hline AVIÃO & -- & -- & 5 & 0 & 5 & 0 \\
\hline IR-DE-AVIÃO & -- & -- & 0 & 4 & 0 & 3 \\
\hline CARRO & -- & -- & 6 & 0 & 3 & 0 \\
\hline DIRIGIR-CARRO & -- & -- & 0 & 2 & 0 & 2 \\
\hline TESOURA & -- & -- & 4 & 2 & 0 & 0 \\
\hline $\begin{array}{l}\text { CORTAR-COM- } \\
\text { TESOURA }\end{array}$ & -- & -- & 2 & 5 & 0 & 1 \\
\hline FACA & -- & -- & 14 & 0 & 5 & 0 \\
\hline $\begin{array}{l}\text { CORTAR-COM- } \\
\text { FACA }\end{array}$ & -- & -- & 2 & 1 & 0 & 2 \\
\hline DANÇA & -- & -- & 0 & 1 & 0 & 0 \\
\hline DANÇAR & -- & -- & 0 & 3 & 0 & 1 \\
\hline
\end{tabular}

Quadro 7: Características de pares nome-verbo na libras

Não observamos nenhuma ocorrência de visemas com verbos. No entanto, é bem grande a variação que observamos no uso (ou não) dos visemas nos nomes. Isso nos mostra que a ocorrência de visemas com a sinalização serve como pista para se identificar a categoria gramatical de alguns sinais. Porém, esse não é um critério definitivo para se diferenciar a categoria dos membros dos pares nomeverbo.

Também observamos, nos dados em (97), que, em alguns verbos, há um mesmo morfema boca sendo realizado, que é o morfema boca MM, seguindo a notação de Bickford \& Fraychineaud (2006), que será detalhada adiante. 
(97) a. IR-DE-AVIÃO

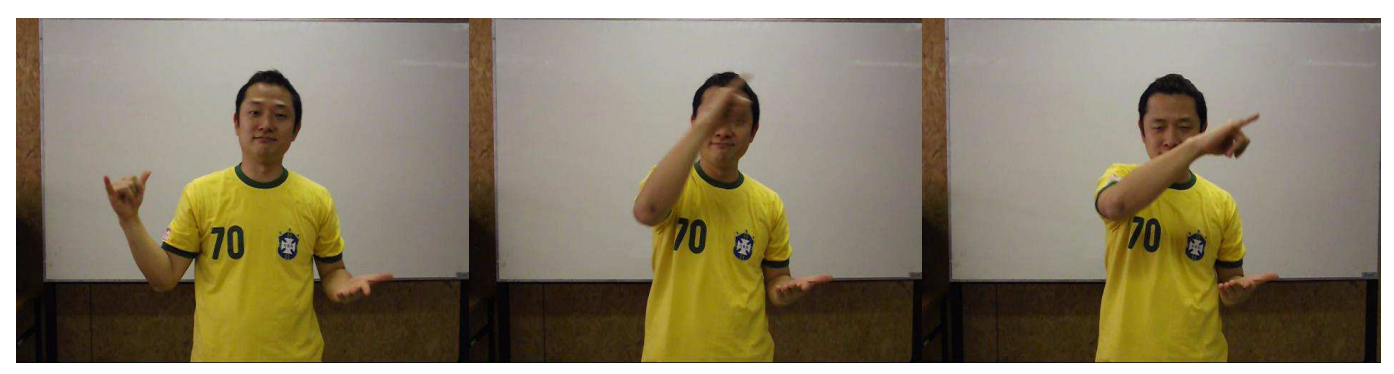

b. IR-DE-AVIÃO (2)

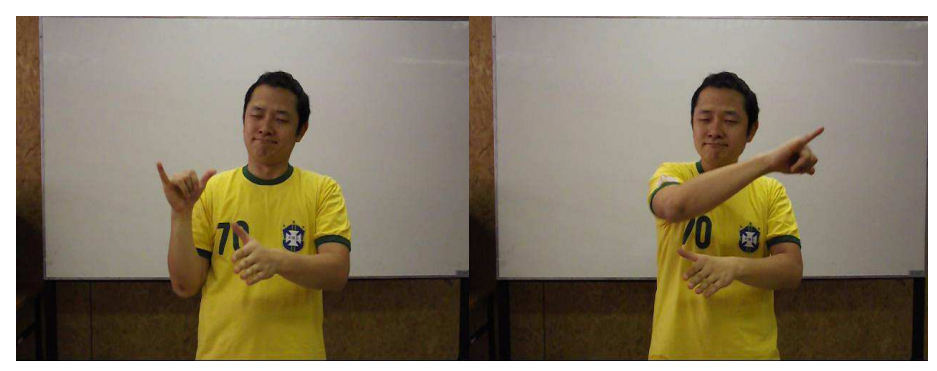

c. DIRIGIR-CARRO

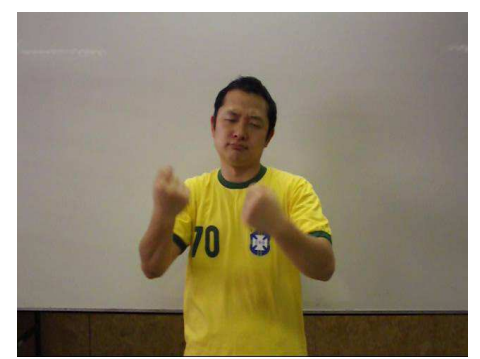

d. CORTAR-COM-FACA

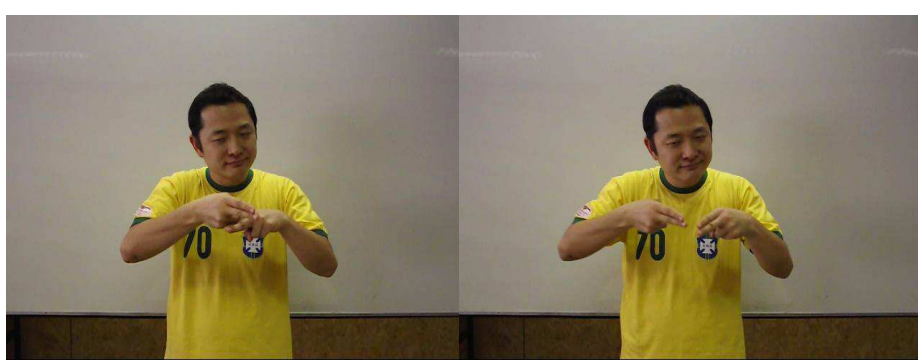


e. CORTAR-COM-FACA (2)

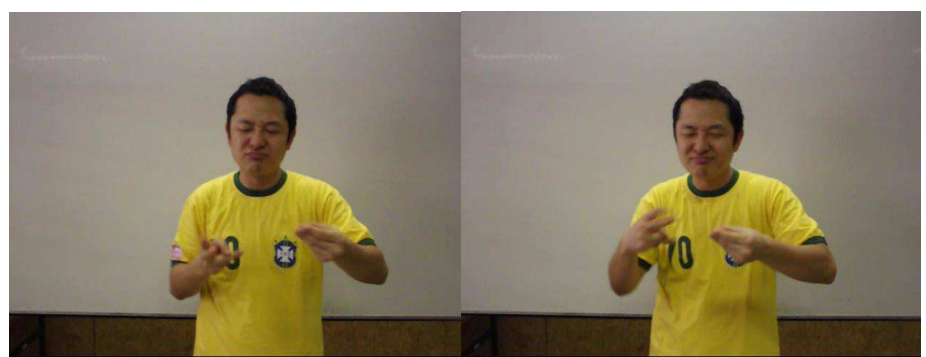

\section{f.TELEFONAR}

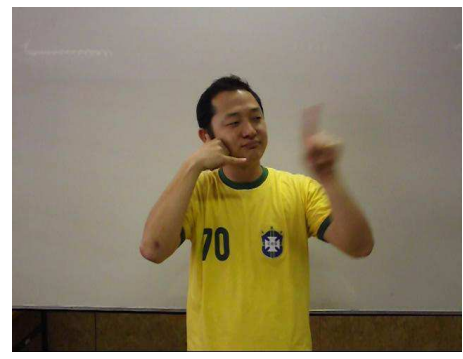

g. DANÇAR

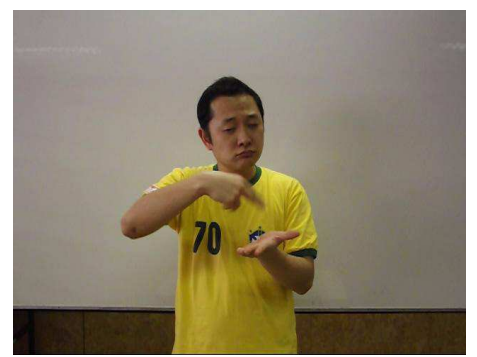

O morfema boca (preso) observado nesses dados, MM, é um morfema realizado com a boca fechada e levemente apertada. Se olharmos no quadro acima, veremos que esse morfema boca ocorreu com quase todos os verbos pesquisados, menos em MORAR. O mesmo morfema apareceu em uma das oito ocorrências do nome, CADEIRA. Das 24 ocorrências verbais (exceto MORAR), MM apareceu em 12 delas.

De qualquer forma, ainda considerando nossa hipótese de que um morfema boca da libras, que apresenta o traço [+expressão facial/boca], poderia ser um 
categorizador verbal, vamos olhar para o comportamento de $M M$, que também ocorre na ASL, antes de atribuirmos o status de categorizador para esse morfema.

Diferentemente de outros linguistas, Bickford \& Fraychineaud (2006) dividem esse morfema em MM e MMM, segundo os dados que mostramos em (98)a/b:
a. MM

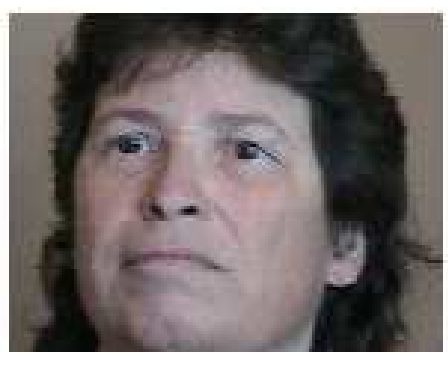

(BICKFORD; FRAYCHINEAUD, 2006, p.42)

\section{b. MMM}

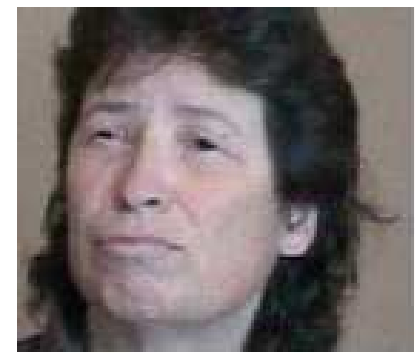

(BICKFORD; FRAYCHINEAUD, 2006, p.43)

Os autores descrevem a fonologia desses sinais respectivamente como: "boca fechada, lábio inferior levemente para fora. Face relaxada" e "lábios superior e inferior levemente para fora, mais que MM. Queixo levemente para frente (cabeça levemente para trás). Frequente inclinação da cabeça para um lado. Movimento manual relaxado e mais lento que o normal, sem mudanças bruscas na velocidade ou na direção"106, respectivamente. Eles apontam que MM ocorre com adjetivos e verbos e tem um significado geral de "como normalmente esperado". Com adjetivos significa "em um grau moderado", com expressões de quantidade "uma quantia moderada", e com verbos "acontecendo bem, em uma velocidade moderada". Já MMM parece ser limitado a verbos dinâmicos e significa "com prazer, agradável".

\footnotetext{
${ }^{106}$ Traduções nossas.
} 
Essa parece ser a diferença que podemos observar em nossos dados em (97)a, MM, e em (97)b, MMM.

Esse morfema boca não é um sinal porque não pode ser realizado sozinho, sem o sinal manual, mas tem um valor adverbial, de forma que se anexa a verbos, o que pode ser mais uma pista para a identificação da categoria gramatical de alguns elementos em pares nome-verbo. Como vimos em nosso levantamento de dados, a ocorrência desse morfema boca não é obrigatória, então, esse critério também não deve ser exclusivamente assumido para a identificação de categorias gramaticais na libras.

Podemos considerar que o morfema boca MM, quando realizado, ocorre em uma posição de categorizador, marcando verbos, atividades. Nesses casos, então, o traço de [+E] (parâmetro abstrato) mapeia na sintaxe o local onde o item de vocabulário MM ou MMM (morfema boca) vai ser inserido pós-sintaticamente, como vemos a seguir:
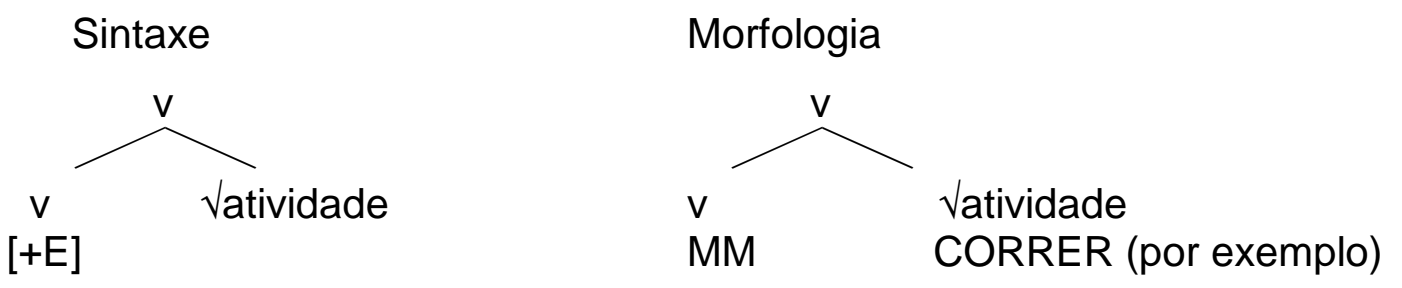

Como já dissemos, Minussi \& Rodero-Takahira (2013) consideram a realização de um movimento com qualidade diferente sendo realizado como categorizador verbal em alguns verbos, principalmente aqueles que têm um toque das mãos, como MORAR e SENTAR. Naquele trabalho também ficou claro que o $\mathrm{M}$ pode variar de forma que essa característica serve apenas como uma pista para a categorização.

Entramos nessa discussão em uma tentativa de avaliar a categoria envolvida nas partes que formam um composto e na categoria do composto como um todo, o que nos ajudaria a pensar na derivação dos compostos na libras. No entanto, até aqui temos apenas algumas pistas para a identificação da categoria gramatical na libras. 
Figueiredo Silva \& Sell (2009) investigam a formação de alguns compostos e, naquele trabalho, as autoras já chamam atenção para o fato de haver pares nomeverbo na libras que muitas vezes são iguais sendo, então, muito difícil de se falar sobre a categoria dos sinais que formam um composto.

Sendo assim, ressaltamos que realmente há grande variação na produção de pares nome-verbo na libras de forma que não há uma característica que destaque todos os membros de uma certa categoria. Mostramos que o parâmetro $\mathrm{M}$ e os morfemas boca MM e MMM servem de pistas para se identificar a categoria gramatical de alguns sinais. .

\subsubsection{Identificando as classes de palavras envolvidas na composição}

Análises sobre a formação de compostos nas LOs olham para a categoria das palavras à qual pertence cada uma das bases que formam o composto. Esse tipo de consideração na libras não parece possível, por conta dos pares nome-verbo que, aparentemente, não se distinguem (Cf. FIGUEIREDO SILVA; SELL, 2009).

Como vimos na seção anterior, na ASL, Supalla \& Newport (1978) mostram que há uma diferença no que concerne ao parâmetro $M$ entre esse tipo de par. Com base nesses autores, Quadros \& Karnopp (2004, p.96-101) mostram alguns pares nome-verbo na libras, que também se diferenciam pela mudança no parâmetro $M$. Felipe (2006, p.204-206) ressalta que nem todos os pares nome-verbo apresentam essas diferenças. A variação e a falta de padronização na qualidade do $\mathrm{M}$ nos pares nome-verbo são detalhadas em Pizzio (2011), que também considera possíveis mudanças em algum dos parâmetros que formam o sinal, ou a tendência a se usar um composto para a contraparte nominal, como indicação da diferenciação do par. $\mathrm{Na}$ seção anterior, defendemos que morfemas boca e mouthings são pistas para a distinção de alguns pares nome-verbo, como em: CARRO / DIRIGIR-CARRO; AVIÃO / IR-DE-AVIÃO, entre outros exemplos em (96) e (97). No entanto, o processo de composição leva à redução de Ms e/ou toques. Além disso, fenômenos que se aplicam a sinais em frases nem sempre se aplicam a sinais em compostos (KLIMA; BELLUGI, 1979; LIDDELL; JOHNSON, 1986), o que torna mais opaca a percepção da categoria das bases que formam o composto, mesmo em dados em 
que se verifica uma maior regularidade na qualidade de Ms ou quantidade de toques, como em:

(100) CASA
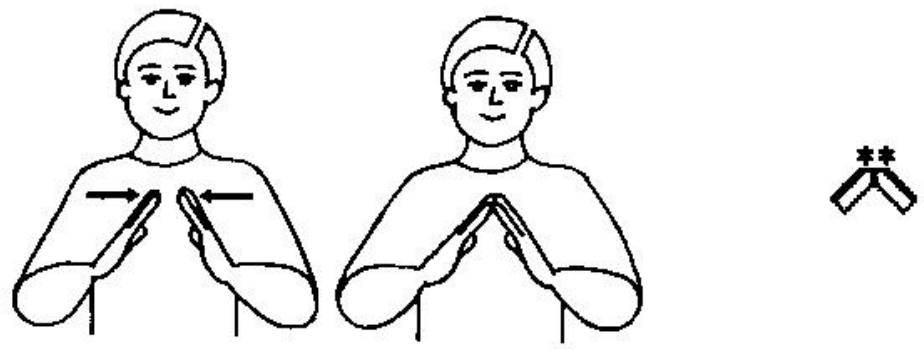

"Mãos verticais abertas, palma a palma, dedos inclinados uns para os outros. Tocar as mãos pelas pontas dos dedos". (CAPOVILLA; RAPHAEL, 2001, p.371)

\section{MORAR}
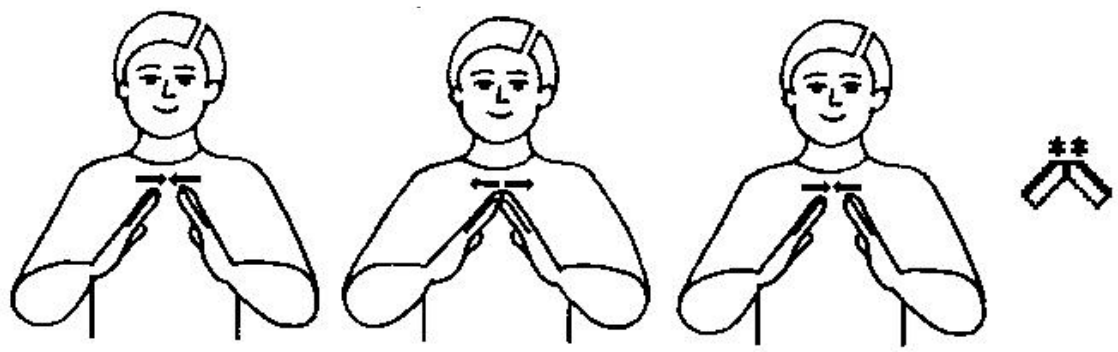

"Fazer o sinal de casa, duas vezes".

(CAPOVILLA; RAPHAEL, 2001, p.920)

Apesar de estar padronizado em Capovilla \& Raphael (2001), atestamos que a quantidade de Ms ou toques em sinais como CASA e MORAR pode variar. Em alguns casos, o mouthing marcou a contraparte nominal ${ }^{107}$.

Em compostos como "escola", CASA^ESTUDO, como no exemplo abaixo, pode ser que a glosa influencie a interpretação da categoria das bases que formam

${ }^{107}$ Em 14 ocorrências do sinal CASA em uma de nossas coletas com um mesmo colaborador, observamos 11 ocorrências com um $\mathrm{M}$ e toque das mãos, e 3 ocorrências com dois Ms e toque das mãos. Nas 14 ocorrências esse M foi curto. Nessa mesma sinalização apareceram 2 ocorrências do sinal MORAR, sendo que as duas foram feitas com um $M$ e toque, e esse $M$ também foi curto. Dessa forma, só pudemos distinguir CASA e MORAR pelo contexto da sinalização, pela sintaxe. Em outras sinalizações que observamos com outros dois sinalizantes, essa variação na quantidade de Ms também ocorreu. 
o composto, quando opta-se por usar CASA ou MORAR e ESTUDO ou ESTUDAR nas glosas:

CASA^ESTUDO "escola"
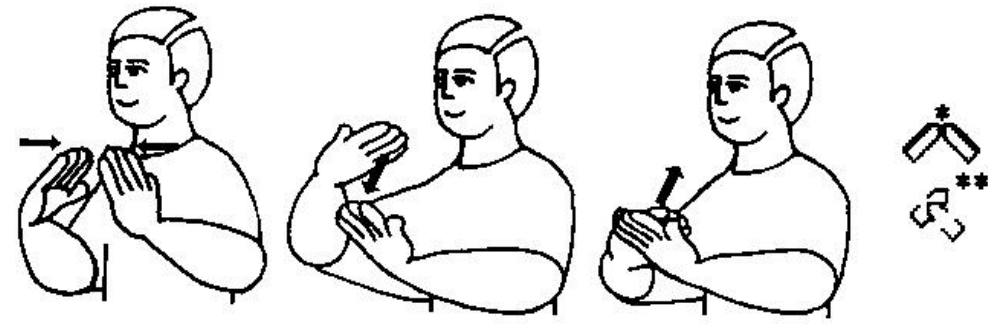

"Fazer o sinal de casa e o sinal de estudar (1), estudo (1), estudante".

(CAPOVILLA; RAPHAEL, 2001, p.599)

Devido à variação na quantidade de toques ou Ms em pares nome-verbo, percebemos que mesmo em dados nos quais o $M$ (toque) pode ser mais padronizado, como em (100) e (101), não há nada na sinalização do composto que mostre que ele seja formado por CASA ou por MORAR, além de ESTUDO ${ }^{108}$, ESTUDAR ou ESTUDANTE. No caso de "escola", há a redução de Ms (toques) no primeiro sinal e, possivelmente, no segundo também.

Assim, principalmente pelo critério semântico, ou seja, porque o composto se refere a um local, decidimos considerar o equivalente nominal na glosa, CASA (em vez de MORAR). Além disso, verbos possibilitam uma modulação do $M$ marcando intensidade ou iteração. Em "escola" não é possível modular o $\mathrm{M}$ do segundo sinal para se marcar intensidade, como vimos em (87)c, logo, consideramos ESTUDO para nossa glosa.

\subsection{Considerações finais do capítulo}

Neste capítulo, trouxemos alguns critérios de identificação de compostos nas LOs e nas LSs. Vimos que muitos não se aplicam translinguisticamente. No entanto,

\footnotetext{
${ }^{108}$ O sinal ESTUDO não está dicionarizado pelo menos até Capovilla; Raphael e Mauricio (2012).
} 
vimos também que há uma série de critérios que servem como pista para se identificar a composição nas LSs.

Trouxemos uma discussão sobre os compostos simultâneos da BSL e da TID. Todos esses dados envolvem sinais CLs. A estrutura que propusemos no capítulo 3 para evidenciar a natureza dos CLs, nos possibilitou entender a participação desses elementos em sinais que formam compostos e vimos que eles são bastante produtivos na libras também (veja quadro 3 , no capítulo 2 para mais exemplos).

Também discutimos a dificuldade de se identificar classes de palavras nas LSs, o que dificulta a identificação da categoria dos membros que forma um composto.

Concluímos esta seção tendo evidenciado alguns padrões para identificação de nomes-verbos e para a formação que observamos nos compostos simultâneos. No capítulo 5, traremos um detalhamento um pouco mais aprofundado dos nossos dados. 


\section{Compostos na libras}

Os compostos da libras foram pouco estudados até hoje. Como vimos mostrando ao longo desta tese, o fenômeno da composição é bastante comum nas LSs e vem sendo estudado em diversas LSs ao longo das últimas décadas. De modo geral, os linguistas consideram compostos sequenciais muito parecidos com os compostos formados nas LOs. Já os compostos simultâneos, apesar de muito produtivos nas LSs, são pouco estudados e ainda necessitam de mais detalhamento. Nesse sentido, neste capítulo, traremos uma discussão um pouco mais aprofundada dos compostos da libras, esmiuçando alguns padrões de formação de compostos, principalmente no que diz respeito a alguns tipos de compostos simultâneos.

Primeiramente, vamos nos valer da discussão dos dados que desenrolamos nos últimos capítulos para começarmos a seção 5.1 indicando caminhos de análise para os compostos sequenciais e simultâneos que vimos discutindo. Seguindo o modelo da MD (HALLE; MARANTZ, 1993), que considera um único mecanismo sintático para a derivação de frases e palavras, defendemos que os dados em tela, sequenciais ou simultâneos, são sintaticamente formados da mesma maneira, como compostos, e tratamos tanto a sequencialidade quanto a simultaneidade como marcadas pós-sintaticamente ${ }^{109}$, como um efeito da externalização particular de uma língua de modalidade vísuo-espacial, a libras. E em 5.2, buscamos esmiuçar alguns padrões de simultaneidade com base em nossos dados.

Para dar continuidade a um detalhamento dos compostos simultâneos, na seção 5.3, apresentaremos uma descrição de dados com um tipo de sinal que não ocorre com muita frequência nas LSs, são sinais que chamaremos de "sinais boca", realizados por lábios, bochecha e língua, como já observamos brevemente no capítulo 2. Em 5.4, estão as considerações finais do capítulo.

\footnotetext{
${ }^{109}$ Agradecemos ao André Xavier e ao Vitor Nóbrega por trazerem alguns aspectos dessa discussão em pauta em nossas conversas.
} 


\subsection{Indicando caminhos para uma análise de compostos na libras}

No capítulo 2, vimos que os dados sequenciais podem ser formados com: i) sinais simples; ii) sinais simples e sinais CLs semânticos ou de traço; ou iii) apenas sinais CLs semânticos, como nos exemplos abaixo, respectivamente:

Dados sequenciais

a. CARNE^VENDER "açougue"

b. FORMA-MEIA-LUA $\mathrm{CL}^{\wedge}$ VIAGEM "lua de mel"

c. $\mathrm{CASA}_{\mathrm{CL}}{ }^{\wedge} \mathrm{CRUZ} \mathrm{Z}_{\mathrm{CL}}(1)$ "igreja"

Tomando os pressupostos teóricos da MD, assumimos que os compostos envolvem a concatenação de duas ou mais raízes categorizadas, e um domínio categorial que recategoriza o composto como um todo dando a ele um valor de uma unidade, uma palavra ${ }^{110}$ (Cf. NÓBREGA, 2014).

Já tendo olhado para nossa base empírica no capítulo 4 e com essas ferramentas em mente, verificaremos agora a derivação de alguns dos dados apresentados. Começaremos pelo dado em (103)a, CARNE^VENDER "açougue", que envolve dois sinais simples formando um composto com realização sequencial.

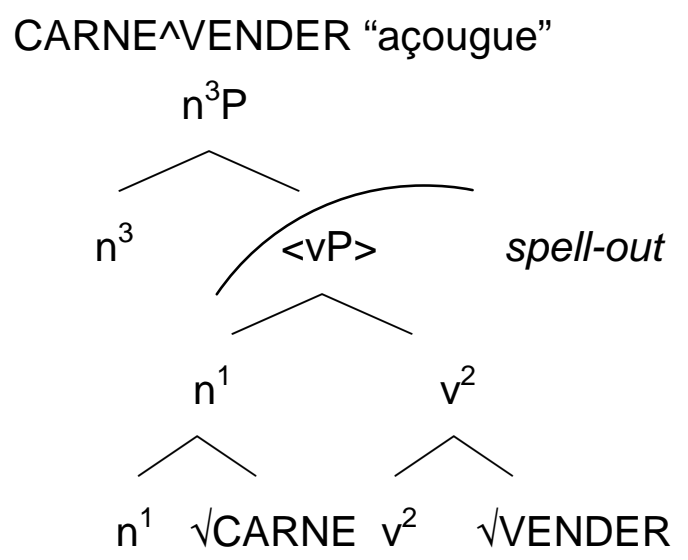

\footnotetext{
110 Estamos trazendo uma proposta muito simplificada, considerando o domínio categorial que recategoriza o composto, com o intuito de apontarmos caminhos para uma análise dos compostos da libras. Para uma análise bastante minuciosa considerando os diversos traços envolvidos no processo de composição e um detalhamento sobre a formação de compostos subordinativos e atributivos, Cf. Nóbrega (2014, cap. 5).
} 
Em (104), as raízes CARNE e VENDER são acategoriais e não possuem conteúdo fonológico. Elas são categorizadas por um $n$ e $v$ e depois supostamente formam um $\langle\mathrm{VP}\rangle$, formando uma única unidade. No passo seguinte da variação, essa construção é recategorizada por um novo domínio, toda a unidade sofre spellout e a partir daí não fica mais disponível para o acesso de dominínios mais altos. Uma vez que os dois ns estão no mesmo domínio de spell-out, pode haver influência de uma raiz na outra, como redução do contorno de $M$ entre os sinais, por exemplo, pois nesse ponto da derivação o conteúdo dos IVs inseridos está acessível um para o outro.

Já o dado em (103)b, FORMA-MEIA-LUA ${ }_{C L}{ }^{\wedge V I A G E M ~ " l u a ~ d e ~ m e l ", ~ e n v o l v e ~}$ um morfema CL, um SASS de traço. No capítulo 3, assumimos que todos os sinais com CLs envolvem a concatenação do morfema CL com uma raiz bem genérica VENTIDADE. Além disso, sugerimos que o spell-out dessa derivação só ocorre quando um segundo núcleo categorizador se anexar a estrutura (Cf. EMBICK, 2010), como em (63), repetido abaixo:

(105) Estrutura morfossintática para os sinais CLs

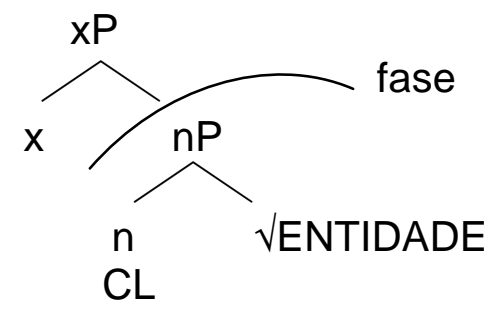

Uma vez que a raiz e o CL estão dentro de uma mesma fase, ao se anexar à raiz o CL transmite seus traços semânticos influenciando na composicionalidade do significado da raiz e em seu spell-out. Assim, propomos a seguinte derivação para o composto apresentado em (103)b: 
(106)

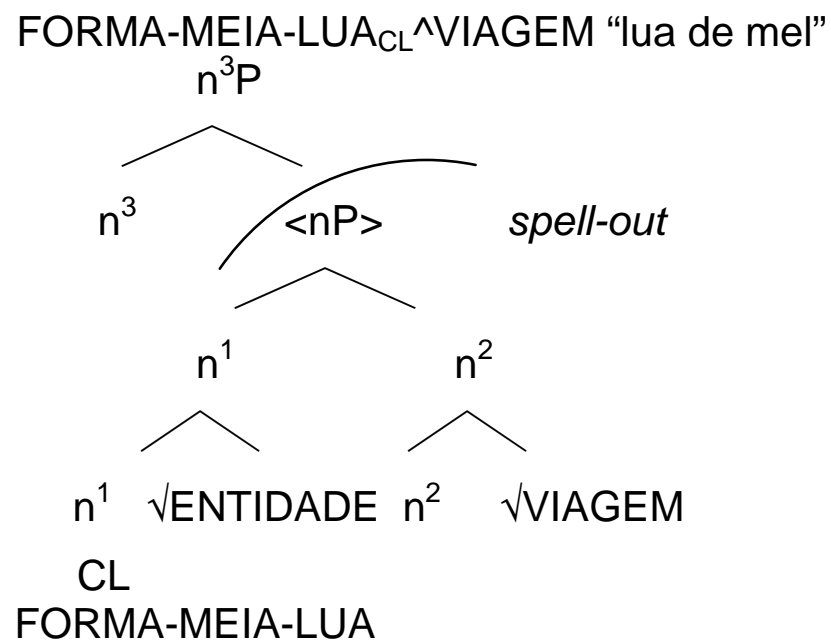

Aqui temos uma raiz bem geral, JENTIDADE, que é categorizada pelo CL SASS de traço, de forma que esse categorizador influencia na semântica da raiz. E há uma segunda raiz também acategorial que é categorizada por um $n$. Esses dois $n$ s supostamente formam um $\langle n \mathrm{P}\rangle$, formando uma única unidade. No passo seguinte da derivação um novo domínio nP recategoriza essa construção. Novamente, como os dois ns estão no mesmo domínio de spell-out, pode haver redução do contorno de $\mathrm{M}$ entre os sinais, uma vez que o conteúdo dos IVs inseridos nos dois nós terminais estão acessíveis um para o outro, em uma mesma fase.

O dado em (103)c traz uma construção com dois sinais CLs semânticos, $\mathrm{CASA}_{\mathrm{CL}}{ }^{\wedge} \mathrm{CRUZ} \mathrm{Z}_{\mathrm{CL}}$ "igreja" apresentando a seguinte derivação:

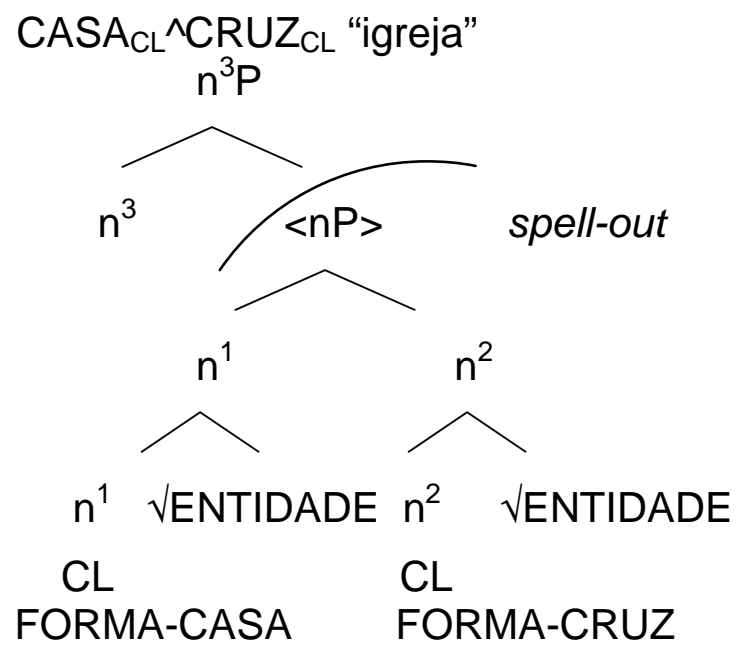


Para os CLs semânticos também assumimos a estrutura com a raiz VENTIDADE categorizada por um $n$ que contribui com o significado da raiz adicionando uma informação sobre sua forma. Isso explica as possibilidades de realização mais "livre" dos sinais CLs semânticos, ou seja, o fato de eles poderem ser realizados com CMs relativamente diferentes, como a CM em B bastante estendida, com o polegar distendido para uma "ótima casa" ou a mesma CM menos estendida e curva para remeter a uma "casinha simples". Ou então, CRUZ realizado com a CM em "1" para remeter a uma cruz pequena, padrão, ou CM em "U" para remeter a uma cruz mais larga ou maior. Com essa derivação assumida em (107), mostramos que esse tipo de significado é englobado à raiz a partir do morfema CL selecionado, explicando, sintaticamente, as possibilidades de variação e a iconicidade superficial desses sinais.

Até este ponto já explicamos a formação de compostos com sinais simples e com CLs, ressaltando também como a alta iconicidade dos CLs semânticos pode ser decodificada estruturalmente. Todos os sinais apresentados nessa seção são realizados sequencialmente. Na próxima seção, entraremos em uma discussão sobre as diferenças de spell-out, sequencial ou simultâneo, e como e onde essa informação deverá ser marcada, uma vez que as estruturas disponíveis para compostos sequenciais ou simultâneos são as mesmas.

\subsection{Por uma especificação das construções simultâneas}

$\mathrm{Na}$ literatura sobre as LSs, as mãos são consideradas os dois articuladores primários potenciais, independentes e idênticos (Meir et al, 2010, p.302). O fato de haver dois articuladores primários já traz a possibilidade de se articularem dois sinais, ou duas informações, ao mesmo tempo, viabilizando o surgimento de compostos simultâneos. Essa possibilidade é explorada na libras principalmente no que diz respeito a formações de compostos simultâneos com CLs, como vimos no capítulo 4.

O surgimento de compostos simultâneos também é viabilizado pela possibilidade de uso da boca (de fato, lábios, bochecha e língua) como articulador 
para um sinal simples. Sabe-se que as ENMs, faciais e corporais, ocorrem junto com um sinal manual e são geralmente divididas em dois tipos: gramaticais, que expressam uma informação gramatical, ou sintática; e as afetivas, que expressam tristeza ou alegria, por exemplo. Com base empírica, no capítulo 2, observamos que há na libras um terceiro tipo de expressões de boca que vem sendo realizadas independentemente do componente manual, com significado independente, se constituindo como um articulador potencial. Na seção 5.3, vamos aprofundar a discussão e investigar a possibilidade de a boca servir como articulador, formando sinais independentes e participando de construções simultâneas com um componente manual.

Através do quadro abaixo, formulado com base nos sinais coletados em contexto natural e apresentados no capítulo 2, é possível observar as possibilidades de realizações de compostos simultâneos:

\begin{tabular}{|c|c|c|}
\hline & i) sequenciais & ii) simultâneas \\
\hline Sinal simples & $\begin{array}{l}\text { CARNE^VENDER "açougue" } \\
\text { SABER^ESTUDAR "acreditar" }\end{array}$ & --- \\
\hline $\begin{array}{l}\text { Sinal simples } \\
\text { e Sinal CL } \\
\text { (semântico ou } \\
\text { traço) }\end{array}$ & 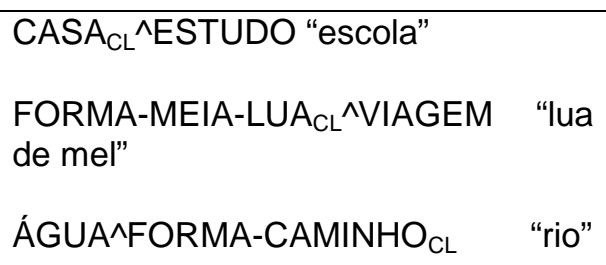 & +-- \\
\hline $\begin{array}{l}\text { Sinal CL } \\
\text { (semântico) }\end{array}$ & $\begin{array}{l}\mathrm{BICO}_{\mathrm{CL}}{ }^{\wedge} \mathrm{ASA}_{\mathrm{CL}} \text { "pássaro" } \\
\mathrm{CASA}_{\mathrm{CL}}{ }^{\wedge} \mathrm{CRUZ} \mathrm{Z}_{\mathrm{CL}} \text { (1) "igreja" }\end{array}$ & --- \\
\hline $\begin{array}{l}\text { Sinal CL com } \\
\text { verbo } \\
\text { (predicados } \\
\text { CLs) e outros } \\
\text { sinais CLs } \\
\text { (qualquer) }\end{array}$ & --- & $\begin{array}{l}\text { CARRO1 } 1_{\mathrm{CL}-\mathrm{BATER}}(\mathrm{M})|| \mathrm{ENTIDADE}- \\
\text { RETA1 } 1_{\mathrm{CL}} \text { "acidente (de carro)" } \\
\text { CARRO2 } \\
\text { PLA-BATER(M)||ENTIDADE- } \\
\text { PLANA }{ }_{\mathrm{CL}} \text { "acidente (de carro)" }\end{array}$ \\
\hline $\begin{array}{l}\text { Sinal CL com } \\
\text { base e outros } \\
\text { sinais CLs } \\
\text { (qualquer) }\end{array}$ & --- & $\begin{array}{l}\text { ENTIDADE-RETA3 } \mathrm{CL}^{-} \\
\text {PINTAR(M)||ENTIDADE-PLANA1 }{ }_{\mathrm{CL}} \\
\text { "desenhar" }\end{array}$ \\
\hline $\begin{array}{l}\text { Três ou mais } \\
\text { sinais } \\
\text { Sinais }\end{array}$ & $\begin{array}{l}\text { LUGAR^LOJA^PAPEL^VÁRIOS } \\
\text { (1)“papelaria” }\end{array}$ & --- \\
\hline
\end{tabular}




\begin{tabular}{|c|c|c|}
\hline $\begin{array}{ll}\text { simples } & \text { e } \\
\text { Sinais CL } & \end{array}$ & 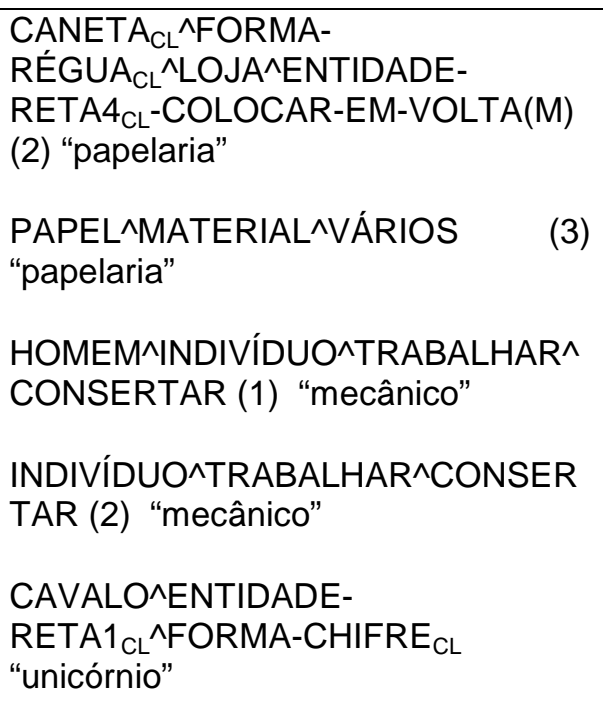 & \\
\hline $\begin{array}{l}\text { Sinal boca e } \\
\text { Sinal simples }\end{array}$ & --- & SEXOb||VIAJAR "lua de mel" \\
\hline $\begin{array}{l}\text { Sinal boca e } \\
\text { Sinal CL }\end{array}$ & --- & $\begin{array}{l}\text { SEXOb||CAMA }{ }_{C L}-B A L A N C ̧ A R(M) \\
\text { "relação sexual" }\end{array}$ \\
\hline
\end{tabular}

QUADRO 8: Tipos de compostos sequenciais e simultâneos na libras

Com base nesse quadro ${ }^{111}$ percebemos que, sempre que um composto sequencial é formado, as duas bases que formam esse composto envolvem sinais simples e/ou sinais CLs do tipo semântico ou do tipo SASS de traço. Já quando um composto simultâneo é formado temos sempre um predicado CL (sinal CL com verbo de $M$ ) ou um $C L$ do tipo base (ENTIDADE-PLANA1 $1_{C L}$ ) mais outro $C L$ de qualquer tipo; ou temos um sinal boca com um sinal simples ou com um sinal CL.

Se é assim, vamos assumir que alguns IVs que serão inseridos nos nós terminais na lista 2 são marcados para ocorrer simultaneamente. Essa marcação pode ser expressa da seguinte forma:

(108) Em contexto de composição

a. sinais boca $>$ simultaneamente com qualquer sinal

b. predicados CLs > simultaneamente com outros CLs

c. $\mathrm{CL}$ do tipo base $\left(\right.$ ENTIDADE-PLANA $\left.1_{\mathrm{CL}}\right)>$ simultaneamente com outros CLS

$\overline{111}$ Veja também os Quadros 2, 3 e 4 no capítulo 2 (sinais coletados em CAPOVILLA; RAPHAEL; MAURÍCIO, 2012). 
Se assumirmos que esses IVs são marcados para realização simultânea em contexto de composição, explicamos a derivação dos compostos sequenciais e simultâneos feita através de uma mesma estrutura, apenas diferenciando-se pela realização pós-sintática.

\subsection{Sinais boca na libras: explorando novas possibilidades de simultaneidade}

Sobre ENMs que envolvem a boca, Sutton-Spence e Boyes-Braem (2001) identificam pelo menos dois tipos de padrões de boca nas LSs, um padrão derivado da língua oral, "mouthings", e outro sem relação com a língua oral, formado como parte das LSs, "gestos de boca". Mouthings e gestos de boca ocorrem simultaneamente com sinais manuais.

Através de um estudo empírico, este trabalho propõe que a libras apresenta um terceiro uso das ENMs, ou ainda, um terceiro tipo de padrão de boca, a saber, a boca como articulador, formando sinais independentes, sinais simples. Mais precisamente, são sinais formados por língua, bochecha e lábios, como em (109) SEXOb ${ }^{112}$ ou (110) LADRÃO/ROUBARb.

"Ato sexual"; "Relação sexual (1) (ato sexual)"; "sexo (ato sexual)"
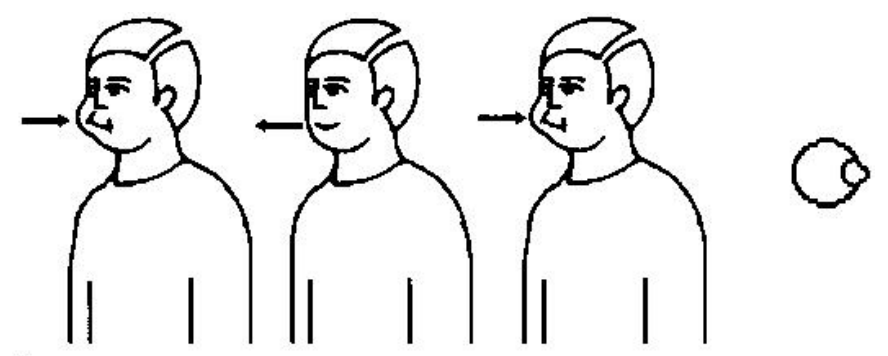

(CAPOVILLA; RAPHAEL, 2001, p.241, 1130 e 1194)

\footnotetext{
112 Lembramos que o "b" ao lado da anotação do sinal indica que o sinal é realizado por movimentos que envolvem "boca", de fato, língua, bochecha e lábios, em contrapartida a sinais realizados manualmente.
} 

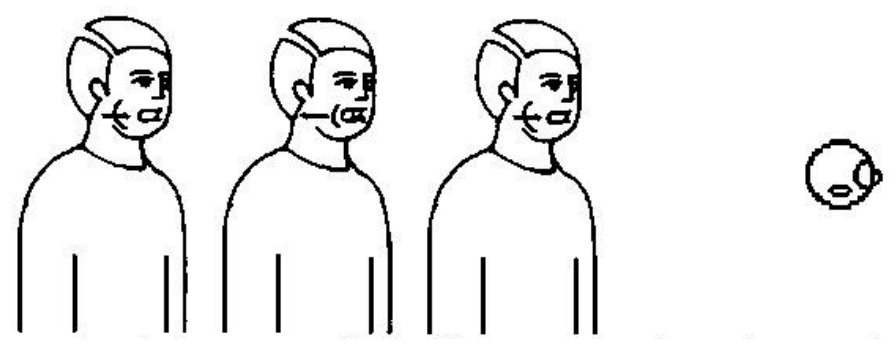

(CAPOVILLA; RAPHAEL, 2001, p.1154)

b. "LADRÃO/ROUBAR"

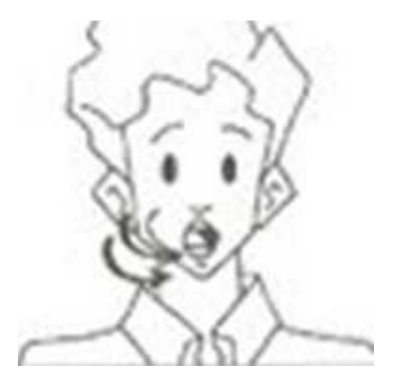

(FELIPE; MONTEIRO, 2006, p.23)

Conforme descrito em Capovilla e Raphael (2001, p.1194), para a realização do sinal em (110)a é necessário "distender a bochecha direita com a ponta da língua, várias vezes". Esse sinal também pode ser realizado inflando-se a bochecha duas ou mais vezes.

Como esses sinais funcionam como sinais simples, ocorrem livremente, nós os chamamos de "sinais boca". Com base na sinalização coletada e conversando com nossos colaboradores, observamos que esses sinais eram mais comumente formados por um sinal realizado pelas mãos e a ENM acompanhava, opcionalmente, a sinalização, como em (111) e (112), realizados sem a ENM: 
(111) "Relação sexual (2) (no contexto de educação sexual)"
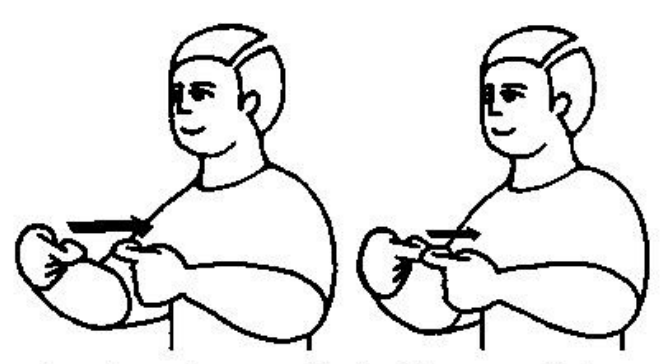

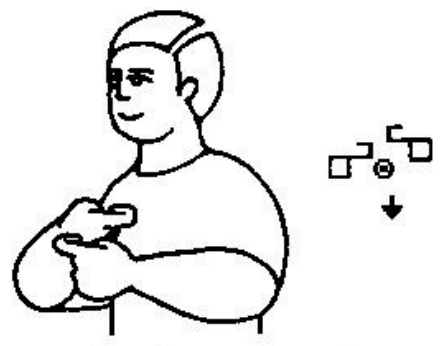

(CAPOVILLA; RAPHAEL, 2001, p.1130)

(112)

"Ladrão (ladra)"; "Roubar (1)"
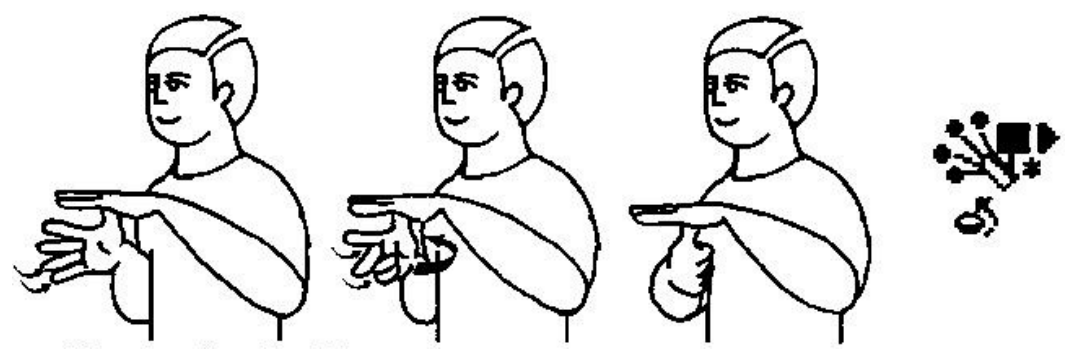

(CAPOVILLA; RAPHAEL, 2001, p.796 e 1153)

Observamos que, hoje em dia, as duas formas coexistem. Com o passar do tempo, cada vez mais o sinal não manual, o sinal boca, vem sendo usado, seja por razões pragmáticas, em contextos em que se quer falar disfarçadamente sobre alguém, ou por razão de maior produtividade morfológica.

Na seção 5.3.1, apontaremos as diferenças entre sinais boca e outras ENMs; na seção 5.3.2, descreveremos e analisaremos dados que mostram a produtividade de sinais boca na formação de compostos simultâneos.

\subsubsection{Padrões de boca: mouthings, morfemas boca e sinais boca}

Boyes-Braem \& Sutton-Spence (2001) assumem que há dois padrões de boca nas LSs: mouthings (ou "visemas", seguindo DEMARTINO, 2005; e MCCLEARY; VIOTTI; LEITE, 2010); e "gestos de boca" (ou "morfemas boca", como 
usamos aqui, seguindo BICKFORD; FRAYCHINEAUD, 2008). As primeiras são palavras emprestadas ou derivadas da língua falada que podem ser pronunciadas parcial ou totalmente, a boca pode reproduzir articulação da língua oral junto com a sinalização; os últimos são formados internamente, nas comunidades sinalizantes, ou seja, não possuem relação com o movimento de boca das LOs (BOYES-BRAEM; SUTTON-SPENCE, 2001).

Pêgo (2013) traz uma descrição inicial dos morfemas boca na libras. Seguindo Bickford \& Fraychineaud (2008), ela assume que, nesses morfemas, a boca é "utilizada como um morfema independente passível de combinações com sinais manuais" e traz os seguintes exemplos nos quais o morfema boca contribui com um significado adverbial na libras:

a. "escrever corretamente" - LÁBIOS APERTADOS + SOBRANCELHAS FRANZIDAS + SINAL ESCREVER

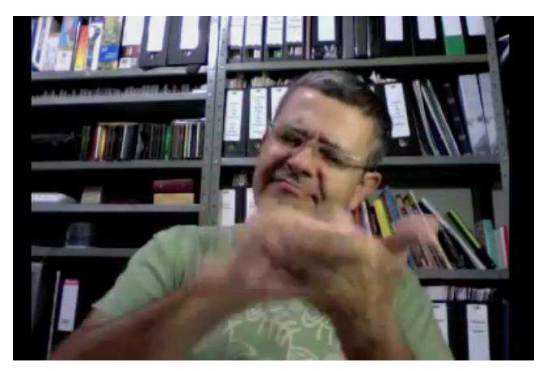

b. "escrever desleixadamente" - LÍNGUA EM "th" + SOBRANCELHA NEUTRA + SINAL ESCREVER

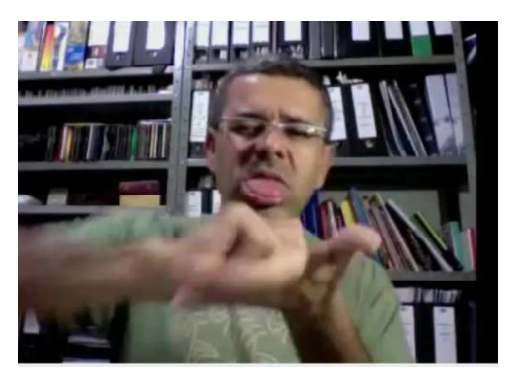

(PÊGO, 2013, p.69)

Bickford \& Fraychineaud (2008) mostram que esse tipo de morfema boca na ASL também leva à mudança do movimento manual no que concerne ao ritmo e ao 
caminho do movimento, como em "desleixadamente" em (113)b. Segundo os autores, esse tipo de mudança no $M$ não tem caráter morfêmico, mas acompanha 0 morfema boca. Eles também ressaltam que há morfemas boca com significados diferentes, como tamanho, quantidade, distância e relativização.

Sobre os visemas na libras, Pêgo (2013) exemplifica com os sinais:

a. COMO?

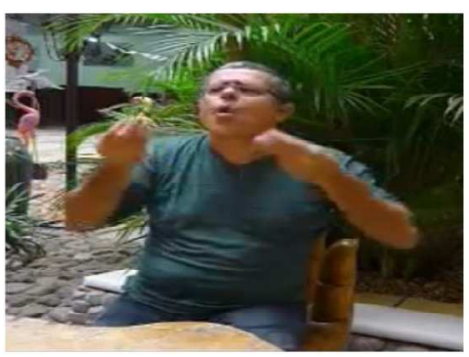

(PÊGO, 2013, p.79)

b. SURDO

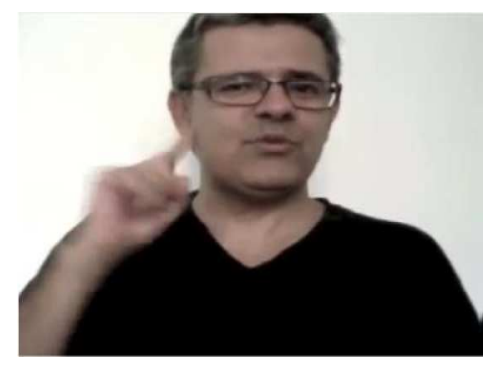

(PÊGO, 2013, p.80)

Nesses sinais, a boca reproduz a articulação de parte da palavra da língua portuguesa simultaneamente com a realização do sinal manual.

No capítulo 4, vimos que há recorrência do uso de mouthings em pares nome-verbo, visemas, na contraparte nominal, como AVIÃO, e de morfemas boca na contraparte verbal, IR-DE-AVIÃO. Tanto os mouthings quanto os morfemas bocas que investigamos são realizados simultaneamente com um sinal manual. Sendo assim, assumimos que o morfema boca não é um sinal porque não pode ser realizado sozinho, sem o sinal manual, mas tem um valor adverbial, de forma que, opcionalmente, se anexa a verbos, o que apontamos como mais uma pista para a 
identificação da categoria gramatical de alguns elementos em pares nome-verbo: mouthings e morfemas bocas identificam nomes e verbos, respectivamente.

Resumidamente, apesar de, na maioria dos sinais, os articuladores primários serem, de fato, as mãos, há também alguns poucos sinais realizados apenas com uma ENM boca, mais especificamente, pelos lábios, bochecha e língua, como vimos em (109) e (110) acima. Bem como os morfemas boca, esses sinais envolvem a boca como seu articulador primário, mas diferentemente daqueles, os sinais boca não têm apenas um valor morfêmico, mas figuram como formas livres, ou seja, são como sinais simples, como vemos em:

\title{
a. SALA COMPUTADOR LIVRO ELE ROUBAR
}

"Ele roubou o computador e o livro que estavam na sala"
3ps-olho
b. SALA COMPUTADOR LIVRO
ROUBAR

"Ele roubou o computador e o livro que estavam na sala"

3ps-olho

c. SALA COMPUTADOR LIVRO ROUBARb

"Ele roubou o computador e o livro que estavam na sala"

\section{d. DIRETOR SEXO ELA}

"O diretor tem/teve uma relação sexual com ela"

3ps-olho

\section{e. DIRETOR SEXO}

"Ela tem/teve uma relação sexual com o diretor"

\author{
3ps-olho \\ f. DIRETOR SEXOb \\ "Ela tem/teve uma relação sexual com o diretor"
}


Em (115)a/b/d/e, ROUBAR e SEXO são realizados como sinais manuais. As formas em a/d são diretas e formais, enquanto que as formas b/e com o pronome marcado pela direcionalidade do olhar são menos diretas e ainda formais, pelo uso do sinal manual. Já nos dados em (115)c/f, ROUBAR e SEXO são realizados pelo sinal boca e são contextos menos formais ou, pelo menos, de comunicação mais discreta. Nesses contextos o pronome também poderia ter sido sinalizado pelo sinal manual com a $L$ na palma da mão, para sinalizar mais discretamente.

É interessante notar que os sinais boca podem ser realizados com a mesma ordem sintática que um sinal simples e, bem como os sinais simples, permite a sobreposição de marcação de referente por uma ENM, o olhar.

\subsubsection{Compostos simultâneos com sinais boca}

Se sinais boca funcionam como um sinal simples na libras, é também natural pensarmos na possibilidade de ocorrência de sinais simultâneos que envolvam um sinal boca e um sinal manual (ou mais). E, de fato, observamos que os sinais boca são muito usados na libras, seja isoladamente, ou em outras construções, ocorrendo simultaneamente com outros sinais manuais diferentes de seu significado, formando um composto, como em (89), repetido abaixo em (116)a, entre outros exemplos:

a. SEXOb||VIAGEM "lua de mel"

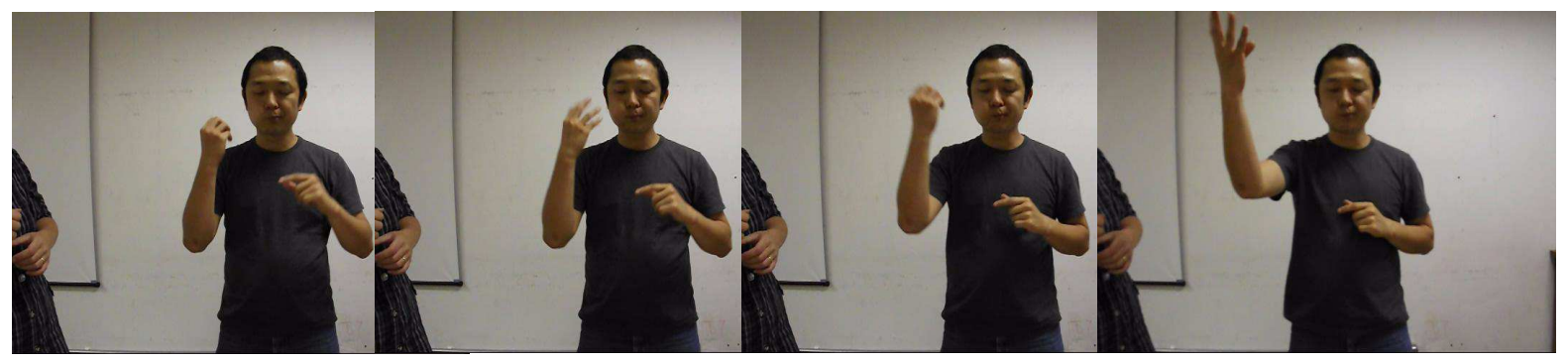

SEXOb||VIAGEMmd 
b. SEXOb||CAMACL-BALANÇAR "sexo (ato sexual intenso)"

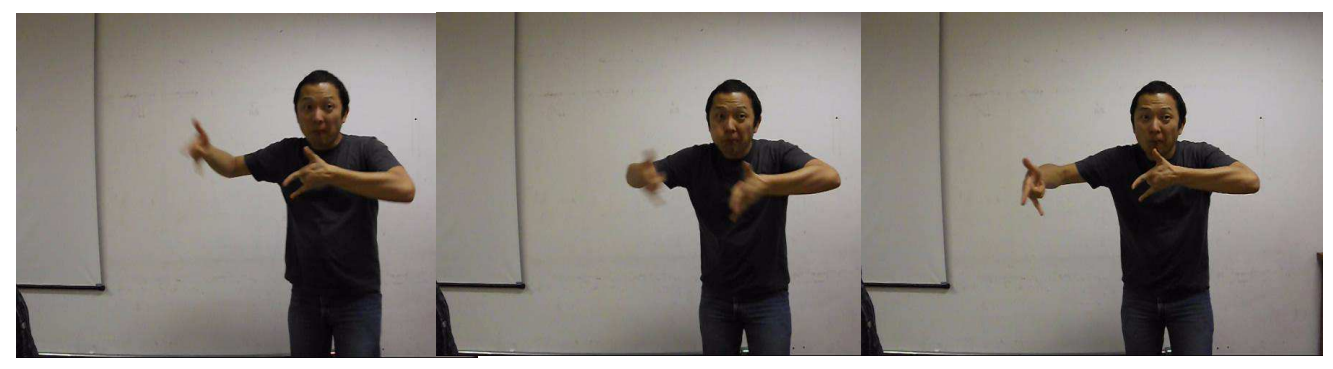

SEXOb\|CAMACLmde-BALANÇAR(M)

c. SEXOb||HOTEL "motel”
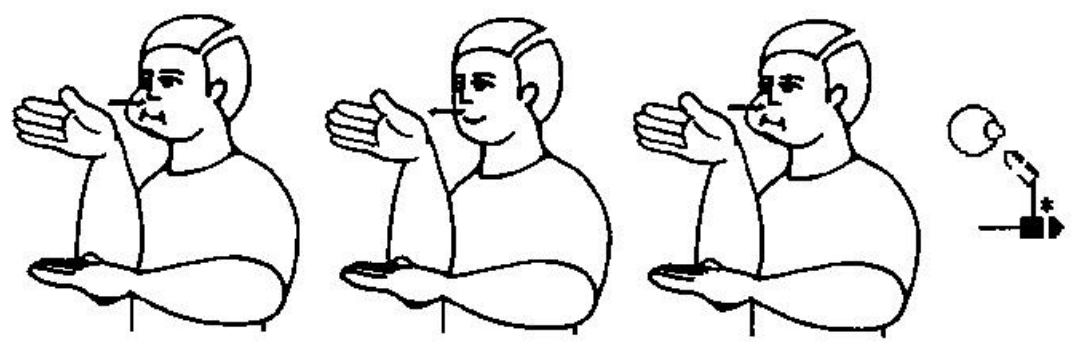

(CAPOVILLA; RAPHAEL, 2001, p.923)

Esses foram os três compostos que encontramos com o sinal boca SEXOb na libras. Além desses sinais, também encontramos: ROUBARb||DISFARÇARmde "roubar escondido" e ROUBARb||TROCARmde "enganar". Propomos a seguinte derivação para esses dados:

(117) SEXOb||VIAGEMmd "lua-de-mel"

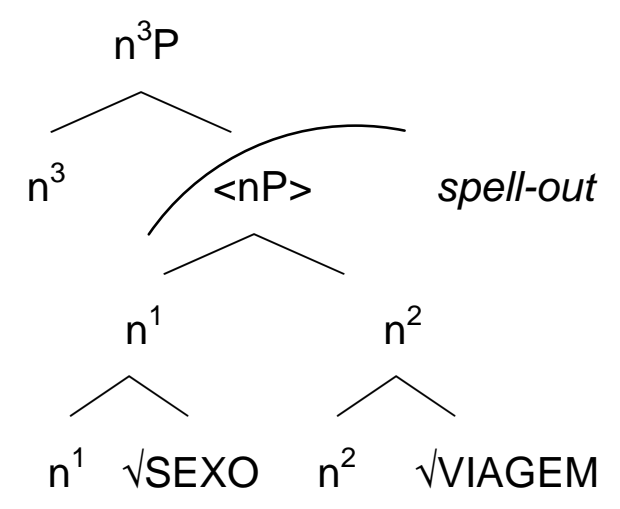




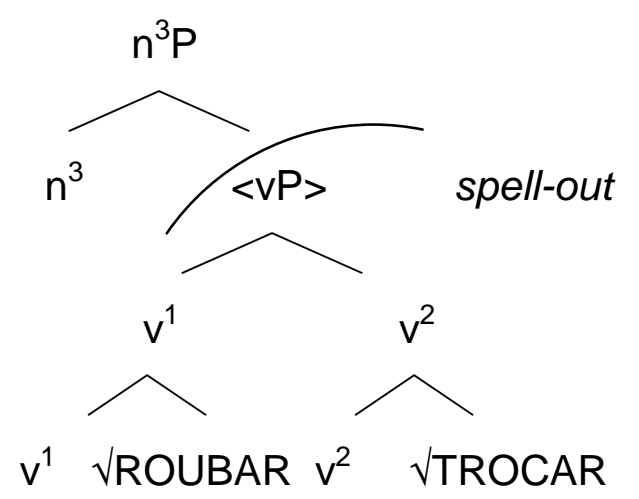

A fase em $\mathrm{nP}$ ou $\mathrm{vP}$, em (117) e (118), respectivamente, explica a possibilidade de realização simultânea do composto, uma vez que os dois nPs ou os dois vPs envolvidos na composição sofrem spell-out em uma mesma fase.

Apesar de a fase facilitar a explicação da simultaneidade nesses compostos, ela não é auto-suficiente para explicar a pronúncia ou realização simultânea. Isso se dá, pois a representação arbórea para a derivação tem natureza linear. Em outras palavras, esse mesmo tipo de estrutura é considerada para compostos sequenciais nas LOs, como no exemplo que vimos em (104), CARNE^VENDER "açougue", (106), FORMA-MEIA-LUA $\mathrm{CL}^{\wedge}{ }^{\mathrm{VIAGEM}}$ "lua de mel", e (107), $\mathrm{CASA}_{\mathrm{CL}}{ }^{\wedge} \mathrm{CRUZ} \mathrm{Z}_{\mathrm{CL}}$ "igreja", acima.

Sendo assim, na seção 5.2 propusemos que os IVs realizados como sinal boca, SEXOb e ROUBARb em (109) e (110), respectivamente, são marcados para serem realizados simultaneamente em compostos.

Essa proposição dá conta de explicar a simultaneidade que sempre ocorre com esses dados em contexto de composição e a sequencialidade dos mesmos em contextos frasais, como vimos em (115) acima.

\subsection{Considerações finais do capítulo}

Sobre os tipos de compostos existentes na libras e sua derivação sintática, mostramos que sinais CLs participam na formação de compostos, bem como sinais 
boca e sinais simples. Nossa proposta corrobora a idéia de que os compostos em qualquer língua devem ter uma mesma estrutura subjacente, uma vez que fazem parte de um mesmo fenômeno e partilham as mesmas características. Mostramos que mesmo os sinais que sofrem uma influência de modalidade, os compostos simultâneos, partilham das mesmas características mais intrínsicas e da mesma estrutura que compostos sequenciais. Para tanto, argumentamos que o efeito de modalidade se dá apenas na externalização da língua, ou seja, deve ser tratado póssintaticamente.

Este capítulo trouxe um avanço na descrição e análise da libras, verificando a ocorrência de dados formados com o que chamamos de sinais boca, sinais CLs e sinais simples. Pelas características verificadas no capítulo 4, tratamos essas formações como compostos nessa língua e indicamos um caminho de análise para esses dados usando um modelo já bastante utilizado para análises de LOs, o modelo teórico da MD (HALLE; MARANTZ, 1993). Isso corrobora com a idéia de haver um mesmo mecanismo subjacente para derivação da linguagem, e ressalta que a atuação desse mecanismo independende dos efeitos superficiais da modalidade, ou seja, explica tanto a formação de compostos sequenciais, em LOs (Cf. HARLEY, 2009; NÓBREGA, 2014) e em LSs, bem como a formação de compostos simultâneos nas LSs, como os sinais sequenciais e simultâneos observados nesta pesaquisa. 


\section{Considerações finais}

Esta pesquisa investigou a estrutura morfológica da libras descrevendo e analisando os elementos que participam na composição de novos sinais (sinais simples, sinais CLs e sinais boca) e explorou as possibilidades de formação de compostos nessa língua, seja sequencialmente ou simultaneamente.

Os objetivos principais desta pesquisa foram descrever e analisar os compostos da libras. Para tanto, verificamos como se formam construções com CLs nessa língua e como elas são derivadas e participam da formação de compostos. Nossas questões centrais giraram em torno da categorização de sinais, formação de sinais com CLs e com sinais boca, com o intuito de identificarmos o processo de composição na libras.

Identificamos os CLs como morfemas categorizadores. Assumimos que todos os sinais com CLs envolvem a concatenação do morfema $C L$ com uma raiz $\checkmark E N T I D A D E$, que é uma raiz bastante genérica. Assumindo que o morfema $C L$ é um categorizador, ele influencia na composição semântica e no spell-out da raiz, formando um sinal CL.

Este trabalho lança luz sobre um fenômeno pouquíssimo explorado nas LSs, nomeadamente, a formação de compostos simultâneos com sinais CLs e com sinais boca. Vale ressaltar que os compostos simultâneos com sinais boca constituem um forte argumento para se sustentar a existência de compostos simultâneos na libras. Em outras palavras, linguistas que analisam CLs como gestos, predicados classificadores ou algum outro tipo de construção, tendem a afirmar que não há compostos simultâneos nas LSs. Mesmo para eles, os dados com sinais boca poderão ser admitidos como compostos simultâneos verdadeiros.

Encerramos concluindo que:

i) Os compostos sequenciais e simultâneos são bastante produtivos na libras;

ii) CLs são morfemas categorizadores; 
iii) Sinais boca são como sinais simples, mas apresentam uma distribuição interessante, no sentido que ocorrem, necessariamente, de maneira simultânea na composição e sequencial em frases;

iv) Predicados CLs formam compostos, necessariamente simultâneos, quando realizados com outro $\mathrm{CL}$;

v) CLs do tipo base (ENTIDADE-PLANA1 $\mathrm{CL}$ ) formam compostos, necessariamente simultâneos, quando realizados com outro CL;

vi) A simultaneidade observada em nossos dados é apenas superficial, uma vez que a sequencialidade e a simultaneidade são tratadas póssintaticamente, ou seja, não interferem na formação sintática.

Em um primeiro olhar, seria comum se pensar que apenas um modelo nãoconcatenativo daria conta de explicar a formação de tais estruturas. No entanto, apresentamos uma proposta de explicação para a formação de tais estruturas dentro de um modelo de morfologia concatenativa, o modelo da MD.

Nomeadamente, os avanços apresentados vêm argumentar sobre a simultaneidade e a sequencialidade nas LSs evidenciando que o que muitas vezes é chamado de não-concatenativo é, na verdade, apenas um dos desdobramentos da derivação quando se tem em jogo uma língua com a possibilidade de três articuladores primários potenciais, cada uma das mãos e a boca (ou o conjunto dos elementos faciais que envolvem boca, língua e bochecha). 


\section{Referências}

AIKHENVALD, Alexandra A. Classifiers: A Typology of Noun Categorization Devices. Oxford: Oxford University Press. 2000. 535 p.

ARONOFF, Mark; MEIR, Irit; PADDEN, Carol; SANDLER, Wendy. Morphological universals and the sign language type. In: BOOIJ, Geert E., VAN MARLE, Jaap (Eds.). The Yearbook of Morphology 2004. Springer. Printed in the Netherlands, 2005, p. 19-39.

ARONOFF, Mark; MEIR, Irit; PADDEN, Carol; SANDLER, Wendy. Classifier constructions and morphology in two sign languages. In: EMMOREY, Karen (Ed.). Perspectives on classifier constructions in sign languages. Mahwah, NJ: Lawrence Erlbaum, 2003, p. 53-84.

BAKER-SHENK, Charlotte; COKELY, Dennis. American Sign Language: a teacher's resource text on grammar and culture. Silver Spring, MD: T.J. Publishers, 1980.

BAKER-SHENK, Charlotte. A microanalysis of the nonmanual components of questions in American sign language. 357f. Tese (Doutorado em linguística). Universidade da Califórnia, Berkeley. 1983.

BARBOSA, Felipe Venâncio; COUTO, Maria Inês Vieira; LICHTIG, Ida; TRETTEL, Marina ; SLOMSKI, Vilma; AKYAMA, Renata. Proposta para Aquisição e Desenvolvimento da Língua de Sinais por Crianças Surdas. Arqueiro, Rio de Janeiro, v. 8, n. Jun-Dez, p. 16-20, 2003.

BARBOSA, Thais Bolgueroni. Uma descrição do processo de referenciação em narrativas contadas em língua de sinais brasileira (libras). 2013. Dissertação (Mestrado em Semiótica e Linguistica Geral) - Faculdade de Filosofia, letras e Ciências Humanas, Universidade de São Paulo, São Paulo, 2013. Disponível em: <http://www.teses.usp.br/teses/disponiveis/8/8139/tde-06052013-112529/pt-br.php>. Acesso em: 2014-11-06.

BATTISON, Robin. Analyzing signs. In: Lexical borrowing in American Sign Language. (2001c). Silver Spring, MD: Linstok Press, 1978, p.19-58.

Phonological deletion in American Sign Language. Sign Language Studies, v.5, 1974, p.1-19. 
BATTISON, Robbin; MARKOWICZ, Harry; WOODWARD, James. A good rule of thumb: Variable phonology in American Sign Language. In: FASOLD, Ralph W.; SHUY, Roger. W. (Eds.). Analyzing variation in language. Washington, D.C.: Georgetown University Press, 1975. p. 291-302.

BAUER, Laurie. When is a sequence of two nouns a compound in English? English Language and Linguistics, v. 2, 1998, p- 65-86.

BELLUGI, Ursula; NEWKIRK, Don. Formal Devices for Creating New Signs in American Sign Language. Sign Language Studies, v. 30, Spring 1981, p. 1-35.

BERNARDINO, Elidéa Lúcia Almeida. The acquisition of classifiers in Verbs of Motion and Verbs of Location in Brazilian Sign Language. Tese de Doutorado em Linguística Aplicada. Graduate School of Arts and Science. Boston: Boston University, 2006.

O uso de classificadores na língua de sinais brasileira. ReVEL, v. 10, n. 19, 2012, p. 250-280.

BICKFORD, J. Albert. Using ELAN: A getting-started guide for use with sign languages. Paper presented at the Summer Institute of Linguistics, University of North Dakota, Grand Forks. October 19, 2005. Disponível em: http://artssciences.und.edu/summer-institute-of-linguistics/teaching-

linguistics/ files/docs/using-elan.pdf. Acesso em: 30-09-2013.

BICKFORD, J. Albert; FRAYCHINEAUD, Kathy. Mouth morphemes in ASL: A closer look. In: QUADROS, Ronice Muller de. (Ed.). Sign Languages: spinning and unraveling the past, present and future. TISLR9, forty five papers and three posters from the 9th. Theoretical Issues in Sign Language Research Conference. Florianópolis, Brasil, Dezembro, 2006. Editora Arara Azul. Petrópolis/RJ. Brazil, 2008, p. 32-47.

BISETTO, Antonietta; SCALISE, Sergio. The classification of compounds. Lingue e Linguaggio, vol. 4, ed. 2, 2005, p. 319-32. Disponível em: http://morbocomp.sslmit.unibo.it/download/classification of compounds.pdf. Acesso em: 20-07-2013.

BOOIJ, Geert E. The Grammar of Words. An Introduction to Morphology, 2nd edition. Oxford, U.K.: Oxford University Press, 2007. 
BOYES BRAEM, Penny; SUTTON-SPENCE, Rachel (Eds.). The Hands are the Head of the Mouth. The Mouth as Articulator in Sign Languages. Hamburg, Signum Press, 2001.

BRASIL. Lei no 10.436, de 24 de abril de 2002. Dispõe sobre a Língua Brasileira de Sinais - Libras e dá outras providências. Diário Oficial da União. Brasília, Destrito Federal, de 25/04/2002, p. 23.

BRASIL. Decreto o 5.626, de 22 de dezembro de 2005. Regulamenta a Lei $n^{0}$ 10.436, de 24 de abril de 2002, que dispõe sobre a Língua Brasileira de Sinais Libras, e o art. 18 da Lei $\mathrm{n}^{\circ} 10.098$, de 19 de dezembro de 2000. Diário Oficial da União. Brasília, Destrito Federal, 23/12/2005, p. 28.

BRASIL. Decreto no 52.785, de 10 de novembro de 2011. Cria as Escolas Municipais de Educação Bilíngue para Surdos - EMEBS na Rede Municipal de Ensino. Diário Oficial da Cidade de São Paulo, 11/11/2011, p. 1.

BRASIL. Portaria no 5.707, de 12 de dezembro de 2011. Regulamenta o decreto 52.785 de 10/11/11 que cria as Escolas Municipais de Educação Bilíngue para Surdos - EMEBS na Rede Municipal de Ensino. Diário Oficial da Cidade de São Paulo, 13/12/2011, p. 15.

BRENNAN, Mary. The Visual World of BSL: An Introduction. In: BRIEN, David (Ed.). Dictionary of British Sign Language/English. London: Faber \& Faber, 1992, p. 2-133.

Word-Formation in British Sign Language. Stockholm: Stockholm University Press, 1990.

BRENTARI; COPPOLA; JUNG; GOLDIN-MEADOW. Acquiring word class distinctions.in American Sign Language: Evidence from handshape. Language Learning and Development, vol. 9(2), 2013, p. 130-150.

CAPOVILLA, Fernando César; RAPHAEL, Walkiria Duarte. Dicionário enciclopédico ilustrado trilíngue da Língua de Sinais Brasileira - Libras. v. I e II. São Paulo: Editora da Universidade de São Paulo/ Imprensa Oficial do Estado, 2001.

CAPOVILLA, Fernando César; RAPHAEL, Walkiria Duarte; MAURÍCIO, Aline Lofrese. Dicionário enciclopédico ilustrado trilíngue da Língua de Sinais Brasileira Libras. v. I e II. São Paulo: Editora da Universidade de São Paulo/ Imprensa Oficial do Estado, 2012. 
CARONE, Flávia de Barros. Sintaxe. In: Morfossintaxe. $9^{\circ}$ edição, $4^{a}$ impressão. São Paulo: Ática, 2006.

CHOMSKY, Noam. Derivation by Phase. In: KENSTOWICZ, Michael (Ed.). Ken Hale: A life in language. Cambridge, MA: MIT, 2001, p. 1-52.

COGILL-KOEZ, Dorothea. A model of signed language classifier predicates as templated visual representation. Sign Language \& Linguistics, vol. 3:2, 2000, p. 209236.

CUXAC, Christian; SALLANDRE, Marie-Anne. Iconicity and arbitrariness in French sign language - highly iconic structures, degenerated iconicity and diagrammatic iconicity. In PIZZUTO, Elena; PIETRANDREA, Paola; SIMONE, Raffaele (Eds.). Verbal and signed languages: comparing structures, constructs and methodologies Mouton de Gruyter. Berlin - New York, 2007, p.13-33.

DEDINO, Magaly de Lourdes Serpa Monteiro. Incorporação de numeral na libras. In: ALBRES, Neiva de Aquino; XAVIER, André Nogueira (Orgs.). Libras em estudo: descrição e análise. São Paulo: FENEIS, 2012, p. 123-139.

DEMARTINO, José Mario. Animação facial sincronizada com a fala: visemas dependentes do contexto fonético para o português do Brasil. 2005. Tese (Doutorado em Engenharia de Computação) - Faculdade de Engenharia Elétrica e de Computação, Universidade de Campinas, São Paulo, 2005. Disponível em: http://www.dca.fee.unicamp.br/ martino/DeMartino,JoseM_D.pdf. Acesso em: 201404-06.

DONALIES, Elke. Grammatik des Deutschen im europäishen Vergleich: Kombinatorische Begriffsbildung - Vol. 1: Substantivkomposition. Mannhein: Institut für deutsche Sprache, 2004.

EMBICK, David. Localism versus Globalism in Morphology and Phonology. Cambridge: MIT Press, 2010.

EMMOREY, Karen (Ed.). Perspectives on classifier constructions in sign languages. Mahwah, NJ: Lawrence Erlbaum, 2003.

FELIPE, Tanya Amara. Os processos de formação de palavras na LIBRAS. ETD Educação Temática Digital, Campinas, v. 7, n. 2, p. 200-217, jun. 2006. 
A relação sintático-semântica dos verbos na Língua Brasileira de Sinais (LIBRAS). Tese (Doutorado) - Universidade Federal do Rio de Janeiro, Rio de Janeiro. v. I e II, 1998.

FERREIRA BRITO, Lucinda; LANGEVIN, R. Sistema Ferreira Brito-Langevin de Transcrição de Sinais. In: FERREIRA BRITO, L. Por uma gramática de Línguas de Sinais. Rio de Janeiro: Babel, 1995.

FERREIRA BRITO, Lucinda. Similarities and differences in two Brazilian Sign Languages. Sign Language Studies, 42, Silver Spring: Linstok., p. 45-56, 1984.

- Comparação de Aspectos Linguísticos da LSCB e do português. Conferência apresentada no II Encontro Nacional de Pais e Amigos de Surdos. Porto Alegre. 27 a 29 de novembro de 1986.

FERREIRA-BRITO, Lucinda. Por uma gramática de línguas de sinais. Rio de Janeiro: Tempo brasileiro, 1995, $273 \mathrm{p}$.

FIGUEIREDO SILVA, Maria Cristina; SELL, Fabíola Ferreira Sucupira. Algumas notas sobre os compostos em português brasileiro e em LIBRAS. Comunicação apresentada na Universidade de São Paulo. São Paulo: 2009. Disponibilizado, na forma de artigo, através do link : http://linguistica.fflch.usp.br/sites/linguistica.fflch.usp.br/files/FIGUEIREDOSILVASELL.pdf . Acesso em: 30/06/2015.

FITCH, William Tecumseh. The Evolution of Language. Cambridge: Cambridge University Press, 2010.

FRISHBERG, Nancy. Arbitrariness and Iconicity: Historical Change in American Sign Language. Language, v.51, n.3 (Sep., 1975), p.696-719. Published by: Linguistic Society of America. Disponível em: http://www.jstor.org/stable/412894. Acesso em: 27 de maio de 2013.

FUENTES, Mariana; MASSONE, María Ignacia. Numeral-incorporating roots in numeral systems: a comparative analysis of two sign languages. Sign Language Studies, v.11, n.1, Fall 2010, p.55-75. Disponível em: https://muse.jhu.edu/login?auth=0\&type=summary\&url=/journals/sign_language_stud ies/v011/11.1.fuentes.pdf. Acesso em: 17 de fevereiro de 2013. 
GÖKSEL, Asli. Compounding. Curso ministrado durante o evento Venice Summer School. Organized by the European Cooperation in Science and Technology. Università Ca' Foscari Venezia, 2014.

GRINEVALD, Colette. A morphosyntactic typology of classifiers. In: SENFT, Gunter (Ed.). Systems of Nominal Classification. Cambridge: Cambridge University Press, 2000, p. 50-92.

Nominal classification in Movima. In: Crevels, Mily, KERKE, Simon van de; MEIRA, Sergio; VOORT, Hein van der (Eds.) Current Studies on South American Languages. Leiden: CNWS Publications, 2002, 215-239.

HALLE, Morris; MARANTZ, Alec. Distributed Morphology and the Pieces of Inflection. In: HALE, Kenneth Locke; KEYSER, Samuel Jay (Eds.). The View from Building 20: Essays in Linguistics in Honor of Sylvain Bromberger. Cambridge, Mass.: MIT Press, 1993. p. 111-176.

HARLEY, Heidi. Compounding in Distributed Morphology. In: LIEBER, Rochelle; ŠTEKAUER, Pavol. (Eds.) The Oxford Handbook of Compounding. Oxford: Oxford University Press, 2009, p. 130-144.

HARLEY, Heidi; NOYER, Rolf. State-of-the-article: Distributed Morphology. Glot International, v. 4, n. 4, 1999, p. 3 -9.

HASPELMATH, Martin; SIMS, Andrea D. Understanding Morphology. 2nd ed. London: Hodder Education, 2010.

HELLWIG, Birgit. ELAN - Linguistic Annotatorversion 4.6.0 - last updated on 201305-13. 2013. Disponível em: http://tla.mpi.nl/tools/tla-tools/elan/. Acesso em: 20-062013.

JOHNSTON, Trevor. Nouns and Verbs in Australian Sign Language: an Open and Shut Case? Journal of Deaf Studies and Deaf Education, 6:4, p. 235-257, 2001.

JOHNSTON, Trevor; SCHEMBRI, Adam. On defining lexeme in a signed language. Sign Language and Linguistics, 2(2), p. 115-185. 1999.

JONES, Vanessa L. Numeral incorporation in American Sign Language. M.A. Theses in Linguistics. University of North Dakota, 2013. 
KARNOPP, Lodenir Becker. Aquisição do Parâmetro Configuração de Mão dos Sinais da LIBRAS: Estudo sobre quatro crianças surdas filhas de pais surdos. Dissertação (Mestrado em Linguística). Instituto de Letras e Artes, PUCRS, Porto Alegre, 1994.

KEHDI, Valter. Morfemas do português. Série Princípios. São Paulo: Ática, 2001.

KLIMA, Edward S.; BELLUGI, Ursula. The Signs of Language. Cambridge, MA: Harvard University Press, 1979.

LAZZARINI-CYRINO; João Paulo; ARMELIN, Paula Roberta Gabbai; MINUSSI, Rafael Dias. Sobre o conhecimento enciclopédico de gênero. Cadernos do NEMP, v. 4, 2013, p. 105-117.

LEITE, Tarcisio de Arantes. A segmentação da língua de sinais brasileira (libras): um estudo lingüístico descritivo a partir da conversação espontânea entre surdos. Tese (Doutorado) - Universidade de São Paulo, São Paulo, 2008.

LIEBER, Rochelle; ŠTEKAUER, Pavol. Introduction: Status and Definition of Compounding. In: . (Eds.) The Oxford Handbook of Compounding. Oxford: Oxford University Press, 2009, p. 3-18.

LIDDELL, Scott K. Grammar, gesture and meaning in American Sign Language. Cambridge: Cambridge University Press, 2003. 384p.

. THINK and BELIEVE: sequentiality in American Sign Language. Language, v. 60, n. 2, p. 372-399, 1984.

LIDDELL, Scott. K.; JOHNSON, Robert. 1989. American Sign Language: The Phonological Base. In: VALLI, Clayton; LUCAS, Ceil (orgs.). Linguistics of American Sign Language: an introduction. Washington, D.C.: Clerc Books/Gallaudet University Press. 2001, p. 267-306.

American Sign Language compound formation processes, lexicalization, and phonological remnants. Natural Language and Linguistic Theory, v. 4, n. 8, p. 445-513, 1986.

LIMA, Hildomar José de. Categorias lexicais na língua brasileira de sinais: nomes e verbo. 137f. Dissertação (Mestrado). Faculdade de Letras, Universidade Federal de Goiás. 2012. 
LOOS, Cornelia. Word formation in American sign language: Investigating headedness in ASL compounds. 2009.

LUCAS, Ceil; VALLI, Clayton. Language Contact in the American Deaf Community. New York: Academic Press, 1992.

LYONS, John. Semantics. Volumes 1-2. Cambridge: Cambridge University Press, 1977.

MARANTZ, Alec. No Escape from Syntax: Don't try Morphological Analysis in the privacy of your own Lexicon. In: DIMITRIADIS, Alexis; SIEGEL, Laura; SUREKCLARK, Clarissa; WILLIAMS, Alexander (orgs). Proceedings of the 21st Penn Linguistics Colloquium, v. 4, n. 2, p. 201-225, 1997. .Words and Things. Manuscrito. NYU, 2001.

MARTINS, Antonielle Cantarelli. Lexicografia da língua de sinais brasileira do Rio Grande do Sul. 103f. Dissertação (Mestrado em Psicologia Experimental). Instituto de Psicologia, Universidade de São Paulo, São Paulo, 2012. Disponível em: http://www.teses.usp.br/teses/disponiveis/47/47132/tde-15032013-104524/pt-br.php.

Accesso em: 12-07-2013.

MARVIN, Tajana. Topics in the Stress and Syntax of Words. PhD Thesis, MIT, Cambridge. 2003.

MATHUR, Gaurav; RATHMANN, Christina. Two Types of Nonconcatenative Morphology in Signed Languages. In: Deaf around the World: The Impact of Language. Oxford University Press, 2011, p. .Disponível em: https://files.nyu.edu/ik747/public/morphbeer/mathur-rathmann11.pdf. Acesso em: 0711-2012.

MAURÍCIO, Aline Cristina Lofrese. Morfemas metafóricos na LIBRAS: análise da estrutura morfêmica de 1577 sinais em 34 morfemas moleculares e 14 classes de morfemas molares. Tese (Doutorado em Psicologia). São Paulo: Universidade de São Paulo, 2009.

MCCLEARY, Leland Emerson; VIOTTI, Evani de Carvalho. Transcrição de dados de uma língua sinalizada: Um estudo piloto de transcrição de narrativas na língua de sinais brasileira (LSB). In: LIMA-SALLES, Heloisa Maria Moreira (Org.). Bilinguismo dos surdos: Questões linguísticas e educacionais. Goiânia, GO: Cânone Editorial, 2007, p. 73-96. 
MCCLEARY, Leland Emerson; VIOTTI, Evani de Carvalho; LEITE, Tarcísio. Descrição das línguas sinalizadas: a questão da transcrição dos dados. Alfa, São Paulo, 54, (1), 2010, p. 265-289.

MCWHORTER, John Hamilton. Identifying the creole prototype: Vindicating a typological class. Language, 74, p. 788-818, 1998.

MEIR, Irit. Verb Classifiers as Noun Incorporation in Israeli Sign Language. In: BOOIJ, Geert; VAN MARLE, Jaap (eds). Yearbookof Morphology 1999. Dordrecht:Kluwer Academic Publishers, 2001, p. 299-319.

MEIR, Irit. Word classes and word formation. In: PFAU, Roland; STEINBACH, Markus; WOLL, Bencie. Sign Language: an internacional handbook. DE GRUYTER MOUTON, 2012, p.77-112.

MEIR, Irit; ARONOFF, Mark; SANDLER, Wendy; PADDEN, Carol. Sign language and compounding. In SCALISE, Sergio; VOGEL, Irene (Eds.). Cross-disciplinary issues in compounding. John Benjamins, 2010, p. 301-322.

MENDONÇA, Cleomasina Stuart Sanção Silva. Classificação Nominal em Libras: uma proposta de revisão. In: VII Congresso Internacional da Abralin, 2011, Curitiba. Abralin Curitiba 2011, 2011. p. 870-884.

MINUSSI, Rafael Dias; RODERO-TAKAHIRA, Aline Garcia. Observações sobre os compostos da LIBRAS: a interpretação das categorias gramaticais. Revista LinguíStica / Revista do Programa de Pós-Graduação em Linguística da Universidade Federal do Rio de Janeiro. Volume 9, número 1, junho de 2013, p. 209225. Disponível em: http://www.letras.ufri.br/poslinguistica/revistalinguistica/wpcontent/uploads/2013/06/revista-linguistica-v9-n1-observacoes-sobre-oscompostos.pdf. Acesso em: 10-10-2013.

MOREIRA, Renata Lúcia. Uma Descrição da Dêixis de Pessoa na Língua de Sinais Brasileira (LSB): Pronomes Pessoais e Verbos Indicadores. 138f. Dissertação (Mestrado). Faculdade de Filosofia, Letras e Ciências Humanas, Universidade de São Paulo, São Paulo, 2007. Disponível em: http://www.teses.usp.br/teses/disponiveis/8/8139/tde-13112007-103644/pt-br.php.

Accesso em: 10-05-2013. 
NÓBREGA, Vitor Augusto. Tópicos em composição: estrutura, formação e acento. Dissertação (Mestrado em Letras) - Faculdade de Filosofia, Letras e Ciências Humanas, Universidade de São Paulo. São Paulo, 2014.

PADDEN, Carol. Interaction of Morphology and Syntax in American Sign Language. Outstanding Dissertations in Linguistics, Series IV. New York: Garland Press.1988.

PÊGO, Carolina Ferreira. Sinais não-manuais gramaticais da LSB nos traços morfológicos e lexicais: um estudo do morfema-boca. 2013. 88f. Dissertação (Mestrado em Linguística) - Universidade de Brasília, Brasília, 2013.

PFAU, Roland; QUER, Josep. V-to-Neg raising and negative concord in three sign languages. Rivista di Grammatica Generativa 27, 2002, 73-86.

PIZZIO, Aline Lemos. A Tipologia linguística e a língua de sinais brasileira: elementos que distinguem nomes de verbos. Tese de Doutorado. Universidade Federal de Santa Catarina (UFSC), 2011.

QUADROS, Ronice Müller de. Phrase struture of Brazilian Sign Language. Tese de Doutorado. Pontifícia Universidade Católica do Rio Grande do Sul. 1999.

Alegre. 1997.

Educação de surdos: a aquisição da linguagem. Artes Médicas. Porto As categorias vazias pronominais: uma análise alternativa com base na LIBRAS e reflexos no processo de aquisição. Dissertação de Mestrado. Porto Alegre. 1995.

QUADROS, Ronice Muller de; KARNOPP, Lodenir Becker. Língua de sinais brasileira: estudos linguísticos. Porto Alegre: Artmed, 2004.

RODERO-TAKAHIRA, Aline Garcia. Questões sobre compostos e morfologia da LIBRAS. Estudos Linguísticos, São Paulo, v. 41, n. 1, 2010, p. 262-276.

Incorporação de numeral na libras. Anais da Abralin 2013. (trabalho aceito para publicação). 
; MINUSSI, Rafael Dias. 2013. Compounds in Brazilian Sign Language:

defining Word formation patterns. Proceedings of the Workshop on Formal Linguistics. UFRJ.

SACKS, Oliver. Seeing voices: A journey into the world of the deaf. Berkeley: University of California Press, 1989.

SCALISE, Sergio; BISETTO, Antonietta. The classification of compounds. In: LIEBER, Rochelle; ŠTEKAUER, Pavol (Eds.), The Oxford handbook of compounding 2011. New York: Oxford University Press. p.34-53, 2009.

SCHEMBRI, Adam; Wigglesworth, Gilliam; Johnston, Trevor; Leigh, Greg; Adam, Robert; Baker, Roz. Issues in Development of the Test Battery of Australian Sign Language Morphology and Syntax. Journal of Deaf Studies and Deaf Education, 7(1), 18-40, 2002.

SCHUIT, Joke. The typological classification of sign language morphology. Master's Thesis, Research MA Linguistics, Universiteit van Amsterdam, 2007.

SIDDIQI, Daniel. Syntax within the word: economy, allomorphy, and argument selection in Distributed Morphology. Amsterdam: John Benjamins, 2009.

SILVA, João Paulo da. Demonstrações em uma narrativa sinalizada em libras. 2014. Dissertação (Mestrado em Semiótica e Linguistica Geral) - Faculdade de Filosofia, letras e Ciências Humanas, Universidade de São Paulo, São Paulo, 2014. Disponível em: <http://www.teses.usp.br/teses/disponiveis/8/8139/tde-07052015170319/pt-br.php>. Acesso em: 2015-05-20.

STOKOE, William. Sign language structure: An outline of the visual communication systems of the American Deaf. Studies in Linguistics, Occasional Papers 8. Buffalo: University of Buffalo Press, 1960. Versão reimpressa em: Journal of Deaf Studies and Deaf Education, v.10, n.1, Oxford University Press, 2005. Disponível em http://jdsde.oxfordjournals.org/. Acesso em: 15 de março de 2013.

STOKOE, William C.; CRONEBERG, Carl; CASTERLINE, Dorothy. A dictionary of american sign language on linguistic principles. Washington: Gallaudet College Press, 1965. (Revisto em 1978, Silver Spring, M.D., Linstok Press).

SUPALLA, Ted. 1986. The Classifier System in American Sign Language. In: CRAIG, Colette (Ed.). Noun Classes and Categorization. Amsterdam/Philadelphia: John Benjamins, p.181-214. 
. Morphology of Verbs of Motion and Location in American Sign Language. In: CACAMISE, F; HICKS, D. (Eds). Proceedings of the Second National Symposium of Sign Language Researchand Teaching, 1978. Silver Spring, MD: National Association of the Deaf, 1980, p. 27-45.

Structure and acquisition of verbs of motion and location in American Sign Language. Ph.D. dissertation. University of California. San Diego, 1982.

SUPALLA, Ted; NEWPORT, Elissa. How many seats in a chair? The derivation of nouns and verbs in American sign language. In: SIPLE, Patricia. (Ed.). Understanding language through sign language research. New York, Academic Press, 1978, p. 91-132.

SUTTON-SPENCE, Rachel; WOLL, Bencie. The linguistics of British Sign Language: An Introduction. Cambridge: Cambridge University Press, 1999.

TEMOTEO, Janice Gonçalves. Lexicografia da língua de sinais brasileira do nordeste. 252f. Tese (Doutorado em Psicologia Experimental). Instituto de Psicologia, Universidade de São Paulo, São Paulo, 2012. Disponível em: file://C:/Users/Marcos/Downloads/janice corrigida.pdf. Accesso em: 12-07-2013.

VELOSO, Brenda Silva. Construções classificadoras e verbos de deslocamento, existência e localização na língua de sinais brasileira. 2008. Tese (Doutorado em Linguística) - Instituto de Estudos da Linguagem, Universidade Estadual de Campinas, São Paulo, 2008. Disponível em: $<$ http://www.bibliotecadigital.unicamp.br/document/?code=000436045>. Acesso em: 2014-01-17.

VERCELLOTTI, Mary Lou; MORTENSEN, David R. A classification of compounds in American Sign Language: an evaluation of the Bisetto and Scalise framework. Morphology. V.22, issue: 4, 2012.

VOGHEL, Amélie. 2005. Phonologically identical noun-verb pairs in Quebec Sign Language (LSQ): form and context. Toronto Working Papers in Linguistics 25: 68-75, 2005.

WOODWARD, James; Erting, Carol; Oliver, Susana. Facing and handling variation in American Sign Language phonology. Sign Language Studies, v.10, 1976, p. 43-51.

XAVIER, André Nogueira. Uma ou duas? Eis a questão!: Um estudo do parâmetro número de mãos na produção de sinais da língua brasileira de sinais (LIBRAS). 
Tese (doutorado). Universidade Estadual de Campinas. Instituto de Estudos da Linguagem. Campinas, 2014.

- Variação fonológica na libras: um estudo da alternância no número de articuladores manuais envolvidos na produção dos sinais. In: XVI SETA - Seminários de Teses em Andamento, 2011, Campinas. Anais do SETA (UNICAMP), 2011. v.5. p.119-145.

Descrição fonético-fonológica dos sinais da língua brasileira de sinais (libras). 2006. 175f. Dissertação (Mestrado) - Faculdade de Filosofia e Ciências Humanas, Universidade de São Paulo, São Paulo, 2006.

YIP, Chak-Lam Colum. Complicating the Oversimplification: Chinese Numeral Classifiers and True Measures. In: CHAN, Marjorie K. M; KANG, Hana (Eds.). Proceedings of the 20th North American Conference on Chinese Linguistics (NACCL-20). Columbus, Ohio: The Ohio State University. V.1, 2008, p.285-295.

ZWITSERLOOD, Inge. Classifiers. In: PFAU, Roland; STEINBACH, Markus; WOLL, Bencie. Sign Language: an internacional handbook. De gruyter mouton, 2012, p.158185.

Morphology below the level of the sign: frozen forms and classifier predicates. In: QUER, J. (Ed.). Proceedings of the 8th Conference on Theoretical Issues in Sign Language Research (TISLR), Hamburg: Signum Verlag, 2008, p. 251272.

. Word formation below and above little $\mathrm{x}$ : evidence from Sign Language of the Netherlands. In: DAHL, Anne; BENTZEN, Kristine; SVENONIUS, Peter. (Eds.). Proceedings of the 19th Scandinavian Conference of Linguistics, vol. 31.2 Working papers on language and linguistics, 2003. Nordlyd Tromsø University, p. 488-502.

The Complex Structure of 'Simple' Signs in NGT. In: KOPPEN, Marjo van; THRIFT, Erica; TORRE, Erik Jan van der; ZIMMERMANN, Malte. (Eds.), Proceedings of ConSole IX, 2002, p. 232-46. 
Anexos 
Anexo I: Compostos em Quadros \& Karnopp (2004)

(1) a. ACREDITAR (saber + estudar ${ }^{113}$ )

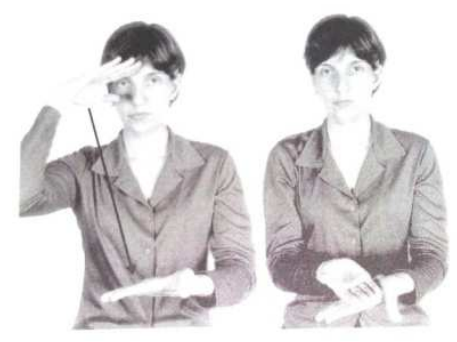

(QUADROS; KARNOPP, 2004, p.103)

b. ESCOLA (casa + estudar)

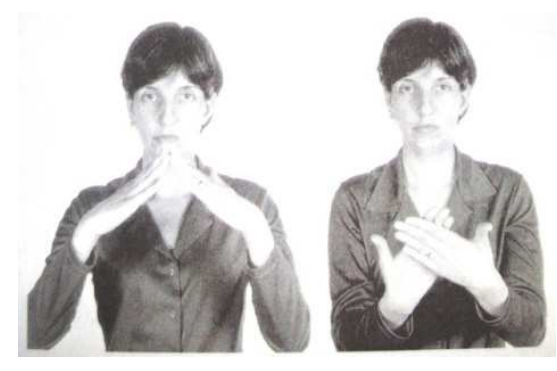

(QUADROS; KARNOPP, 2004, p.103)

c. PAIS (PAI + MÃE)

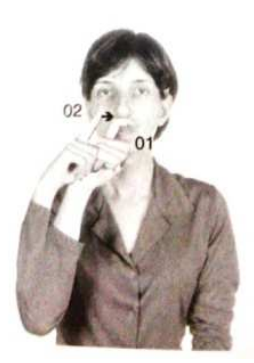

(QUADROS; KARNOPP, 2004, p.104)

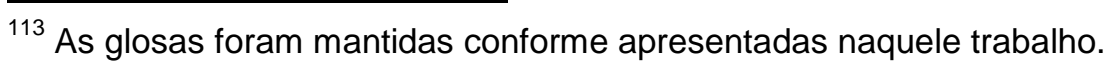


d. BOA-NOITE $(B O A+N O I T E)$
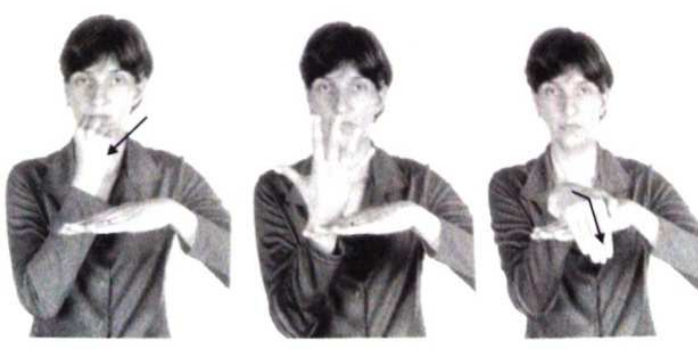

(QUADROS; KARNOPP, 2004, p.105)

e. ACIDENTE (carro + bater)

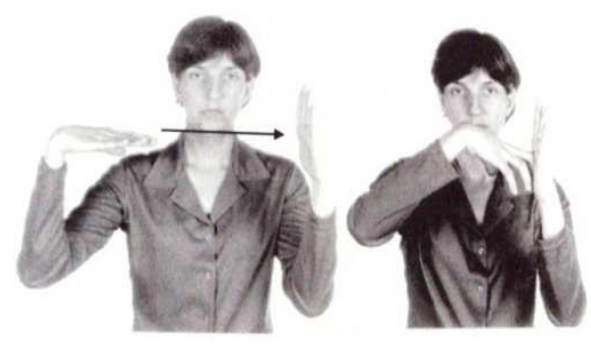

(QUADROS; KARNOPP, 2004, p.105) 
Anexo II: Alfabeto datilológico (CAPOVILLA; RAPHAEL, 2001)
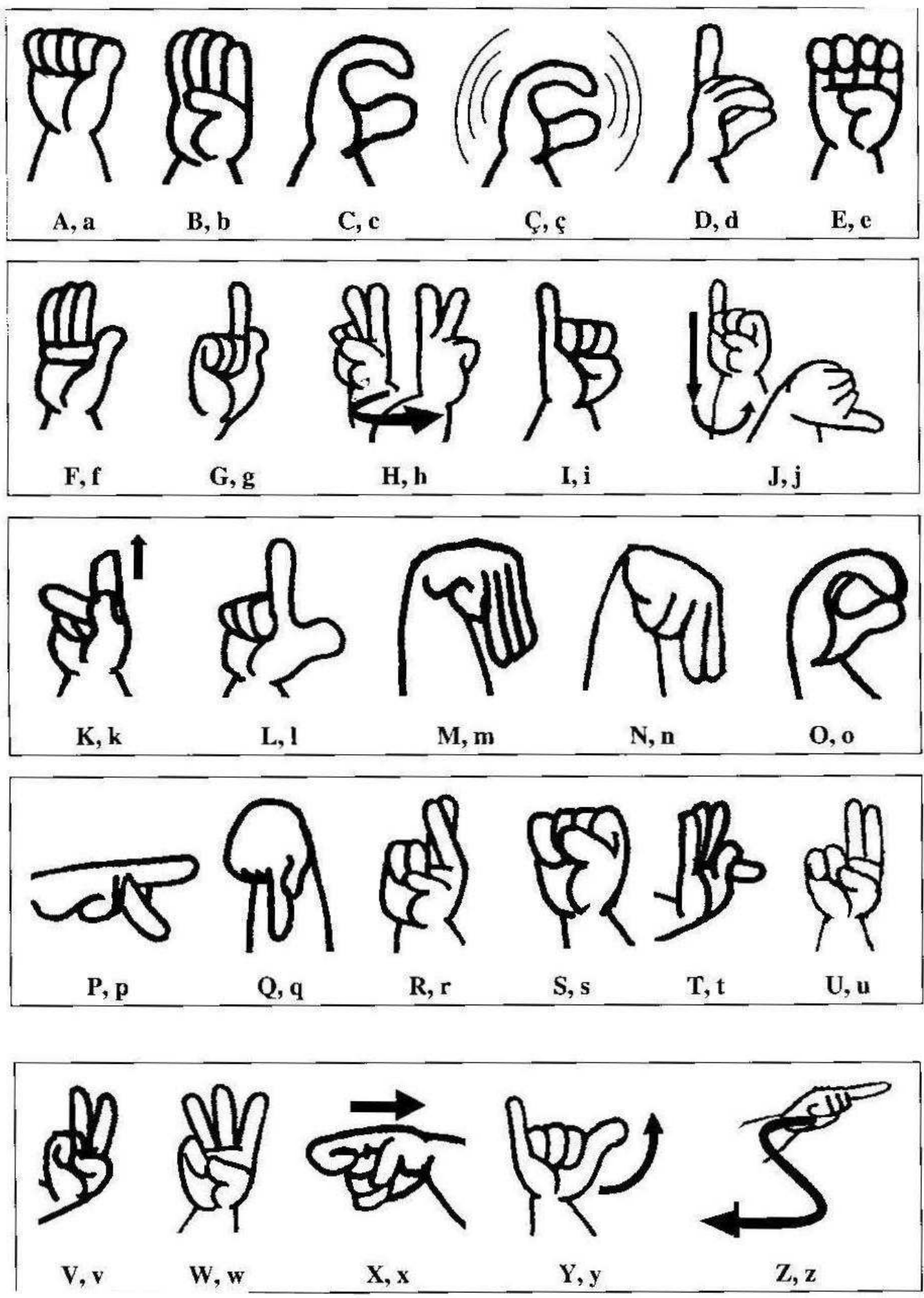

"Alfabeto Manual da Libras usado para soletração digital" (CAPOVILLA; RAPHAEL, 2001, p.51 e 52). 
Anexo III: Numerais (CAPOVILLA; RAPHAEL, 2001)
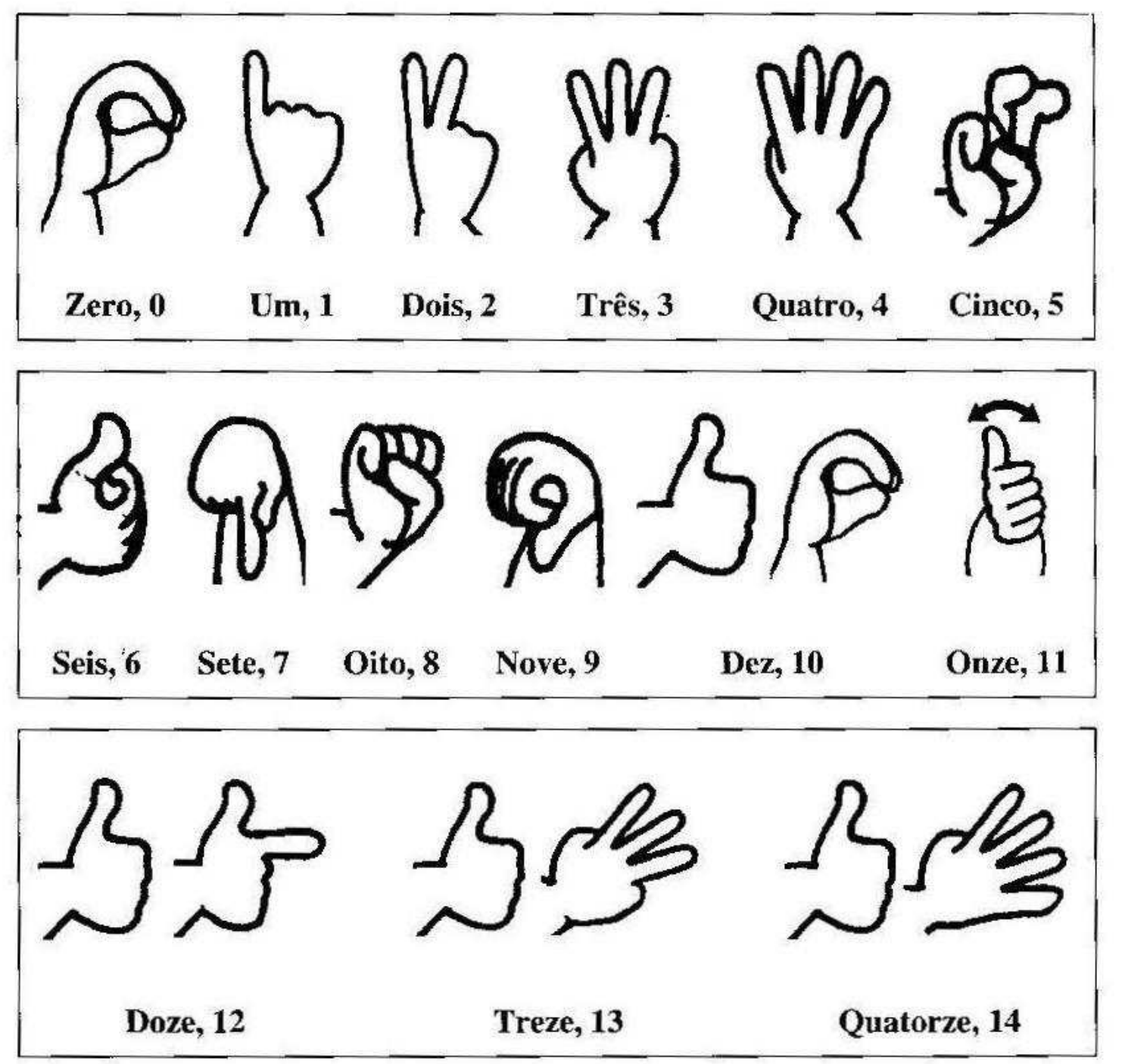

“Números em Libras” (CAPOVILLA; RAPHAEL, 2001, p.52) 

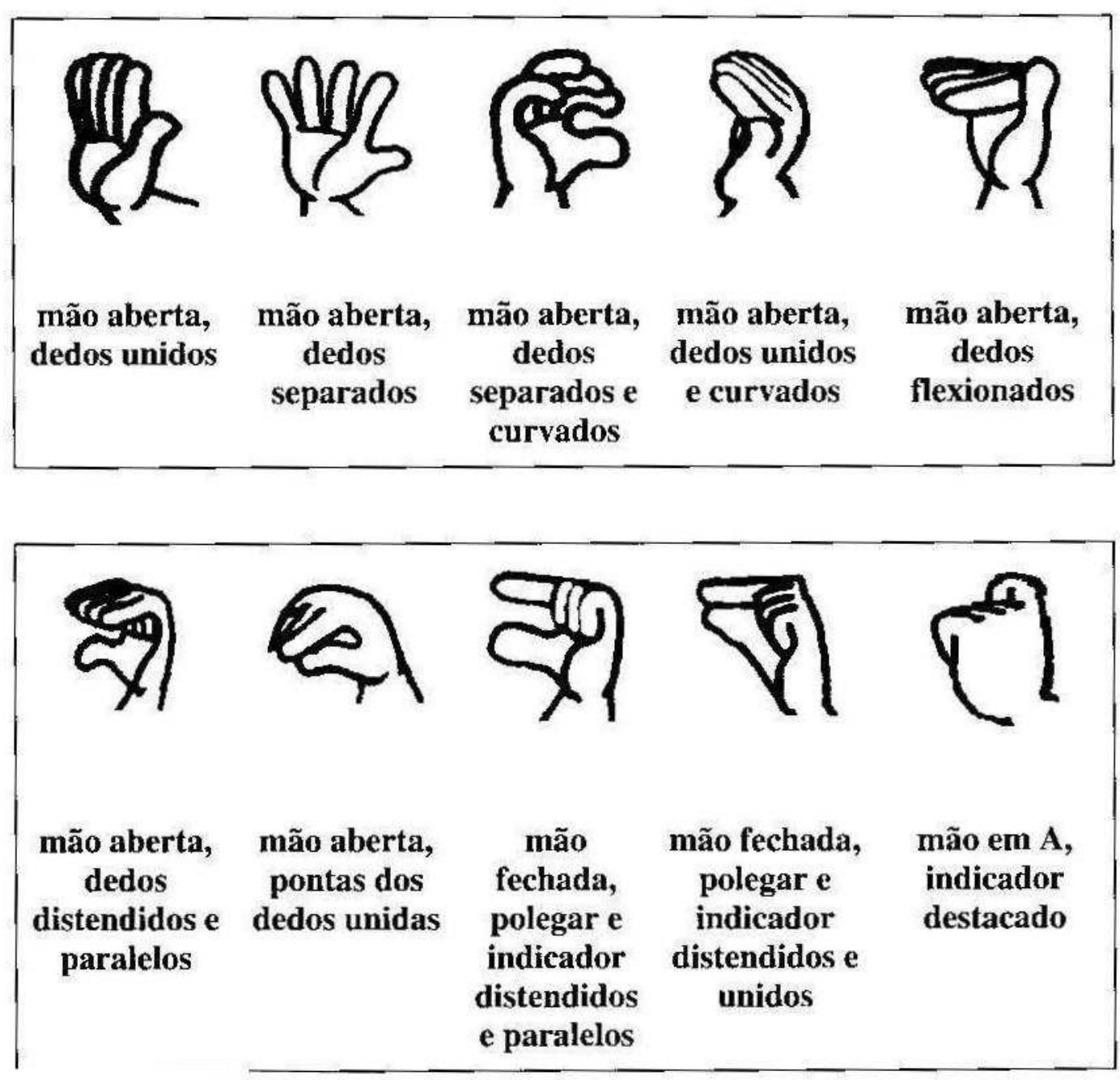

"Formas adicionais de mão usadas em Libras" (CAPOVILLA; RAPHAEL, 2001, p.54) 
Anexo V: ELICIANDO DADOS

Desenhos e fotos usadas para eliciação de dados da pesquisa

Coleta de dados com sinalizante da LIBRAS (1)

09-05-2013

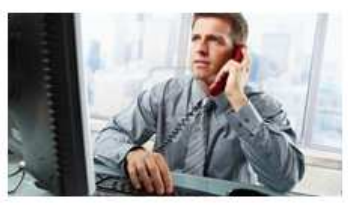

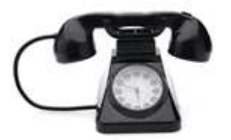

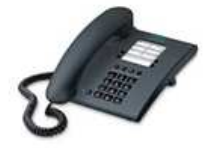

R\$ 69,90

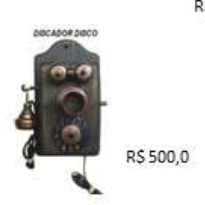

RS 129,00

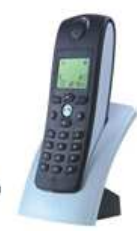

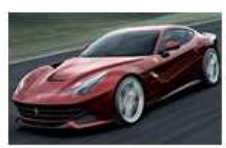
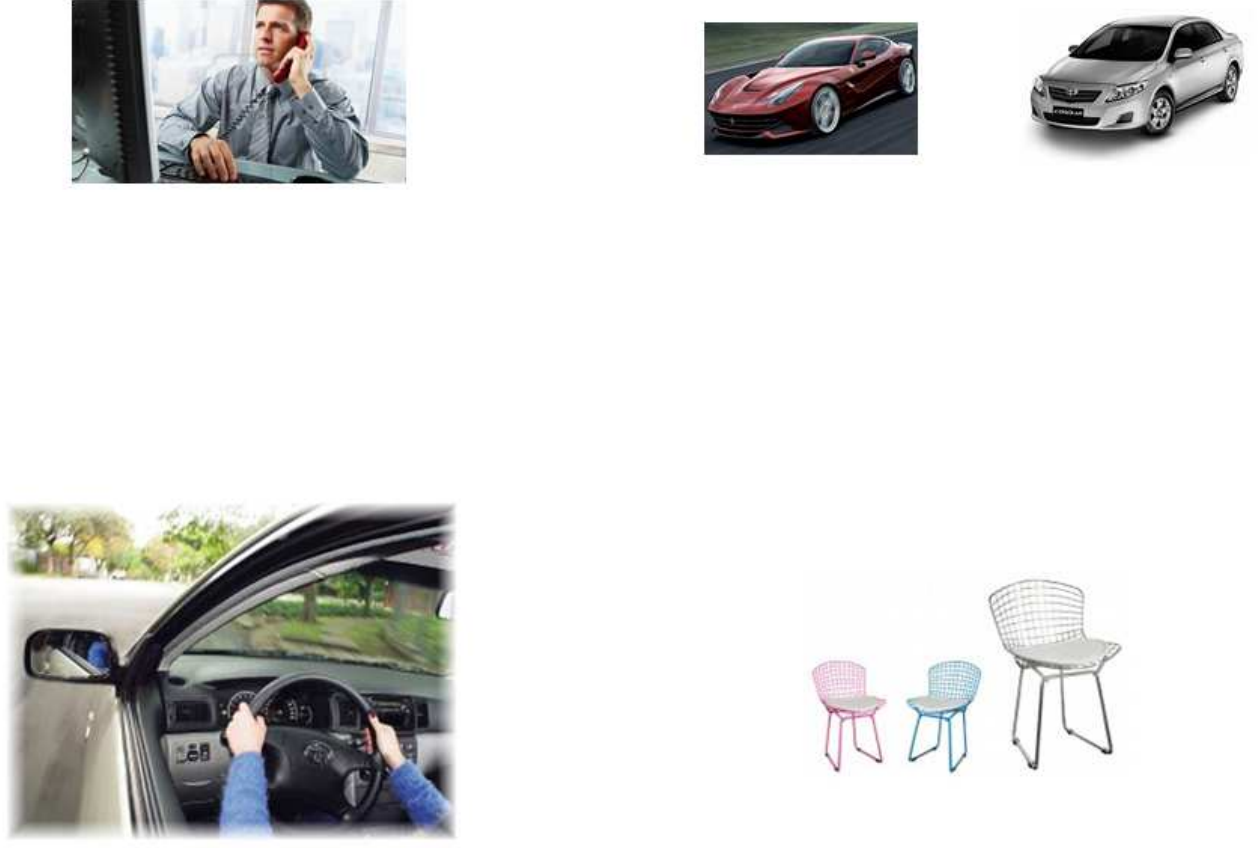

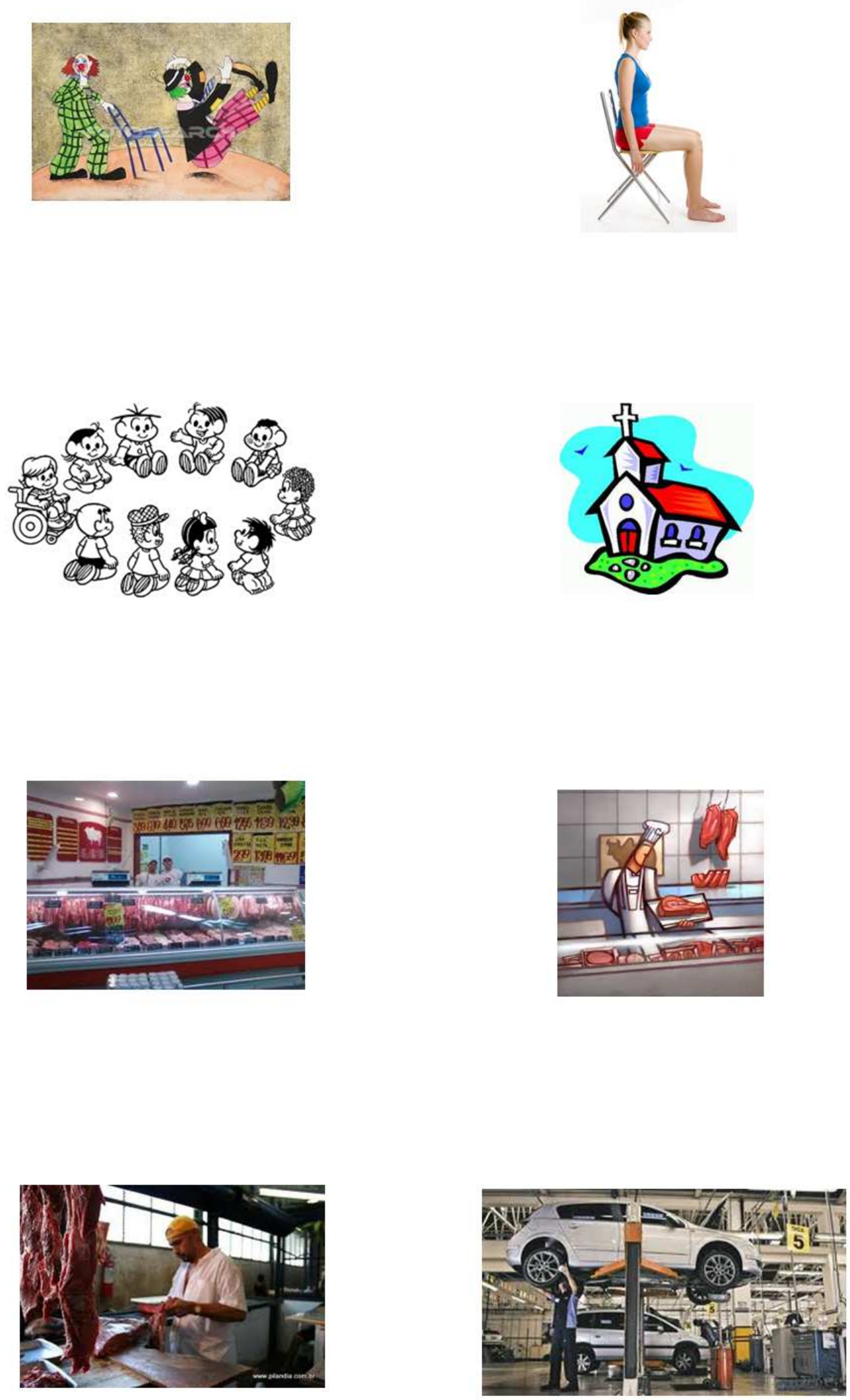

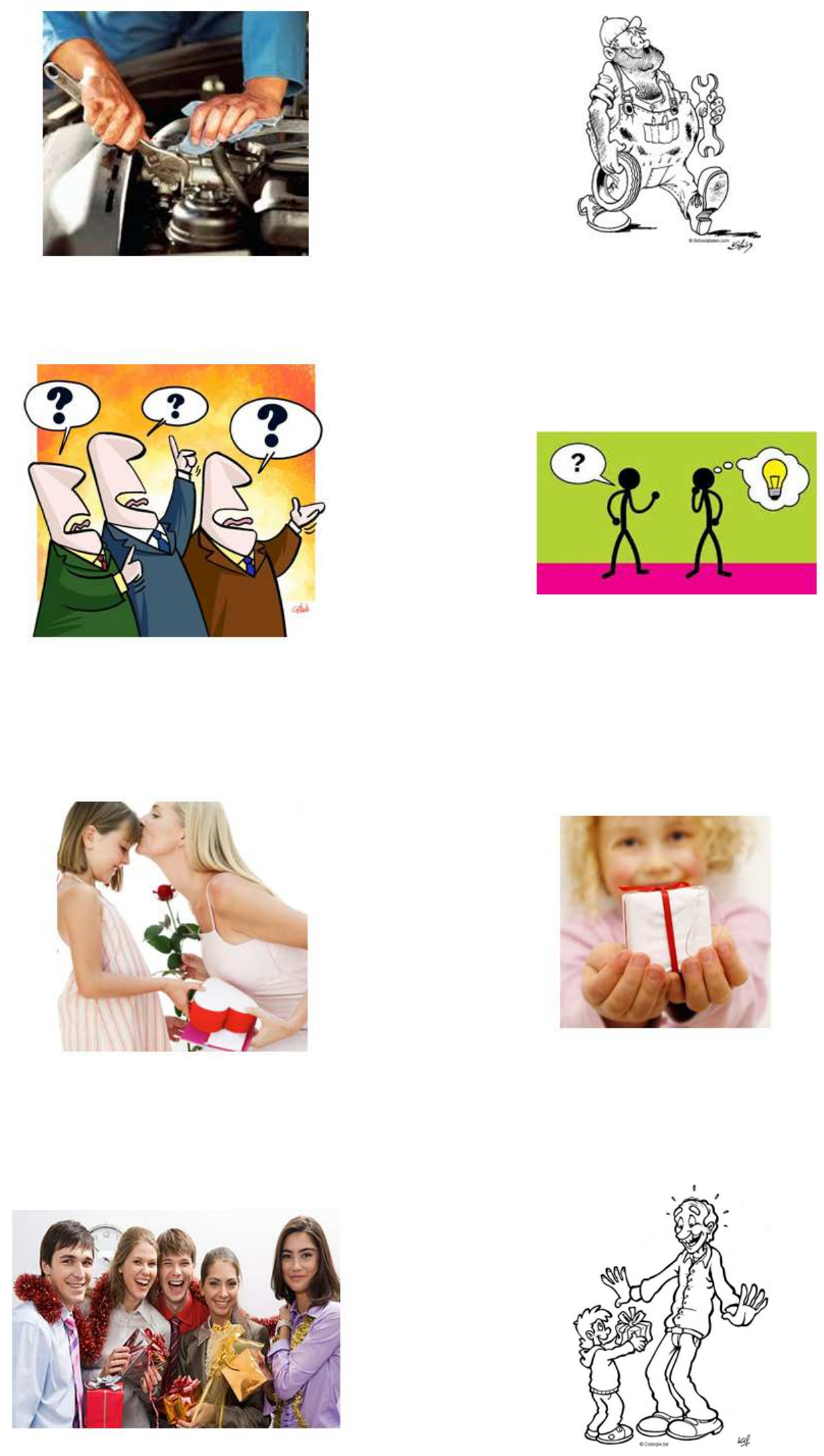
Coleta de dados com sinalizante da LIBRAS (2)

06-07-2013
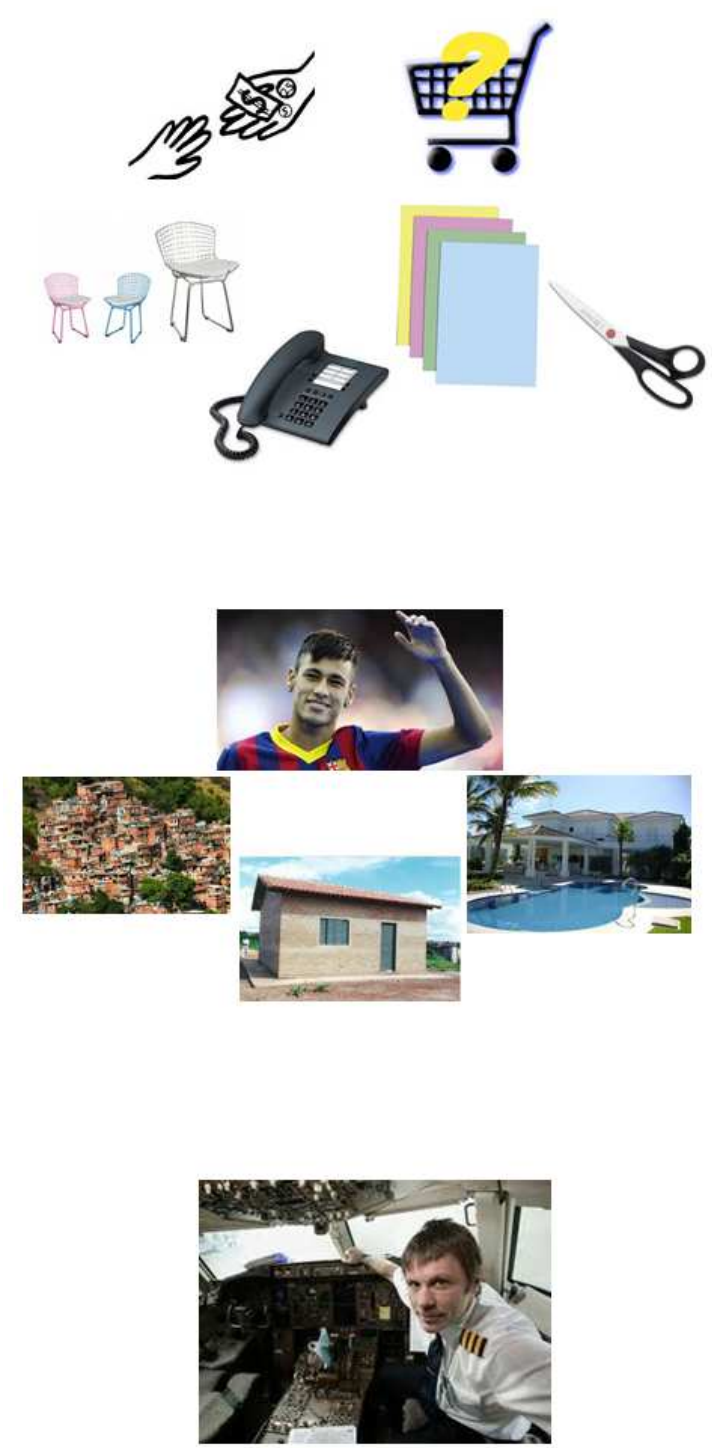
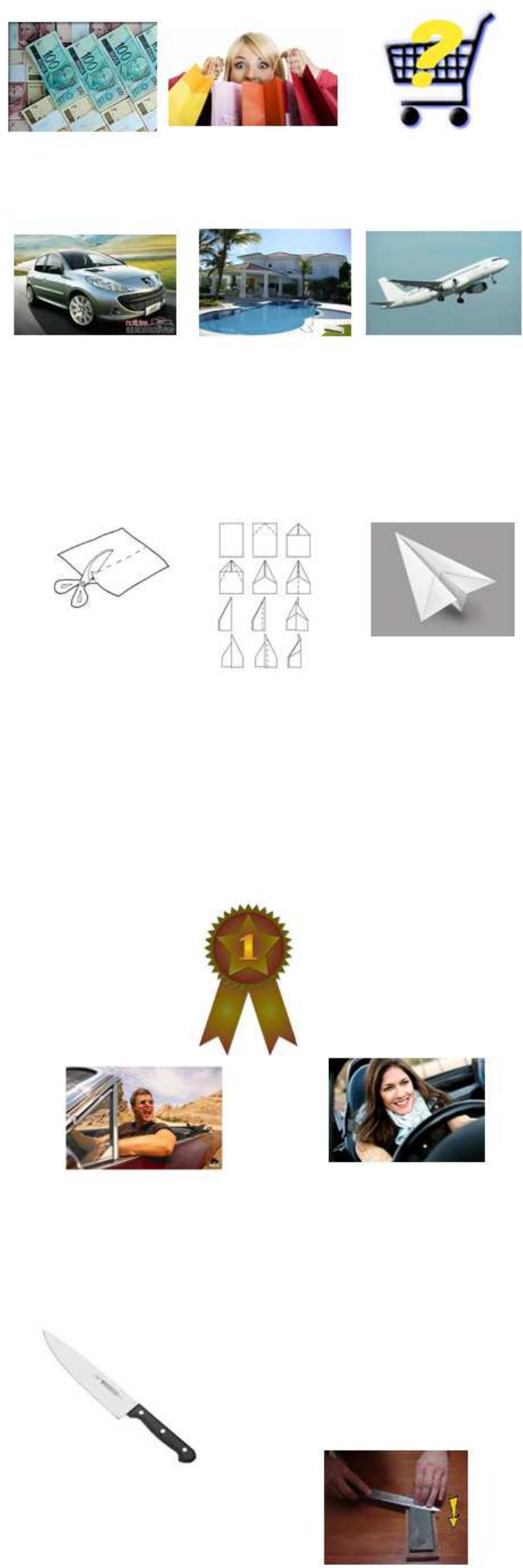

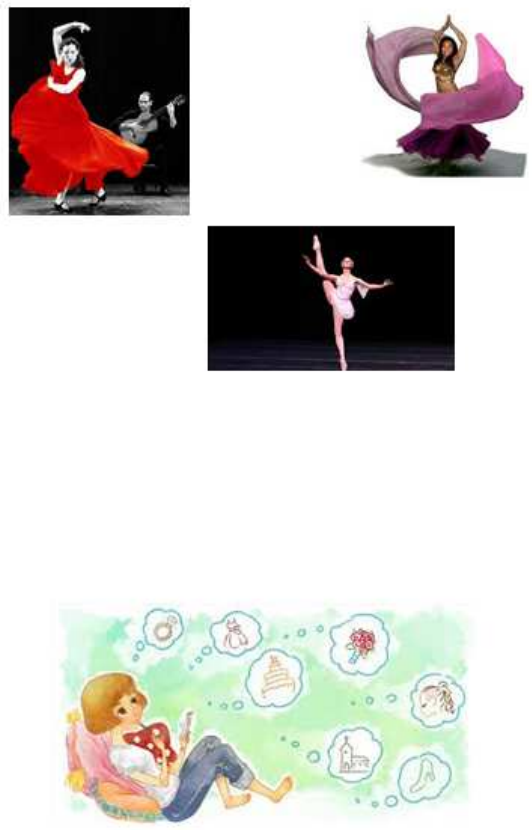

Coleta de dados com sinalizante da LIBRAS (3)

29 e $31-10$

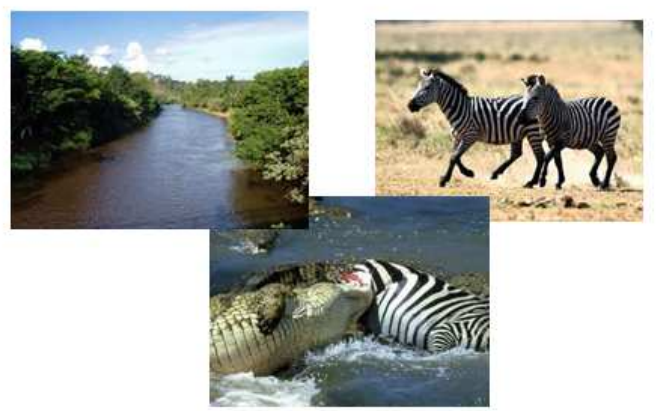

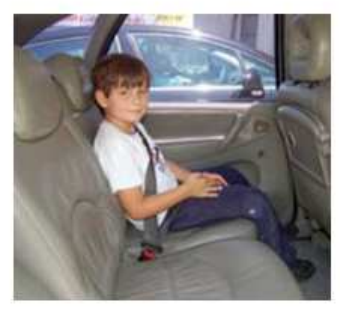

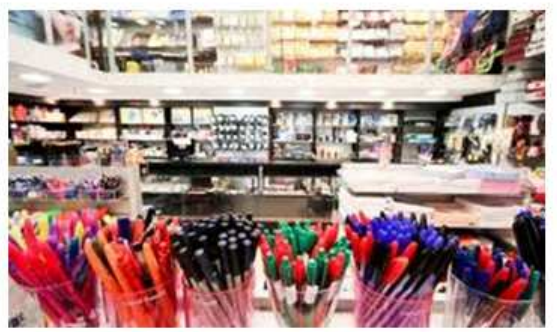

(3)
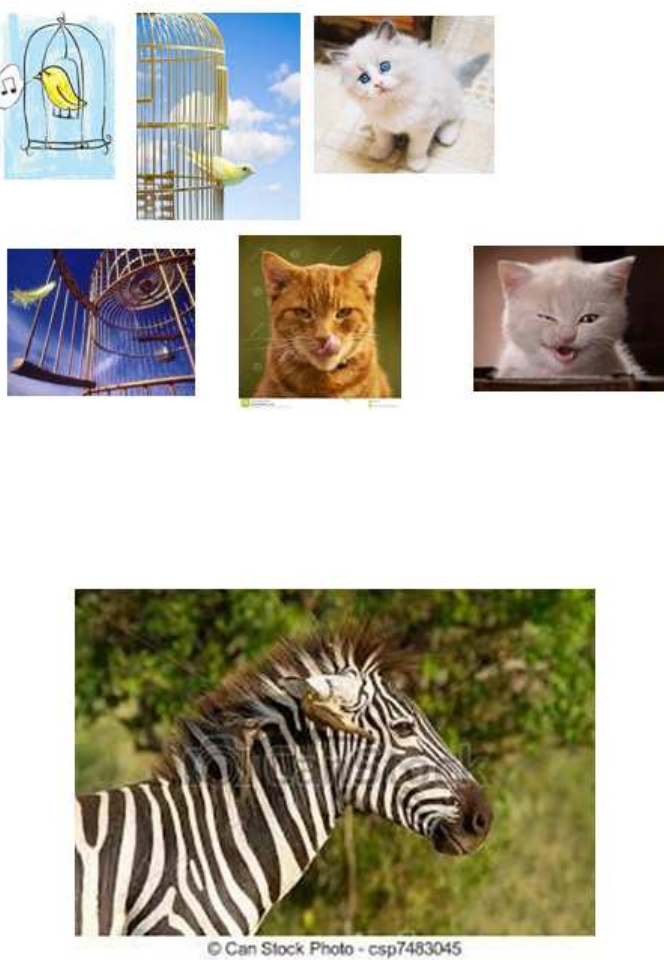

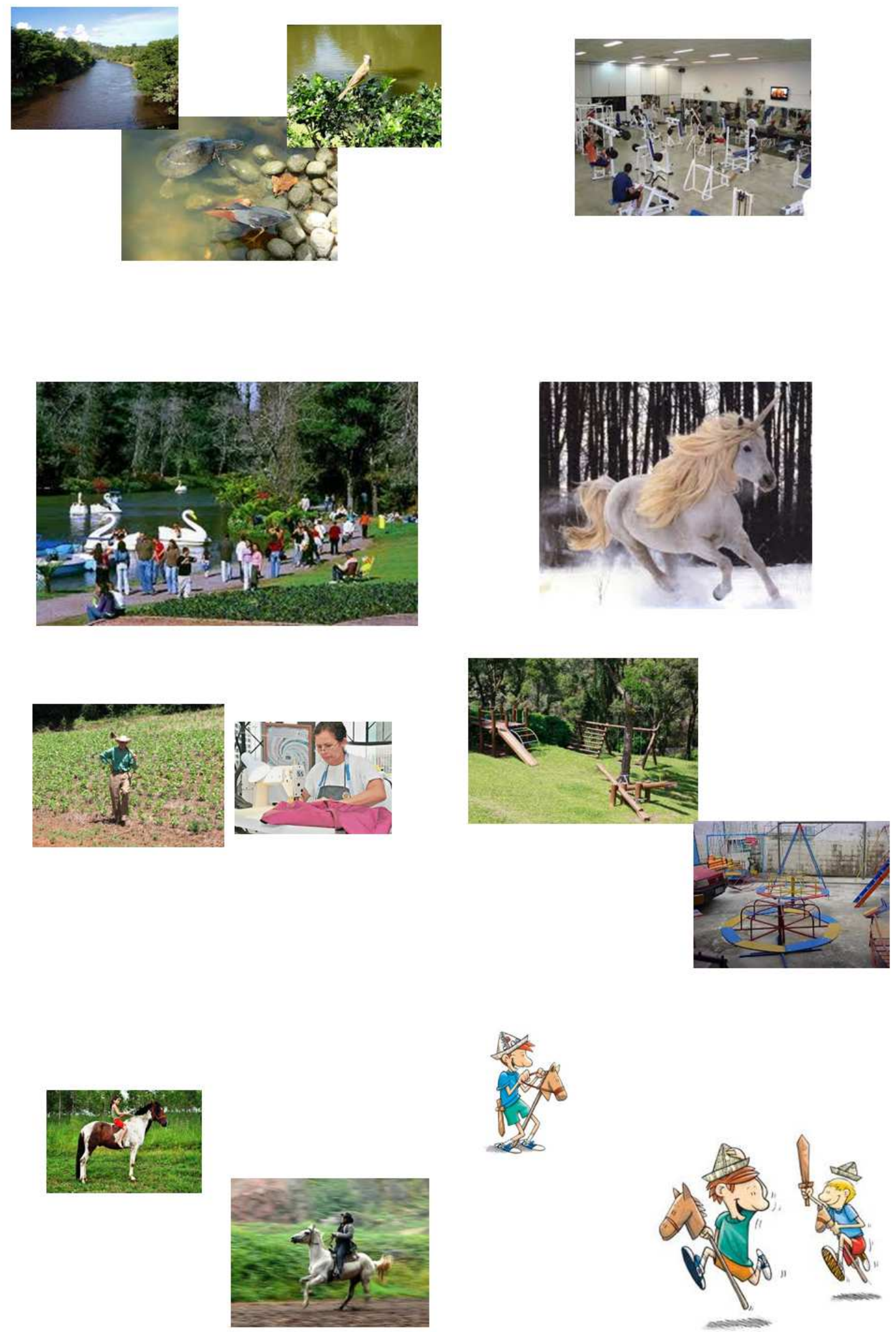

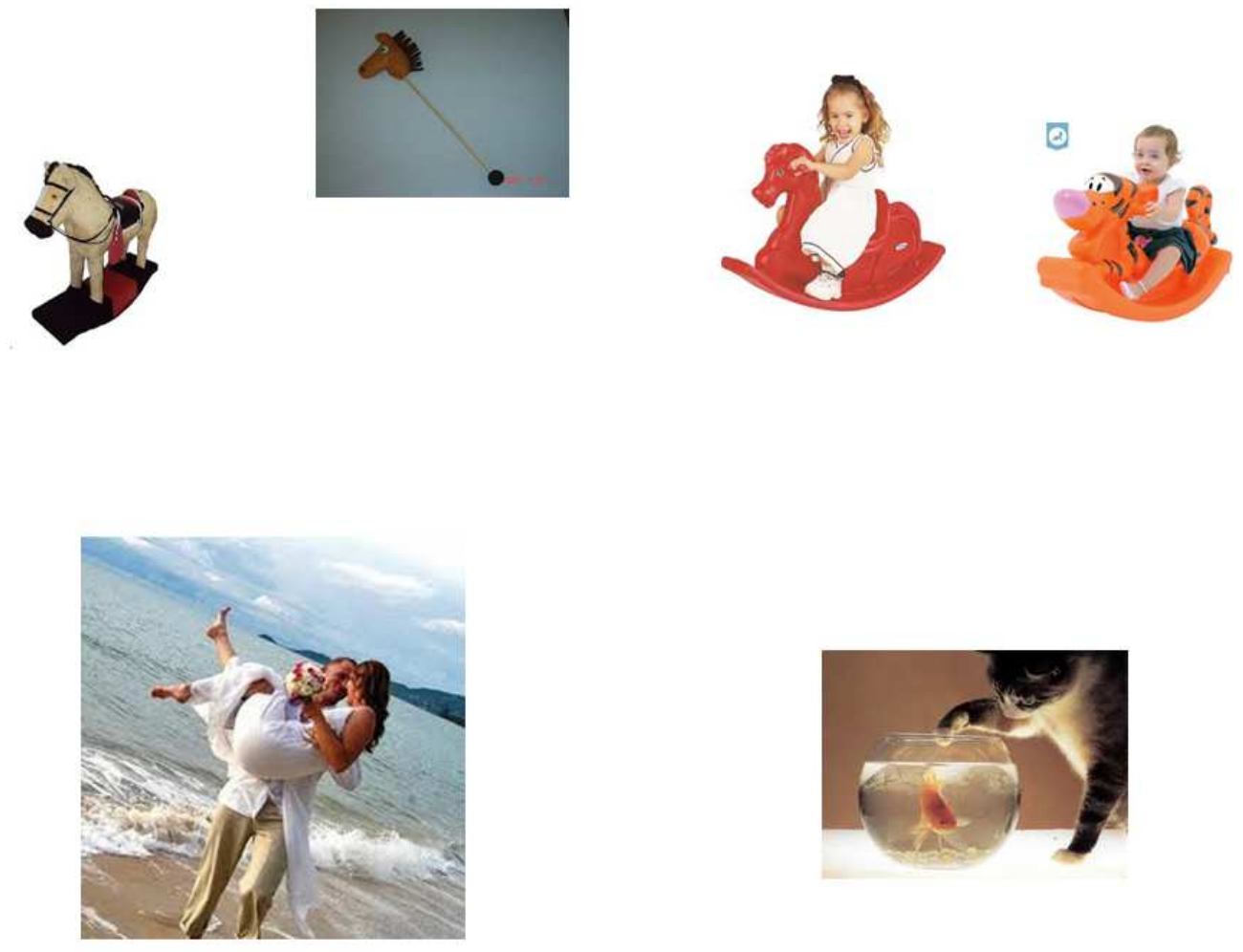
Anexo VI: TCLE

Universidade de São Paulo

Instituto de Ciências Biomédicas

\section{TERMO DE CONSENTIMENTO LIVRE E ESCLARECIDO}

ESTUDO: As alterações no processamento da linguagem expressas na Língua de Sinais Brasileira por surdos com lesão cerebral

Você está sendo convidado(a) a participar do projeto de pesquisa acima citado. O documento abaixo contém todas as informações necessárias sobre a pesquisa que estamos fazendo. Sua colaboração neste estudo será de muita importância para nós, mas se desistir a qualquer momento, isso não causará nenhum prejuízo a você.

$\mathrm{Eu}$,

(nome),

(profissão), residente e domiciliado

na , portador da Cédula de identidade, RG , e inscrito no CPF/MF

nascido(a) em 1 I__ abaixo assinado(a), concordo de livre e espontânea vontade em participar como voluntário(a) do estudo "As alterações no processamento da linguagem expressas na Língua de Sinais Brasileira por surdos com lesão cerebral". Declaro que obtive todas as informações necessárias, bem como todos os eventuais esclarecimentos quanto às dúvidas por mim apresentadas.

Estou ciente que:

I) $O$ estudo se faz necessário para que se possam compreender o funcionamento da língua de sinais produzida por surdos com derrame (lesão cerebral); 
II) Serão feitas uma avaliação de linguagem geral, que será realizada em no máximo quatro períodos de duas horas, com a filmagem dos sinais que serão realizados por mim naturalmente ou dos sinais que serão realizados por mim com base em um desenho;

III) A participação neste projeto não tem objetivo de me submeter a um tratamento, bem como não me acarretará qualquer despesa financeira com relação aos procedimentos médico-clínico-terapêuticos efetuados no estudo;

IV) Tenho a liberdade de desistir ou de interromper a colaboração neste estudo no momento em que desejar, sem necessidade de qualquer explicação;

V) A desistência não causará nenhum prejuízo à minha saúde ou bem estar físico. Não virá interferir no atendimento ou tratamento médico;

VI) Os resultados obtidos durante este ensaio serão mantidos em sigilo, mas concordo que sejam divulgados em publicações científicas, desde que meus dados pessoais não sejam mencionados;

VII) Caso eu desejar, poderei pessoalmente tomar conhecimento dos resultados, ao final desta pesquisa.

( ) Desejo conhecer os resultados desta pesquisa.

( ) Não desejo conhecer os resultados desta pesquisa.

VIII) Concordo que o material possa ser utilizado em outros projetos desde que autorizado pela Comissão de Ética deste Instituto e pelo responsável por esta pesquisa. Caso minha manifestação seja positiva, poderei retirar essa autorização a qualquer momento sem qualquer prejuízo para mim.

( ) Sim ou ( ) Não

IX) Poderei contatar a Secretaria da Comissão de Ética em Pesquisa com Seres Humanos - ICB/USP -, no Fone 3091.7733 (e-mail: cep@icb.usp.br) ou com o Professor Doutor Felipe Venâncio Barbosa, no Fone xxxxxxxx e e-mail felipebarbosa@usp.br para recursos ou reclamações em relação ao presente estudo.

X) O sujeito de pesquisa ou seu representante, quando for o caso, deverá rubricar todas as folhas do Termo de Consentimento Livre e Esclarecido TCLE - apondo sua assinatura na última página do referido Termo. 
XI) O pesquisador responsável deverá da mesma forma, rubricar todas as folhas do Termo de Consentimento Livre e Esclarecido - TCLE - apondo sua assinatura na última página do referido Termo.

XII) Resolução 196/96 - Estou recebendo uma cópia deste Termo de Consentimento Livre e Esclarecido.

São Paulo, de de

Participante:

Testemunha 1:

Nome / RG / Telefone

Testemunha 2:

Nome / RG / Telefone

Responsável pelo Projeto:

Prof. Dr. Felipe Venâncio Barbosa 
Anexo VII: DADOS EXTRAS

(1) $\mathrm{CASA}_{C L}{ }^{\wedge} \mathrm{CRUZ} Z_{C L}(2)$ "igreja"
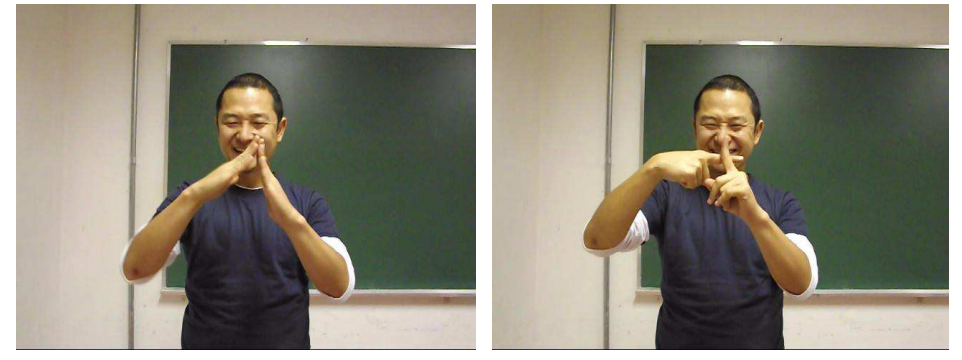

$\mathrm{CASA}_{\mathrm{CL}}$ $\mathrm{CRUZ} C \mathrm{C}$

(2) HOMEM^INDIVÍDUO^TRABALHAR^CONCERTAR (1) "mecânico"

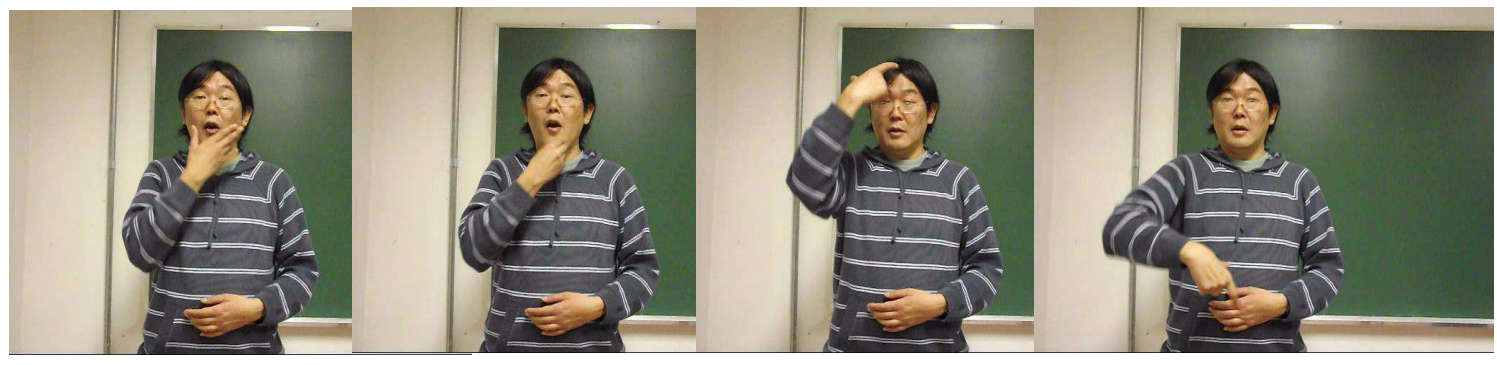

HOMEM

INDIVÍDUO

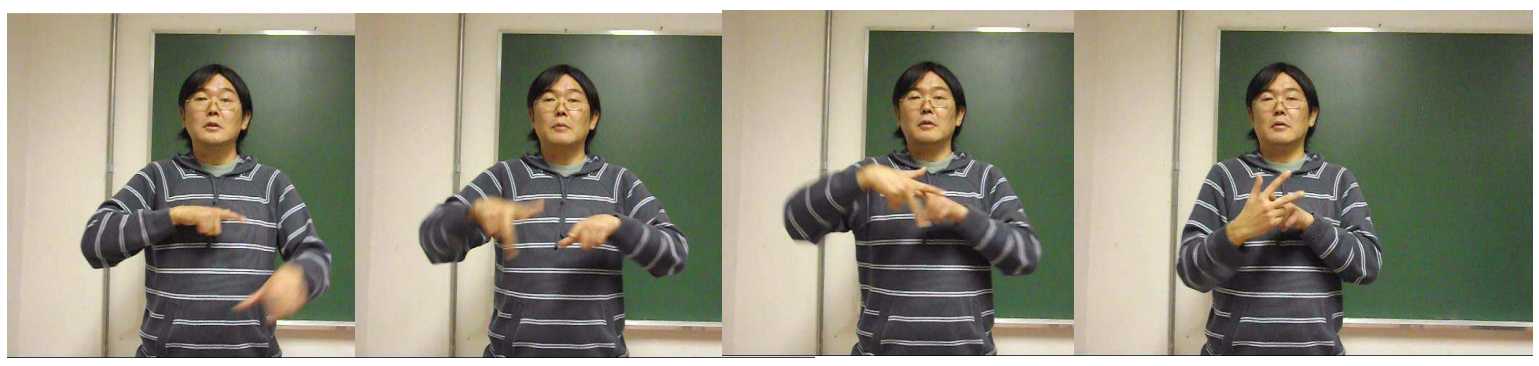

TRABALHAR CONCERTAR 
(3) PAPEL^MATERIAL^VÁRIOS (3) "papelaria"

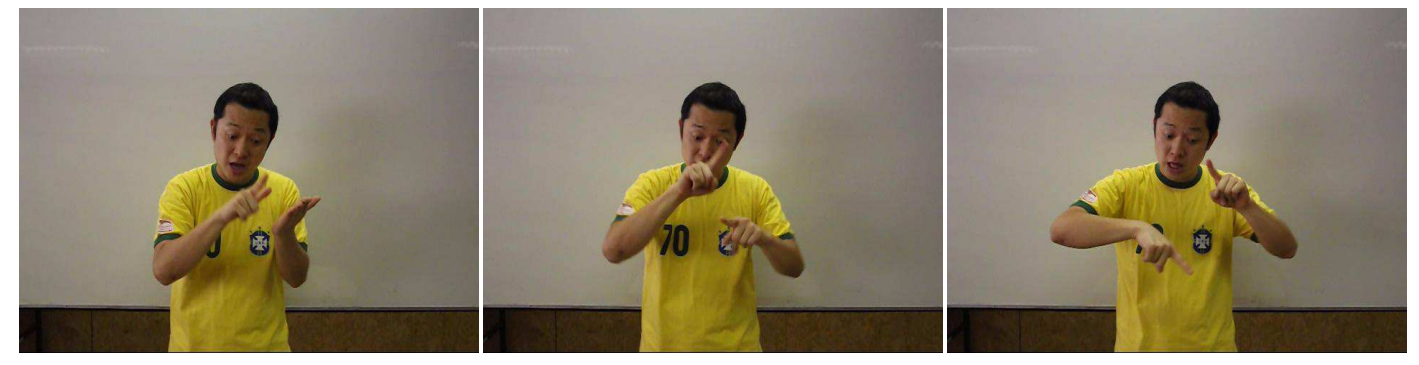

PAPEL

MATERIAL

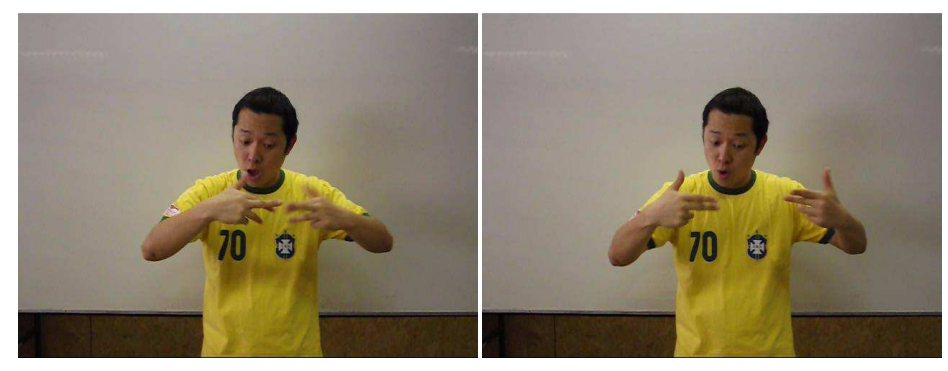

VÁRIOS

(4) CANETA ${ }_{C L}{ }^{\wedge} F O R M A-R E ́ G U A_{C L} L^{\wedge} L O J A \wedge E N T I D A D E-R E T A 4_{C L}-C O L O C A R-E M-$ $\operatorname{VOLTA(M)~(2)~"papelaria"~}$
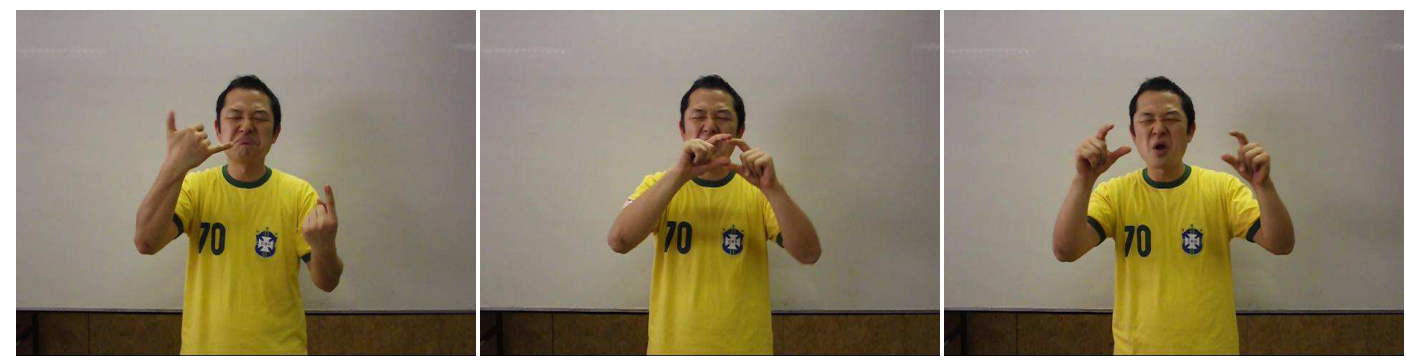

CANETA

FORMA-RÉGUA
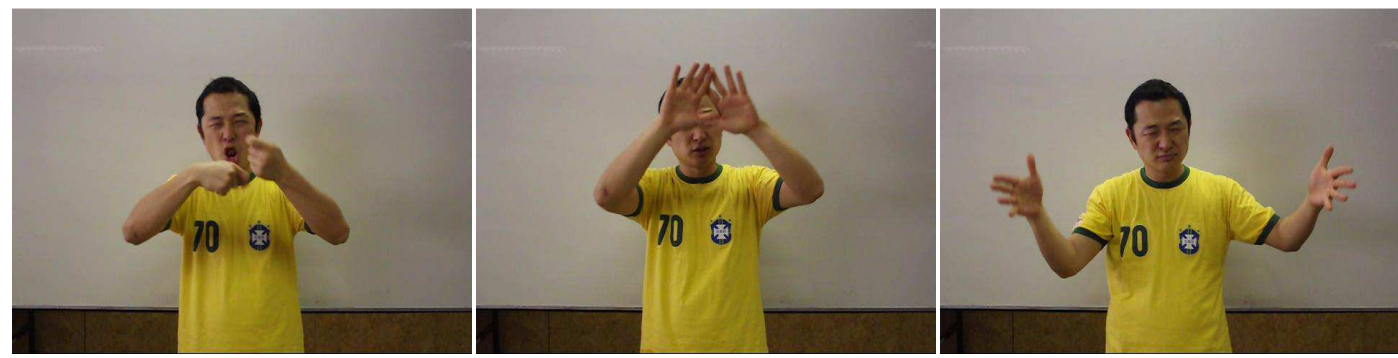

LOJA ENTIDADE-RETA4 ${ }_{\mathrm{CL}}$-COLOCAR-EM-VOLTA(M) - 
(5) VIDRO^FORMA-BALCÃO $\mathrm{CL}^{\wedge}{ }^{\wedge}$ CARNE^ENTIDADE-SEMI-CIRCULAR1 ${ }_{\mathrm{CL}}{ }^{-}$ COLOCAR(M)||ENTIDADE-PLANA1 1 CL "balcão frigorífico"

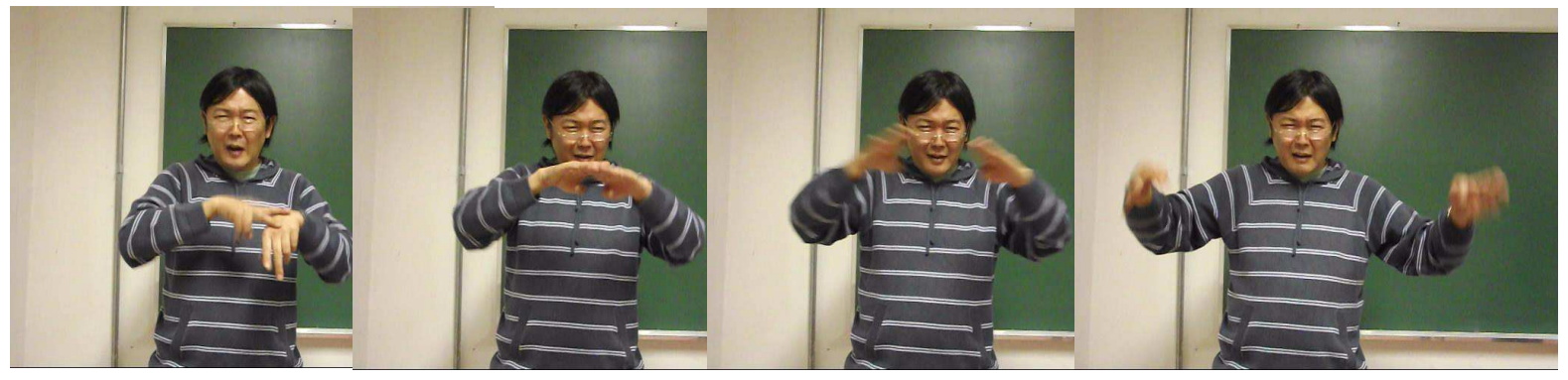

VIDRO

FORMA-BALCÃO
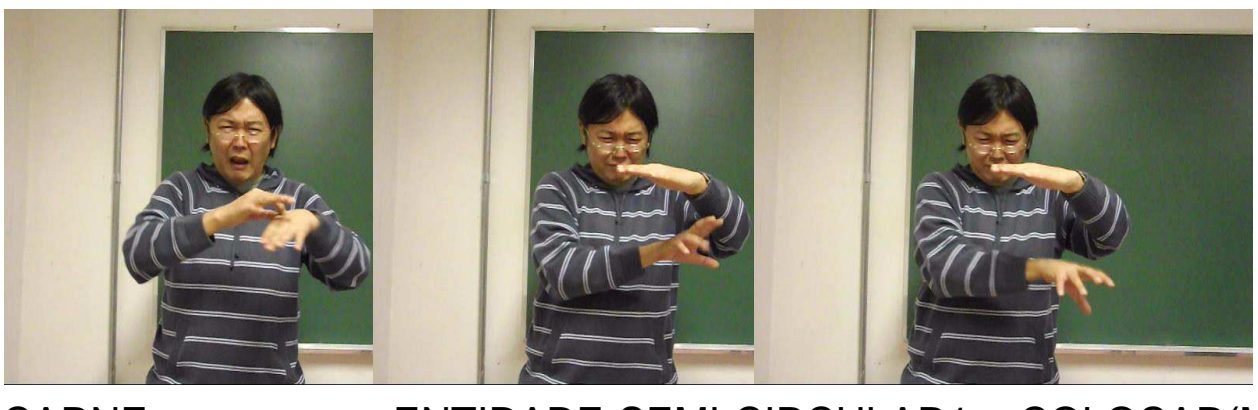

CARNE

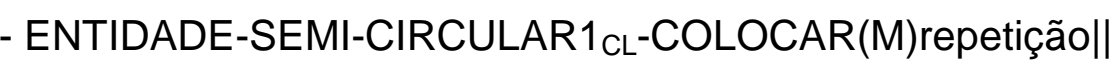

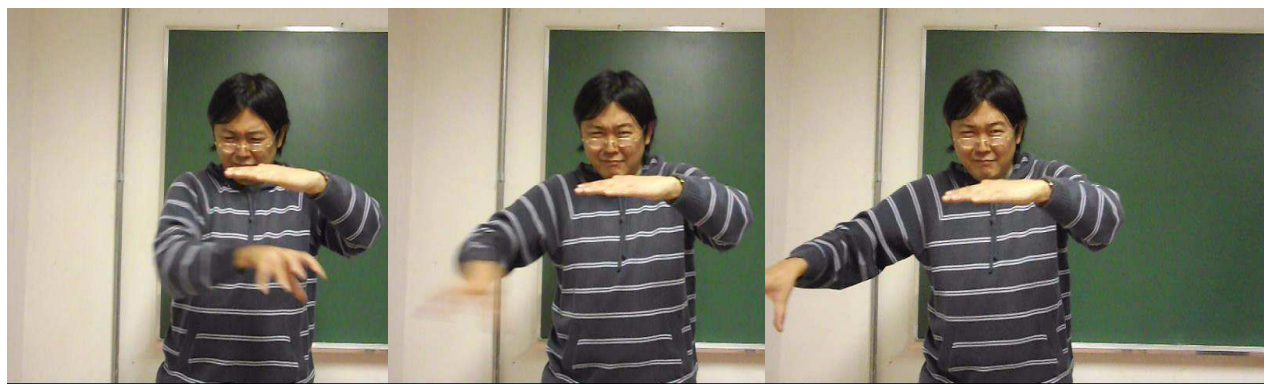

ENTIDADE-PLANA1 $\mathrm{CL}$

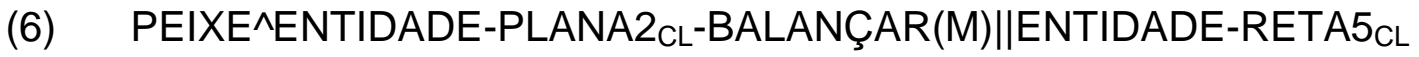
"peixinho de balanço"
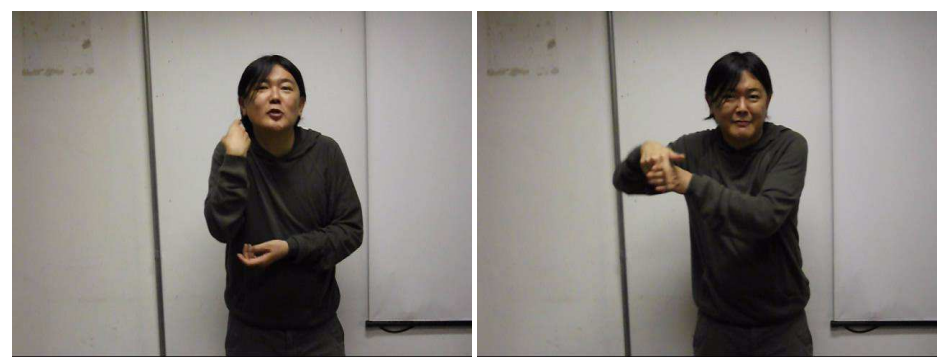

PEIXE

ENTIDADE-PLANA2 $\mathrm{CL}-B A L A N C ̧ A R(M) m e \|$

ENTIDADE-RETA5 $\_$md 


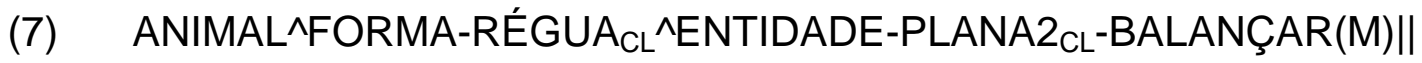
ENTIDADE-RETA5 $\mathrm{CL}$ "zebrinha de balanço"

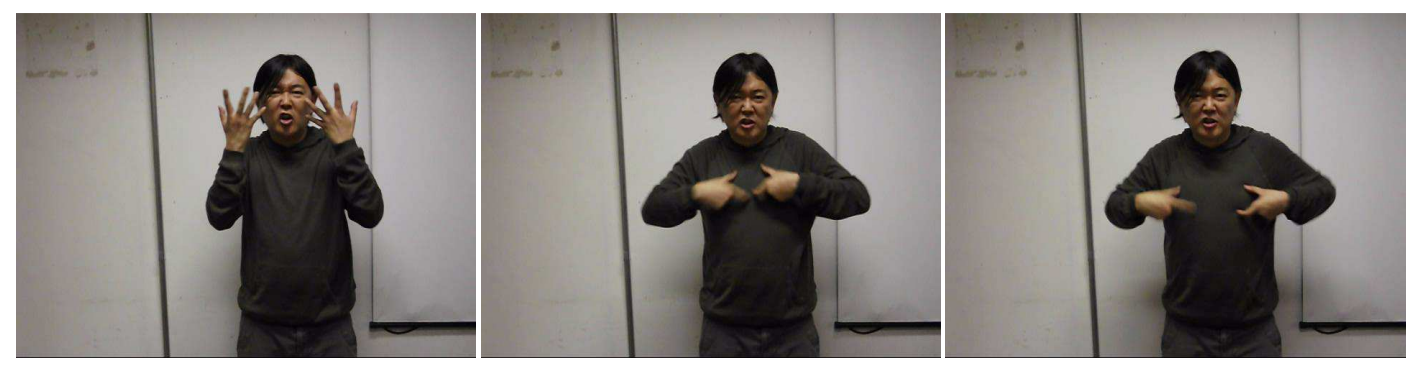

ANIMAL --------------- FORMA-RÉGUA

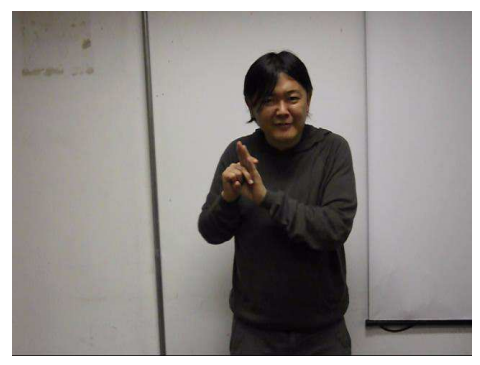

ENTIDADE-PLANA2 2 L-BALANÇAR(M)me||ENTIDADE-RETA5 $5_{C L} m d$ - 